\title{
vMONGLUCO - Sistema DE MONITORAMENTO ContínUo DE GLICOSE
}

Dissertação apresentada à Escola Politécnica da Universidade de São Paulo para obtenção do título de Mestre em Engenharia

Área de Concentração:

Engenharia Elétrica - Sistemas Eletrônicos

Orientador:

Prof. Dr. Marco Antonio Gutierrez

São Paulo

2007 
AUTORIZO A REPRODUÇÃO E DIVULGAÇÃO TOTAL OU PARCIAL DESTE TRABALHO, POR QUALQUER MEIO CONVENCIONAL OU ELETRÔNICO, PARA FINS DE ESTUDO OU PESQUISA, DESDE QUE CITADA A FONTE.

Este exemplar foi revisado e alterado em relação à versão original, sob responsabilidade única do autor e com a anuência de seu orientador.

São Paulo, 26 de abril de 2007.

Assinatura do autor

Assinatura do orientador

FICHA CATALOGRÁFICA

Murakami, Alexandre

vMonGluco: sistema de monitoramento contínuo de glicose

/ A. Murakami. -- São Paulo, 2007.

$157 \mathrm{p}$.

Dissertação (Mestrado) - Escola Politécnica da Universidade de São Paulo. Departamento de Engenharia de Telecomunicações e Controle.

1.Sistemas de informação 2.Informática médica 3.Prontuário eletrônicos do paciente 4.Redes sem fio I.Universidade de São Paulo. Escola Politécnica. Departamento de Engenharia de Telecomunicações e Controle II.t. 


\section{Agradecimentos}

Ao Prof. Dr. Marco Antonio Gutierrez, meu orientador e diretor do Serviço de Informática do Instituto do Coração, pela orientação calorosa e incondicional durante a elaboração deste trabalho.

Ao Prof. Dr. Sérgio S. Furuie e ao sr. Fábio A. Pires, diretores do Serviço de Informática do Instituto do Coração, e ao sr. Umberto Tachinardi, Diretor Técnico de Departamento da Secretaria de Estado da Saúde de São Paulo, pelo apoio e confiança em mim depositados durante a minha permanência no Instituto do Coração.

À Dr ${ }^{a}$ Sílvia H. G. Lage, diretora da Unidade de Terapia Intensiva Clínica do Instituto do Coração, e a toda equipe médica e de enfermagem das UTIs, pelo apoio exaustivo durante a realização dos testes em pacientes.

Ao Dr. José Antônio F. Ramirez, diretor geral do Instituto do Coração, pelo apoio entusiasta ao projeto.

À Medtronic do Brasil, em especial, ao sr. Renato Borges e à sra. Mieco Hashimoto. A Medtronic do Brasil forneceu equipamentos (monitores MiniMed CGMS, bases de comunicação, glucosímetros de ponta de dedo e sensores) e treinamento, sem os quais a realização deste trabalho seria impossível.

Ao Conselho Nacional de Desenvolvimento Científico e Tecnológico (CNPq) pelo suporte financeiro (processo individual 380958/03-1, processo institucional 552026/02-6)

Aos colegas, professores e funcionários da Escola Politécnica da USP, cujo apoio foi fundamental na minha formação como aluno e como pessoa.

A todos os colegas do Serviço de Informática do Instituto do Coração que, de maneira direta ou indireta, apoiaram a realização deste projeto, além de oferecerem sua amizade, 
respeito e confiança. Peço desculpas por não citar o nome de todos, já que a lista é extensa. Para este projeto em particular, gostaria de agradecer à Marina F. S. Rebelo pela orientação na manipulação dos monitores de beira de leito, ao Luciano Imamura, que confeccionou os cabos seriais null-modem e configurou as redes sem-fio e dos monitores, aos alunos de intercâmbio Kim Nielsen e Thomas Iversen, da Dinamarca, que participaram da realização dos testes com pacientes, e ao Ricardo Guiraldelli, que auxiliou na realização dos testes com pacientes e no tratamento dos dados obtidos.

A todos os amigos e familiares que, através da sua amizade, carinho e alegria, trouxeram-me forças para a finalização deste projeto.

Finalmente, agradeço ao meu pai Jundi e à minha mãe Hiroko, que, de maneira sábia e amorosa, mostraram a mim e a meus irmãos a importância do estudo. A eles, dedico este trabalho. 
"Persiga a sua bem-aventurança". Descubra onde ela está e não tenha medo de segui-la. (...) Ao fazer isso, você salva o mundo. Uma pessoa vitalista sempre traz uma influência vitalizadora, não tenha dúvidas a respeito disso. O mundo sem espírito é uma terra devastada. As pessoas têm a ilusão de salvar o mundo trocando as coisas ao redor, mudando as regras, quem está no comando e assim por diante. Nada disso! Qualquer mundo é um mundo válido se estiver vivo. A coisa a fazer é trazer vida a ele, e a única maneira de fazer isso é descobrir, em você mesmo, onde está a vida e manter-se vivo.

Joseph Campbell ${ }^{1}$

${ }^{1}$ CAMPBELL, J. O Poder do Mito. São Paulo : Palas Athena, 1990. p. 158. 


\section{RESUMO}

MURAKAMI, A. vMonGluco - Sistema de Monitoramento Contínuo de Glicose. 2007. 158 f. Dissertação de Mestrado em Engenharia Elétrica - Escola Politécnica, Universidade de São Paulo, São Paulo.

Pacientes críticos tratados em uma UTI comumente apresentam quadros severos de hiperglicemia. Estudos mostram que o controle da glicemia a níveis restritos leva à melhoria no prognóstico de tais pacientes. O controle glicêmico é feito através da medição freqüente da glicemia através de um exame de "ponta de dedo", aliada à infusão de insulina, numa atividade bastante trabalhosa para a equipe de enfermagem. Nos últimos anos, surgiram os primeiros sistemas comerciais de monitoramento contínuo de glicose para uso ambulatorial. Entretanto, há uma série de limitações que dificultam seu uso em uma UTI. No presente trabalho, foi desenvolvido um sistema de monitoramento contínuo de glicose para pacientes críticos hiperglicêmicos, batizado de vMonGluco. Esse sistema utiliza um monitor contínuo de glicose, disponível comercialmente, conectado a um palmtop, de forma a obter leituras de glicose em tempo real. Os dados coletados são enviados a um servidor seguindo a norma Health Level Seven (HL7). O servidor redireciona os dados a um monitor de beira de leito, disponibilizando as leituras de maneira prática. As informações também são armazenadas em um sistema de Prontuário Eletrônico do Paciente. Testes realizados em pacientes comprovaram a validade das leituras obtidas. Assim, com o presente trabalho, espera-se trazer uma contribuição prática e significativa no tratamento de pacientes críticos hiperglicêmicos.

Palavras-chave: sistemas de informação, informática médica, Prontuário Eletrônico do Paciente, redes sem fio. 


\section{AbSTRACT}

MURAKAMI, Alexandre. vMonGluco - Sistema de Monitoramento Continuo de Glicose. 2007. 158 p. Master Thesis in Electrical Engineering - Escola Politecnica, Universidade de Sao Paulo, Sao Paulo.

Critical patients in an $I C U$ usually experience severe hyperglycemia. Studies show that the control of glycemia to restricted levels can increase the prognosis of these patients. This control is usually done through the frequent reading of glycemia using a fingerstick test, together with the infusion of insulin, in a troublesome activity for the nursery team. In the last few years, the first commercial glucose monitoring systems for ambulatory use have been created. However, several difficulties limit its use in an ICU. In the present work, a continuous glucose monitoring system, named as vMonGluco, was developed. The system uses a commercially available continuous glucose monitor connected to a palmtop, in order to get glucose readings in real time. The collected data are sent to a server using the Health Level Seven (HL7) standard. The server redirects the data to a bedside monitor, so the readings can be accessed in practical way. The information is also stored in an Electronic Health Record system. Tests applied to patients showed the validity of the obtained readings. This way, with the present work, it is expected to bring a practical and significant contribution to the treatment of critical hyperglycemic patients.

Keywords: information systems, medical informatics, Electronic Health Record, wireless nets. 


\section{LISTA DE FIGURAS}

Figura 1.1 - Diagrama esquemático do vMonGluco - Sistema de Monitoramento Contínuo de Glicose................ 4

Figura 2.1 - Exemplo de leitura obtida através de um sistema de monitoramento contínuo de glicose (MiniMed $C G M S$ ). O gráfico mostra a variação da glicemia ao longo de um dia. Duas linhas horizontais delimitam a faixa ideal de glicemia para este paciente (entre 80 e $140 \mathrm{mg} / \mathrm{dL}$ ). As marcas em forma de estrela indicam leituras obtidas através do meio tradicional de medição de glicemia ("ponta de dedo"). Nota-se que, entre aproximadamente 1:00 e 4:00 da madrugada, o paciente apresentou uma hipoglicemia noturna, isto é, a glicemia ficou abaixo da faixa ideal. Essa hipoglicemia não foi detectada pelo exame tradicional, já que não foram feitas leituras nesse intervalo de tempo.

Figura 2.2 - Esquema ilustrativo de um sistema de pâncreas artificial........................................................ 13

Figura 2.3 - Um exemplo hipotético de gráfico de Bland \& Altman. 20

Figura 2.4 - Grade de erro de Clarke (considerando uma faixa de glicemia normal entre 70 e $180 \mathrm{mg} / \mathrm{dL}$ ) (Adaptado de Clarke et al., 1987).

Figura 2.5 - Exemplo de sensor enzimático (adaptado de Pickup et al., 1999) 26

Figura 2.6 - A relação entre corrente (I) e glicose (G) é definida por uma reta, usualmente chamada de reta de calibração. A reta de calibração é mostrada na figura. A partir da realização de duas medições de glicemia (utilizando-se, por exemplo, o exame de "ponta de dedo"), pode-se determinar dois pares de valores de corrente e glicose $\left(\mathrm{I}_{1}, \mathrm{G}_{1}\right)$ e $\left(\mathrm{I}_{2}, \mathrm{G}_{2}\right)$. Assim, a reta de calibração é perfeitamente determinada. $\mathrm{O}$ ponto de cruzamento da reta de calibração e o eixo da corrente determina o valor da corrente de fundo $\left(\mathrm{I}_{0}\right)$. $\mathrm{O}$ fator de escala $(\mathrm{S})$ é determinado pela inclinação da reta.

Figura 2.7 - O sensor enzimático mede a concentração de glicose no líquido intersticial e não no sangue (imagem de divulgação da Medtronic Diabetes).

Figura 2.8 - Neste gráfico hipotético, assume-se a hipótese que, quando a concentração de glicose no sangue varia, essa variação é refletida no líquido intersticial com um atraso de 10 minutos.

Figura 2.9 - Modelo simplificado do ciclo de glicose no organismo. $\mathrm{G}_{\mathrm{ex}}$ é a glicose exógena, obtida a partir dos alimentos ingeridos. $G_{e n d}$ é a glicose endógena, liberada pelo fígado. $G_{k}$ é a glicose eliminada pela urina. $O$ fluxo I (entrada) ocorre por difusão, enquanto que o fluxo $\mathrm{O}$ (saída) ocorre por um processo ativo, estimulado pela insulina. A figura mostra ainda a influência da insulina sobre o ciclo, aumentando o fluxo de absorção de glicose pelas células $(\mathrm{O})$ e reduzindo ou invertendo o fluxo de glicose do fígado para o sangue $\left(\mathrm{G}_{\mathrm{end}}\right)$. Adaptado de Aussedat et al. (2000).

Figura 2.10 -Gráfico adaptado de Aussedat et al. (2000). As concentrações de glicose sangüínea (círculos abertos) e intersticial (linhas retas) foram medidas em ratos não diabéticos. Foi aplicada uma dose de insulina seguida da administração de glicose. Nota-se que, após a aplicação de insulina, o nível de glicose intersticial cai com um pequeno atraso em relação à glicose sangüínea (90-120 min). Logo após, há um retorno da glicemia a níveis normais (120-300 min). Nesse intervalo de tempo, a concentração de glicose sangüínea mantém-se acima da concentração de glicose intersticial. Após a administração de glicose (300 min), as disparidades entre glicose sangüínea e glicose intersticial aumentam bastante. Como se pode concluir, esse resultado não pode ser explicado por um simples atraso entre as leituras de glicose sangüínea e intersticial.

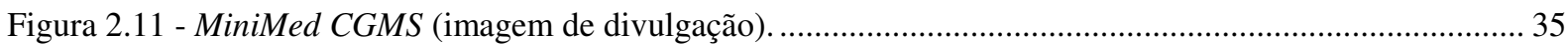

Figura 2.12 - MiniMed CGMS em uso (imagem de divulgação) 36

Figura 2.13 - O MiniMed CGMS é conectado a um computador através de uma base de comunicação. Um cabo serial interliga a base de comunicação ao computador (imagem de divulgação).

Figura 2.14 - Gráfico obtido através do software do MiniMed CGMS. O gráfico mostra a variação da glicemia ao longo de um dia. Duas linhas horizontais demarcam a faixa ideal de glicemia para este paciente (entre 80 e 
$140 \mathrm{mg} / \mathrm{dL})$. As marcas em forma de estrela indicam os valores de calibração. Além disso, as marcas próximas ao eixo das horas indicam eventos especiais, como refeições e uso de insulina.

Figura 2.15 - Exemplo de tela do software do MiniMed CGMS. É mostrada uma tabela com os dados registrados no aparelho. Date/Time é a data e o horário de cada amostra. Sample é o número da amostra. ISIG é a leitura da corrente gerada pelo sensor enzimático. VCTR é a tensão aplicada no sensor. Meter Value é o valor de glicemia obtido no procedimento de calibração pelo usuário. User Events, System Events e Alarms (à direita) indicam outras informações armazenadas no aparelho. As demais colunas intermediárias mostram dados calculados pelo software, isto é, que não são armazenados no aparelho. 40

Figura 2.16 - MiniMed Guardian RT - Sucessor do CGMS, este sistema possui comunicação sem fio entre o sensor e o monitor, além de apresentar leituras de glicemia em tempo real (imagens de divulgação) ........ 49

Figura 3.1 - Integração entre os monitores de beira de leito e o sistema de informações médicas do Instituto do Coração (adaptado de Oliveira et al., 2002)

Figura 3.2 - Os sinais de um monitor de beira de leito são visualizáveis a partir de uma interface Web (adaptado de Oliveira et al., 2002). .

Figura 3.3 - O padrão NCCLS POCT1-A. São definidos quatro tipos de dispositivos: dispositivos de $P O C T$, pontos de acesso, POC Data Manager e sistemas de LIS/HIS. Entre os dispositivos de POCT e os pontos de acesso, é utilizado, na camada de transporte, o protocolo IEEE 107.3.2. Entre os pontos de acesso e os sistemas de informação, é utilizada uma rede TCP/IP. Para as camadas de aplicação, entre os dispositivos POCT e os POC Data Managers, é usado um protocolo próprio (indicado na figura como CIC). Para a comunicação entre os POC Data Managers e os sistemas de informação, é utilizado o padrão $H L 7$ (adaptado de Knafel, 2001)......

Figura 4.1 - Diagrama esquemático do vMonGluco - Sistema de Monitoramento Contínuo de Glicose. 66

Figura 4.2 - Montagem física do sistema.

Figura 4.3 - A curva contínua em $A$ indica a leitura contínua obtida a partir de um sensor intersticial de glicose. A leitura de calibração corresponde ao ponto indicado na curva. Nota-se que, entre a leitura de calibração e a leitura contínua, há uma diferença de tempo de dez minutos, pois a leitura de calibração é coletada a partir do sangue e o sinal do sensor, a partir do líquido intersticial. Para corrigir essa diferença, o algoritmo do MiniMed CGMS adota a abordagem mostrada em $B$, onde a leitura contínua é adiantada em dez minutos. Já o gráfico $C$ mostra a abordagem do algoritmo em tempo real, onde a leitura de calibração é atrasada em dez minutos. .75

Figura 4.4 - A interface gráfica do vMonGluco Client ............................................................................... 80

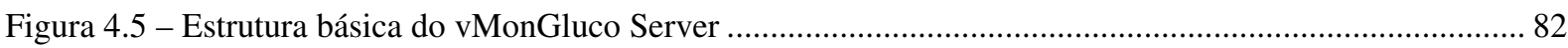

Figura 4.6 - A comunicação entre os monitores de beira de leito e os computadores da rede. 84

Figura 4.7 - O sistema funcionando em uma bancada de testes. Embaixo, à direita, vê-se o MiniMed CGMS gerando leituras simuladas de glicemia. Embaixo, à esquerda, está o palmtop com o programa vMonGluco Client. Ao fundo, o monitor de beira de leito exibe as leituras de glicemia na forma de uma tabela. 86

Figura 4.8 - Tela do vMonGluco Web mostrando os dados de um paciente (foi feita uma montagem para que todos os dados fosse exibidos numa única figura).

Figura 5.1 - Os gráficos mostram os pontos de calibração coletados no intervalo de tempo de algumas horas. Todos os pontos coletados em uma janela de 12 horas são incluídos no cálculo. O gráfico A representa o algoritmo em tempo real original, onde todos os pontos de calibração recebem a mesma ponderação. No gráfico B, os pontos de calibração são ponderados segundo uma função linear crescente. Um ponto no início da janela recebe ponderação nula (é descartado), enquanto que um ponto no fim da janela recebe ponderação unitária. No gráfico C, os pontos de calibração são ponderados segundo uma função normal, cujo topo, de valor unitário, localiza-se no final da janela......

Figura 5.2 - No gráfico à esquerda, a resposta do sensor é aproximada segundo uma função linear. À direita, a resposta do sensor é aproximada segundo uma função quadrática.

Figura 5.3 - Gráfico de Clarke comparando o algoritmo em tempo real com as leituras de "ponta de dedo"....... 98

Figura 5.4 - Gráfico de Clarke comparando o software do MiniMed CGMS com as leituras de "ponta de dedo".98

Figura A.1 - Numeração dos pinos de um conector serial (macho - 9 pinos). 
Figura B.1 - Gráfico de correlação.

Figura B.2 - Gráfico de dispersão centrado no ponto médio e com escalas uniformes ......

Figura D.1 - Gráfico de glicemia do paciente 1.

Figura D.2 - Gráfico de glicemia do paciente 2.

Figura D.3 - Gráfico de glicemia do paciente 3. .130

Figura D.4 - Gráfico de glicemia do paciente 4. .130

Figura D.5 - Gráfico de glicemia do paciente 5. .131

Figura D.6 - Gráfico de glicemia do paciente 6. .131

Figura D.7 - Gráfico de glicemia do paciente 7. .132

Figura D.8 - Gráfico de glicemia do paciente 9. .132

Figura D.9 - Gráfico de glicemia do paciente 10. .133

Figura D.10 - Gráfico de glicemia do paciente 11.

Figura D.11 - Gráfico de glicemia do paciente 12. .134

Figura D.12 - Gráfico de glicemia do paciente 13. .134

Figura E.1 - Folha de registro do protocolo de testes - página 1. .136

Figura E.2 - Folha de registro do protocolo de testes - página 2. .137

Figura E.3 - Folha de registro do protocolo de testes - página 3. .138

Figura E.4 - Folha de registro do protocolo de testes - página 4. 


\section{LiSTA DE TABELAS}

Tabela 3.1 - Lista cronológica das últimas versões do padrão $H L 7$..............................................................59

Tabela 5.1 - Exemplo de saída gerada pelo software do MiniMed CGMS ...................................................... 90

Tabela 5.2 - Variação do atraso das leituras de calibração (janela de calibração $=12$ horas, outros parâmetros $=$ $0)$

Tabela 5.3 - Variação da janela de calibração (atraso de 10 min, outros parâmetros $=0$ ).

Tabela 5.4 - Variação da janela de suavização (janela de calibração $=12$ horas, atraso $=10$ min, outros parâmetros $=0)$.

Tabela 5.5 - Variação do offset (janela de calibração $=12$ horas, atraso $=10 \mathrm{~min}$, janela de suavização $=0$ ) $\ldots 95$

Tabela 5.6 - Algoritmo ponderado linear, variação da janela de calibração (atraso = 10 min, janela de suavização $=0$, offset $=-3 / 3 / 1.5)$

Tabela 5.7 - Algoritmo ponderado normal, variação do desvio padrão (atraso $=10$ min, janela de suavização $=0$, offset $=-3 / 3 / 1.5)$

Tabela 5.8 - Algoritmo quadrático, variando desvio padrão do termo de segunda ordem (janela de calibração = 12 horas, atraso $=10 \mathrm{~min}$, janela de suavização $=0$, offset $=-3 / 3 / 1.5$ ).

Tabela 5.9 - Diferença entre os valores de glicemia obtidos pelo algoritmo do software do MiniMed CGMS e pelo algoritmo em tempo real ótimo. O coeficiente de correlação obtido foi 0,922 .......

Tabela 5.10 - Diferença entre os valores de glicemia obtidos pelo algoritmo em tempo real ótimo e pelas "pontas de dedo". O coeficiente de correlação obtido foi 0,764 .

Tabela 5.11 - Diferença entre os valores de glicemia obtidos pelo software do MiniMed CGMS e pelas "pontas de dedo". O coeficiente de correlação obtido foi 0,868 .

Tabela A.1 - Função dos pinos de um conector serial (macho - 9 pinos). ...................................................118

Tabela A.2 - Esquema de ligação de pinos no cabo serial null-modem de 9 pinos (duplo macho)....................119

Tabela B.1 - Cálculo do coeficiente de correlação..................................................................................121

Tabela C.1 - Valores de exemplo de corrente elétrica e glicemia. ..............................................................123

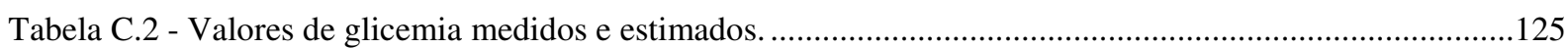




\section{LISTA DE ABREVIATURAS E SIGLAS}

- ANSI - American National Standards Institute: entidade norte americana que desenvolve e regulamenta normas.

- CGMS - Continuous Glucose Monitoring System: dispositivo criado pela Medtronic Diabetes para monitoramento contínuo de glicose.

- CIC - Connectivity Industry Consortium: consórcio formado em 2000 por fabricantes de equipamentos médicos e instituições de saúde para a criação de uma norma de comunicação para dispositivos POCT. Essa norma é hoje administrada pela NCCLS.

- FDA - Food and Drug Administration: órgão do governo norte-americano que regulamenta, entre outros, a comercialização de aparelhos médicos.

- HIS - Hospital Information System: sistema de informações clínicas utilizado em um hospital.

- HL7 - Health Level Seven: protocolo de comunicação utilizado em sistemas de informações médicas.

- JDBC - Java Database Connectivity: protocolo padrão de acesso a banco de dados relacionais a partir de softwares desenvolvidos em Java.

- LIS - Laboratory Information System: sistema de informações clínicas utilizado em um laboratório de análises clínicas.

- $\quad$ NCCLS - National Committee for Clinical Laboratory Standards: organização norteamericana que administra a norma de comunicação para dispositivos POCT (NCCLS POCT1-A).

- OSI - Open Systems Interconnection: modelo conceitual de arquitetura de comunicação em redes proposto pela ISO (International Standards Organization). 
- Pocket PC: sistema operacional da Microsoft Corp. utilizado em computadores portáteis do tipo palmtop. Em alguns casos, emprega-se o mesmo termo para os palmtops que utilizam tal sistema operacional.

- POCT - Point of Care Testing: categoria de testes clínicos realizados à beira de leito através do uso de dispositivos portáteis.

- TCP/IP - Transmission Control Protocol / Internet Protocol: protocolos de comunicação utilizados em redes locais e na Internet.

- USB - Universal Serial Bus: porta para conexão de dispositivos a um computador.

- UTI - Unidade de Terapia Intensiva: ala de um hospital dedicada ao monitoramento e tratamento de pacientes críticos.

- WiFi: tecnologia de rede sem fio de médio alcance (da ordem de $100 \mathrm{~m}$ ). A rede sem fio é equivalente a uma rede tradicional de computadores (Ethernet), diferindo-se no uso de ondas de rádio para a transmissão de dados, ao invés do uso tradicional de cabos elétricos. 


\section{LISTA DE SÍMBOLOS}

\section{Calibração de sensores enzimáticos (seção 2.5.2 e Apêndice C)}

- $G$ - valor de glicemia.

- $\hat{G}$ - valor estimado de glicemia.

- I- corrente elétrica gerada pelo sensor de glicose.

- $I_{0}$ - corrente de fundo (corrente gerada pelo sensor de glicose quando a glicemia é nula).

- $n$ - número de pontos de calibração.

- $\quad S$ - fator de escala entre a corrente elétrica gerada pelo sensor de glicose (I) e o valor de glicemia $(\mathrm{G})$.

- $S_{1}$ - fator de escala linear (para o método de regressão quadrática).

- $S_{2}$ - fator de escala quadrático (para o método de regressão quadrática).

Modelo do ciclo de glicose (seção 2.5.3)

- $G_{e n d}-$ glicose endógena, liberada pelo fígado para a corrente sangüínea.

- $G_{e x}-$ glicose exógena, obtida a partir dos alimentos ingeridos.

- $G_{I}-$ concentração de glicose no líquido intersticial

- $G_{K}-$ glicose eliminada na urina

- $G_{S}$ - concentração de glicose no sangue

- $\quad$ - fluxo de glicose entre o sangue e o líquido intersticial

- $O$ - fluxo de glicose entre o líquido intersticial e as células 


\section{Algoritmos de calibração (seções 2.6 .2 e 4.5.2)}

- $D A$ - soma das diferenças absolutas entre os valores de glicemia estimados pelo algoritmo e as glicemias de calibração equivalentes.

- $D A M$ - diferença absoluta média entre os valores de glicemia estimados pelo algoritmo e as glicemias de calibração equivalentes.

- $\quad I S I G$ - corrente elétrica gerada pelo sensor (nomenclatura da Medtronic Diabetes).

- Meter $B G$ - valor de glicemia obtido a partir de um procedimento de calibração (nomenclatura da Medtronic Diabetes).

- OFFSET - corrente de fundo (corrente gerada pelo sensor de glicose quando a glicemia é nula, nomenclatura da Medtronic Diabetes).

- Sensor $B G$ - valor de glicemia medido através do sensor de glicose (nomenclatura da Medtronic Diabetes).

- $S L O P E$ - fator de escala entre a corrente elétrica gerada pelo sensor de glicose e o valor de glicemia (nomenclatura da Medtronic Diabetes).

- VALID ISIG - corrente elétrica gerada pelo sensor de glicose, considerando-se um atraso de dez minutos para a compensação da diferença entre a concentração de glicose sanguiínea e intersticial (nomenclatura da Medtronic Diabetes).

\section{Coeficiente de correlação (Apêndice B)}

- $x$ - corrente elétrica gerada pelo sensor de glicose.

- $\quad \bar{x}$ - média dos valores de corrente elétrica.

- $y$ - valor de glicemia.

- $\quad \bar{y}$ - média dos valores de glicemia.

- $\quad D P(\cdot)$ - desvio padrão

- $\quad r$-coeficiente de correlação. 


\section{Lista DE ALgoritMos}

Algoritmo 2.1 - Algoritmo de calibração (software do MiniMed CGMS) …...................................................44

Algoritmo 4.1 - Algoritmo de calibração em tempo real ................................................................................78 


\section{SUMÁRIO}

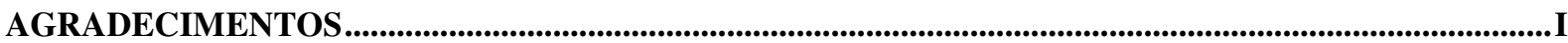

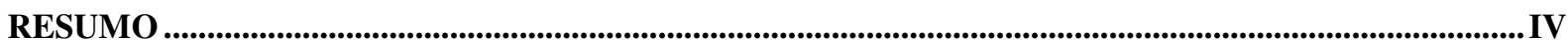

ABSTRACT .......................................................................................................................................................... V

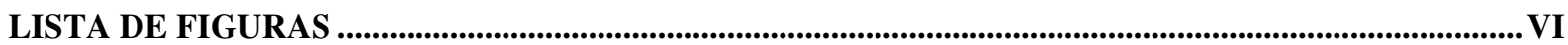

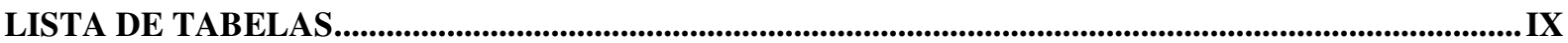

LISTA DE ABREVIATURAS E SIGLAS ........................................................................................................ X

LISTA DE SÍMBOLOS ............................................................................................................................................. XII

CALIBRAÇÃO DE SENSORES ENZIMÁTICOS (SEÇÃO 2.5.2 E APÊNDICE C) ............................................................. XII

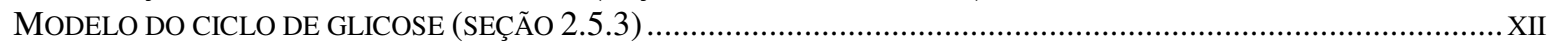

ALGORITMOS DE CALIBRAÇÃO (SEÇÕES 2.6.2 E 4.5.2) ……..........................................................................

COEFICIENTE DE CORRELAÇÃO (APÊNDICE B) …………..........................................................................

LISTA DE ALGORITMOS ................................................................................................................................ XIV

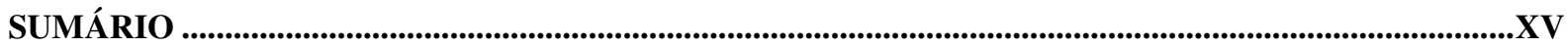

CAPÍTULO 1. INTRODUÇÃO .......................................................................................................................................... 1

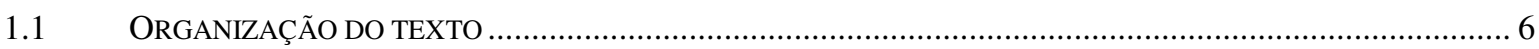

CAPÍTULO 2. SISTEMAS DE MONITORAMENTO CONTÍNUO DE GLICOSE ....................................... 8

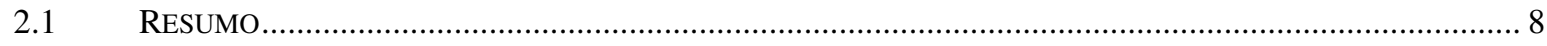

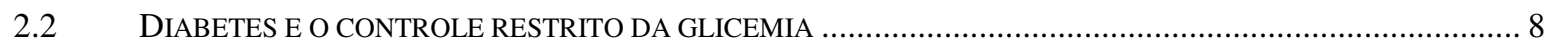

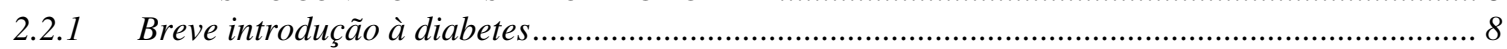

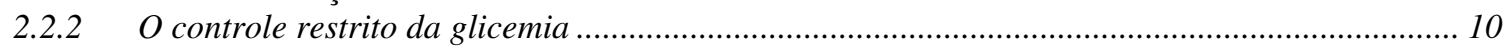

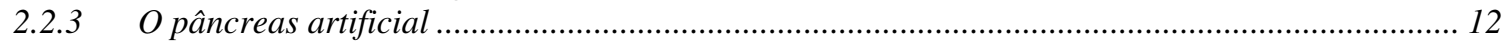

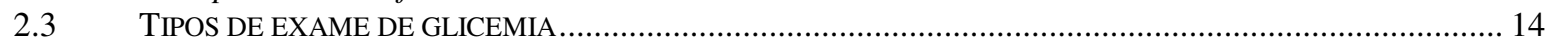

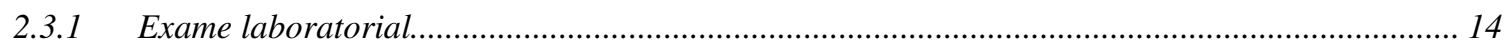

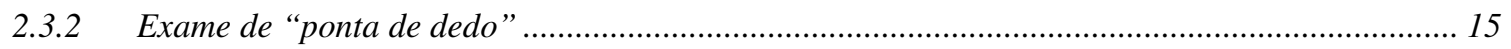

2.3.3 Sensores contínuos semi-invasivos ....................................................................................... 16

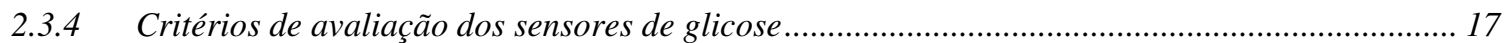

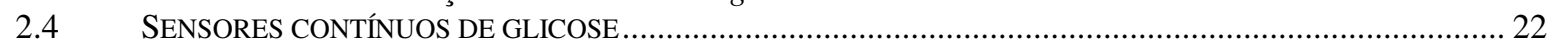

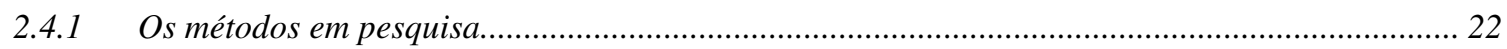

2.4.2 Sistemas comerciais de monitoramento contínuo de glicose......................................................... 24

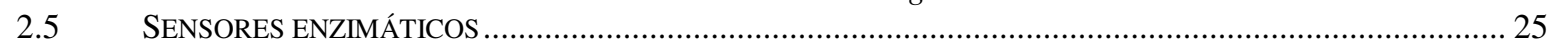

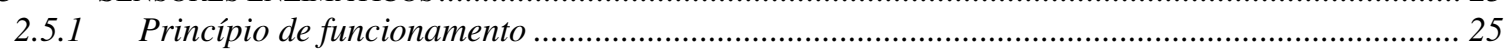

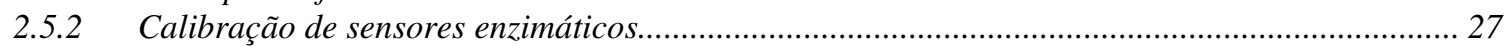

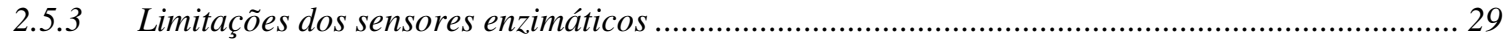

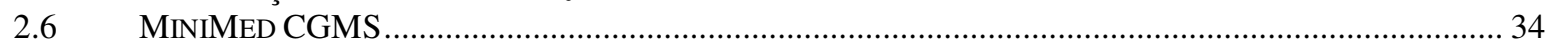

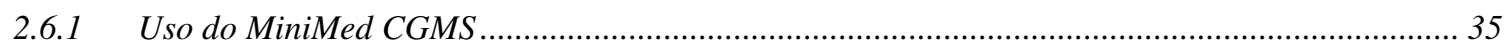

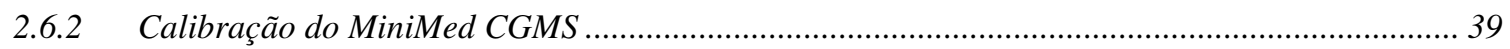

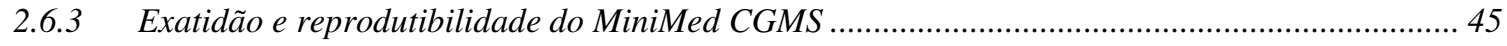

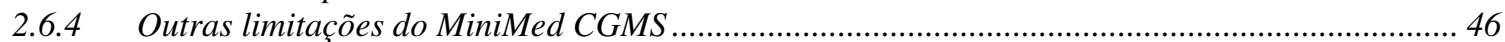

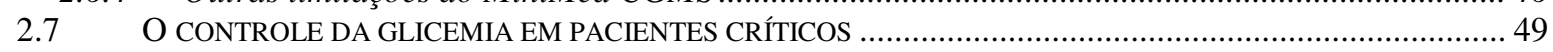

2.7.1 A hiperglicemia em pacientes críticos.................................................................................... 49 


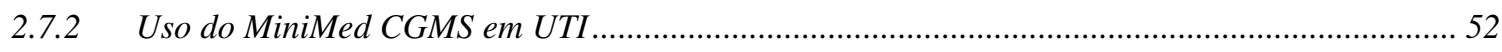

CAPÍTULO 3. INTEGRAÇÃO DE SISTEMAS DE MONITORAMENTO DE PACIENTES .................... 55

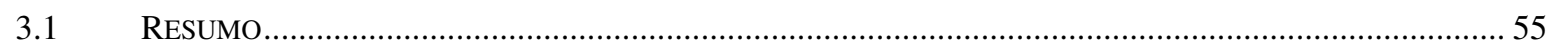

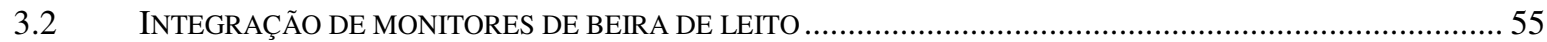

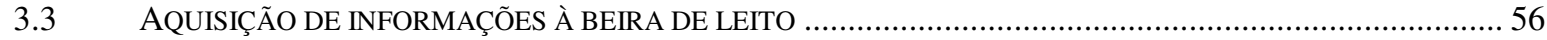

3.4 O PROTOCOLO DE COMUNICAÇ̃̃O HEALTH LEVEL SEVEN ……......................................................59

3.5 O PADRÃO NCCLS POCT1-A DE CONECTIVIDADE DE EQUIPAMENTOS MÉDICOS .............................. 62

CAPÍTULO 4. IMPLEMENTAÇÃO ............................................................................................................................ 65

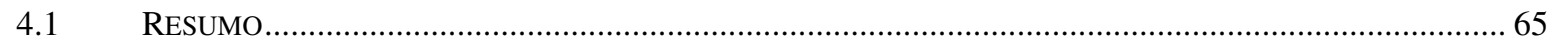

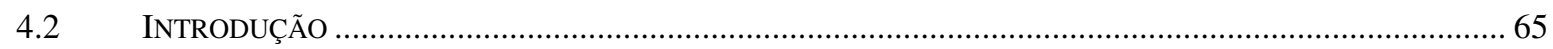

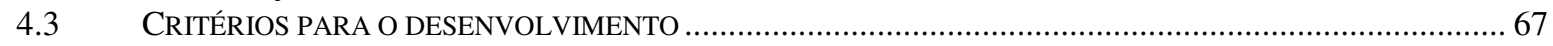

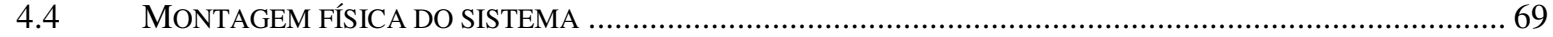

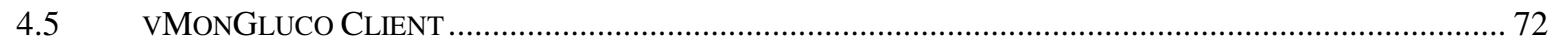

4.5.1 O protocolo de comunicação do MiniMed CGMS ....................................................................... 73

4.5.2 O algoritmo de calibração em tempo real...................................................................... 74

4.5.3 Interface gráfica do vMonGluco Client........................................................................... 79

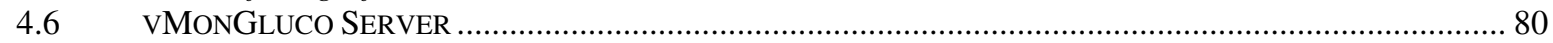

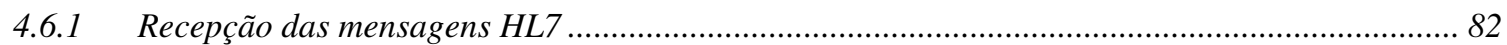

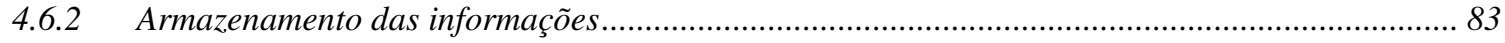

4.6.3 Envio das leituras ao monitor de beira de leito ................................................................. 83

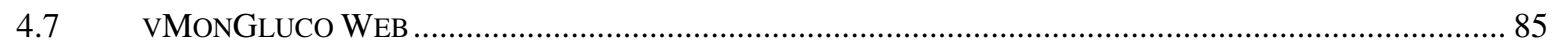

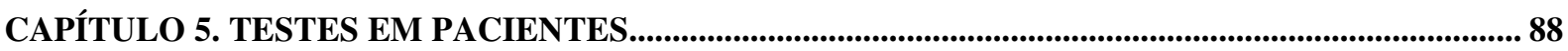

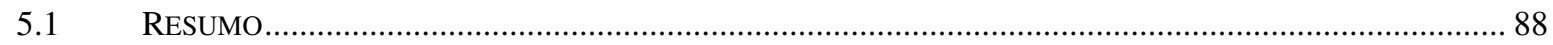

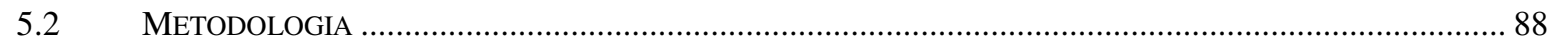

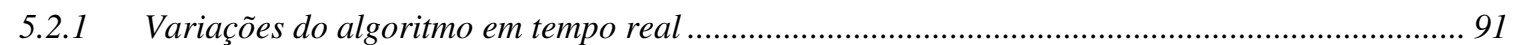

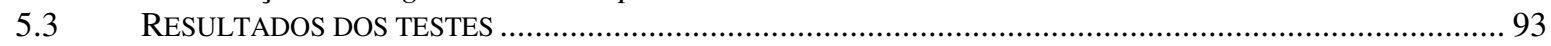

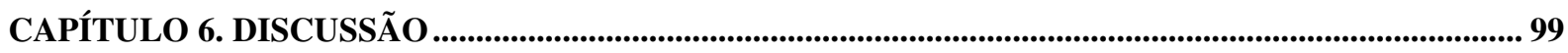

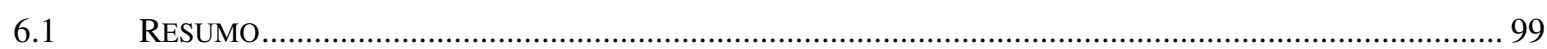

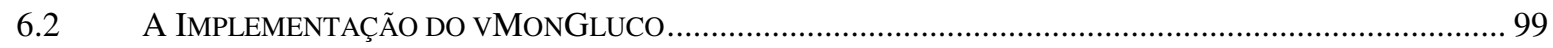

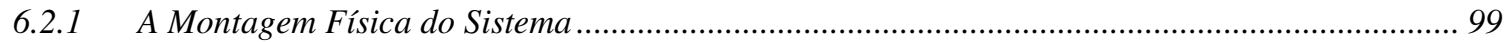

6.2.2 A Implementação do Software ............................................................................................... 101

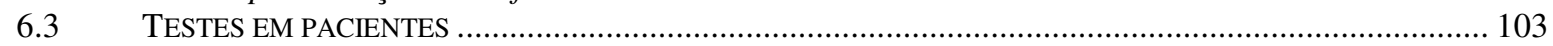

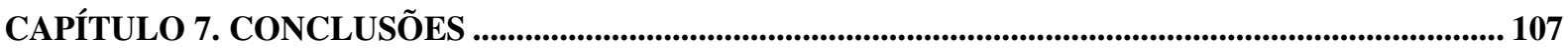

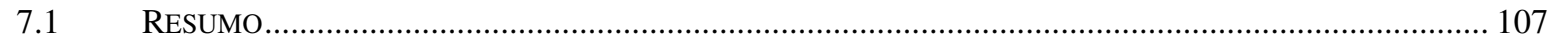

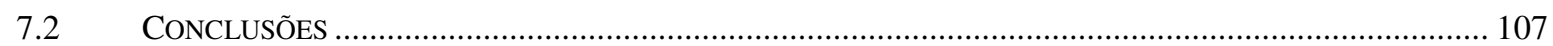

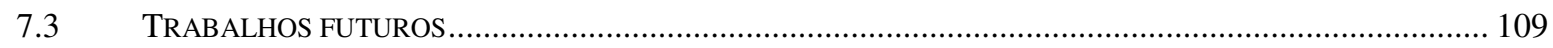

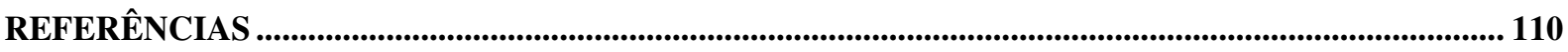

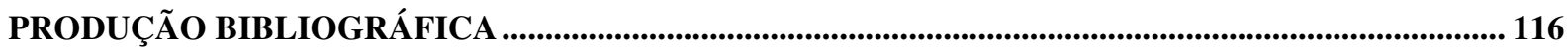

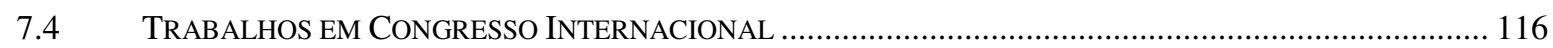

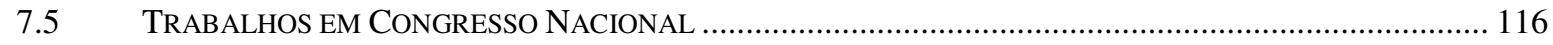

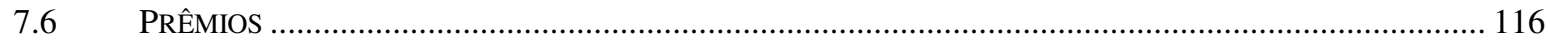

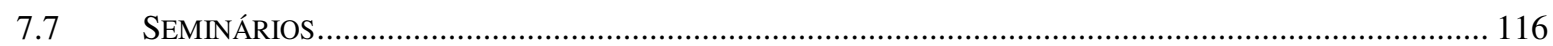

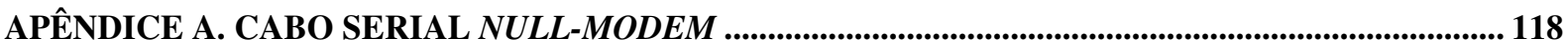

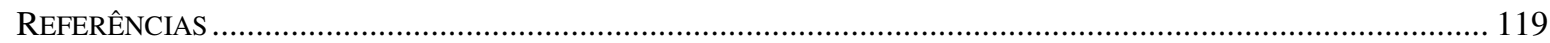

APÊNDICE B. COEFICIENTE DE CORRELAÇÃO ..................................................................................... 120

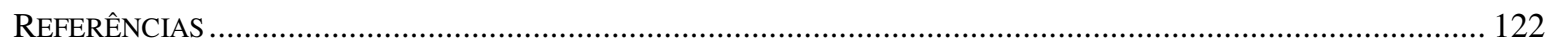

APÊNDICE C. REGRESSÃO LINEAR - MÉTODO DOS MÍNIMOS QUADRADOS.............................. 123

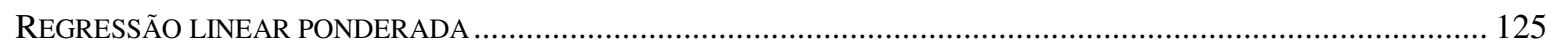

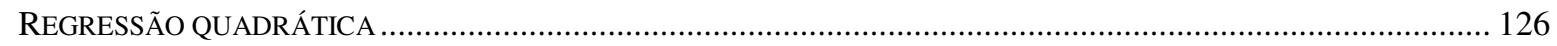

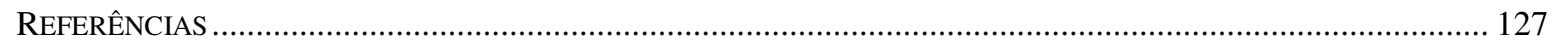


APÊNDICE D. GRÁFICOS DE GLICEMIA DOS TESTES COM PACIENTES

APÊNDICE E. FOLHAS DE REGISTRO - PROTOCOLO DE TESTES ............................................... 135 


\section{Capítulo 1. INTRODUÇÃO}

Diabetes é o nome dado a um conjunto de doenças que alteram o metabolismo de glicose no corpo humano. Uma taxa insuficiente de produção de insulina (hormônio que regula a concentração de glicose sangüínea), aliada a uma baixa sensibilidade das células à insulina, podem desencadear a diabetes, causando o surgimento de altos valores de glicemia (concentração de glicose sangüínea). A diabetes é uma doença grave que, se não tratada adequadamente, traz uma série de complicações ao paciente. Em casos extremos, a hiperglicemia (alta concentração de glicose sangüínea) pode levar um paciente ao coma e até à morte. A médio e longo prazo, a diabetes pode causar o surgimento de doenças cardíacas, hipertensão, nefropatias, neuropatias, entre outros.

O principal meio de diagnóstico da diabetes é através da medição da glicemia. Tradicionalmente, é feito um exame laboratorial a partir de uma amostra de sangue para essa medição. É também comum a medição da glicemia através de dispositivos portáteis, a partir de pequenas amostras de sangue, colhidas, geralmente, através de um furo na ponta do dedo. Esse tipo de exame é menos exato, mas permite a obtenção do resultado em apenas alguns minutos.

Nos casos mais graves de diabetes, o controle de glicemia é feito através de várias medições de glicemia ao longo do dia, aliadas à injeção de insulina. Vários estudos mostram que um controle glicêmico restrito, isto é, a manutenção da glicemia em uma faixa bastante restrita, pode reduzir a ocorrência de complicações, trazendo, assim, um aumento significativo da expectativa de vida desses pacientes (DIABETES CONTROL AND COMPLICATIONS TRIAL..., 1993; FURNARY et al., 1999; MALMBERG, 1997). 
Pacientes críticos tratados em uma UTI também podem apresentar quadros de hiperglicemia e baixa sensibilidade à insulina, mesmo que não sejam previamente diabéticos. Esse quadro de hiperglicemia está freqüentemente associado a outros diagnósticos bastante sérios, como infecção severa, choque séptico e infarto de miocárdio, e tais pacientes possuem um prognóstico bastante pessimista (CHASE et al., 2006; VAN DEN BERGHE, 2004). Estudos mostram que, da mesma forma que na diabetes, o controle glicêmico restrito pode reduzir a mortalidade e morbidade de pacientes críticos hiperglicêmicos, reduzindo também seu tempo de internação (VAN DEN BERGHE, 2004; VAN DEN BERGHE et al.; 2006).

Atualmente, o controle glicêmico nos pacientes críticos de uma UTI é feito através de medições constantes (a cada uma hora, aproximadamente) a partir de pequenas amostras de sangue. Esse controle é bastante trabalhoso para a equipe de enfermagem; além disso, eventos de hipo ou hiperglicemia (baixa ou alta concentração de glicose sangüínea) são detectados muito tardiamente. Assim, existe a necessidade de se encontrar novos métodos de medição da glicemia, se possível, de forma contínua e automatizada, e com o mínimo de desconforto ao paciente.

Nos últimos anos, surgiram os primeiros sistemas comercias de monitoramento contínuo de glicose para pacientes diabéticos (uso ambulatorial), como o MiniMed CGMS (CGMS SYSTEM GOLD..., 2005), o GlucoWatch (GLUCOWATCH, 2005) e o GlucoDay (GLUCODAY S..., 2007). Embora alguns desses equipamentos ofereçam leituras em tempo real, para se ter acesso aos registros armazenados ao longo do tempo, é necessária a transferências das leituras armazenadas no equipamento para um computador pessoal. Tal procedimento dificulta a utilização desses equipamentos em ambientes e condições severas, como nas UTIs cirúrgicas ou clínicas, onde eventos de hipo ou hiperglicemia são bastante freqüientes. 
O trabalho apresentado a seguir foi desenvolvido no Serviço de Informática do Instituto do Coração (Hospital das Clínicas da Faculdade de Medicina da Universidade de São Paulo). O objetivo do trabalho foi a implementação do vMonGluco, um sistema de monitoramento contínuo de glicose, com leituras em tempo real, utilizando-se, como base, um equipamento de registro contínuo de glicose.

Para o desenvolvimento do projeto, idealizou-se, como caso de uso, um paciente crítico hiperglicêmico internado em uma UTI clínica. Tal paciente necessita de um monitoramento contínuo da glicemia. Utiliza-se, para este fim, um monitor contínuo de glicose disponível comercialmente. O monitor de glicose é acoplado a um palmtop, baseado no sistema operacional Pocket PC (Microsoft, EUA), através de um cabo serial. O palmtop obtém os dados gerados pelo sensor de glicose e gera uma leitura a cada cinco minutos. O valor da glicemia é exibido na tela do aparelho, juntamente com um gráfico, onde é apresentada a série histórica dos valores coletados desde o início da monitoração. Dessa forma, buscou-se ampliar as capacidades originais do monitor de glicemia (Figura 1.1).

Considerando-se a situação clínica apresentada (controle glicêmico de um paciente crítico), e comparando-se a freqüência da geração das leituras a outros tipos de exame existentes (como o exame laboratorial e a "ponta de dedo"), tomou-se a liberdade de denominar as leituras geradas como leituras contínuas em tempo real. Assim, ao longo deste trabalho, as leituras geradas pelo sistema vMonGluco recebem tal denominação, mesmo que estas sejam, na realidade, obtidas a cada cinco minutos. 


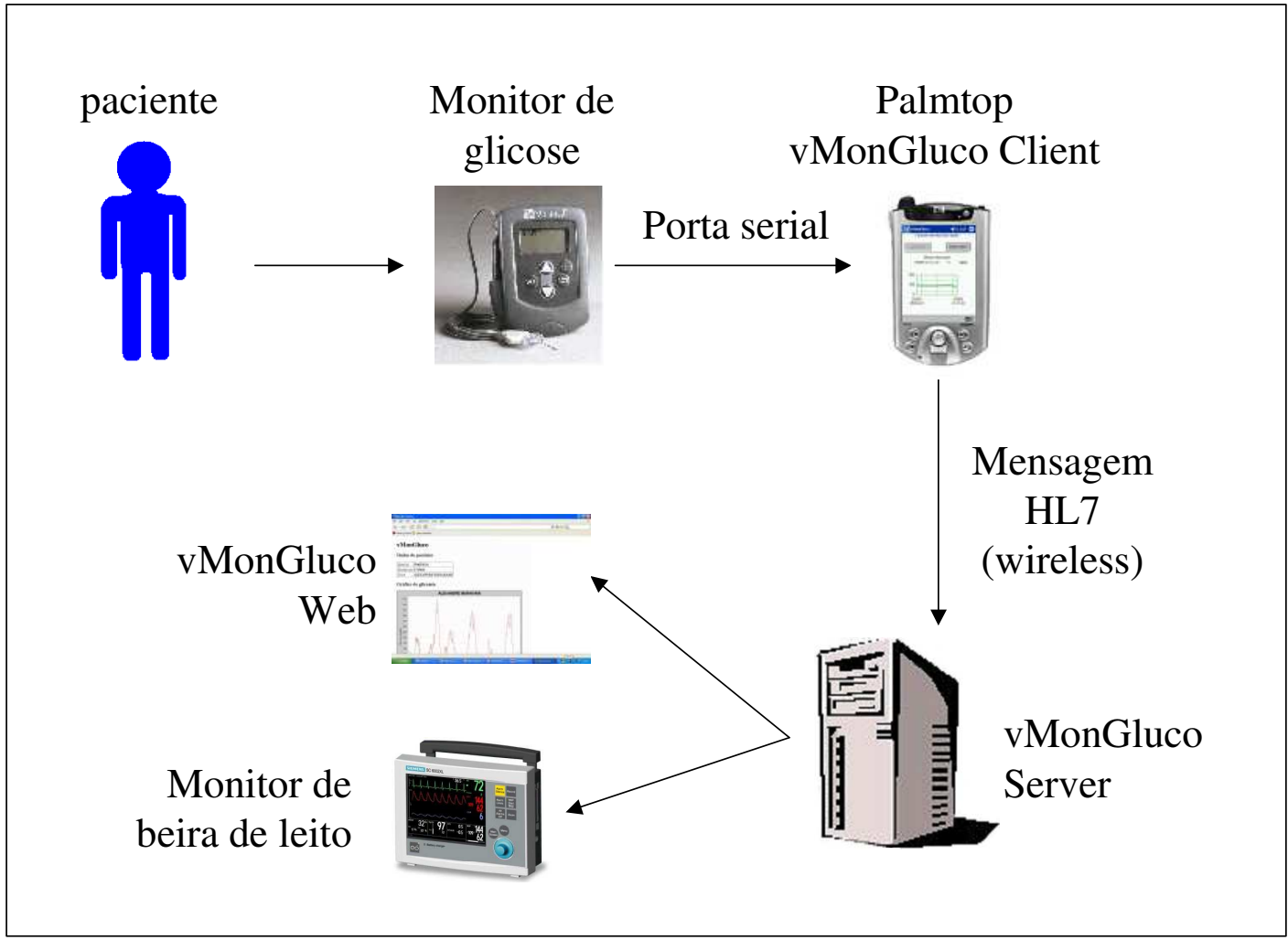

\section{Figura 1.1 - Diagrama esquemático do vMonGluco - Sistema de Monitoramento Contínuo de Glicose.}

As leituras de glicemia são transmitidas e armazenadas em um sistema de informações hospitalares (Hospital Information System- HIS), o que permite o rápido fluxo de informações. As leituras também são transmitidas e exibidas em um monitor de beira de leito, facilitando o trabalho da equipe médica local. A transmissão das informações é feita através do protocolo Health Level Seven (HEALTH LEVEL SEVEN, 2007), norma internacional de comunicação para sistemas de informações médicas. Do ponto de vista tecnológico, a aderência a normas de comunicação internacionais permite que a integração entre os diversos módulos de um sistema seja feita de maneira muito mais rápida e eficaz.

Uma primeira etapa do projeto incluiu o desenvolvimento de um programa para palmtop, chamado aqui de vMonGluco Client, com as seguintes funções:

- Comunicação com o monitor de glicose para a obtenção das leituras (de corrente elétrica) do sensor. 
- Calibração e conversão das leituras (de corrente elétrica) do sensor em valores de glicemia.

- Exibição, na tela do Pocket PC, do último valor de glicemia coletado, bem como de um gráfico, contendo a série histórica dos valores de glicemia armazenados.

- Transmissão dos valores de glicemia para o vMonGluco Server. Essa transmissão é realizada utilizando-se o protocolo $H L 7$, norma de comunicação para informações médicas.

Desenvolveu-se, também, um programa servidor, batizado de vMonGluco Server. Esse servidor possui as seguintes funções:

- O servidor recebe as leituras de glicemia geradas pelo vMonGluco Client.

- O servidor armazena as informações coletadas em um banco de dados. Essas informações podem ser visualizadas posteriormente através de uma interface web denominada vMonGluco Web.

- O servidor retransmite as informações recebidas para um monitor de beira de leito. Dessa forma, as leituras de glicemia podem ser facilmente visualizadas pela equipe médica.

O projeto incluiu ainda a realização de testes de campo em pacientes reais. A realização de tais testes teve, como objetivo, a validação das leituras de glicemia geradas pelo sistema vMonGluco. Deve-se notar que, para gerar as leituras de glicemia em tempo real, o vMonGluco Client utiliza um método de calibração diferente do software original do MiniMed $C G M S$, o que justifica a realização dos testes.

Os testes de campo foram realizados com a colaboração da Unidade de Terapia Intensiva Clínica do Instituto do Coração. Os dados coletados foram analisados e interpretados neste trabalho. 
Não se pretende, com o presente projeto, apresentar uma solução definitiva. O projeto utiliza-se basicamente de equipamentos disponíveis no mercado brasileiro. A busca de um sistema para utilização prática efetiva envolve esforços de maior porte, como o desenvolvimento de hardware especializado e busca por sensores de maior exatidão. Mesmo assim, pode-se dizer que o sistema proposto é razoavelmente próximo de uma solução definitiva.

Vale citar ainda que não se propõe, para este trabalho, uma análise detalhada sobre os aspectos clínicos da utilização do sistema. O ponto de partida para o desenvolvimento do projeto, obviamente, é a necessidade clínica. Entretanto, o presente trabalho foca a análise sob o ponto de vista da Engenharia, pois, caso contrário, o escopo do projeto tornar-se-ia exageradamente abrangente.

Resumindo, portanto, os tópicos discutidos ao longo deste capítulo, pretendeu-se desenvolver o vMonGluco, um sistema de monitoramento contínuo de glicose, com a obtenção de leituras em tempo real. Além disso, propôs-se uma solução de integração do vMonGluco a um sistema de informações médicas, com o uso de tecnologias móveis e a aderência a normas de integração. Assim, com o presente trabalho, esperou-se trazer uma contribuição prática e significativa no tratamento de pacientes críticos hiperglicêmicos, além de explorar algumas das vantagens proporcionadas pela integração de sistemas de informações médicas.

\subsection{Organização do texto}

Este texto está organizado da seguinte forma:

- No Capítulo 2 (Sistemas de Monitoramento Contínuo de Glicose), é apresentada uma revisão da literatura a respeito dos sistemas de monitoramento contínuo de glicose, dando ênfase aos sistemas baseados em sensores enzimáticos de glicose. São discutidas, também, algumas particularidades do MiniMed CGMS, o sistema 
comercial de monitoramento contínuo de glicose utilizado durante o desenvolvimento deste trabalho.

- No Capítulo 3 (Integração de Sistemas de Monitoramento de Pacientes), é apresentada uma revisão da literatura a respeito da integração de sistemas de monitoramento de paciente a sistemas de informação médica.

- No Capítulo 4 (Implementação), é explicada a metodologia de trabalho utilizada na implementação do sistema vMonGluco, objeto de estudo deste trabalho.

- No Capítulo 5 (Testes em pacientes), é apresentada a metodologia de testes do vMonGluco em pacientes, além dos resultados obtidos.

- No Capítulo 6 (Discussão), é feita uma discussão crítica dos resultados obtidos.

- Finalmente, no Capítulo 7 (Conclusões), são apresentadas as conclusões a respeito dos resultados do trabalho, além da proposição de trabalhos futuros. 


\section{Capítulo 2. Sistemas de MONITORAMENTO ConTínuo de GLicose}

\subsection{Resumo}

Neste capítulo, é apresentada uma revisão da literatura a respeito dos sistemas de monitoramento contínuo de glicose, dando ênfase aos sistemas baseados em sensores enzimáticos de glicose. São discutidas, também, algumas particularidades do MiniMed CGMS, o sistema comercial de monitoramento contínuo de glicose utilizado durante o desenvolvimento deste trabalho.

\subsection{Diabetes e o controle restrito da glicemia}

\subsubsection{Breve introdução à diabetes}

A principal fonte de energia do corpo humano é um açúcar chamado glicose. A glicose é obtida a partir dos alimentos ingeridos pelo indivíduo. Durante o processo de digestão dos alimentos, a glicose obtida passa para a circulação sangüínea. Para a maior parte das células do corpo, para que estas possam absorver a glicose sangüínea, é necessária a presença de um hormônio, a insulina. A insulina é produzida no pâncreas pelas chamadas células beta.

Há um conjunto de doenças crônicas que afetam o metabolismo da glicose e da insulina. Essas doenças são conhecidas como diabetes.

Há dois tipos de diabetes mais comuns, elas são conhecidas como diabetes tipo 1 e diabetes tipo 2. A diabetes tipo 1 é causada pela diminuição ou ausência de produção de insulina, levando a glicose a uma concentração sangüínea elevada. A diabetes tipo 1 ocorre com maior freqüência entre crianças e jovens. Normalmente, inclui-se, no tratamento, a 
injeção de insulina várias vezes ao dia. A diabetes tipo 2 é normalmente causada pela redução da sensibilidade à insulina. Isto significa que o corpo continua produzindo insulina, mas esta possui um efeito reduzido sobre as células do corpo. Assim, leva-se a uma produção elevada de insulina, associada a níveis elevados de glicose sanguiínea. A diabetes tipo 2 ocorre com maior freqüência após os 40 anos de idade. Normalmente, um tratamento que combina uma dieta controlada e a prática de exercícios físicos é suficiente para o controle da doença, reservando-se a aplicação de insulina aos casos mais graves.

Uma série de complicações graves podem ocorrer em virtude do descontrole da diabetes. Concentração elevadas de glicose sangüínea (hiperglicemia) podem levar ao emagrecimento e à desidratação. Em casos extremos, a hiperglicemia pode levar ao coma e até à morte. Em pacientes que utilizam insulina injetada, é comum a ocorrência do processo inverso, isto é, baixas concentrações de glicose sangüínea (hipoglicemia). Esse processo é igualmente grave e também pode levar ao coma se não for tratado. Mais preocupantes ainda são as complicações que podem surgir a longo prazo. O tratamento irregular da diabetes pode levar a complicações como doenças cardíacas (infarto agudo de miocárdio, hipertensão arterial, derrame etc.), lesões nos pés, nefropatias, neuropatias, além da retinopatia diabética, que pode levar à redução ou à perda da visão.

O principal meio de diagnóstico da diabetes é feito através da medição da concentração de glicose sangüínea (também conhecida como glicemia). Usualmente, a diabetes caracteriza-se por altas concentrações de glicose sangüínea (hiperglicemia). A medição da glicemia pode ser feita através de um exame laboratorial a partir de uma amostra de sangue. O resultado é bastante exato e pode ser obtido em algumas horas.

Em alguns casos de diabetes, especialmente na diabetes tipo 1, faz-se necessária a aplicação de insulina. A injeção de insulina pode ser feita várias vezes ao dia, de acordo com a gravidade da doença. Dependendo do caso, utiliza-se uma bomba de insulina, dispositivo 
que injeta a insulina de maneira aproximadamente contínua. A quantidade de insulina injetada varia de acordo com a glicemia no momento da aplicação. Por isso, o diabético precisa medir a glicemia antes de cada aplicação.

Devido à frequiência com que a glicemia deve ser medida, tornou-se necessária a criação de outros meios de medição além do exame laboratorial de sangue. Um tipo de medição bastante comum inclui o uso de fitas de teste e medidores portáteis de glicose. Esses dispositivos permitem que o próprio paciente meça a glicemia através da coleta de uma ou duas gotas de sangue. Normalmente, essa gota é colhida através de um pequeno furo feito na ponta de um dos dedos; por isso, o exame é informalmente conhecido como "exame de ponta de dedo". O resultado é obtido em alguns minutos e apresenta um grau de exatidão satisfatório (ver seção 2.3).

\subsubsection{O controle restrito da glicemia}

No início da década de 90, o Diabetes Control And Complications Trial (DCCT) Research Group acompanhou o desenvolvimento da diabetes em cerca de 1500 pacientes ao longo de 6,5 anos. Mostrou-se, de maneira bastante conclusiva, que um controle restrito da glicemia, isto é, a manutenção da glicemia em uma faixa restrita de valores, reduz a incidência de diversas complicações, em especial, a retinopatia (DIABETES CONTROL AND COMPLICATIONS TRIAL..., 1993).

O método tradicional de controle da glicemia implica na sua medição várias vezes ao dia, seguida da injeção de insulina. Alternativamente, pode-se utilizar uma bomba de insulina no lugar das aplicações manuais, com resultados ainda melhores. Neste caso, as medidas de glicemia servem para o ajuste da taxa de injeção de insulina. Tradicionalmente, para a medição da glicemia, são usados medidores portáteis de glicose do tipo “ponta de dedo". Essa rotina de controle da glicemia é realizada pelo próprio paciente, e é bastante trabalhosa, resultado numa redução da qualidade de vida do paciente. 
Além disso, os métodos tradicionais de medição de glicemia fornecem medidas pontuais, e isso é um fator limitante sério. Eles medem a glicemia em um dado instante, mas não permitem saber qual foi a variação da glicemia entre duas medições. A obtenção de uma leitura contínua de glicemia seria de grande valia para a realização de um controle glicêmico mais eficiente.

Por exemplo, um evento difícil de ser detectado é a hipoglicemia noturna. A hipoglicemia noturna é geralmente causada por uma aplicação excessiva de insulina antes do repouso noturno. Durante o sono, a glicemia do paciente atinge níveis muito baixos. Os sintomas da hipoglicemia noturna são discretos e de difícil detecção. Além disso, a medição de glicemia durante o sono do paciente diabético ambulatorial é um procedimento raramente adotado, devido à dificuldade prática da sua execução.

A detecção de hipoglicemia noturna tem sido facilitada ultimamente pelo uso de sistemas de monitoramento contínuo de glicose (BODE et al., 1999; BOLAND et al., 2001; MONSOD et al., 2002; PITZER et al., 2001). Idealmente, um sistema de monitoramento contínuo de glicose permite a obtenção da leitura de glicemia de modo contínuo, a todo instante. As leituras de glicemia obtidas ao longo do dia ficam registradas no aparelho. Dessa forma, a ocorrência de hipoglicemia noturna pode ser identificada imediatamente ou, quando muito, na manhã seguinte ao evento. As doses de insulina aplicadas antes do repouso noturno podem, então, ser corrigidas, evitando-se novas incidências do evento. Embora ainda haja várias restrições (ver seção 2.5.3), o uso de sistemas de monitoramento contínuo de glicose tem apresentado bons resultados (Figura 2.1). 


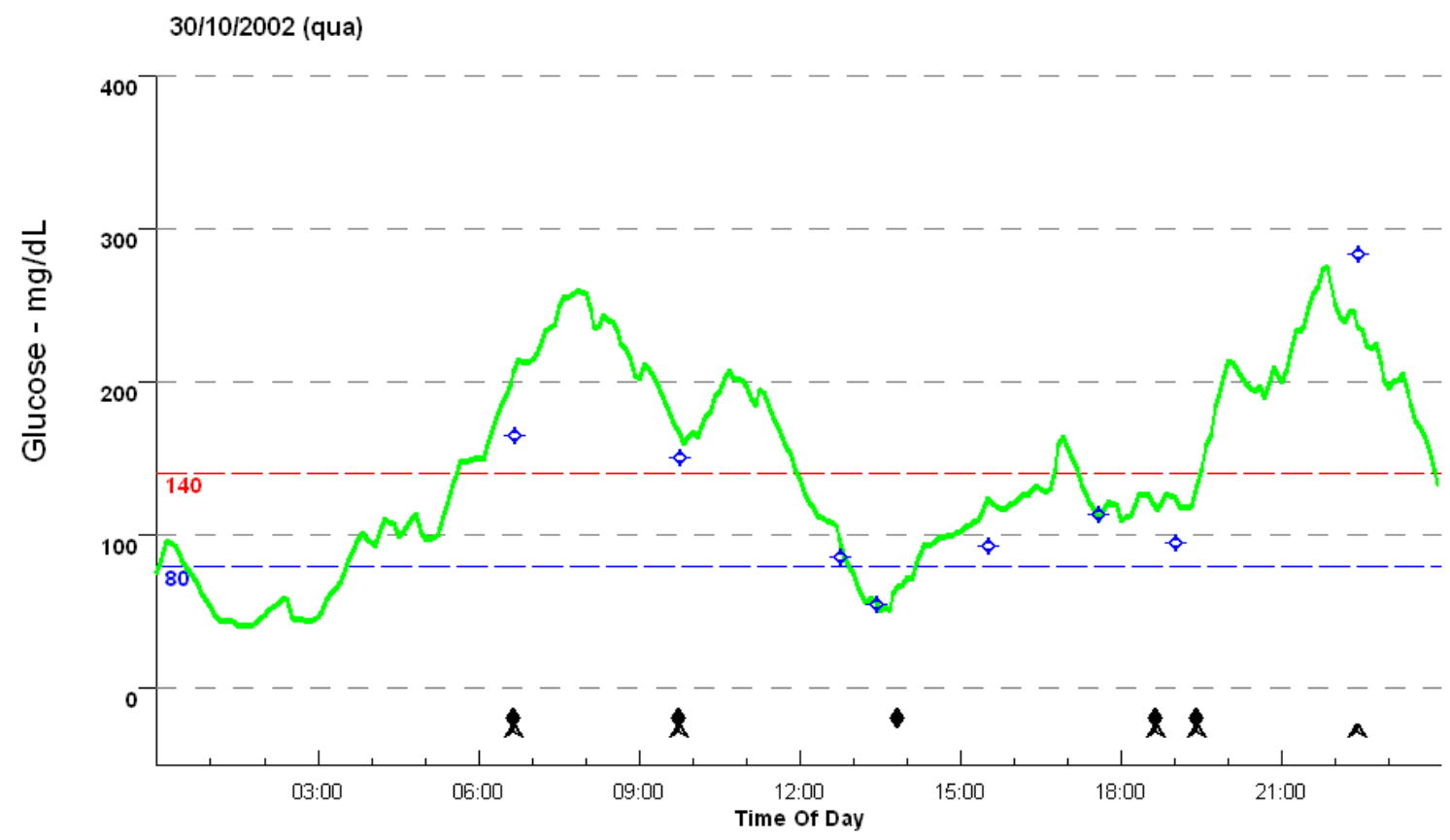

Figura 2.1 - Exemplo de leitura obtida através de um sistema de monitoramento contínuo de glicose (MiniMed CGMS). O gráfico mostra a variação da glicemia ao longo de um dia. Duas linhas horizontais delimitam a faixa ideal de glicemia para este paciente (entre 80 e $140 \mathrm{mg} / \mathrm{dL}$ ). As marcas em forma de estrela indicam leituras obtidas através do meio tradicional de medição de glicemia ("ponta de dedo"). Nota-se que, entre aproximadamente 1:00 e 4:00 da madrugada, o paciente apresentou uma hipoglicemia noturna, isto é, a glicemia ficou abaixo da faixa ideal. Essa hipoglicemia não foi detectada pelo exame tradicional, já que não foram feitas leituras nesse intervalo de tempo.

\subsubsection{O pâncreas artificial}

O controle restrito da glicemia seria plenamente atingido, idealmente, através do uso de um sistema de controle em laço-fechado da glicemia. Esse sistema de controle é conhecido na literatura como pâncreas artificial (CHASE et al., 2006; CHEE; FERNANDO; VAN HEERDEN, 2003; JAREMKO; RORSTAD, 1998; STEIL; PANTELEON; REBRIN, 2004). 


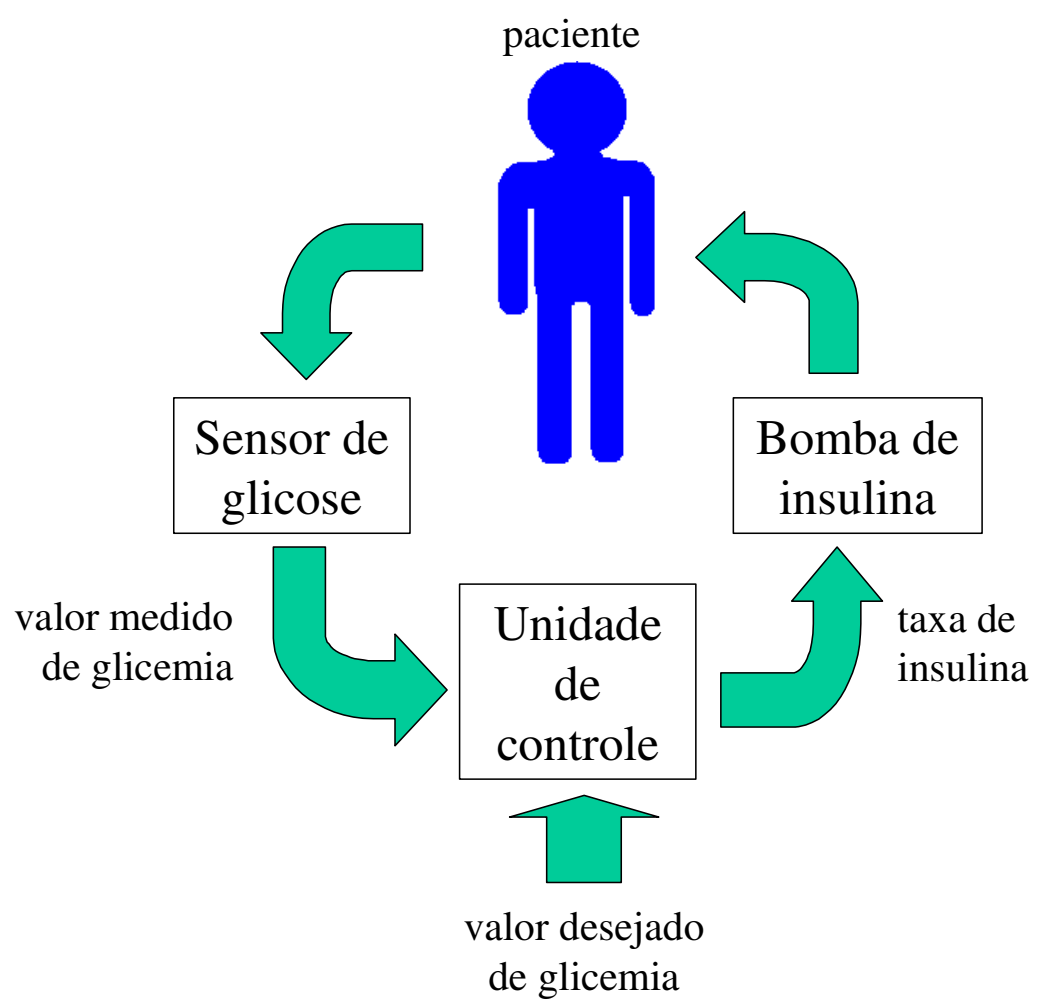

Figura 2.2 - Esquema ilustrativo de um sistema de pâncreas artificial

O pâncreas artificial é constituído por três partes distintas: um sensor contínuo de glicose, uma unidade de controle e uma bomba de insulina (Figura 2.2). O sensor de glicose obtém a leitura contínua da glicemia. Essa leitura é utilizada pela unidade de controle para calcular uma taxa de injeção de insulina. O cálculo da dosagem de insulina visa à estabilização da glicemia a níveis considerados normais. A insulina é aplicada de maneira contínua através do uso de uma bomba de insulina. O sistema de controle se reajusta de maneira automática, permitindo um controle acurado da glicemia do paciente.

A injeção de insulina a taxas contínuas e controladas é plenamente realizável através da tecnologia existente. Entretanto, faz-se necessário o desenvolvimento de modelos de controle mais eficientes. Os modelos existentes atualmente utilizam-se tanto de técnicas empíricas quanto técnicas baseadas no funcionamento natural do corpo humano. Devido aos 
diversos fatores envolvidos no metabolismo da glicemia, torna-se muito difícil sua modelagem.

Além disso, a medição contínua de glicemia ainda carece de desenvolvimento. Os sensores atualmente existentes apresentam desvios de leitura consideráveis, além de possuírem limitações técnicas que dificultam seu uso prático. O presente trabalho possui foco no desenvolvimento de um sistema de medição contínua de glicemia. Sendo assim, apresentaremos rapidamente os principais tipos de exame de glicemia existentes atualmente.

\subsection{Tipos de exame de glicemia}

Como se pôde observar, a medição eficiente da glicemia é um fator crítico no tratamento da diabetes. Os métodos atualmente utilizados na medição da glicemia podem ser divididos em três grandes grupos: os exames laboratoriais, os exames de "ponta de dedo" e a medição por sensores contínuos semi-invasivos.

\subsubsection{Exame laboratorial}

O exame laboratorial é o tipo mais tradicional de exame de glicemia, feito a partir de uma amostra de sangue. As amostras de sangue colhidas são enviadas a um laboratório e examinadas. Vários são os métodos utilizados para a medição da glicose. Em geral, é feita uma separação do plasma sanguiíneo por centrifugação e aplicação de enzimas específicas, como a glicose oxidase ou a hexoquinase. As enzimas causam reações químicas que levam à degradação da glicose, com a formação de algum produto que seja facilmente medido, seja através da geração de corrente elétrica (reação de oxi-redução) ou mudança de cor da mistura.

Os resultados obtidos possuem alto grau de exatidão, apresentando erros estimados em 2 a 3\% (BÖHME et al., 2003; POIRIER et al.; 1998). Assim, o exame laboratorial é considerado um "gold standard" quando comparado a outros tipos de medição. Entretanto, são necessárias algumas horas para a obtenção do resultado do exame, devido à logística 
necessária para o transporte das amostras para o laboratório. Isso dificulta o seu uso prático no controle da glicemia, o que levou ao desenvolvimento de dispositivos portáteis de medição de glicemia.

\subsubsection{Exame de "ponta de dedo"}

O exame de "ponta de dedo" é feito a partir de uma pequena amostra de sangue capilar (uma ou duas gotas), colhida através de um pequeno furo feito na ponta do dedo do paciente. A amostra de sangue é aplicada a uma fita, que, por sua vez, é inserida em um dispositivo portátil de medição. Diferentes métodos de medição são utilizados nesse tipo de aparelho. Em geral, de maneira semelhante aos exames laboratoriais, utilizam-se fitas com enzimas específicas para a degradação da glicose, e a medição dos produtos formados é feita pelo aparelho.

Em geral, o dispositivo portátil oferece uma leitura de glicemia em menos de meio minuto, totalizando um tempo total de realização do exame inferior a cinco minutos. Devido à rapidez e facilidade com que o exame de "ponta de dedo" pode ser realizado, ele é o tipo de exame mais utilizado pelos pacientes diabéticos. As medições podem ser feitas pelo próprio paciente, várias vezes ao dia, o que permite um controle adequado da glicemia.

A principal desvantagem do exame de "ponta de dedo" é a exatidão das suas leituras, inferior à do exame laboratorial. Quando comparadas ao exame laboratorial, as leituras de "ponta de dedo" apresentam desvios da ordem de 15\% (BÖHME et al., 2003). Além disso, a exatidão das leituras varia consideravelmente conforme a habilidade da pessoa que executa o exame (SKEIE et al., 2002). Por isso, é importante que o paciente diabético que utiliza tal equipamento seja adequadamente treinado. 


\subsubsection{Sensores contínuos semi-invasivos}

Nos últimos anos, surgiram os primeiros dispositivos de medição contínua de glicemia. O MiniMed CGMS (CGMS SYSTEM GOLD..., 2005) e o GlucoWatch (GLUCOWATCH, 2005) são exemplos característicos. Tais dispositivos utilizam-se de técnicas semi-invasivas ou não invasivas, geralmente obtendo as leituras através de sensores cutâneos ou subcutâneos, de modo a minimizar o desconforto do paciente. Apesar da denominação de "contínuos", os dispositivos existentes geram, na realidade, leituras pontuais em intervalos curtos, da ordem de cinco a quinze minutos.

A grande desvantagem dos sensores contínuos são os erros nas leituras geradas. O MiniMed CGMS, por exemplo, apresenta desvios médios da ordem de $15 \%$ a $20 \%$ quando comparado ao exame laboratorial e às "pontas de dedo" (BODE et al.; 1999; CHEE; FERNANDO; VAN HEERDEN, 2003; GOLDBERG et al, 2004; GROSS et al., 2000). Entretanto, sob certas condições, os desvios podem ampliar-se de maneira errática, chegando a valores da ordem de 50\% (METZGER et al., 2002; ver também MASTROTOTARO; GROSS, 2003; METZGER et al., 2003).

Dessa maneira, observa-se que os métodos de medição mais exatos oferecem uma freqüência de medição menor, e vice-versa. Assim, os uso combinado dos diferentes tipos de exame descritos fornece o melhor resultado no diagnóstico e tratamento da diabetes. Para a implementação de um pâncreas artificial, tanto a exatidão das leituras quanto a frequiência são fatores críticos no bom funcionamento do sistema. Sendo assim, torna-se crítico o desenvolvimento de métodos que forneçam leituras de glicemia exatas e a intervalos de tempo bastante curtos.

Como o presente trabalho aborda um método de medição contínua de glicose, os sensores contínuos serão abordados em maiores detalhes mais adiante (seção 2.4). Entretanto, é conveniente incluir, nesse ponto, uma explanação sobre os critérios de avaliação mais 
utilizados para os diversos métodos de leitura de glicemia. Sendo assim, esse assunto será abordado logo a seguir.

\subsubsection{Critérios de avaliação das leituras de glicose}

Qualquer método de medição apresenta algum erro em suas medidas; por isso, devemse adotar critérios para se avaliar a dimensão de tais erros. No caso dos exames de glicemia, vários critérios diferentes são utilizados combinadamente para a avaliação do erro das leituras. Nesse aspecto, uma importante referência foi elaborada pelo FDA (FOOD AND DRUG ADMINISTRATION, 1997). Nesse documento, aparece a seguinte citação (PANEL ENDORSES HOME BLOOD GLUCOSE TESTING, $1987^{1}$ apud FOOD AND DRUG ADMINISTRATION, 1997, tradução livre):

O objetivo de todos os futuros sistemas de automonitoramento de glicemia deve ser atingir uma variabilidade (erros do sistema e do usuário) de $10 \%$ para concentrações de glicose entre 30 e $400 \mathrm{mg} / \mathrm{dL}$ durante $100 \%$ do tempo. Entretanto, este painel sabe que a exatidão necessária para o uso clínico ainda não foi rigorosamente definida. Para os atuais sistemas de automonitoramento de glicose, as leituras devem possuir um desvio máximo de $15 \%$, quando comparadas às leituras de referência.

Tradicionalmente, consideram-se os exames laboratoriais como os mais exatos e, por isso, o valor obtido através do exame laboratorial é tomado como leitura de referência ("goldstandard"), isto é, uma boa estimativa do valor real.

A avaliação de sistemas de monitoramento contínuo de glicose, como o desenvolvido neste trabalho, apresenta uma dificuldade extra. Tais sistemas geram medidas de glicose a intervalos de tempo muito curtos, da ordem de cinco a quinze minutos. Os outros tipos de exame existentes não podem fornecer leituras nessa freqüência. $O$ exame laboratorial, tradicionalmente adotado como "gold standard", só pode ser aplicado em um paciente a intervalos de tempo bem maiores (da ordem de algumas horas), devido à dificuldade prática de se fazer medições a freqüências maiores. Assim, o número de leituras obtidas é insuficiente 
para uma comparação estatística adequada. Já a "glicemia de ponta de dedo" permite um intervalo de tempo bem menor entre as leituras, da ordem de quinze minutos, mas apresenta erros superiores ao exame laboratorial, e da mesma ordem de grandeza dos sistemas contínuos (seção 2.3.2). Assim, a realização de testes para a avaliação de leituras contínuas de glicose esbarra em dificuldades de ordem prática. Por isso, durante a sua avaliação, faz-se necessária a avaliação combinada das leituras obtidas utilizando-se vários critérios diferentes.

Um critério simples e bastante utilizado para a avaliação das leituras da glicemia é a diferença entre a leitura avaliada e uma leitura de referência. Pode-se, por exemplo, analisar a média e o desvio padrão das diferenças entre leituras de "ponta de dedo" e leituras “contínuas”. Esses valores podem ser avaliados globalmente ou dividindo-se as leituras em faixas de glicemia. Pode-se, também, avaliar-se a diferença relativa (diferença entre leituras $\div$ leitura de referência). Também é comum avaliar-se a porcentagem de leituras com desvio inferior a um certo limite, usualmente 5 ou $10 \%$.

Outro critério bastante utilizado é o coeficiente de correlação. O coeficiente de correlação é uma medida estatística que indica o quanto duas variáveis estão relacionadas (ver Apêndice B).

Muitos trabalhos na área clínica utilizam o coeficiente de correlação de maneira incorreta, como alertaram Bland e Altman (1986):

- Rigorosamente, o coeficiente de correlação não mede o grau de proximidade entre duas variáveis, mas, sim, o quanto elas se aproximam de medidas proporcionais. Isso significa que, se tivermos duas medidas $A$ e $B$, tal que $A=2 B$, o grau de correlação será máximo $(1,0)$, mas as medidas serão completamente diferentes.

- O coeficiente de correlação depende da largura do intervalo das leituras avaliadas. Por exemplo, suponha um conjunto de leituras entre 100 e $200 \mathrm{mg} / \mathrm{dL}$ com um alto 
coeficiente de correlação. O intervalo das leituras tem uma largura de $200-100=$ $100 \mathrm{mg} / \mathrm{dL}$. Agora, se tomarmos o subgrupo das leituras entre 100 e $110 \mathrm{mg} / \mathrm{dL}$, teremos, muito provavelmente, um coeficiente de correlação muito mais baixo. Nesse caso, o intervalo das leituras tem uma largura de $110-100=10 \mathrm{mg} / \mathrm{dL}$, valor da mesma ordem de grandeza do desvio de uma "ponta de dedo".

Bland e Altman (1986) sugerem que seja plotado um gráfico de "média entre leituras" x “diferença entre leituras" para a avaliação da exatidão. Nesse caso, é usada a "média entre leituras" (isto é, a média entre a leitura avaliada e a leitura de referência) porque se considera que as duas leituras possuem erros da mesma ordem de grandeza. Por isso, a melhor estimativa do valor real é a média.

No mesmo trabalho, é sugerido ainda que sempre seja calculada a média e o desvio padrão das diferenças. A média das diferenças é chamada de bias. No gráfico, pode-se traçar uma linha horizontal na média das diferenças (que deve estar próxima de zero) além de uma indicação do intervalo de confiança de +/- 2 desvios padrões (aproximadamente 95\%). O gráfico assim obtido é conhecido na literatura como gráfico de Bland \& Altman (Figura 2.3). Através dele, pode-se avaliar a variabilidade das leituras ao longo de toda a escala do aparelho.

Outro critério bastante utilizado para a avaliação da exatidão de exames de glicemia é a grade de erro de Clarke. Segundo Clarke et al. (1987), os critérios tradicionais não avaliam o real impacto clínico dos erros das leituras no tratamento dos pacientes. Por exemplo, consideremos uma faixa normal de glicemia de 70 a $180 \mathrm{mg} / \mathrm{dL}$. Um desvio de $50 \%$ sobre um valor real de $40 \mathrm{mg} / \mathrm{dL}$ de glicemia $(1,5$ x $40=60 \mathrm{mg} / \mathrm{dL})$ leva a um diagnóstico correto (hipoglicemia). Entretanto, um desvio de $50 \%$ para uma glicemia de $150 \mathrm{mg} / \mathrm{dL}(1,5 \times 150=$ $225 \mathrm{mg} / \mathrm{dL}$ ) pode levar a um diagnóstico incorreto (diagnóstico de hiperglicemia quando o paciente apresenta glicemia regular). 


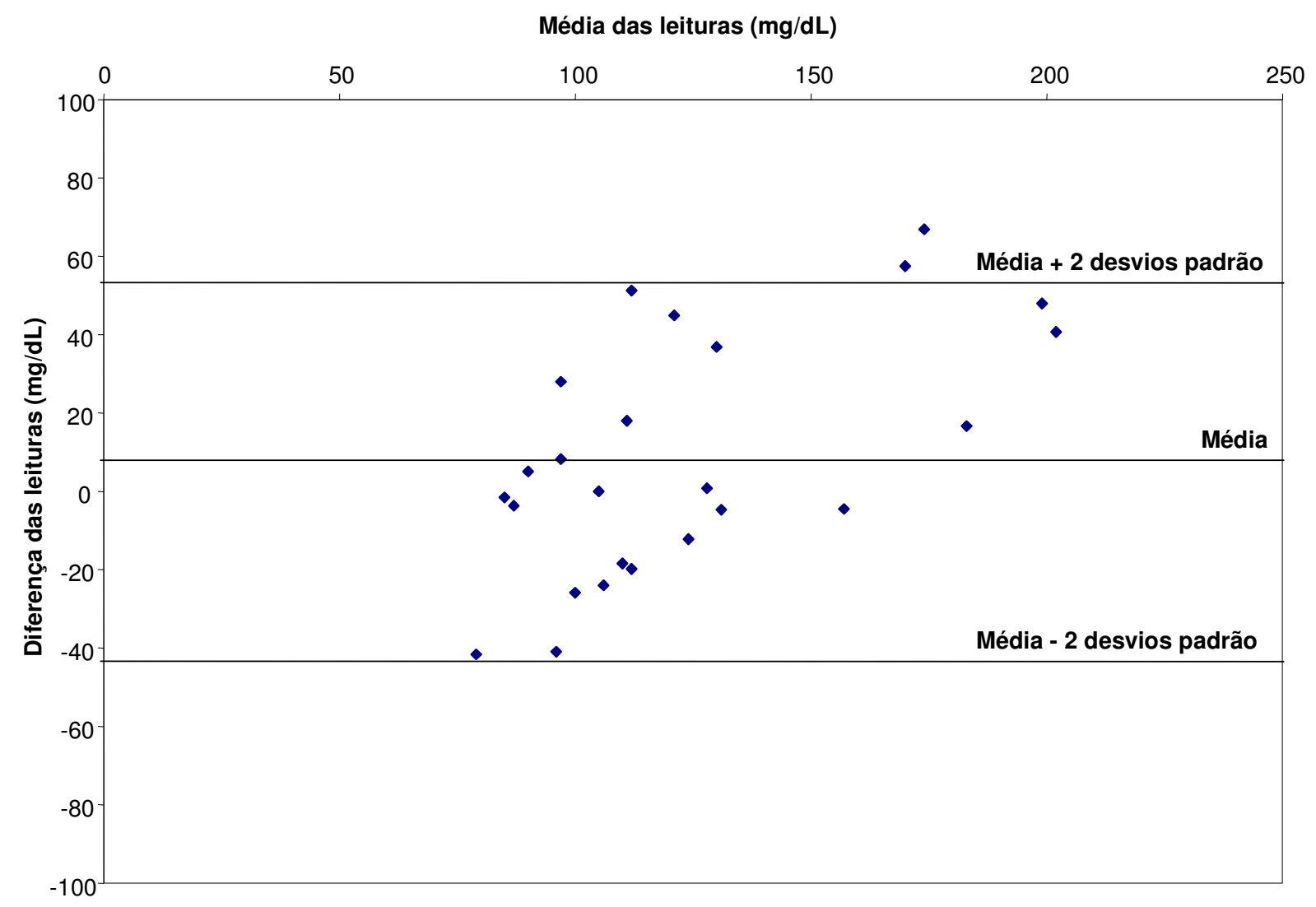

Figura 2.3 - Um exemplo hipotético de gráfico de Bland \& Altman.

Dessa forma, foi idealizada uma "grade de erro". O gráfico de dispersão "leitura de referência" x "leitura sob avaliação" é dividido nas zonas A, B, C, D e E, de acordo com o impacto clínico resultante da leitura (Figura 2.4):

- Zona A: engloba leituras com menos de $20 \%$ de erro. Considera também as situações onde tanto a leitura sob avaliação quanto a leitura de referência indicam hipoglicemia. Diz-se que as leituras na zona A são clinicamente eficientes. 


\section{Grade de erro de Clarke}

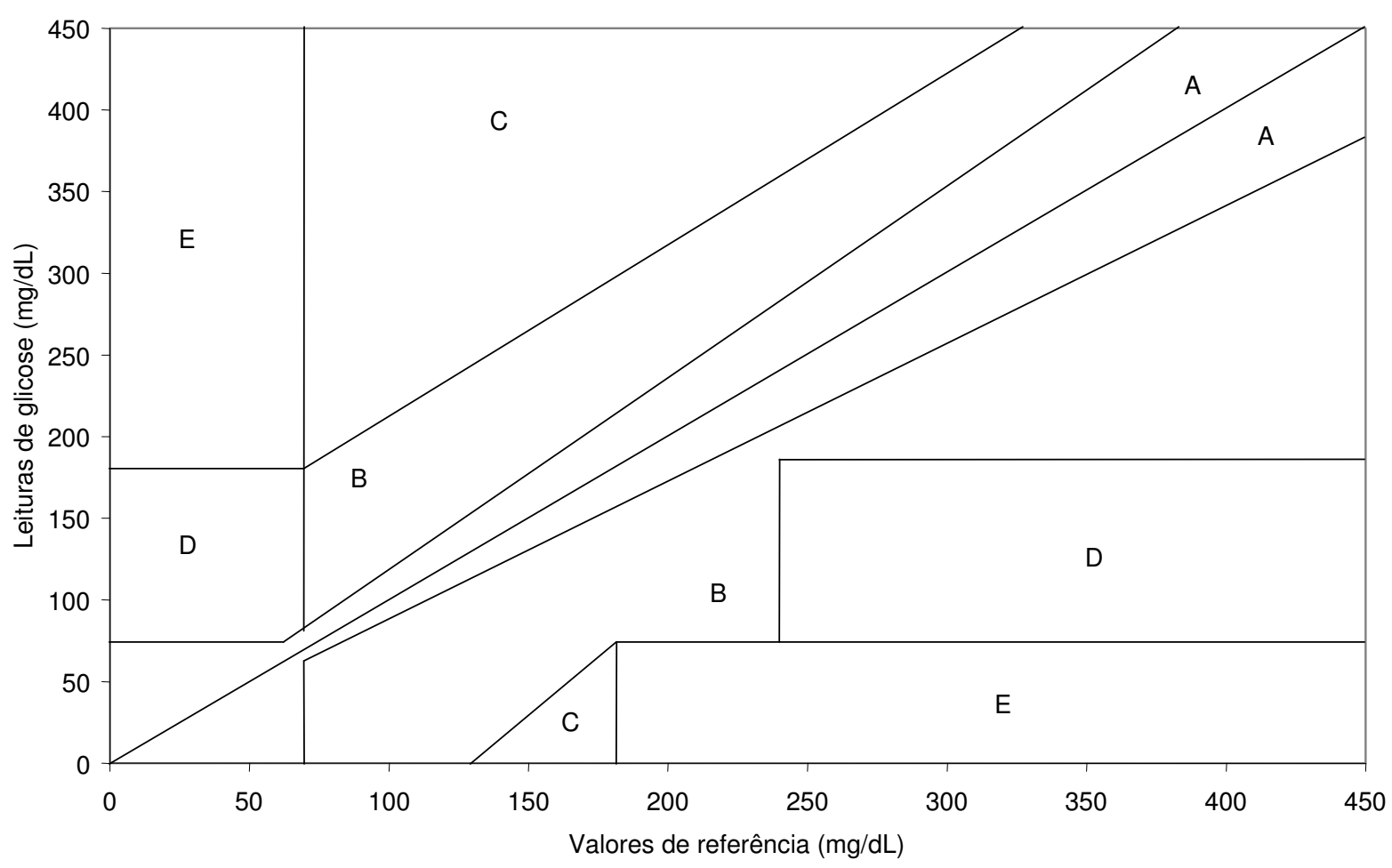

Figura 2.4 - Grade de erro de Clarke (considerando uma faixa de glicemia normal entre 70 e $180 \mathrm{mg} / \mathrm{dL}$ ) (Adaptado de Clarke et al., 1987).

- Zona B: engloba situações que não pertencem à zona $\mathrm{A}$, mas que não levam a um tratamento incorreto. Por exemplo, se a leitura de referência é de $80 \mathrm{mg} / \mathrm{dL}$ e a leitura sob avaliação é de $120 \mathrm{mg} / \mathrm{dL}$, existe um desvio de $(120-80) \div 80=50 \%$, superior aos $20 \%$ da zona A. Entretanto, ambas as leituras indicam uma glicemia normal (para uma faixa de glicemia normal entre 70 e $180 \mathrm{mg} / \mathrm{dL}$ ), levando ao mesmo tratamento clínico.

- $\mathrm{C}, \mathrm{D}, \mathrm{E}$ : englobam leituras que levam a um tratamento incorreto.

Assim, segundo esse critério, um método de medição de glicemia é avaliado pela porcentagem de leituras obtidas em cada uma das zonas.

Muitas críticas foram feitas à grade de erro de Clarke. Podemos citar, por exemplo (GOUGH; BOTVINICK, 1997): 
- A divisão das zonas baseou-se somente no bom senso dos autores. Não foi feita nenhuma comprovação experimental da eficiência da divisão escolhida.

- Para a divisão das zonas, no artigo original de Clarke et al. (1987), foi considerada uma faixa de glicemia normal de 70 a $180 \mathrm{mg} / \mathrm{dL}$. Entretanto, essa faixa varia conforme a situação clínica analisada. Assim, como é afirmado no próprio artigo, a divisão das zonas deve ser adaptada conforme a faixa de glicemia normal a ser considerada. Entretanto, essa adaptação não é realizada na maioria dos trabalhos que utilizam a grade de erro de Clarke.

- "Erro" significa a diferença entre o valor obtido pelo método a ser avaliado (isto é, valor estimado) e o valor real. No entanto, no critério apresentado por Clarke et al. (1987), faz-se a comparação entre duas leituras de glicemia obtidas a partir de métodos diferentes. Assim, cada uma dessas leituras possui o seu valor de erro. Por isso, a designação "grade de erro" não é apropriada, podendo levar a interpretações incorretas.

Apesar das críticas, a grade de erro de Clarke é extensamente utilizada na literatura, sendo citada, pelo FDA, como uma referência válida para medidores de glicose (FOOD AND DRUG ADMINISTRATION, 1997). Entretanto, a grade de erro de Clarke, como qualquer outro critério de avaliação, não deve ser utilizada isoladamente. Um conjunto de critérios diferentes deve ser adotado para que se possa avaliar, de maneira conclusiva, o grau de exatidão de um método de medição de glicemia.

\subsection{Leitura contínua de glicose}

\subsubsection{Os métodos em pesquisa}

Como se pôde observar, o uso de um sistema de monitoramento contínuo de glicose pode trazer enormes benefícios ao tratamento da diabetes. Assim, nas últimas décadas, vários 
estudos foram feitos na busca de tal sistema (JAREMKO; RORSTAD, 1998; PICKUP et al., 1999). Idealmente, busca-se obter sensores contínuos de glicose que tenham um reduzido grau de invasão do paciente. Sensores desse tipo são conhecidos na literatura como sensores minimamente invasivos e sensores não-invasivos.

Um método bastante estudado utiliza sensores enzimáticos. O sensor enzimático é composto por um eletrodo coberto por uma camada de enzima. Essa enzima causa uma reação química de oxidação da glicose. A reação química gera uma corrente elétrica, que é proporcional à concentração de glicose no meio. O sensor enzimático geralmente possui o formato de uma agulha, sendo inserido através da pele, em contato com o líquido intersticial. Dessa forma, medindo-se a corrente elétrica gerada, pode-se estimar a concentração de glicose no líquido intersticial e, conseqüentemente, no sangue (partindo do pressuposto que a concentração de glicose intersticial é igual à glicose sangüínea, ver seção 2.5.3). O estudo de sensores enzimáticos é bastante importante para o desenvolvimento deste trabalho. Por isso, eles serão abordados com maiores detalhes posteriormente, na seção 2.5.

Outro método importante é chamado de iontoforese reversa. Aqui, dois eletrodos aplicam uma tensão elétrica sobre a pele do indivíduo. A tensão elétrica aplicada cria um fluxo de líquido intersticial para a superfície da pele. O líquido intersticial assim extraído contém glicose, que é então medida usando-se um sensor enzimático.

A espectroscopia por radiação infravermelha é outro método estudado. A pele humana é razoavelmente "transparente" para ondas eletromagnéticas de comprimento de onda da ordem de 600 a $1300 \mathrm{~nm}$. Dessa maneira, radiação nessa faixa de freqüência consegue atravessar a pele e é parcialmente refletida por substâncias químicas presentes no líquido intersticial, como é o caso da glicose. Analisando-se o espectro da radiação refletida, podemse obter informações sobre o tipo e a concentração dessas substâncias. Entretanto, a análise do espectro é complexa. O grande número de substâncias presentes no líquido intersticial torna 
difícil a identificação da absorção de luz causada por cada substância. Além disso, o resultado pode variar bastante em função de fatores como temperatura, intensidade da luz e alinhamento do sensor. Dessa maneira, ainda há muitas dificuldades a serem solucionadas antes que esse método possa ser utilizado na prática.

Os métodos citados são apresentados aqui a título de exemplo. Além deles, muitos outros estão em estudo. A riqueza de estudos na área demonstra a importância prática dos sistemas de monitoramento contínuo de glicose.

\subsubsection{Sistemas comerciais de monitoramento contínuo de glicose.}

A partir dos diversos métodos estudados, estão sendo desenvolvidos produtos comerciais para monitoramento contínuo de glicose. Em junho de 1999 (FOOD AND DRUG ADMINISTRATION..., 1999), um dispositivo de monitoramento contínuo de glicose, o MiniMed CGMS (Medtronic Diabetes; Northridge, EUA), foi aprovado para uso clínico pelo FDA (Food and Drug Administration, órgão do governo americano que regulamenta, entre outros, o uso de equipamentos médicos). O MiniMed CGMS utiliza sensores enzimáticos como princípio de funcionamento. Apesar das limitações, a regulamentação do dispositivo é uma amostra da viabilidade prática dos sensores enzimáticos. O MiniMed CGMS será descrito de maneira mais cuidadosa na seção 2.6.

Um segundo dispositivo de monitoramento contínuo de glicose lançado comercialmente utiliza o método de iontoforese reversa, de caráter não invasivo. É chamado de GlucoWatch (Cygnus) e obteve aprovação do FDA em 2002 para uso ambulatorial (FOOD AND DRUG ADMINISTRATION, 2002). O GlucoWatch, inclusive, apresenta as leituras à medida que elas são geradas, com um tempo de resposta da ordem de quinze minutos.

Além dos dispositivos citados, outros estão em estágio avançado de desenvolvimento e poderão ser aprovados pelo FDA dentro em breve (DIABETES MALL..., 2005; SOCIEDADE BRASILEIRA DE DIABETES, 2005). O GlucoDay (A.Menarini Diagnostics) 
utiliza microdiálise e, embora não tenha obtido a aprovação do $F D A$, é comercializado na Europa. O FreeStyle Navigator (TheraSense) utiliza sensores enzimáticos, como o MiniMed CGMS. Os aparelhos da Pendragon Medical utilizam espectroscopia de impedância. Vale ainda citar a segunda geração de monitores da Medtronic Diabetes, o Guardian RT (seção 2.6.4).

\subsection{Sensores enzimáticos}

A medição de glicemia por sensores enzimáticos é um dos métodos mais promissores de leitura contínua de glicemia. Ele é utilizado no MiniMed CGMS, no GlucoDay e em outros dispositivos de medição de glicemia existentes e em desenvolvimento. $\mathrm{O}$ sistema desenvolvido no presente trabalho utiliza sensores enzimáticos e, sendo assim, é adequado, nesse ponto, a inserção de uma análise a respeito do funcionamento e das características de tais sensores.

\subsubsection{Princípio de funcionamento}

O sensor enzimático é composto, basicamente, por um fio metálico recoberto por uma camada de enzima. O sensor é inserido no subcutâneo, ficando em contato direto com o líquido intersticial. O líquido intersticial faz o transporte de diversas substâncias, incluindo a glicose, entre o sangue e as células. Dessa forma, o sensor fica em contato direto com a glicose intersticial.

A enzima que recobre o sensor causa a oxidação da glicose do meio, conforme ilustrado na Equação 2.1.

$$
\text { Glicose }+\mathrm{O}_{2} \stackrel{\text { enzima }}{\longrightarrow} \text { Ácido glucônico }+\mathrm{H}_{2} \mathrm{O}_{2}
$$




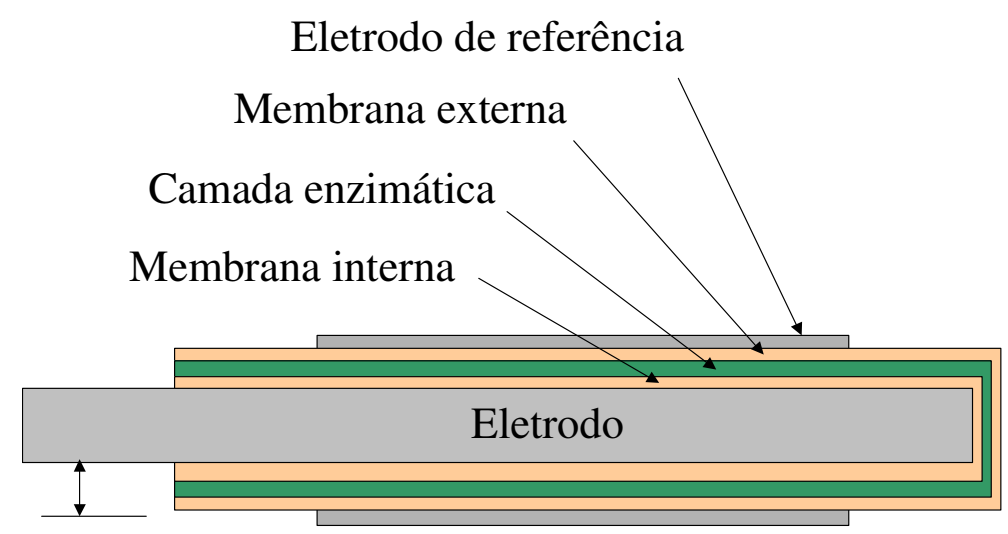

Tensão elétrica

\section{Figura 2.5 - Exemplo de sensor enzimático (adaptado de Wilson et al., 1992)}

Sob a presença de tensão elétrica, a molécula de peróxido de oxigênio $\left(\mathrm{H}_{2} \mathrm{O}_{2}\right)$ pode ser quebrada, gerando corrente elétrica (Equação 2.2).

$$
\mathrm{H}_{2} \mathrm{O}_{2} \stackrel{\text { tensão elétrica }}{\longrightarrow} \mathrm{O}_{2}+2 \mathrm{H}^{+}+2 e^{-}
$$

A corrente elétrica assim gerada é aproximadamente proporcional à concentração de glicose presente no meio. Assim, a medição da corrente elétrica gerada pode servir como uma medida indireta da concentração de glicose presente no meio.

Para que a tensão elétrica possa ser aplicada, existe um segundo eletrodo recobrindo o sensor. Para permitir e regular a circulação das substâncias envolvidas, camadas de membranas permeáveis intercalam os elementos do sensor. Um esquema de um sensor enzimático é mostrado na Figura 2.5.

Sensores enzimáticos têm sido estudados há vários anos. Eles foram testados, com bons resultados, em animais e em seres humanos. Entretanto, diversos problemas técnicos têm dificultado a sua utilização prática. Esses problemas serão discutidos a seguir. 


\subsubsection{Calibração de sensores enzimáticos}

Conforme foi explicado anteriormente (seção 2.5.1), sensores enzimáticos geram uma corrente elétrica aproximadamente proporcional à concentração de glicose do meio. Dessa forma, conhecendo-se o valor da corrente elétrica gerada (I), pode-se determinar a concentração de glicose (G) multiplicando-se o valor da corrente por um fator de escala (S) (Equação 2.3).

$$
G=S \cdot I
$$

Entretanto, a priori, o fator de escala entre valor de glicose e corrente não é conhecido. Para se determinar o fator de escala, utiliza-se um procedimento de calibração. Para isso, obtém-se uma leitura de glicemia através de um outro método, como, por exemplo, a partir de um "exame de ponta de dedo". Assim, sabendo-se o valor da glicemia e o valor da corrente elétrica gerada pelo sensor, pode-se determinar, para um determinado instante, o fator de escala (Equação 2.4).

$$
S=\frac{G}{I}
$$

Pode-se considerar o fator de escala como um valor constante, ao menos para o intervalo de algumas horas (esse fato será discutido novamente na seção 2.5.3). Assim, após a calibração, pode-se calcular o valor da glicemia a partir de qualquer valor de corrente elétrica gerada pelo sensor.

No modelo de cálculo demonstrado, assumimos implicitamente que, para uma concentração de glicose nula, a corrente gerada também é nula. Na prática, isso não ocorre. A experiência mostra que, para valores nulos de glicose, obtém-se um pequeno valor de corrente, conhecido na literatura como corrente de fundo. Dessa forma, a Equação 2.3 deve ser reescrita (Equação 2.5). 


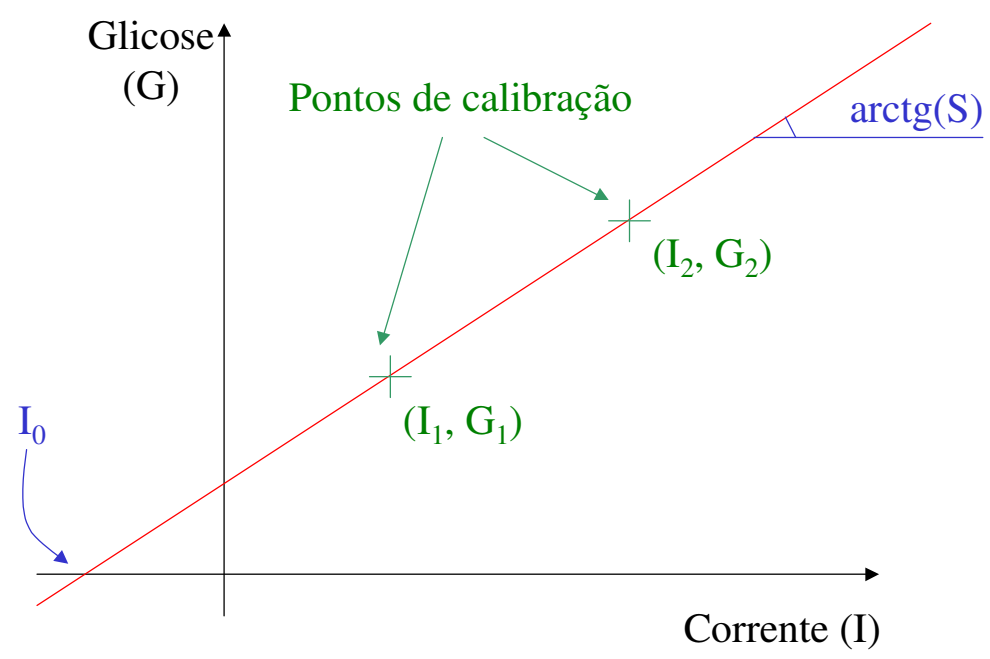

Figura 2.6 - A relação entre corrente (I) e glicose (G) é definida por uma reta, usualmente chamada de reta de calibração. A reta de calibração é mostrada na figura. A partir da realização de duas medições de glicemia (utilizando-se, por exemplo, o exame de "ponta de dedo"), pode-se determinar dois pares de valores de corrente e glicose $\left(\mathrm{I}_{1}\right.$, $\left.G_{1}\right)$ e $\left(I_{2}, G_{2}\right)$. Assim, a reta de calibração é perfeitamente determinada. $O$ ponto de cruzamento da reta de calibração e o eixo da corrente determina o valor da corrente de fundo $\left(I_{0}\right)$. O fator de escala $(S)$ é determinado pela inclinação da reta.

$$
G=S \cdot\left(I-I_{0}\right)
$$

Portanto, para se determinar o valor da glicose a partir da corrente gerada pelo sensor, deve-se conhecer o fator de escala e a corrente de fundo. Para que isso seja possível, é necessária a realização de pelo menos duas calibrações. A Figura 2.6 ilustra esse fato.

A partir da obtenção de duas medidas de calibração, pode-se determinar dois pares de valores de corrente e glicose $\left(\mathrm{I}_{1}, \mathrm{G}_{1}\right)$ e $\left(\mathrm{I}_{2}, \mathrm{G}_{2}\right)$. Assim, a corrente de fundo $\left(\mathrm{I}_{0}\right)$ e o fator de escala (S) podem ser determinados por um sistema de equações de duas incógnitas (Equação 2.6).

$$
\left\{\begin{array}{l}
G_{1}=S \cdot\left(I_{1}-I_{0}\right) \\
G_{2}=S \cdot\left(I_{2}-I_{0}\right)
\end{array}\right.
$$

Em muitos casos, pode ser interessante o uso de um número maior de pontos de calibração. Através do uso de vários pontos de calibração, pode-se reduzir a influência de erros nas leituras. Nesse caso, costuma-se usar um método estatístico de regressão linear, 
como o método dos mínimos quadrados (ver Apêndice C). Além disso, para se corrigir algumas limitações dos sensores enzimáticos (seção 2.5.3), podem ser usados métodos mais sofisticados para a calibração. Na seção 2.6.2, discutiremos o método de calibração do MiniMed CGMS, um sistema comercial que utiliza sensores enzimáticos.

\subsubsection{Limitações dos sensores enzimáticos}

Os sensores enzimáticos possuem uma série de limitações, o que dificulta a sua aplicação prática. Por exemplo, uma limitação desses dispositivos é a dificuldade de se medir a corrente de fundo $\left(I_{0}\right)$. Conforme foi apresentado anteriormente (seção 2.5.2), um método de se estimar a corrente de fundo é através da medição de dois ou mais pontos de calibração. Obviamente, uma má estimativa da corrente de fundo pode prejudicar a exatidão no cálculo da concentração de glicose.

Há um segundo método proposto em alguns trabalhos (JEONG et al., 2003; WARD; WOOD; TROUPE, 2000), onde a corrente de fundo é efetivamente medida. Para isso, são usados dois sensores. O primeiro sensor é o tradicional, conforme descrito anteriormente (seção 2.5.1). O segundo sensor é idêntico ao primeiro, exceto pela ausência da camada enzimática. Dessa forma, a corrente medida pelo segundo sensor equivale à corrente gerada por uma concentração nula de glicose, ou seja, é a corrente de fundo. Esse método apresenta bons resultados, aparentemente superiores ao método por calibração. Além disso, com uma montagem mecânica adequada, os dois sensores podem ser reduzidos a uma única peça (WARD; WOOD; TROUPE, 2000). Isso elimina a inconveniência de se usar dois sensores ao mesmo tempo. 


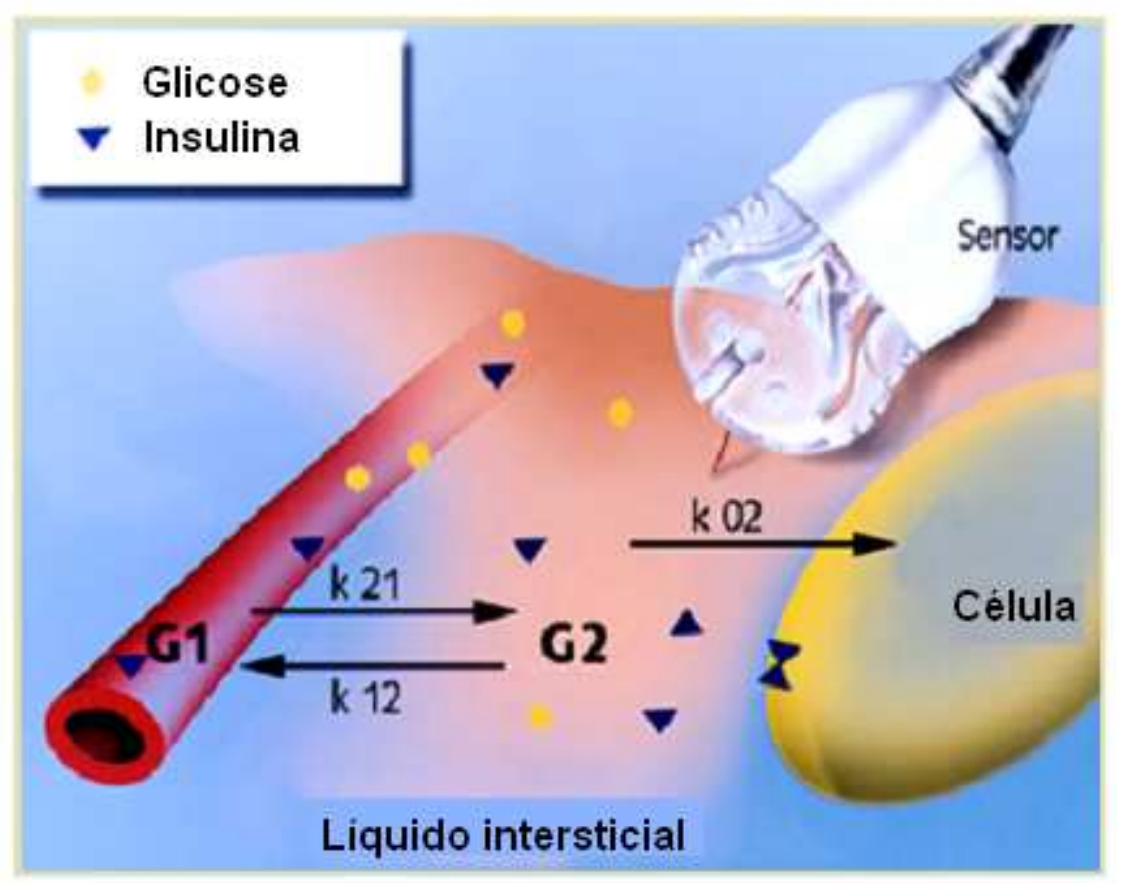

Figura 2.7 - Esta figura mostra, de maneira simplificada, um vaso sangüíneo (à esquerda) e uma célula (embaixo à direita). $O$ transporte de substâncias (incluindo a glicose) entre o sangue e as células é feito pelo líquido intersticial, que preenche o espaço entre as células. $O$ sensor enzimático (no alto à direita) é aplicado no subcutâneo, em contato com o líquido intersticial. Dessa forma, o sensor mede a concentração de glicose no líquido intersticial e não no sangue (imagem de divulgação da Medtronic Diabetes).

É importante notar ainda que, conforme Ward, Wood e Troupe (2000), a corrente de fundo pode variar substancialmente com o tempo. O mesmo ocorre com a sensibilidade do sensor (S) (PICKUP et al., 1999). Essas variações são erráticas e suas causas ainda são desconhecidas. Por isso, medições de calibração devem ser feitas ao longo de todo o tempo de uso do sensor.

Uma segunda limitação importante do sensor enzimático é o fato das medições serem feitas a partir do líquido intersticial, e não do sangue, como seria desejável (Figura 2.7). Dessa maneira, assume-se implicitamente que a concentração de glicose no líquido intersticial é idêntica à do sangue. Entretanto, essa hipótese não é totalmente correta. A relação entre a concentração de glicose intersticial e sangüínea ainda não é completamente compreendida. 


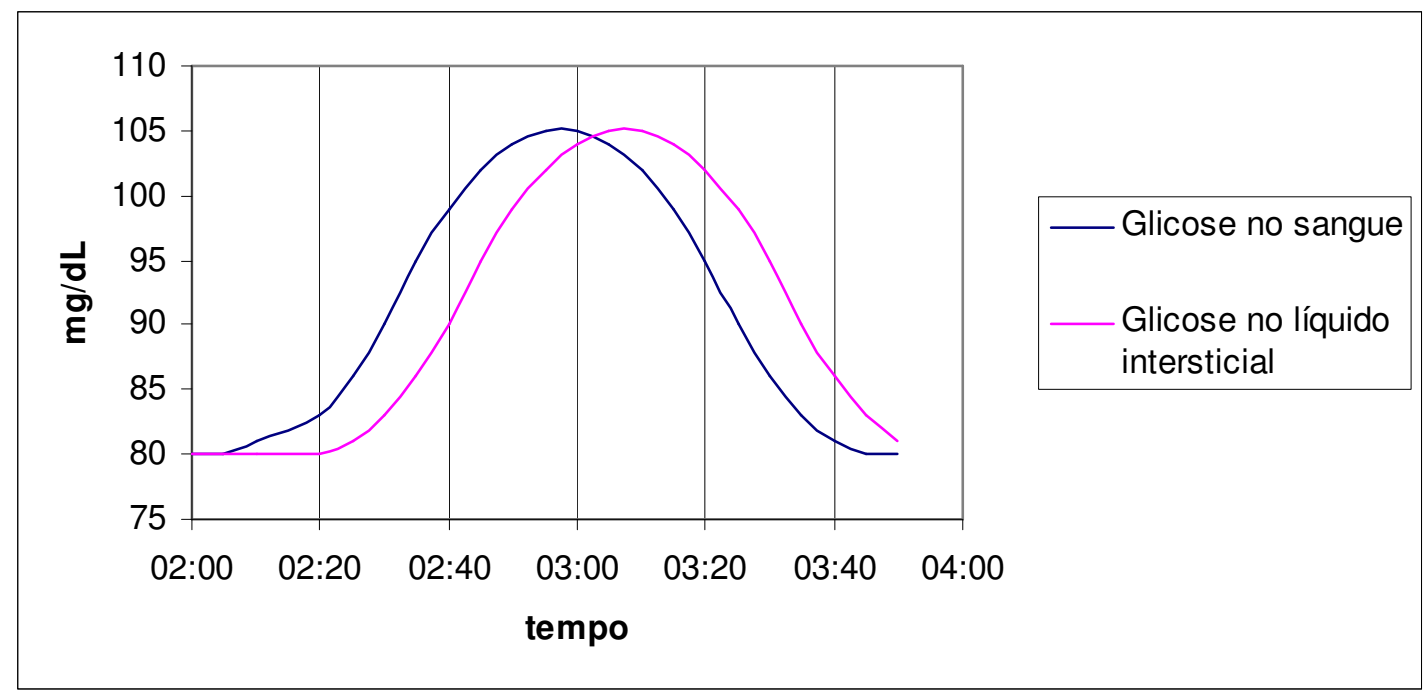

Figura 2.8 - Neste gráfico hipotético, assume-se a hipótese que, quando a concentração de glicose no sangue varia, essa variação é refletida no líquido intersticial com um atraso de 10 minutos.

Há basicamente dois modelos que tentam estabelecer a relação entre a concentração de glicose sangüínea e a intersticial. A glicose presente no sangue passa para o líquido intersticial em um processo contínuo de difusão. Por isso, em um primeiro modelo, assume-se que, quando a concentração de glicose no sangue é constante, a concentração de glicose no líquido intersticial também é constante, e é igual à no sangue. Entretanto, quando a concentração de glicose no sangue varia, essa variação é refletida no líquido intersticial após um certo intervalo de tempo (REBRIN et al., 1999; BOYNE et al., 2003). A Figura 2.8 ilustra esse fato.

Em uma segunda abordagem (AUSSEDAT et al., 2000; KULCU et al., 2003), as concentrações de glicose no sangue e no líquido intersticial são analisadas segundo um modelo simplificado do ciclo de glicose no organismo. Esse modelo é apresentado de maneira esquemática na Figura 2.9. Nesse modelo, assume-se a existência de duas fontes de glicose para o sangue. Uma é exógena, composta pela glicose obtida dos alimentos ingeridos $\left(\mathrm{G}_{\mathrm{ex}}\right)$. A outra é endógena, composta pela glicose liberada pelo fígado $\left(\mathrm{G}_{\mathrm{end}}\right)$. A glicose pode ser 
eliminada do sangue através da urina $\left(\mathrm{G}_{\mathrm{k}}\right)$. Além disso, há um fluxo de glicose entre o sangue e o líquido intersticial (I). A glicose do líquido intersticial é consumida pelas células (O).

Segundo o modelo apresentado, após uma refeição, por exemplo, há um aumento no fluxo de glicose exógena $\left(\mathrm{G}_{\mathrm{ex}}\right)$. Isso causa um aumento da concentração de glicose sanguiínea $\left(\mathrm{G}_{\mathrm{S}}\right)$. O desequilíbrio entre a taxa de glicose sangüínea e intersticial causa um aumento do fluxo I de $\mathrm{G}_{\mathrm{S}}$ para $\mathrm{G}_{\mathrm{I}}$ (glicose intersticial). Portanto, nessa situação, a variação de glicose no sangue é refletida no líquido intersticial após um certo intervalo de tempo. Isso está de acordo com o primeiro modelo apresentado anteriormente.

Entretanto, após a aplicação de uma dose de insulina, há uma maior absorção de glicose pelo fígado, isto é, há um aumento no fluxo de glicose do sangue $\left(\mathrm{G}_{\mathrm{S}}\right)$ para o fígado $\left(\mathrm{G}_{\text {end }}\right)$. Além disso, há um aumento da absorção da glicose intersticial pelas células $(\mathrm{O})$. Portanto, a aplicação de insulina causa a redução da concentração de glicose tanto no sangue quanto no líquido intersticial. Isso contraria o primeiro modelo apresentado anteriormente (ver Figura 2.10).

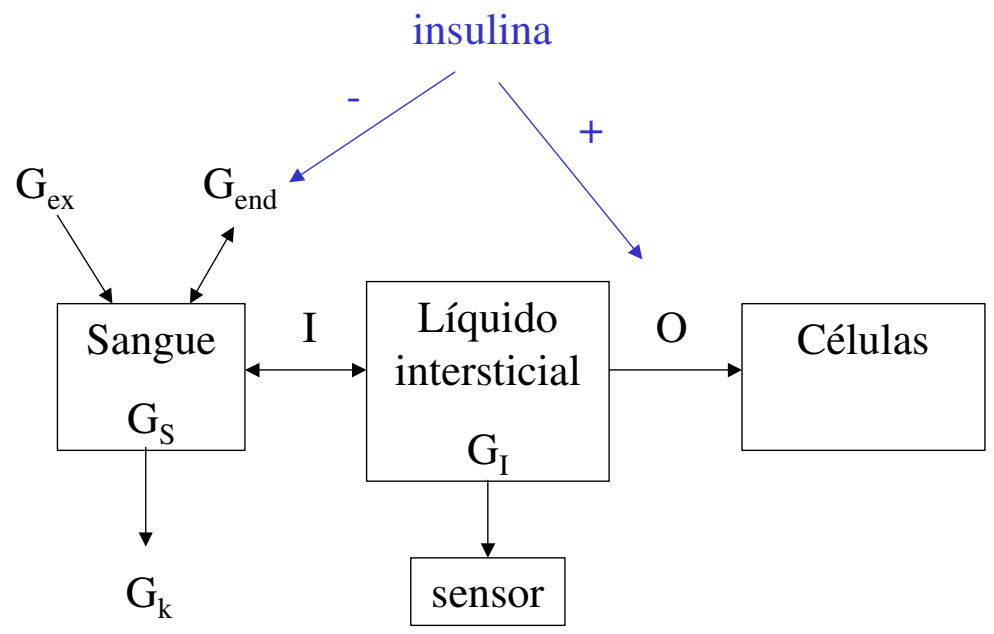

Figura 2.9 - Modelo simplificado do ciclo de glicose no organismo. $G_{e x}$ é a glicose exógena, obtida a partir dos alimentos ingeridos. $G_{\text {end }}$ é a glicose endógena, liberada pelo fígado. $G_{k}$ é a glicose eliminada pela urina. $O$ fluxo I (entrada) ocorre por difusão, enquanto que o fluxo $O$ (saída) ocorre por um processo ativo, estimulado pela insulina. A figura mostra ainda a influência da insulina sobre o ciclo, aumentando o fluxo de absorção de glicose pelas células $(O)$ e reduzindo ou invertendo o fluxo de glicose do fígado para o sangue $\left(G_{\text {end }}\right)$. Adaptado de Aussedat et al. (2000). 


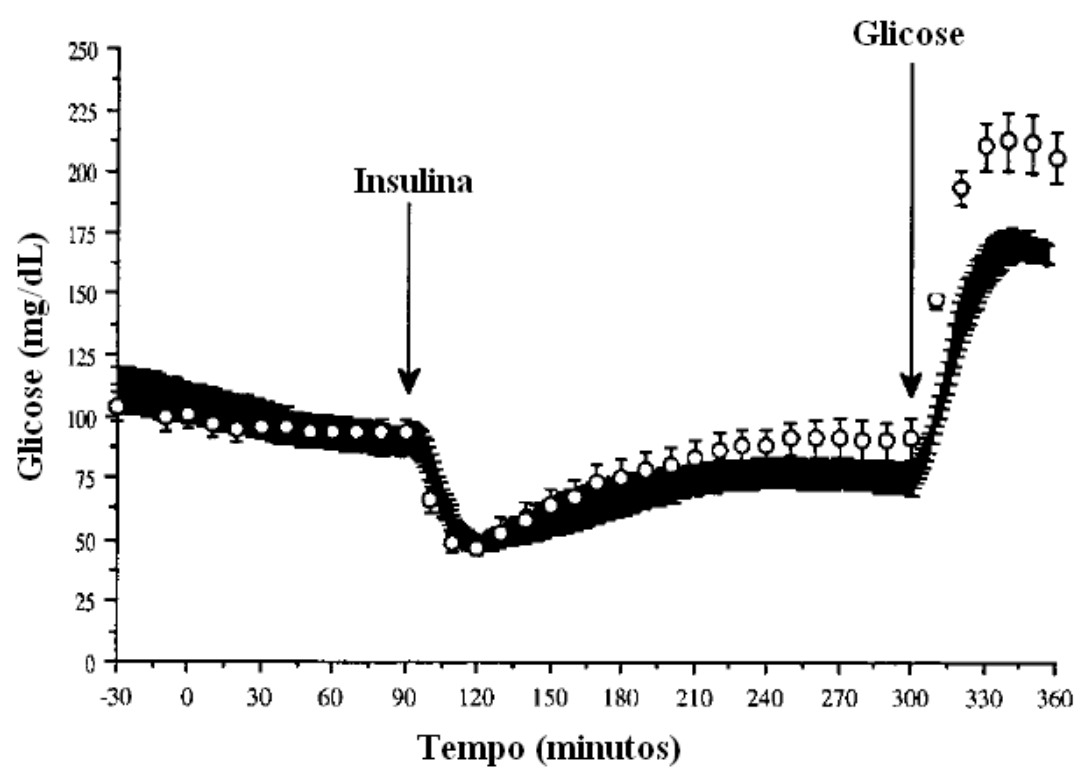

Figura 2.10 -Gráfico adaptado de Aussedat et al. (2000). As concentrações de glicose sanguínea (círculos abertos) e intersticial (linhas retas) foram medidas em ratos não diabéticos. Foi aplicada uma dose de insulina seguida da administração de glicose. Notase que, após a aplicação de insulina, o nível de glicose intersticial cai com um pequeno atraso em relação à glicose sangüínea $(90-120 \mathrm{~min})$. Logo após, há um retorno da glicemia a níveis normais (120-300 min). Nesse intervalo de tempo, a concentração de glicose sangüínea mantém-se acima da concentração de glicose intersticial. Após a administração de glicose (300 min), as disparidades entre glicose sangüínea e glicose intersticial aumentam bastante. Como se pode concluir, esse resultado não pode ser explicado por um simples atraso entre as leituras de glicose sangüínea e intersticial.

Não há um consenso sobre qual dos dois modelos apresentados está correto. O que se pode concluir é que existe uma diferença entre as leituras de glicose sangüínea e intersticial. A relação entre a concentração de glicose sangüínea e intersticial, aparentemente, não pode ser facilmente estabelecida.

A diferença entre os dois valores influencia o processo de calibração dos sensores enzimáticos. Deve-se observar que, durante o processo de calibração, é feita uma medição da glicemia através de um exame de ponta de dedo (ver seção 2.5.2). A medida obtida é usada para se calcular a relação entre o valor de glicose sangüínea e o valor da corrente gerada pelo sensor. Mas o sensor gera sinais a partir da taxa de glicemia intersticial. Assim, durante o 
processo de calibração, é feita uma comparação direta entre valores de glicemia sangüínea e intersticial. Por isso, o cálculo só seria totalmente correto se o valor da glicose sangüínea e o da glicose intersticial fossem idênticos ou diretamente proporcionais, o que não ocorre.

A diferença entre glicose sangüínea e intersticial também pode levar a resultados clínicos incorretos. Por exemplo, após o surgimento dos primeiros sistemas comerciais de monitoramento contínuo (MiniMed CGMS e GlucoWatch), houve uma maior incidência de diagnósticos de hipoglicemia noturna. Entretanto, segundo Monsod et al. (2002), há indícios de que, quando a concentração de glicose sangüínea é inferior a $90 \mathrm{mg} / \mathrm{dL}$, a concentração de glicose intersticial é até 30\% inferior à sangüínea (ver também MCGOWAN; THOMAS; MORAN, 2002; PITZER et al, 2001). Isso poderia levar a um falso diagnóstico de hipoglicemia noturna.

As limitações apresentadas pelos sensores enzimáticos causam uma redução na exatidão das leituras. Isso dificulta o desenvolvimento de dispositivos práticos e comerciais que utilizem essa tecnologia. O MiniMed CGMS, o primeiro sistema comercial de monitoramento contínuo de glicose, utiliza sensores enzimáticos. Assim, as limitações de tais sensores devem ser consideradas quando se avalia as leituras do MiniMed CGMS. Esse assunto será abordado em maiores detalhes mais a seguir, ao longo da seção 2.6.

\subsection{MiniMed CGMS}

O presente trabalho utiliza o MiniMed CGMS para a coleta de informações de glicemia. O MiniMed CGMS foi escolhido por ser o único monitor contínuo de glicose disponível comercialmente no país no início do desenvolvimento deste trabalho. Dessa maneira, torna-se adequado incluir, neste ponto, uma descrição sucinta das características desse aparelho. 


\subsubsection{Uso do MiniMed CGMS}

O MiniMed CGMS (CGMS SYSTEM GOLD..., 2005), conforme foi citado anteriormente (seção 2.4.2), foi o primeiro sistema de monitoramento contínuo de glicose aprovado para uso clínico pelo FDA. O aparelho utiliza um sensor enzimático semelhante a uma agulha. O sensor é conectado a um dispositivo de armazenamento de dados (chamado de monitor) através de um cabo elétrico. O monitor é uma pequena caixa, semelhante a um pager, onde os valores de corrente elétrica são captados e armazenados. Ele possui um visor de cristal líquido e alguns botões para a interação com o usuário (ver Figura 2.11).

O MiniMed CGMS não mostra, em tempo real, os valores de glicose obtidos através do sensor. Nesse aspecto, o MiniMed CGMS assemelha-se a um holter (dispositivo para levantamento de eletrocardiograma). O paciente diabético utiliza o aparelho, sob supervisão médica, durante alguns dias. Nesse intervalo de tempo, o aparelho registra valores de glicemia. Esses valores são analisados pelo médico responsável ao final do tempo de uso. A análise dos dados permite suplementar o diagnóstico tradicional da diabetes.

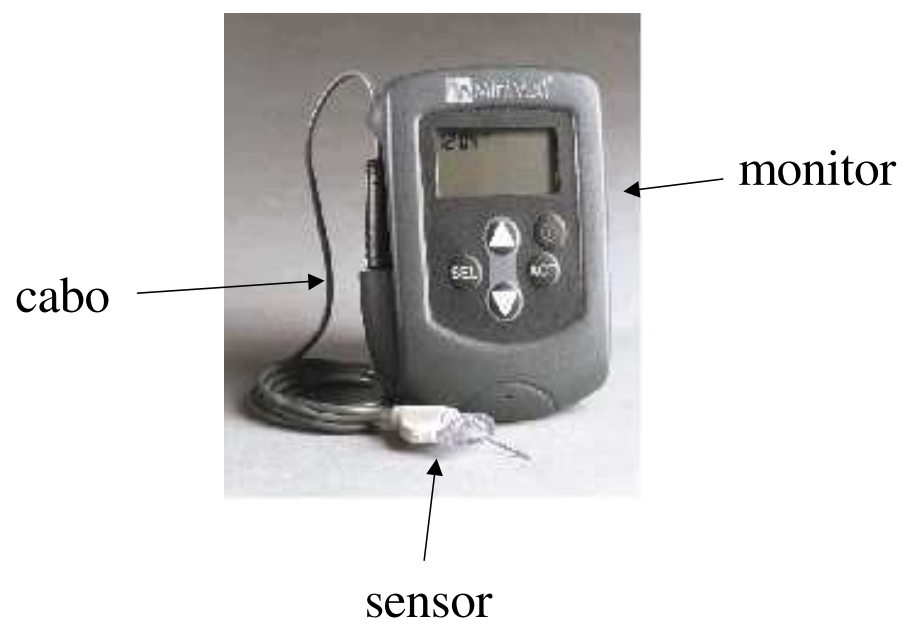

Figura 2.11 - MiniMed CGMS (imagem de divulgação). 


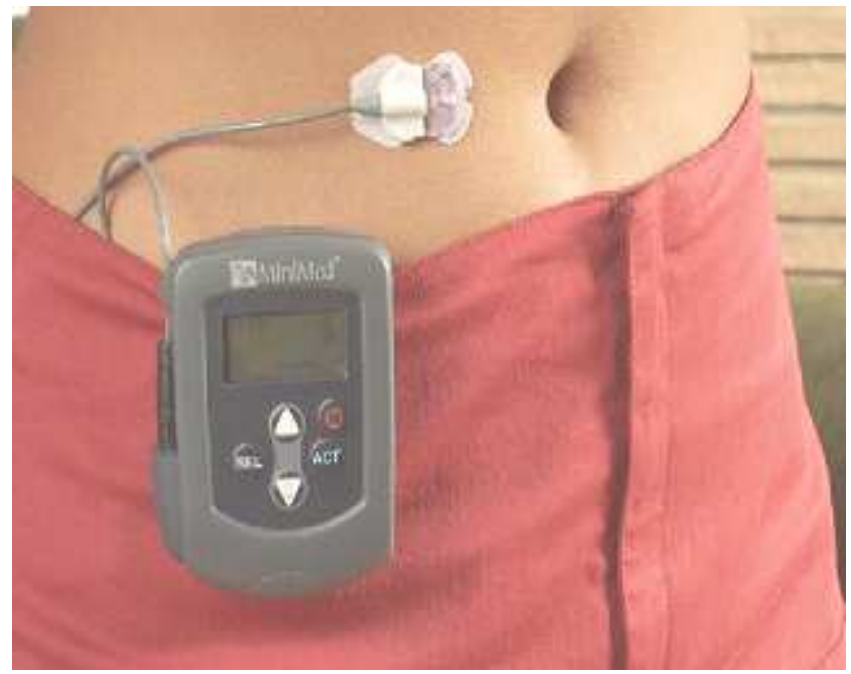

Figura 2.12 - MiniMed CGMS em uso (imagem de divulgação)

No início do exame, o sensor é inserido através da pele do paciente, usualmente no abdômen ou no braço (ver Figura 2.12). O sensor é composto por um fio flexível, o que torna seu uso indolor ao paciente. Uma agulha guia metálica envolve o sensor e facilita a sua inserção, sendo removida após a mesma. Um dispositivo chamado MiniMed SenSerter pode ser opcionalmente utilizado para auxiliar a tarefa. Após a inserção, o sensor é conectado ao monitor através de um cabo. O monitor é preso, através de uma presilha, à cintura do paciente.

Logo após a inserção do sensor, o aparelho passa por um processo de inicialização com duração de uma hora. Essa inicialização é necessária para a estabilização da corrente elétrica gerada pelo sensor. Ao final da inicialização, é registrada uma leitura de calibração e o MiniMed CGMS passa a armazenar as leituras de corrente.

O sensor tem vida útil de um a três dias. Ele gera uma leitura de corrente a cada dez segundos. A cada cinco minutos, é calculada uma média das leituras obtidas no período (trinta leituras em cinco minutos). Essa média é registrada na memória do aparelho. Portanto, são registradas 288 médias de corrente por dia (cada média de corrente equivale a uma leitura de glicose). 
Durante o exame, o paciente deve exercer suas atividades normais. Alguns eventos especiais, como refeições, injeção de insulina e prática de exercícios, podem ser opcionalmente registrados no monitor. Além disso, a cada seis horas, o paciente deve realizar um procedimento de calibração do aparelho (ver seções 2.5.2 e 2.6.2). Nesse procedimento, o paciente faz uma medição de glicemia através, por exemplo, do exame de "ponta de dedo". Essa leitura é registrada no MiniMed CGMS pelo usuário. Posteriormente, ao final do uso do aparelho, as medidas de calibração são utilizadas para o cálculo dos valores de glicemia.

Finalizado o tempo de uso (que geralmente corresponde à vida útil de um sensor, de um a três dias), o profissional de saúde responsável retira o aparelho do paciente. O MiniMed CGMS é então conectado a um computador pessoal através de uma base de comunicação (MiniMed Com-Station). Um cabo serial interliga a base ao computador (ver Figura 2.13).

Os dados de glicose colhidos ao longo do exame são descarregados no computador. Para essa operação, e para a posterior análise dos dados, é utilizado um software proprietário (MiniMed CGMS System Solutions Software). Através desse software, podem ser obtidos gráficos da variação da glicose sangüínea durante o uso do aparelho (ver Figura 2.14). Analisando os gráficos, o médico pode identificar o padrão diário de variação da glicemia no paciente. Assim, podem ser diagnosticados eventos como, por exemplo, a hipoglicemia noturna (ver seção2.2.2). O tratamento da diabetes pode ser reajustado com uma mudança nas doses de insulina ou nos horários de aplicação. 


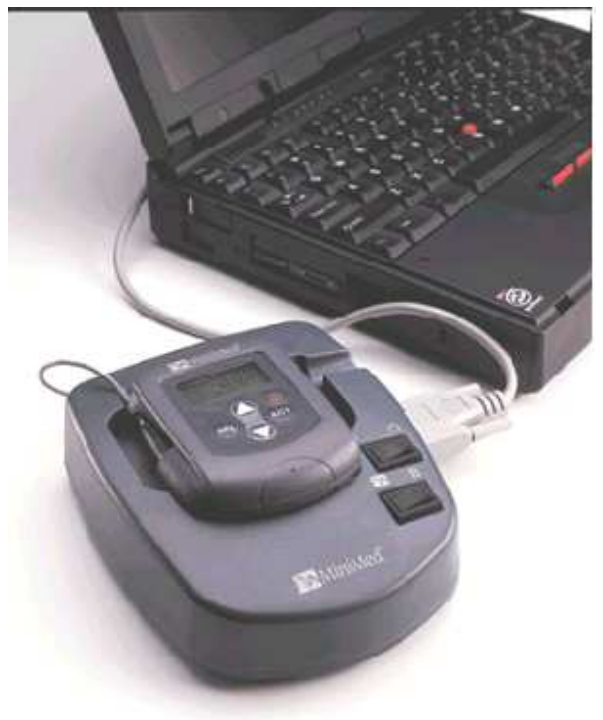

Figura 2.13 - O MiniMed CGMS é conectado a um computador através de uma base de comunicação. Um cabo serial interliga a base de comunicação ao computador (imagem de divulgação).

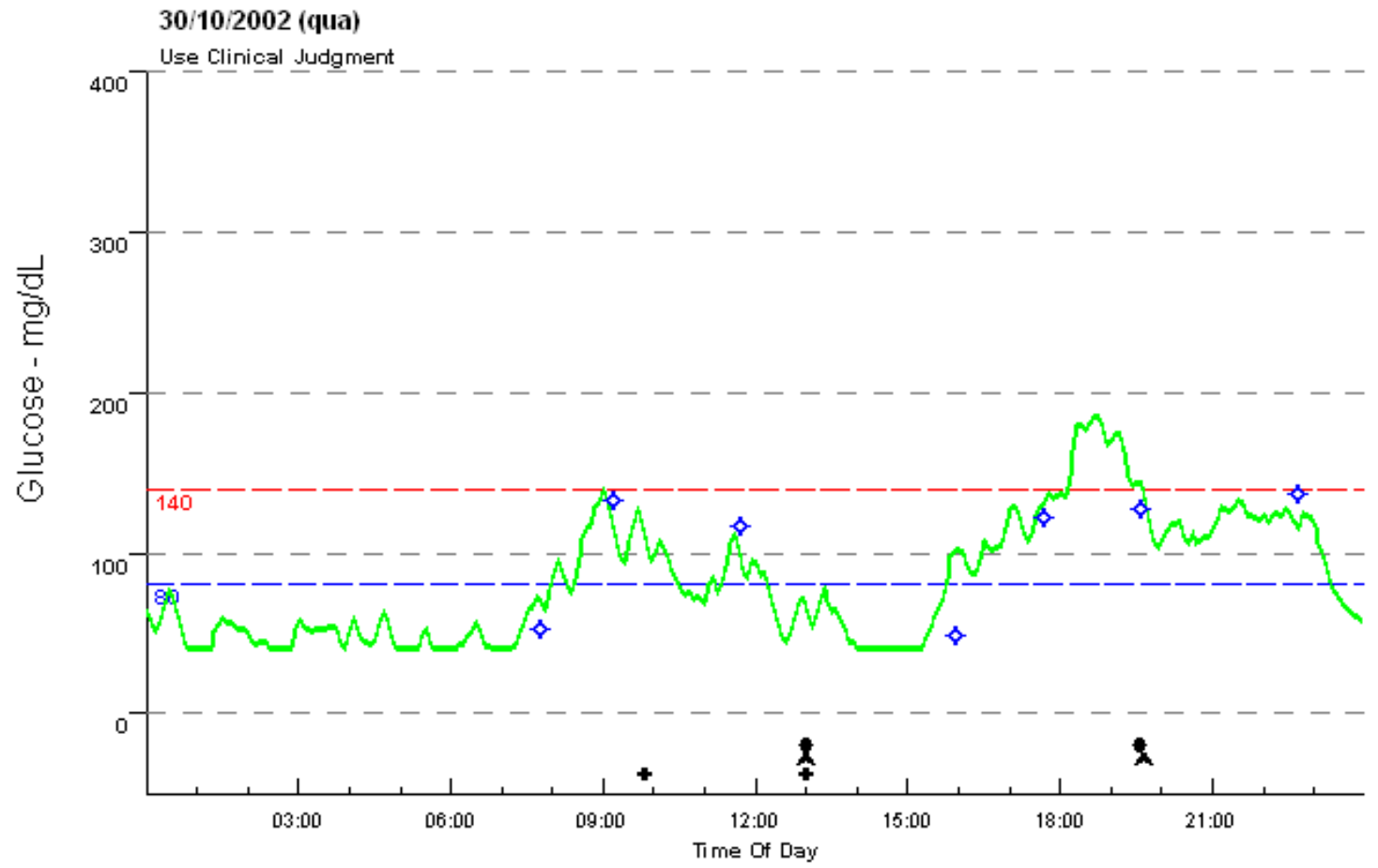

Figura 2.14 - Gráfico obtido através do software do MiniMed CGMS. O gráfico mostra a variação da glicemia ao longo de um dia. Duas linhas horizontais demarcam a faixa ideal de glicemia para este paciente (entre 80 e $140 \mathrm{mg} / \mathrm{dL}$ ). As marcas em forma de estrela indicam os valores de calibração. Além disso, as marcas próximas ao eixo das horas indicam eventos especiais, como refeições e uso de insulina. 


\subsubsection{Calibração do MiniMed CGMS}

Conforme apresentado anteriormente (seção 2.5.2), sensores enzimáticos geram uma corrente elétrica proporcional à concentração de glicose do meio. A relação entre corrente elétrica e concentração de glicose é estabelecida através de um processo conhecido como calibração. No MiniMed CGMS, a calibração é realizada a partir dos dados coletados no procedimento de calibração. O procedimento de calibração consiste na medição de glicemia através de um método alternativo. Usualmente, essas medições são realizadas pelo próprio paciente, através da coleta de amostras de sangue e uso de medidores portátes de glicose (exame de "ponta de dedo").

O manual de uso do MiniMed CGMS recomenda a realização de um procedimento de calibração a cada seis horas de uso do aparelho (MEDTRONIC MINIMED, 2003, p. 17). Após cada medição, o paciente registra o resultado obtido no aparelho.

Ao longo do tempo de uso (cerca de três dias), o aparelho guarda, em sua memória, as leituras de corrente elétrica geradas pelo sensor (288 leituras por dia), além dos valores de glicemia obtidos nos procedimentos de calibração (uma leitura a cada seis horas). O aparelho também armazena eventos especiais relativos às condições do aparelho (aparelho desligado, aparelho reinicializado, sensor desconectado etc.) e outros eventos registrados pelo paciente (refeições, uso de insulina, prática de esportes etc.). Cada valor registrado é associado a uma informação de data e hora (timestamp). A Figura 2.15 mostra uma tela do software do MiniMed CGMS com os dados registrados pelo aparelho. 


\begin{tabular}{|c|c|c|c|c|c|c|c|c|c|c|c|}
\hline Date/Time & Sample \# & ISIG & VCTR & $\begin{array}{c}\begin{array}{c}\text { Meter } \\
\text { Value } \\
\text { (mg/dL) }\end{array} \\
\end{array}$ & Slope & Offset & Valid Isig & $\begin{array}{c}\text { Sensor } \\
\text { Value } \\
\text { (mg/dL) }\end{array}$ & User Events & $\begin{array}{l}\text { System } \\
\text { Events }\end{array}$ & Alarms \\
\hline 19j:jul:00 15:03 & 17 & 26,00 & $-0,769$ & & 6,6 & 6 & 24,70 & 123 & & & \\
\hline 19j:ul:00 15:08 & 18 & 25,30 & $-0,771$ & & 6,6 & 6 & 26,00 & 132 & & & \\
\hline 19:jul:00 15:13 & 19 & 24,70 & $-0,774$ & 129 & 6,6 & 6 & 27,70 & 143 & & ESI & \\
\hline 19:jul:00 15:18 & 20 & 26,00 & $-0,782$ & & 6,6 & 6 & 25,80 & 130 & & & \\
\hline 19j:jul:00 15:23 & 21 & 27,70 & $-0,790$ & & 6,6 & 6 & 23,00 & 112 & & & \\
\hline 19jul:00 15:28 & 22 & 25,80 & $-0,787$ & & 6,6 & 6 & 21,70 & 103 & & Legend & 凶 \\
\hline 19:jul:00 15:33 & 23 & 23,00 & $-0,782$ & & 6,6 & 6 & 19,40 & 88 & EMe,EEx & \multirow{11}{*}{\multicolumn{2}{|c|}{$\begin{array}{ll}\text { EMe } & \text { Meal } \\
\text { Eln Insulin } \\
\text { EEx Exercise } \\
\text { EOt Other } \\
\text { EPU Power On } \\
\text { EPD Power Off } \\
\text { ESI Sensor Initializatior } \\
\text { ELE Link Event } \\
\text { SeDi Sensor Disconnect } \\
\text { SROR Isig Out of Range } \\
\text { HiMF } & \text { Memony Full } \\
\text { CalE } & \text { Cal Error } \\
\text { Nois } & \text { Noise }\end{array}$}} \\
\hline 19:jul:00 15:38 & 24 & 21,70 & $-0,787$ & & 6,6 & 6 & 19,30 & 88 & & & \\
\hline 19:julioo $15: 43$ & 25 & 19,40 & $-0,784$ & & 6,6 & 6 & 21,30 & 101 & & & \\
\hline 19:jul:00 $15: 48$ & 26 & 19,30 & $-0,794$ & & 6,6 & 6 & 24,10 & 119 & & & \\
\hline 19julion $15: 53$ & 27 & 21,30 & $-0,808$ & & 6,6 & 6 & 24,90 & 124 & & & \\
\hline 19:jul:00 15:58 & 28 & 24,10 & $-0,820$ & & 6,6 & 6 & 23,80 & 117 & & & \\
\hline 19:jul:00 16:03 & 29 & 24,90 & $-0,825$ & & 6,6 & 6 & 21,70 & 103 & & & \\
\hline 19/jul:00 16:08 & 30 & 23,80 & $-0,824$ & & 6,6 & 6 & 21,30 & 101 & & & \\
\hline 19j:jul:00 16:13 & 31 & 21,70 & $-0,810$ & & 6,6 & 6 & 21,10 & 99 & & & \\
\hline 19j:jul:00 16:18 & 32 & 21,30 & $-0,814$ & & 6,6 & 6 & 20,90 & 98 & & & \\
\hline 19:jul:00 $16: 23$ & 33 & 21,10 & $-0,815$ & & 6,6 & 6 & 18,80 & 84 & & & \\
\hline 19:jul:00 16:28 & 34 & 20,90 & $-0,813$ & & 6,6 & 6 & 17,40 & 75 & EMe & & \\
\hline
\end{tabular}

Figura 2.15 - Exemplo de tela do software do MiniMed CGMS. É mostrada uma tabela com os dados registrados no aparelho. Date/Time é a data e o horário de cada amostra. Sample é o número da amostra. ISIG é a leitura da corrente gerada pelo sensor enzimático. VCTR é a tensão aplicada no sensor. Meter Value é o valor de glicemia obtido no procedimento de calibração pelo usuário. User Events, System Events e Alarms (à direita) indicam outras informações armazenadas no aparelho. As demais colunas intermediárias mostram dados calculados pelo software, isto é, que não são armazenados no aparelho.

É importante notar que o aparelho não registra valores de glicose obtidos pelo sensor, mas valores de corrente elétrica. A conversão dos valores de corrente em valores de glicose não é feita pelo MiniMed CGMS. Ela só ocorre depois que os dados são descarregados para o computador, e é realizada pelo software que acompanha o aparelho.

O método de cálculo dos valores de glicose é descrito no manual do software (MEDTRONIC MINIMED, 2004, Chapter V, p. 39-42). Ele é baseado no método de calibração apresentado na seção 2.5.2. A descrição encontrada no manual do software não é completa. De qualquer forma, será feita, a seguir, uma descrição aproximada do método. É importante observar que o método descrito refere-se à versão 3.0C do software, já que as versões anteriores utilizavam métodos ligeiramente diferentes. 
O cálculo da glicose é feito a partir dos valores de corrente (ISIG na nomenclatura do manual do software) e dos valores de glicose obtidos pelos procedimentos de calibração (Meter $B G)$. O objetivo do processo é o cálculo da glicemia a partir das medidas geradas pelo sensor. Esse valor é chamado aqui de Sensor BG.

Cada leitura de calibração (Meter BG) é associada a um valor de corrente. Esse valor não é $I S I G$, que é a corrente gerada pelo sensor no momento da calibração. Em seu lugar, é usado um valor chamado VALID ISIG, que é a corrente gerada pelo sensor dez minutos após a calibração. Esse atraso é aplicado para compensar a diferença entre concentração de glicose sangüínea e intersticial (ver seção 2.5.3). Além disso, também é compensado aqui o tempo de resposta do aparelho. Como o aparelho fornece uma leitura média para cada período de cinco minutos, podemos considerar o tempo médio de resposta do aparelho como igual a 2,5 minutos. Dessa forma, assume-se implicitamente que o atraso entre os valores de glicose sangüínea e intersticial é de aproximadamente 7,5 minutos.

O primeiro passo da calibração é a validação das leituras de glicemia registradas pelo usuário (Meter BG). Quando duas leituras de Meter BG são digitadas no aparelho com um intervalo de tempo de até dez minutos, somente o último valor é considerado. Dessa maneira, o usuário pode corrigir a entrada de valores digitados incorretamente. Além disso, o valor de Meter BG só é considerado válido se a razão entre Meter BG e o VALID ISIG correspondente estiver entre 1,5 e 15.

Após a validação dos pontos de calibração, o segundo passo é o cálculo do fator de escala (aqui chamado de SLOPE) e da corrente de fundo (chamada de OFFSET). Esse cálculo é feito para cada valor de corrente (VALID ISIG). São usados, como dados de entrada, os pontos de calibração (pares de Meter BG e VALID ISIG) obtidos na etapa anterior. Relembrando, a relação entre estas variáveis é indicada pela Equação 2.7. Esta equação é 
idêntica à Equação 2.5, mostrada anteriormente na seção 2.5.2 (Calibração de sensores enzimáticos), exceto pela nomenclatura.

$$
\text { MeterBG }=S L O P E \times(V A L I D I S I G-O F F S E T)
$$

Para o cálculo da glicemia em um dado instante, são selecionados todos os pontos de calibração (pares de Meter BG e VALID ISIG) presentes em uma janela móvel de \pm 12 horas. Por exemplo, para se calcular o valor da glicemia no dia 2, às 8:00, toma-se todos os pontos de calibração registrados entre o dia 1, às 20:00, e o dia 2, às 20:00.

São considerados cinco valores possíveis para OFFSET: -6, -3, 0, 3 e 6. Segundo o manual do software, é escolhido o valor que minimiza a diferença absoluta média (DAM) entre os valores de glicose estimados pelo algoritmo (Sensor $B G$ ) e as glicemias de calibração equivalentes (Meter BG) (Equação 2.8). Para a realização do cálculo da diferença absoluta média, são utilizados os dados colhidos durante todo o tempo de uso do sensor. Assim, o valor de OFFSET escolhido é único para cada sensor.

$$
D A M(O F F S E T)=\frac{\sum_{i=1}^{n} \mid \text { SensorBG }_{i}(\text { OFFSET })-\text { MeterB }_{i} \mid}{n}
$$

O método da escolha do OFFSET não é descrito em detalhes no manual do software. Uma suposta maneira de se realizar essa escolha seria assumir um valor de OFFSET igual a 0 e realizar o cálculo de todos os valores de glicemia, (o SLOPE seria calculado através de regressão linear, ver Apêndice C). Depois, todo o processo seria repetido para cada um dos possíveis valores de OFFSET. Finalmente, o valor de OFFSET que minimiza a diferença absoluta média seria escolhido.

Como já foi citado anteriormente, o cálculo do $S L O P E$ é feito através de regressão linear. Considerando-se um certo valor fixo de OFFSET e tendo-se $n$ pontos de calibração (presentes na janela móvel de \pm 12 horas), obtêm-se um sistema com $n$ equações e apenas uma 
incógnita (Equação 2.9). Aplicando-se o método de regressão linear (Apêndice C), obtém-se um valor adequado de SLOPE.

$$
\left\{\begin{array}{l}
\text { MeterBG }_{1}=S L O P E \times\left(V A L I D \cdot I S I G_{1}-O F F S E T\right) \\
M_{\text {eter } B G_{2}}=S L O P E \times\left(V A L I D \cdot I S I G_{2}-O F F S E T\right) \\
\cdots \\
\text { MeterB }_{n}=S L O P E \times\left(V A L I D \cdot I S I G_{n}-O F F S E T\right)
\end{array}\right.
$$

Após o cálculo do SLOPE, é aplicado um algoritmo de suavização nos valores obtidos. Isso é feito para se evitar diferenças bruscas de SLOPE entre dois pontos adjacentes. O algoritmo utiliza uma janela móvel de \pm 1 hora. O manual do software do MiniMed CGMS não especifica maiores detalhes sobre o tipo de algoritmo de suavização utilizado. Provavelmente, é aplicado um algoritmo simples de média móvel, onde cada valor de SLOPE é substituído pela média dos valores de $S L O P E$ presentes na janela.

Tendo-se determinado os valores de SLOPE e OFFSET, a terceira etapa do método consiste no cálculo do valor estimado de glicose (chamado aqui de Sensor BG) a partir do valor de corrente (VALID ISIG). O cálculo é feito através da Equação 2.10.

$$
\text { SensorBG }=S L O P E \times(V A L I D \cdot I S I G-O F F S E T)
$$

É importante observar que o processo descrito é repetido para cada sensor utilizado. Se, durante o exame, o sensor for trocado, os dados colhidos por cada sensor serão tratados separadamente (o aparelho possui mecanismos para detectar a troca do sensor). Cada sensor possui um valor de OFFSET diferente. Além disso, as janelas móveis consideram somente os pontos relativos ao sensor em questão.

O Algoritmo 2.1 resume o processo de cálculo discutido ao longo desta seção. Vale notar que o algoritmo foi simplificado para facilitar a compreensão. Em uma implementação real, algumas tarefas, como a seleção das janelas e a regressão linear, tornam o algoritmo mais complexo. 


\title{
Algoritmo 2.1 - Algoritmo de calibração (software do MiniMed CGMS)
}

\section{Entradas:}

- $\quad I S I G(t)=$ valor de corrente para o instante $t$

- $\operatorname{MeterBG}(t)=$ valor de glicose (obtido no procedimento de calibração) para o instante $t$

Saída:

- $\quad$ SensorBG $(t)=$ valor de glicose estimado (a partir das leituras do sensor) para o instante $t$

\author{
Algoritmo: \\ // validação das entradas \\ para cada $t$
}

// aplica atraso nos valores de corrente

$\operatorname{ValidISIG}(t)=I S I G(t+10 \mathrm{~min})$

// desconsidera pontos de calibração digitados erroneamente

se $\operatorname{MeterBG}(t) \neq 0$ e MeterBG $(t+5 \mathrm{~min})=0$ e $\operatorname{MeterB} G(t+10 \mathrm{~min})=0$

PairedMeterBG $(t)=\operatorname{MeterBG}(t)$

fim se

// desconsidera pontos de calibração inválidos

se PairedMeterBG $(t) /$ ValidISIG $(t)<1,5$ ou PairedMeterBG $(t) / \operatorname{ValidISIG}(t)>15$

fim se

$$
\text { PairedMeterBG }(t)=0
$$

fim para

// escolha de OFFSET

para OFFSET $=-6,-3,0,3,6$

// cálculo do SLOPE

para cada

procura início da janela ( $t$ - 12 horas com o mesmo sensor) procura fim da janela $(t+12$ horas com o mesmo sensor $)$ calcula SLOPE( $t$, OFFSET) usando regressão linear

fim para

// suavização do SLOPE

para cada $t$

procura início da janela ( $t$ - 1 horas com o mesmo sensor)

procura fim da janela $(t+1$ horas com o mesmo sensor $)$

$S L O P E(t, O F F S E T)=$ média dos SLOPE $(t$, OFFSET $)$ presentes na janela

fim para

// calcula a diferença absoluta

$D A(O F F S E T)=0$

para cada $t$

SensorBGauxiliar $(t$, OFFSET $)=\operatorname{SLOPE}(t$, OFFSET $) x(\operatorname{ValidISIG}(t)-$ OFFSET $)$

se PairedMeterBG $(t) \neq 0$

$D A($ OFFSET $)=D A($ OFFSET $)+\mid$ PairedMeterBG $(t)-$ SensorBGauxiliar $(t$, OFFSET)|

fim se

fim para

fim para

// retorna as leituras de glicemia

escolho OFFSET tal que DA(OFFSET) é mínima

para cadat

SensorBG $(t)=$ SensorBGauxiliar $(t$, OFFSET $)$

fim para

retorna SensorBG 


\subsubsection{Exatidão e reprodutibilidade do MiniMed CGMS}

O MiniMed CGMS foi o primeiro sistema de monitoramento contínuo de glicose lançado comercialmente. Entretanto, pelo seu próprio caráter inovador, ele apresenta uma série de limitações. Uma primeira grande limitação do aparelho é a exatidão das suas medidas.

Gross et al. (2000) compararam as leituras do MiniMed CGMS a "pontas de dedo" num grupo de 135 pacientes e chegaram aos seguintes resultados:

- Coeficiente de correlação $r=0,91$;

- Diferença média (bias) de $-3 \mathrm{mg} / \mathrm{dL}$

- Diferença média absoluta de $18 \%$;

- $96 \%$ de leituras nas zonas A e B da grade de erro de Clarke (70\% na zona A, 26\% na zona B).

Tais resultados são bastante positivos, e são compatíveis com outros trabalhos encontrados na literatura (BODE et al., 1999; GOLDBERG et al., 2004; CHEE; FERNANDO; VAN HEERDEN, 2003). Além disso, alguns trabalhos (BODE et al., 1999; CHASE et al., 2001) mostraram uma redução na concentração de hemoglobina glicada em pacientes diabéticos com o uso do MiniMed CGMS, o que indica a eficiência clínica do uso do dispositivo.

Entretanto, alguns trabalhos apresentam resultados mais pessimistas. Metsger et al. (2002) (ver também MASTROTOTARO; GROSS, 2003; METZGER et al., 2003) fizeram testes de reprodutibilidade das leituras do MiniMed CGMS. Para tanto, utilizaram dois sensores por paciente em um grupo de 11 voluntários e compararam as leituras obtidas. Foi observado que $69 \%$ das leituras do CGMS possuíam um desvio superior a 10\%. Além disso, desvios superiores a $50 \%$ foram observados em $7 \%$ das leituras. 
A partir desses dados, pode-se concluir que o MiniMed CGMS não deve ser utilizado isoladamente para a leitura de glicemia. Seu uso deve estar sempre aliado a outros métodos de controle de glicemia. Entretanto, o MiniMed CGMS, por ser um sistema de monitoramento contínuo, fornece informações que não podem ser obtidas através dos exames tradicionais e, por isso, compõe um instrumento importante e válido no diagnóstico e tratamento da diabetes.

\subsubsection{Outras limitações do MiniMed CGMS}

Devido às restrições de exatidão nas leituras, o MiniMed CGMS não foi originalmente concebido para apresentá-las em tempo real. As leituras de glicemia são acessadas pelo clínico somente ao final do exame. Isso impede que o aparelho seja usado para um ajuste em tempo real da dosagem de insulina.

A obtenção de leituras em tempo real causaria uma redução na exatidão do aparelho. Vimos na seção 2.5.2 que, durante o cálculo das taxas de glicose, o software do MiniMed CGMS utiliza uma janela móvel para selecionar os pontos de calibração. Para o cálculo do valor de glicose em um dado instante, são considerados todos os pontos de calibração presentes em uma janela móvel de \pm 12 horas. Entretanto, para o cálculo em tempo real, não estão disponíveis os pontos de calibração das horas futuras (das próximas 12 horas). Por isso, a forma da janela móvel deve ser outra.

Se considerarmos os pontos de calibração das últimas 12 horas até o momento atual, usaremos menos pontos de calibração. Se o procedimento de calibração for realizado a cada 6 horas, serão usados para o cálculo, em média, apenas dois pontos de calibração. Entretanto, se considerarmos um número maior de horas (por exemplo, as últimas 24 horas), estaremos correndo o risco de utilizar pontos de calibração inválidos, já que a sensibilidade do sensor altera-se com o tempo. Por isso, fazendo o cálculo das leituras ao final do processo, o software do MiniMed CGMS consegue um acréscimo na exatidão do aparelho. 
Provavelmente, esse fato foi considerado ao se optar por uma estratégia de pós-processamento das leituras.

$\mathrm{Na}$ seção 2.5.3, foram discutidas as limitações dos sensores enzimáticos. Como o CGMS utiliza um sensor enzimático para suas medições, todas as limitações discutidas naquela seção aplicam-se a este aparelho. Uma das dificuldades citadas foi a obtenção de uma boa estimativa da corrente de fundo. Relembrando, a corrente de fundo é a corrente elétrica gerada pelo sensor enzimático quando a concentração de glicose no meio é nula. No CGMS, a corrente de fundo não é medida diretamente; ela é estimada a partir dos pontos de calibração (ver seção 2.5.2). Não foram encontrados trabalhos na literatura que verifiquem a influência da corrente de fundo nas leituras do CGMS.

Uma outra limitação dos sensores enzimáticos discutida na seção 2.5.3 é a diferença entre a taxa de glicose no líquido intersticial e no sangue. No MiniMed CGMS, esse problema é abordado de maneira bastante simples. É aplicado um atraso de dez minutos para todas as leituras obtidas pelo aparelho (ver seção 2.6.2). O CGMS fornece uma leitura de glicose a cada cinco minutos. Portanto, podemos considerar o tempo de resposta do aparelho como igual a 2,5 minutos (já que a leitura gerada pelo aparelho a cada cinco minutos é uma média do período). Dessa forma, assume-se um atraso entre os valores de glicose sangüínea e intersticial de aproximadamente 7,5 minutos. Deve-se observar que, conforme discutido na seção 2.5.3, há algumas controvérsias sobre a validade de tal abordagem.

Quanto à praticidade do MiniMed CGMS, há alguns pontos a serem aprimorados. O sensor do CGMS ainda causa um certo incômodo ao paciente e, se mal instalado, pode levar a irritação e infecção local, conforme descrito no próprio manual do aparelho (MEDTRONIC MINIMED, 2003). O uso do monitor é inadequado para algumas situações, como na prática de esportes e durante o banho. O cabo entre o sensor e o monitor limita a movimentação do paciente, o que poderia ser resolvido pela substituição por uma conexão sem fio, como é 
proposto para outros dispositivos do gênero. Todos esses fatores diminuem a usabilidade do aparelho, dificultando a sua utilização por longos intervalos de tempo.

Outra questão importante é a integração do MiniMed CGMS a outros dispositivos e sistemas. As informações colhidas pelo aparelho podem ser transmitidas para um computador. Entretanto, para essa transmissão, utiliza-se um protocolo de comunicação proprietário. A transmissão e visualização dos dados devem ser feitos utilizando-se o software que acompanha o produto. Uma abordagem mais eficiente seria o uso de normas internacionais de transmissão de dados, como a norma Health Level Seven (ver seção 3.4). Isso permitiria, por exemplo, que as leituras fossem facilmente armazenadas em um sistema eletrônico de informações médicas (Prontuário Eletrônico do Paciente).

De qualquer forma, os benefícios proporcionados pelo uso do MiniMed CGMS, mesmo considerando-se as suas limitações, foram substanciais. O CGMS foi o primeiro sistema de monitoramento contínuo de glicose disponibilizado comercialmente. Pelo seu caráter inovador, é natural que haja vários aspectos a serem estudados e aprimorados no aparelho. Alguns desses aspectos, como os métodos de calibração em tempo real e a integração da coleta de dados a sistemas de informação, serão abordados neste trabalho. 

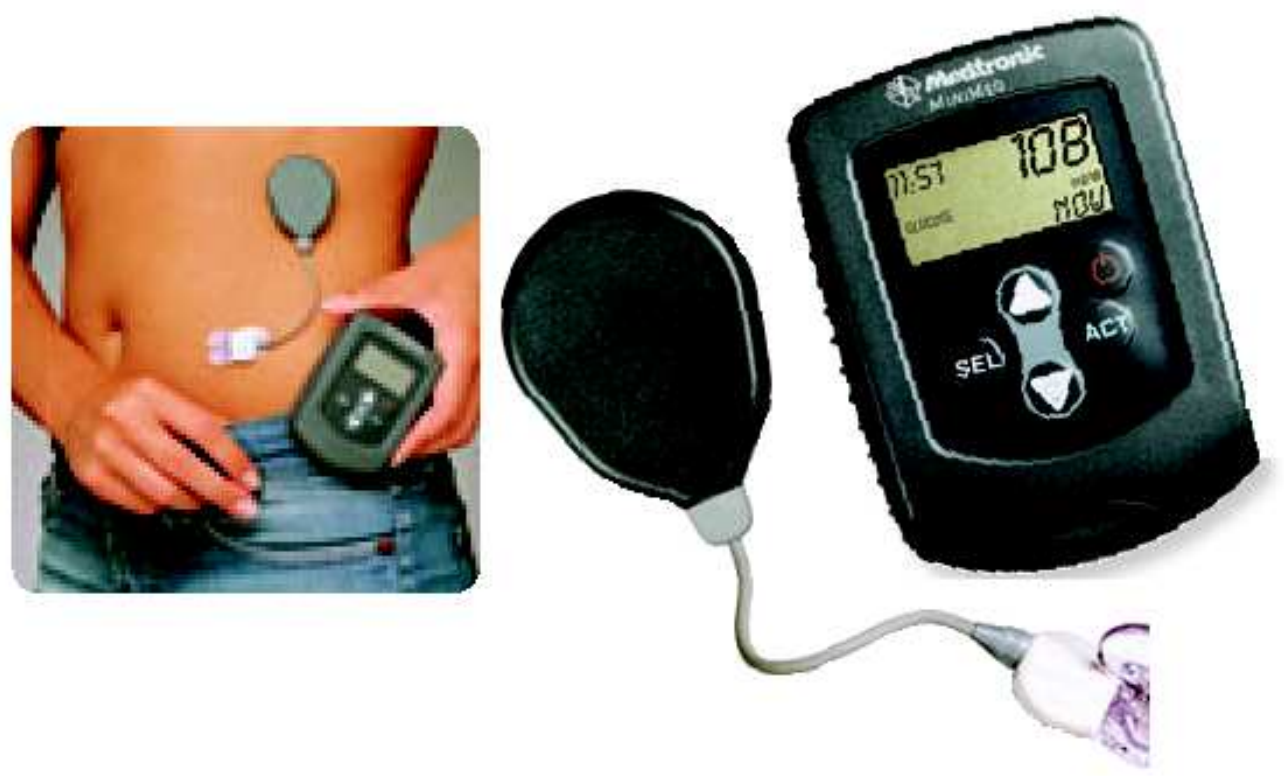

Figura 2.16 - MiniMed Guardian RT - Sucessor do CGMS, este sistema possui comunicação sem fio entre o sensor e o monitor, além de apresentar leituras de glicemia em tempo real (imagens de divulgação)

É interessante observar que algumas das limitações discutidas aqui prometem ser resolvidas pela nova geração do CGMS. O Guardian $R T$, produto em desenvolvimento pela Medtronic Diabetes, possui uma conexão sem fio entre o sensor e o monitor. Além disso, diferentemente do seu antecessor, apresenta leituras em tempo real, além de alarmes para eventos de hipo e hiperglicemia (Figura 2.16). O sistema está atualmente em testes e poderá ser lançado comercialmente dentro em breve (MEDTRONIC EUROPE SÀRL, 2004).

\section{7 controle da glicemia em pacientes críticos}

\subsubsection{A hiperglicemia em pacientes críticos}

Pacientes críticos tratados em uma UTI (Unidade de Terapia Intensiva) também podem apresentar quadros de hiperglicemia e baixa sensibilidade à insulina, mesmo que não sejam previamente diabéticos. Esse quadro, induzido pelo stress, é causado por alterações na produção de vários hormônios, que afetam no metabolismo da glicemia. Outros fatores, como 
administração de esteróides e regimes nutricionais com alta concentração de glicose, podem contribuir para o aumento do quadro. A hiperglicemia em pacientes críticos está freqüentemente associada a quadros de infecção severa, choque séptico, infarto do miocárdio e falência múltipla de órgãos (VAN DEN BERGHE, 2004; CHASE, 2006).

Até recentemente, acreditava-se que a hiperglicemia em pacientes críticos era um mecanismo de auto-defesa do organismo. Dessa maneira, pacientes críticos eram mantidos em um estado de hiperglicemia moderada (160-200 mg/dL). Entretanto, alguns estudos trouxeram evidências de que esse poderia ser um conceito incorreto. Furnary et al. (1999) demonstraram que o uso de controle glicêmico em pacientes diabéticos submetidos a uma cirurgia cardíaca leva uma menor incidência de infecção profunda do osso externo. O DIGAMI Study Group (MALMBERG, 1997) demonstrou uma redução na mortalidade de pacientes diabéticos que sofreram infarto agudo do miocárdio.

Essas evidências nortearam os trabalhos de Van den Berghe et al., que demonstraram que pacientes críticos hiperglicêmicos (diabéticos ou não) podem beneficiar-se de um controle rígido da glicemia a níveis normais $(80-110 \mathrm{mg} / \mathrm{dL})$. Em pacientes pós-cirúrgicos, observouse uma redução significativa tanto da mortalidade (de $11 \%$ para $7 \%$ ) quanto da incidência de complicações, como infecção severa e falência múltipla de órgãos (VAN DEN BERGHE et al., 2003; VAN DEN BERGHE, 2004). Em pacientes clínicos, não se obteve uma redução significativa da mortalidade, mas reduziu-se a incidência de complicações (VAN DEN BERGHE, 2006).

Assim, nos últimos anos, pacientes críticos hiperglicêmicos internados em uma UTI passaram a ser mantidos em níveis normais de glicemia. É feita a administração constante de insulina através de uma bomba de insulina. Medições de "ponta de dedo" são realizadas a intervalos de tempo regulares (em geral, de hora em hora), para ajuste da taxa de infusão da insulina. Ajustes na nutrição enteral ou parenteral são feitos de acordo com as leituras obtidas. 
Além disso, são tomados cuidados especiais na administração de medicamentos que afetem a glicemia, como os esteróides.

Toda essa rotina associada ao controle da glicemia é bastante desgastante para a equipe médica e de enfermagem de uma UTI. Assim, de maneira análoga ao paciente diabético ambulatorial, observou-se a necessidade de se desenvolver métodos mais eficientes para o controle da glicemia. Em especial, divisa-se a possibilidade de criação de um método automatizado, o pâncreas artificial (seção 2.2.3). Como foi observado anteriormente, o desenvolvimento de métodos de medição contínua de glicose é um dos pontos-chave para a realização de um controle glicêmico mais eficiente.

Como uma observação final para esta seção, podemos notar que, quando um paciente é tratado em uma UTI, a equipe médica tem um bom controle sob diversos fatores que influenciam a glicemia, como a nutrição e o uso de medicamentos. Além disso, os testes de "ponta de dedo" são realizados por uma equipe treinada, e não pelo próprio paciente, o que contribui bastante para a exatidão dos resultados. Assim, sob esse ponto de vista, o paciente de UTI está em um ambiente muito mais controlado do que o paciente diabético ambulatorial.

Entretanto, o metabolismo glicêmico alterado de um paciente crítico contribui de maneira bastante negativa na estabilização da taxa de glicose sangüínea. Quando tais pacientes são mantidos sob controle glicêmico, observa-se variações bastante bruscas de glicemia, o que ocorre com uma freqüência bem menor na diabetes comum. Além disso, sabese que uma redução na circulação periférica pode causar leituras errôneas em medidores de “ponta de dedo". Pode-se supor que o mesmo ocorra em medidores contínuos semi-invasivos, já que estes coletam informações a partir do líquido intersticial (embora não tenham sido encontrados trabalhos na literatura que verifiquem este fato). Fatores como desidratação severa, hipotensão, choque, insuficiência cardíaca congestiva grave ou doença vascular 
periférica, comuns em pacientes críticos, podem causar essa situação (ROCHE DIAGNOSTICS, 2004; CHEE; FERNANDO; VAN HEERDEN, 2003).

\subsubsection{Uso do MiniMed CGMS em UTI}

O MiniMed CGMS, assim como os demais monitores contínuos de glicemia disponíveis comercialmente, foi originalmente concebido para uso ambulatorial. Entretanto, para o presente trabalho, esse dispositivo foi aplicado em pacientes críticos hiperglicêmicos tratados em uma UTI. Serão apresentados a seguir dois relatos encontrados na literatura sobre esse caso de uso.

Em um primeiro trabalho (CHEE; FERNANDO; VAN HEERDEN, 2003), o MiniMed CGMS foi aplicado em cinco pacientes críticos. As leituras geradas eram descarregadas, em tempo real, para um computador. Foi utilizado o próprio software do MiniMed CGMS (versão 1.1A), aliado a um sistema de macros (seqüências automáticas de apertos de tecla e comandos de mouse) para simular a interação com um usuário. As leituras de glicemia alimentavam um algoritmo de controle de laço fechado. Esse algoritmo calculava uma taxa de insulina a ser injetada no paciente para que a glicemia fosse mantida em um nível normal. A insulina era injetada, através de uma bomba de insulina, à taxa de infusão definida automaticamente pelo algoritmo de controle. Dessa forma, tentou-se implementar um sistema simples de pâncreas artificial. As leituras de glicemia obtidas eram comparadas a "leituras de ponta de dedo", realizadas paralelamente.

Pela grade de erro de Clarke, 64,6\% das leituras encontravam-se na zona A (clinicamente eficiente) e 28,8\% encontravam-se na zona B (sem efeito clínico). Os desvios de leitura reportados nesse trabalho são levemente superiores aos encontrados para o MiniMed CGMS em uso ambulatorial. Os autores tentam levantar algumas explicações para o fato, como uma maior diferença entre glicose sangüínea e intersticial, causada pela reduzida movimentação do paciente na UTI ou pelas condições críticas do mesmo (veja seção 2.7.1). 
Entretanto, como o próprio artigo afirma, seria necessário um número maior de testes para confirmar esses resultados. O artigo ainda cita a ocorrência de grandes flutuações na leitura de um dos pacientes, atribuída ao mal posicionamento do sensor. Também relata, para outro paciente, o atraso de aproximadamente uma hora entre as medidas do MiniMed CGMS e do exame de "ponta de dedo". O atraso é atribuído, novamente, à diferença entre glicose sangüínea e intersticial. Quanto ao sistema de controle em laço fechado, Chee, Fernando e Van Heerden (2003) concluem que os resultados são comparáveis, mas não superiores, ao controle manual. Segundo o artigo, um sensor mais acurado e um refinamento no algoritmo de controle poderiam aprimorar o resultado obtido.

Em um segundo trabalho, Goldberg et al. (2004) relata o uso do MiniMed CGMS em 22 pacientes de $U T I$. Nesse trabalho, entretanto, não foram feitas medidas em tempo real. O MiniMed CGMS foi utilizado da maneira tradicional por até três dias. Posteriormente, as leitura de glicemia obtidas foram comparadas a medidas de "ponta de dedo", obtidas, pelo menos, quatro vezes ao dia. O coeficiente de correlação obtido foi 0,88 , a diferença média foi de $3,3 \pm 26,7 \mathrm{mg} / \mathrm{dL}(0,6 \pm 17,4 \%)$ e a diferença absoluta média, 19,7 $\pm 18,3 \mathrm{mg} / \mathrm{dL}(12,8 \pm$ $11,9 \%)^{1}$. A análise pela grade de erro de Clarke resultou em $78,4 \%$ dos pontos na zona A (clinicamente eficiente) e 20,3\%, na zona B (sem efeito clínico). Quanto à exatidão das medidas, portanto, os resultados são compatíveis com os obtidos em pacientes ambulatoriais. O artigo reporta, ainda, que os desvios (diferença média absoluta) são menores para valores altos de glicemia.

Foram citadas falhas em sete dos 41 sensores utilizados durante a experiência. O MiniMed CGMS acusou "CAL ERROR" (erro de calibração), um sintoma de desgaste prematuro do sensor. A razão dessas falhas não foi encontrada. Em particular, esse erro

\footnotetext{
${ }^{1}$ O símbolo “ \pm ” representa o desvio padrão da medida.
} 
ocorreu em um mesmo paciente para três sensores diferentes. Não foram reportadas ocorrências sérias de sangramento, irritação, infecção ou outros efeitos colaterais.

Goldberg et al. (2004) ainda tentaram avaliar a influência das condições do paciente crítico nos resultados de glicemia. Foram avaliadas as seguintes variáveis: idade, sexo, raça, altura, peso, índice APACHE II (KNAUS et al., 1985), diagnóstico primário e intervenções clínicas (prescrição de corticosteróides e vasopressores, nutrição enteral ou parenteral). Não foi encontrada nenhuma influência das condições analisadas, embora, pelo pequeno número de pacientes, o resultado não seja conclusivo.

Ao final do artigo, Goldbert et al. (2004) afirmam (p. 346, tradução livre):

Se desenvolvido posteriormente como um sensor de glicose em "tempo real", a tecnologia CGMS pode provar-se clinicamente útil em uma UTI, reduzindo a carga de trabalho da equipe de enfermagem e/ou fornecendo sinais de alarme no início das excursões glicêmicas. Tal tecnologia derrubaria as mais importantes barreiras para a implementação bem sucedida de tratamentos intensivos de infusão de insulina, facilitando o uso de tais protocolos em pacientes críticos. Conseqüentemente, um melhor controle glicêmico em UTI levaria a uma redução na morbidade e na mortalidade de pacientes críticos.

Dessa forma, Goldberg et al. (2004) explicitam claramente a importância clínica de um sistema de medição contínua de glicose, conforme discutido ao longo deste capítulo, justificando, assim, a existência do presente trabalho. 


\section{Capítulo 3. INTEGRAÇÃo DE SISTEMAS DE Monitoramento de PaCientes}

\subsection{Resumo}

Neste capítulo, é apresentada uma revisão da literatura a respeito da integração de sistemas de monitoramento de paciente a sistemas de informação médica. É dada uma ênfase especial à integração de monitores de beira de leito, à integração de sistemas de Point-of-care Testing (POCT) e às normas de comunicação Health Level Seven (HL7) e NCCLS POCT1-A.

\subsection{Integração de monitores de beira de leito}

Sistemas de informações médicas (HIS - Hospital Information Systems) proporcionaram um avanço significativo no serviço de assistência à saúde. Graças a esses sistemas, profissionais de saúde podem acessar, a partir de um computador, uma infinidade de informações a respeito de seus pacientes, como histórico clínico, exames e laudos, medicamentos prescritos, procedimentos realizados e outros. Portanto, os computadores de um hospital, interligados via rede local, formam hoje instrumentos poderosos de coleta, armazenamento e consulta de informações médicas.

Entretanto, além dos computadores pessoais, há outros importantes geradores e consumidores de informação. Podemos destacar, por exemplo, sistemas geradores de imagens médicas, como aparelhos de tomografia, ressonância magnética e ultra-som, e os monitores de beira de leito, utilizados para o monitoramento de sinais vitais de pacientes críticos ou em cirurgia. Dessa forma, tais sistemas, quando integrados ao sistema de informações médicas do hospital, potencializam ainda mais o rápido fluxo de informações clínicas dos pacientes. 
Dentro dessa perspectiva, o Instituto do Coração realizou, em anos anteriores, um importante projeto de integração de monitores de sinais vitais (OLIVEIRA et al., 2002). Neste projeto, batizado de vMon, as informações colhidas pelos monitores de beira de leito (SIEMENS MEDICAL SOLUTIONS, 2001) eram transmitidas, usando-se o protocolo $H L 7$ (ver seção 3.4), para um servidor. Ali, os sinais vitais eram armazenados em um banco de dados, de maneira integrada ao sistema de informações médicas do hospital (Figura 3.1). Além disso, o mesmo servidor permitia, através de uma interface $W e b$, a visualização remota dos sinais colhidos pelos monitores do hospital (Figura 3.2). Finalmente, houve uma extensão no projeto (vMon-Mobile) para permitir a visualização dos sinais através de um palmtop. Assim, o projeto vMon permitiu o acompanhamento à distância das condições de saúde dos pacientes críticos do hospital.

O presente trabalho utilizou-se de parte da estrutura e do conhecimento desenvolvidos durante o projeto vMon, o que justifica, inclusive, o nome adotado para o sistema desenvolvido (vMonGluco).

\subsection{Aquisição de informações à beira de leito}

Desde muito tempo atrás, os testes laboratoriais têm ocupado um papel de destaque na Medicina. Nas últimas décadas, uma nova modalidade de testes vem crescendo de maneira significativa. Os exames de laboratórios vêm sendo substituídos, ao menos parcialmente, por testes rápidos realizados à beira de leito. Essa nova categoria de testes é conhecida na literatura como Point-of-Care Testing (POCT) (ver BAILEY et al., 1997; BISSEL; SANFILIPPO, 2002; GUTIERRES; WELTY, 2004; KOST, 2001). 


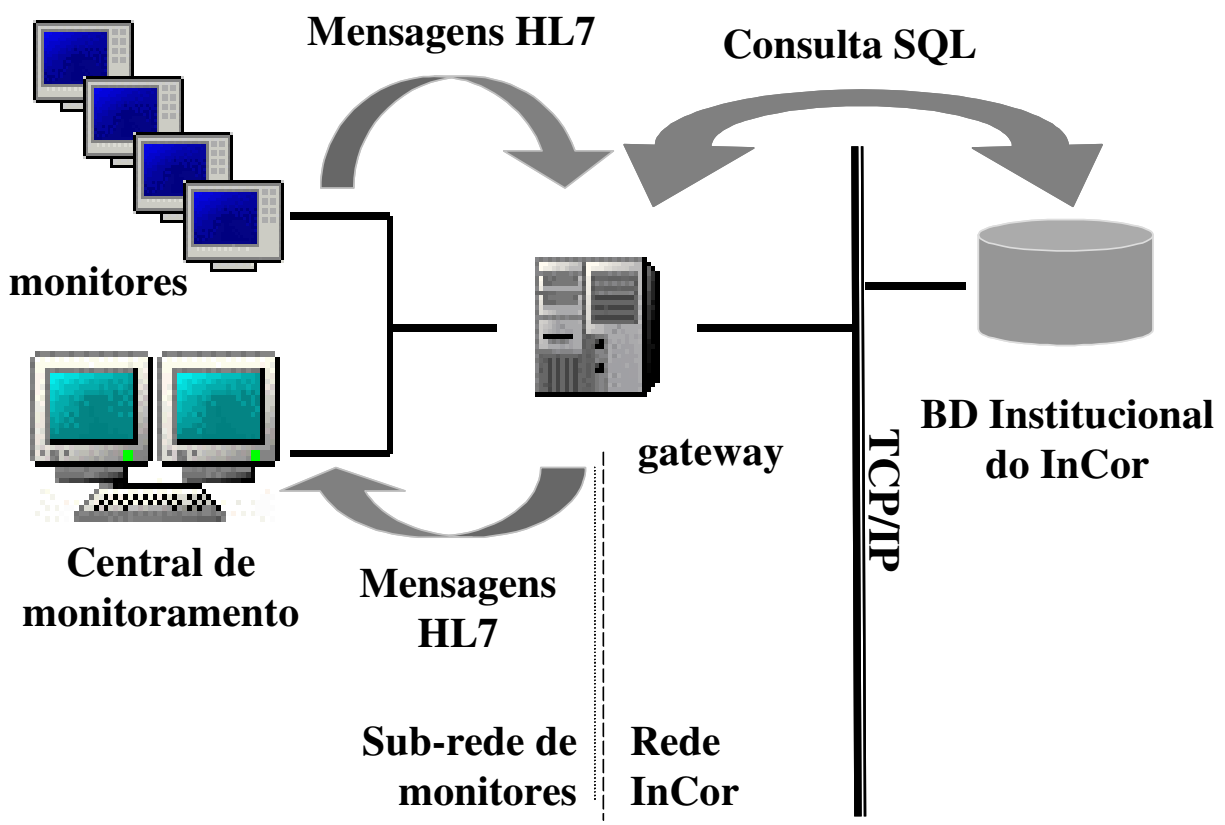

Figura 3.1 - Integração entre os monitores de beira de leito e o sistema de informações médicas do Instituto do Coração (adaptado de Oliveira et al., 2002)

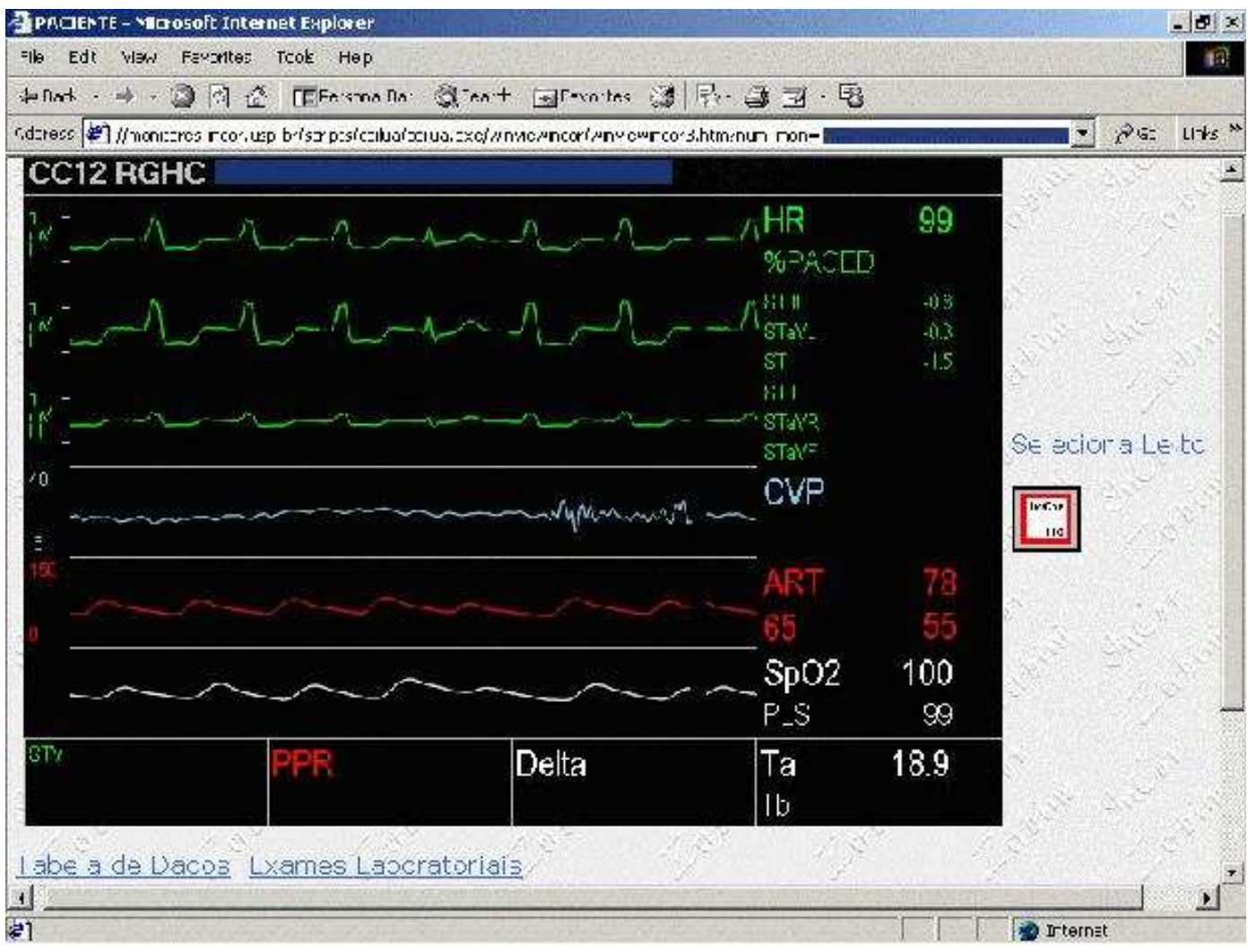

Figura 3.2 - Os sinais de um monitor de beira de leito são visualizáveis a partir de uma interface Web (adaptado de Oliveira et al., 2002). 
O College of American Pathologists (CAP) faz a seguinte definição de Point-of-Care Testing (POINTOFCARE.NET..., 2004, tradução livre):

... atividades de testes analíticos em pacientes oferecidos por uma instituição, mas realizados fora do ambiente físico de um laboratório clínico. Não requer um espaço dedicado permanente, mas, pelo contrário, inclui kits e instrumentos que são carregados ou transportados para as proximidades do paciente para teste imediato nessa localidade.

Dispositivos portáteis, conhecidos como POCT devices, são utilizados para a leitura de vários parâmetros clínicos à beira de leito ou na casa do paciente. Na prática, entretanto, a definição do que pode ser classificado como um dispositivo de POCT é um pouco difusa. No caso dos medidores de glicose, assunto do presente trabalho, costuma-se considerar gasômetros "portáteis" como dispositivos de POCT. Tais dispositivos são muito semelhantes aos utilizados em exames laboratoriais, mas possuem dimensões menores. Assim podem ser transportados sobre um carrinho até o quarto do paciente, permitindo a realização do exame em alguns minutos. Já os medidores de glicose de "ponta de dedo" e os medidores contínuos nem sempre são considerados como POCT devices. De qualquer forma, julgou-se relevante para o presente trabalho uma breve análise sobre tais dispositivos.

Um dos aspectos mais importantes a serem desenvolvidos nos dispositivos de POCT é a conectividade (BISSEL; SANFILIPPO, 2002; FERMANN; SUYAMA, 2002; KOST, 2001). A transmissão dos dados adquiridos para sistemas eletrônicos de informação médica, ou para outros dispositivos de $P O C T$, aumenta enormemente a flexibilidade e a facilidade de uso desses aparelhos. Entretanto, para que isso possa ocorrer, é necessária a definição de padrões claros e abertos de conectividade. A norma Health Level Seven (HL7) é bastante usada em várias áreas de informática médica, incluindo POCT. Assim, a norma $H L 7$ será descrita na seção 3.4. Limitações da norma $H L 7$ levaram ao desenvolvimento de outras normas, específicas para POCT. Assim, surgiu o NCCLS POCT1-A, descrito na seção 3.5. 


\subsection{O protocolo de comunicação Health Level Seven}

Um protocolo de comunicação bastante conhecido na informática médica é o Health Level Seven (HL7). A norma $H L 7$ foi criada pela organização americana de mesmo nome, fundada em 1987. Em 1994, a HL7 obteve reconhecimento da ANSI (American National Standards Institute) como uma entidade desenvolvedora de normas ANSI. No mesmo ano, a versão 2.2 da norma $H L 7$ foi reconhecida como uma norma ANSI. Atualmente, a norma $H L 7$ é utilizada em instituições de saúde do mundo inteiro para a troca eletrônica de informações clínicas, financeiras e administrativas. (HEALTH LEVEL SEVEN, 1998a).

A Tabela 3.1 mostra uma lista cronológica das últimas versões da norma $H L 7$.

Tabela 3.1 - Lista cronológica das últimas versões da norma $H L 7$

\begin{tabular}{ccl}
\hline Versão & $\begin{array}{c}\text { Aprovado como } \\
\text { norma ANSI em }\end{array}$ & Observações \\
\hline 2.2 & 1994 & Primeira norma HL7 aprovada pela ANSI \\
2.3 & 1997 & \\
2.3 .1 & 1999 & Incorpora mensagens de POCT. \\
2.4 & 2000 & \\
2.5 & 2003 & $\begin{array}{l}\text { Mensagens } X M L, \text { norma mais restrita, nova metodologia de } \\
\text { elaboração de normas. }\end{array}$ \\
\hline
\end{tabular}

O protocolo $H L 7$ utiliza mensagens de texto para a troca de informações entre dois sistemas computacionais. A título ilustrativo, é mostrado a seguir um trecho de mensagem HL7 para a transmissão de dados radiológicos não solicitados (HEALTH LEVEL SEVEN, 2003, seção 7.5.2). A mensagem é dividida em segmentos, separados por um caractere de mudança de linha $(<c r>)$. O segmento é formado por três letras que identificam a sua função, seguidas pelos campos de informação (separados pelo caractere "l"): 


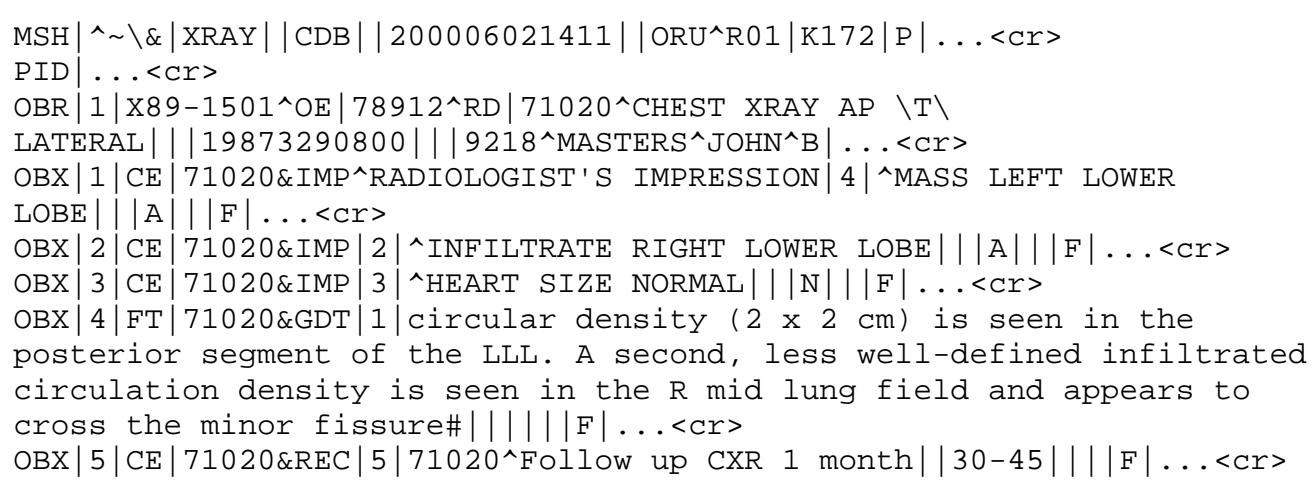

Foi acrescentado à versão 2.4 (2000) um conjunto de mensagens para a transmissão de leituras de dispositivos de POCT. Foram especificados três tipos de mensagens (HEALTH LEVEL SEVEN, 2003, seções 7.3.4 a 7.3.6).

- Mensagem não solicitada de $P O C T$ - sem ordem prévia $\left(O R U^{\wedge} R 30\right)$. A mensagem sem ordem prévia é utilizada, por exemplo, quando um médico instrui verbalmente uma enfermeira a realizar um teste. Esse pedido, entretanto, não é registrado no sistema. Espera-se que um Servidor $H L 7$, ao receber essa mensagem, registre o pedido de exame juntamente com o resultado obtido.

- Mensagem não solicitada de $P O C T$ - procurar por uma ordem $\left(O R U^{\wedge} R 31\right)$. Neste caso, o dispositivo de POCT não sabe se uma ordem foi registrada no sistema. O Servidor HL7 deve verificar se a ordem existe. Se ela existir, deve ser enviada uma mensagem de resposta com um número de identificação da ordem. Caso contrário, o servidor irá tomar uma outra ação, que depende das regras da instituição de saúde.

- Mensagem não solicitada de POCT - com ordem prévia $\left(O R U^{\wedge} R 32\right)$. Normalmente, é bastante incomum que um exame do tipo POCT tenha uma ordem previamente registrada no sistema. Entretanto, caso isso ocorra, pode-se utilizar este tipo de mensagem. 
Desse modo, o protocolo define um padrão bastante simples e eficiente para a comunicação entre um dispositivo de POCT e, por exemplo, os sistemas eletrônicos de informação de um hospital. Porém, há algumas deficiências.

$\mathrm{O}$ “7” no nome da norma (HL7) refere-se à sétima camada (camada de aplicação) do modelo OSI (Open Systems Interconnection) de comunicação em redes. Isso significa que a norma $H L 7$ não faz nenhum tipo de restrição quanto às outras camadas $O S I$. Por exemplo, não é especificado se as mensagens $H L 7$ devem ser transmitidas através de uma rede Ethernet ou através de um cabo serial. Isso porque a norma $H L 7$ foi criada para uma gama muito grande de aplicações. A norma $H L 7$ pode ser usada, por exemplo, para a transmissão de leituras de glicose entre um medidor de glicose e um monitor de beira de leito, mas também pode ser usado para transmitir o histórico clínico de um paciente entre dois hospitais diferentes. Isso significa que, mesmo que dois sistemas computacionais implementem corretamente a norma $H L 7$, eles podem não ser compatíveis, caso as camadas inferiores do modelo OSI utilizem padrões diferentes de comunicação. A indefinição das camadas inferiores do modelo OSI traz flexibilidade no uso do $H L 7$, mas também traz incompatibilidades entre diferentes implementações do protocolo.

Outro fator bastante questionável na norma $H L 7$ é que, usualmente, nem todos os campos das mensagens são normalmente utilizados. Cada implementação da norma $H L 7$ utiliza, usualmente, um subconjunto dos campos de cada tipo de mensagem. Isso pode causar problemas de incompatibilidade, mesmo que os protocolos das camadas OSI inferiores sejam idênticos. Por exemplo, podemos comparar a implementação de mensagens HL7 nos monitores de beira de leito da Philips (PHILIPS MEDICAL SYSTEMS, 2003) e da Siemens (SIEMENS MEDICAL SOLUTIONS, 2001). Para o segmento de mensagem PID (Pacient Identification), o sistema da Philips utiliza somente o campo 2 de informações (Patient ID) para identificar numericamente um paciente. Já o sistema da Siemens coloca a mesma 
informação nos campos 2 (Patient ID) e 18 (Patient Account Number). Um Servidor HL7 construído para se comunicar com o sistema da Siemens poderia ler a identificação do paciente no campo 18 do segmento $P I D$, mas esse mesmo servidor não encontraria a mesma informação se recebesse uma mensagem do sistema da Philips.

A própria $H L 7$ reconhece essas limitações (HEALTH LEVEL SEVEN, 1998b, p. 1 tradução livre):

Por causa da substancial opcionalidade da norma $H L 7$, é difícil especificar termos precisos de contrato para as interfaces $H L 7$. Isso pode conduzir a expectativas irreais que ferem vendedores e compradores igualmente. Além disso, não havia nenhuma maneira para que o comprador julgasse exatamente a competência do sistema ou da equipe de funcionários de um vendedor antes de decidir-se por um vendedor.

Dessa forma, a $H L 7$ procurará, na versão 3 da norma, sanar alguns desses problemas.

Quanto às normas de interface para dispositivos POCT, o National Committee for Clinical Laboratory Standards (NCCLS) englobou a norma HL7 e outras normas de conectividade (para as demais camadas $O S I$ ) numa norma única. Essa nova norma, conhecido como NCCLS POCT1-A, acabou tornando-se a principal norma de comunicação para dispositivos POCT. O NCCLS POCT1-A será discutido a seguir (seção 3.5).

\subsection{A norma NCCLS POCT1-A de conectividade de equipamentos médicos}

O Connectivity Industry Consortium (CIC) foi um consórcio formado em 2000 por fabricantes de equipamentos médicos e instituições de saúde. O objetivo do $C I C$ era a criação de uma norma de conectividade para dispositivos de POCT. Em apenas 18 meses, o consórcio cumpriu o seu objetivo, desfazendo-se logo em seguida. A norma resultante agora é mantida pelo National Committee for Clinical Laboratory Standards (NCCLS) e é chamado de POCT 1-A (CONNECTIVITY INDUSTRY CONSORTIUM, 2001; KNAFEL, 2001).

A norma POCT1-A considera uma rede com quatro tipos de dispositivos: os dispositivos de POCT, pontos de acesso, POC Data Manager e sistemas de LIS/HIS. Os 
dispositivos de POCT são os dispositivos que geram as informações médicas, como, por exemplo, um leitor de glicemia. Os pontos de acesso são gateways, computadores que convertem o protocolo de baixo nível dos dispositivos de POCT (IEEE 1073.3.2) para TCP/IP. O POC Data Manager recebe as informações dos dispositivos de POCT (através dos pontos de acesso), fazendo um armazenamento temporário das leituras. As informações colhidas pelo POC Data Manager são posteriormente enviadas para o LIS (Laboratory Information System) ou HIS (Hospital Information System) da instituição (Figura 3.3).

A norma NCCLS POCT1-A é amplamente adotada nos chamados gasômetros portáteis. Entretanto, nenhum dispositivo portátil de medição de glicose, contínuo ou não, utiliza a norma, apesar de, comumente, serem classificados na literatura como dispositivos de POCT.

Considerou-se inviável a adoção de tal norma para o presente projeto (por motivos a serem expostos posteriormente). De qualquer forma, a norma POCT1-A tem a sua importância. Ela é uma amostra importante da direção a ser seguida na busca por normas de interconexão de dispositivos hospitalares. A formação de normas de comunicação é fundamental para a integração dos diversos dispositivos e sistemas utilizados no hospital, possibilitando um ganho significativo na agilidade das informações e, conseqüentemente, no serviço de assistência à saúde. 


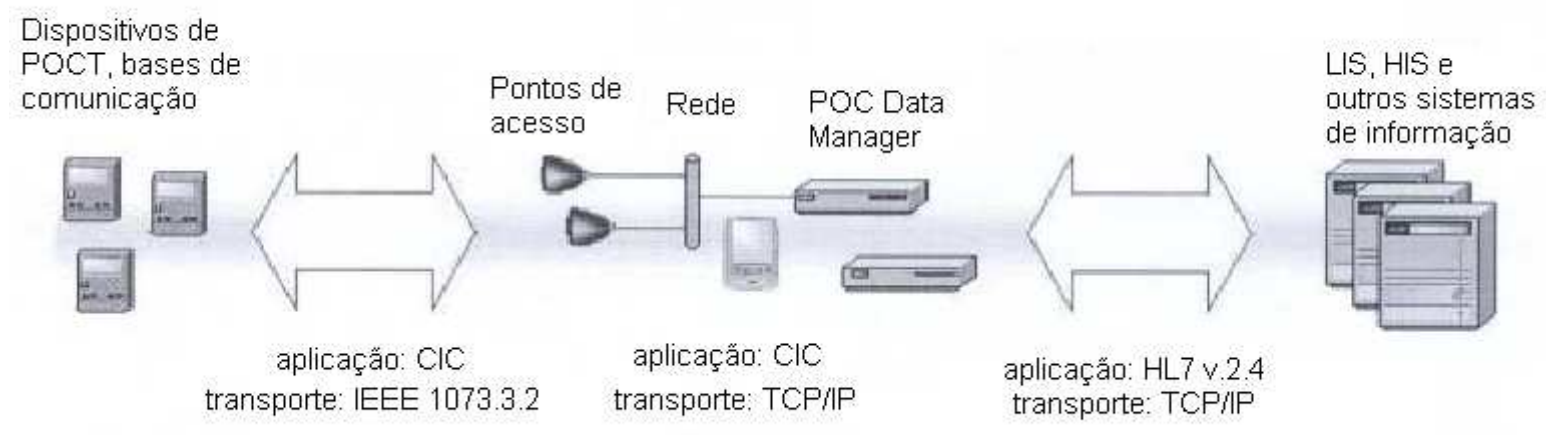

Figura 3.3 - A norma NCCLS POCT1-A. São definidos quatro tipos de dispositivos: dispositivos de POCT, pontos de acesso, POC Data Manager e sistemas de LIS/HIS. Entre os dispositivos de POCT e os pontos de acesso, é utilizado, na camada de transporte, o protocolo $I E E E$ 107.3.2. Entre os pontos de acesso e os sistemas de informação, é utilizada uma rede $T C P / I P$. Para as camadas de aplicação, entre os dispositivos POCT e os POC Data Managers, é usado um protocolo próprio (indicado na figura como CIC). Para a comunicação entre os POC Data Managers e os sistemas de informação, é utilizada a norma HL7 (adaptado de Knafel, 2001). 


\section{Capítulo 4. IMPLEMENTAÇão}

\subsection{Resumo}

Neste capítulo, é explicada a metodologia de trabalho utilizada na implementação do sistema vMonGluco, objeto de estudo deste trabalho.

\subsection{Introdução}

O controle rigoroso da glicemia, conforme discutido previamente (Capítulo 2), possibilita uma melhora significativa no prognóstico dos pacientes críticos hiperglicêmicos, além de reduzir a carga de trabalho da equipe médica. A adoção extensiva desse procedimento requer o desenvolvimento de sistemas de monitoramento contínuo de glicose. Os sistemas comerciais desenvolvidos até o momento possuem ainda diversas limitações, mas representam um passo importante no tratamento dos pacientes críticos hiperglicêmicos.

O Capítulo 3 procurou mostrar a importância da integração de sistemas de monitoramento clínico e Point-of-Care Testing (POCT) aos sistemas de informações hospitalares, além de algumas tendências na formação de normas de comunicação paras esses sistemas. A integração dos diversos sistemas utilizados por um hospital proporciona uma agilidade sem precedentes no fluxo de informações médicas, trazendo, assim, enormes benefícios ao serviço assistencial prestado pela instituição de saúde.

Dentro do contexto apresentado, propôs-se, para este trabalho, a implementação de um sistema de monitoramento contínuo de glicose, batizado de vMonGluco. A especificação do projeto foi definida previamente, no Capítulo 1. Relembrando, propõe-se, como caso de uso, um paciente crítico hiperglicêmico internado em uma UTI. A obtenção de leituras de glicemia em tempo real é feita utilizando-se um monitor contínuo de glicose, disponível 
comercialmente, aplicado ao paciente. O monitor de glicose é conectado, através de um cabo serial, a um palmtop. Um programa, chamado aqui de vMonGluco Client, comunica-se com o monitor de glicose para a obtenção das leituras (de corrente elétrica) do sensor. O programa utiliza, então, um algoritmo de calibração para converter os valores de corrente elétrica em leituras de glicemia. Estes são exibidos, de maneira gráfica, na tela do palmtop.

Em seguida, as informações geradas são transmitidas, via rede sem fio WiFi (IEEE 802.11b), para um servidor (vMonGluco Server). Para isso, utiliza-se o protocolo $H L 7$, norma de comunicação de informações médicas. O vMonGluco Server possui duas funções. Ele pode armazenar as informações em um banco de dados, que podem ser visualizadas através de uma interface web (vMonGluco Web). Além disso, o servidor pode retransmitir as informações a um monitor de beira de leito próximo ao paciente. A Figura 4.1 mostra um diagrama esquemático do funcionamento do vMonGluco.

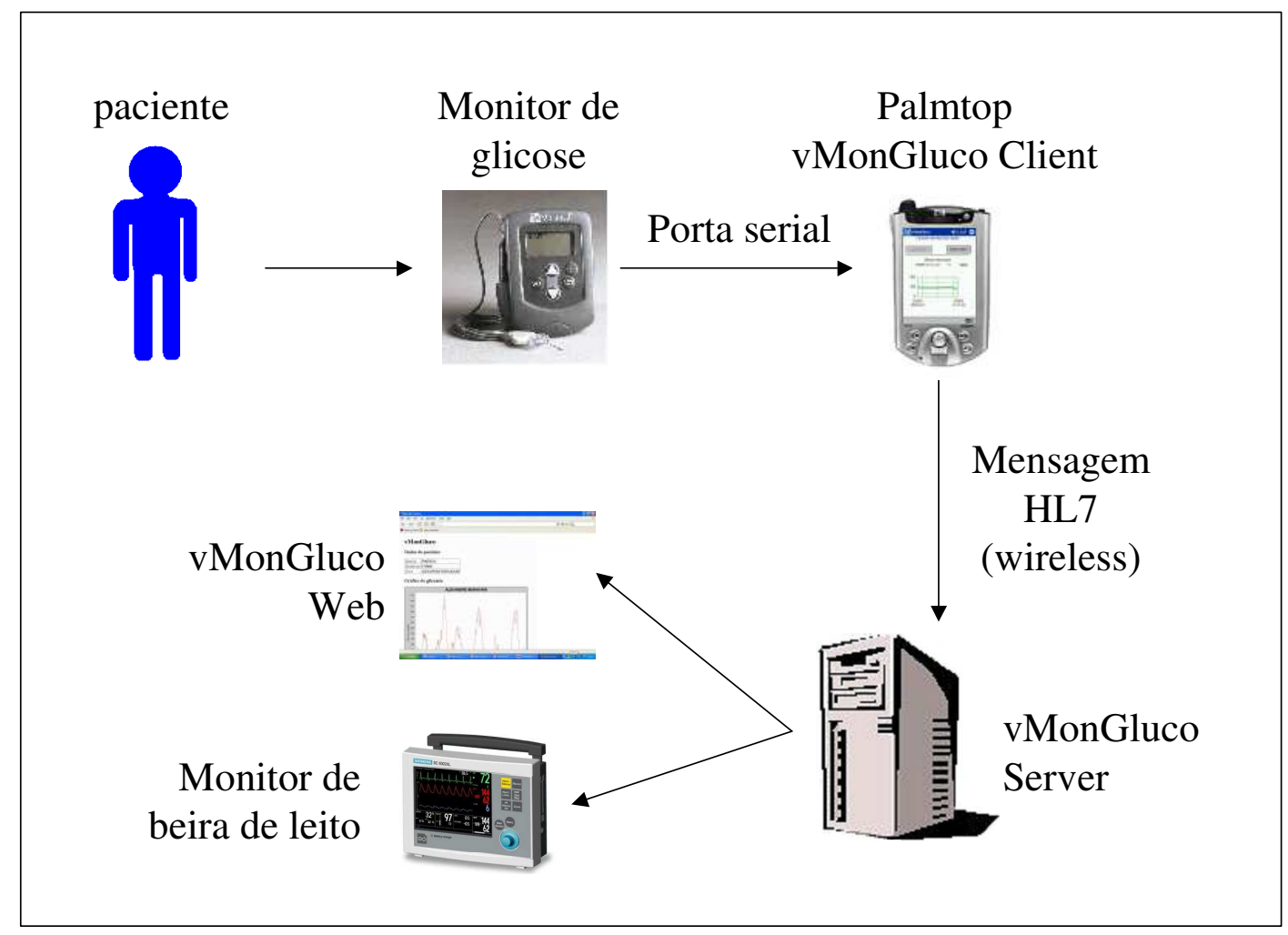

Figura 4.1 - Diagrama esquemático do vMonGluco - Sistema de Monitoramento Contínuo de Glicose. 
Nas seções a seguir, será descrito o processo de desenvolvimento do sistema vMonGluco, bem como os critérios adotados nas diversas decisões tomadas durante o processo.

\subsection{Critérios para o desenvolvimento}

O MiniMed CGMS foi comercialmente lançado no Brasil no início de 2004. Nesse momento, a equipe do Instituto do Coração vislumbrou a possibilidade de se implementar um sistema de monitoramento contínuo de glicose em tempo real. Lembrando, o MiniMed CGMS é um monitor contínuo de glicose semelhante a um "holter". Nele, as leituras de glicemia podem ser visualizadas retrospectivamente, ao final do uso do aparelho. Portanto, o MiniMed CGMS não apresenta leituras em tempo real. Atualmente, existem outros sistemas de monitoramento contínuo de glicose que fornecem leituras em tempo real, como o GlucoWatch. Entretanto, tais sistemas ainda não estão comercialmente disponíveis no País; por isso, o MiniMed CGMS foi escolhido para a implementação do sistema. De qualquer forma, os conceitos utilizados no desenvolvimento do vMonGluco poderiam ser aplicados a outros dispositivos de monitoramento contínuo de glicose.

Para que fosse possível a obtenção das leituras em tempo real, os dados obtidos pelo MiniMed CGMS deveriam ser descarregados, de tempos em tempos, para um computador. O MiniMed CGMS disponibiliza, através da sua base de comunicação, uma interface serial para comunicação com um computador pessoal. Imaginou-se, entretanto, o uso do novo sistema em um ambiente de UTI. O espaço físico em um quarto de UTI é, de certa forma, limitado, o que tornaria o uso de um computador pessoal bastante inconveniente. Além disso, freqüentemente, os pacientes são transferidos de quarto por questões operacionais ou transportados para outras áreas do hospital para a realização de exames. Assim, uma infraestrutura que permita a mobilidade do paciente, sem prejuízo dos registros, é altamente 
recomendável. Por esses motivos, foi escolhido o uso de um computador portátil, do tipo palmtop, conectado a uma rede sem fio WiFi, como principal recurso computacional.

Os objetivos da criação do vMonGluco Client (software que roda no palmtop) foram a obtenção de leituras de glicemia em tempo real (a partir do MiniMed CGMS) e a disponibilização dessas leituras para a equipe médica. Além disso, o vMonGluco Client deveria possibilitar a integração do sistema vMonGluco a sistemas de informações médicas. Como foi citado anteriormente, o vMonGluco foi concebido para uso em ambiente hospitalar; assim, espaço físico reduzido e praticidade são requisitos do projeto. Além disso, os usuários do sistema, usualmente, são profissionais de saúde (médicos e enfermeiros). Assim, a facilidade de uso também deve ser um requisito importante. Eventualmente, o sistema poderia ser configurado por um técnico especializado. Assim, para algumas tarefas específicas de manutenção, o sistema poderia ter a facilidade de uso reduzida em detrimento da funcionalidade.

No caso do vMonGluco Server, o software que faz a integração entre o sistema vMonGluco e o sistema de informações hospitalares, um requisito muito importante é a aderência a padrões e protocolos abertos de comunicação. Dessa forma, garante-se que o vMonGluco Server seja compatível não só com o ambiente computacional instalado no Instituto do Coração, mas também com uma grande variedade de sistemas hospitalares.

Para a comunicação entre o vMonGluco Client e o vMonGluco Server, foi utilizada uma rede sem fio WiFi (IEEE 802.11b) instalada no Instituto do Coração. O uso da rede sem fio teve como objetivo aumentar a mobilidade e a praticidade do sistema. Esse objetivo foi apenas parcialmente alcançado devido a limitações técnicas (ver seção 6.2.1). De qualquer forma, o uso da rede sem fio permite uma instalação mais rápida do sistema em um quarto de UTI, pois não depende da existência de uma rede cabeada de comunicação. Além disso, como 
foi citado anteriormente, o transporte do paciente entre quartos ou para outras áreas do hospital pode ser realizado com relativa facilidade, sem interrupções na coleta de dados.

As leituras armazenadas deveriam ser disponibilizadas para a equipe médica de maneira rápida e prática. Assim, optou-se pela utilização de uma interface web (vMonGluco Web), que é de fácil utilização. Além disso, através da interface web, as informações poderiam ser consultadas de maneira remota, de qualquer ponto do hospital ou, eventualmente, fora dele. Também foi escolhida a exibição das leituras através de um monitor de beira de leito, para facilitar o acesso às informações pela equipe médica local.

Um fator importante a ser considerado em sistemas hospitalares é a segurança das informações. Os dados sobre o paciente são pessoais e sigilosos e, por isso, deve haver mecanismos que garantam a privacidade das informações. Além disso, devem existir mecanismos que garantam a autenticidade das informações, evitando, por exemplo, que falsas leituras de glicemia possam ser armazenadas no Prontuário Eletrônico do Paciente. Nesse sentido, alguns cuidados básicos foram tomados. A transmissão das informações na rede sem fio é cifrada, com chave de 128 bits. Além disso, os palmtops são cadastrados junto aos pontos de acesso, evitando, assim, o acesso indevido à rede. Entretanto, para um controle de segurança mais efetivo, outras medidas deveriam ser tomadas, como a cifragem das informações não só na rede sem fio, mas ao longo de todo o seu trajeto. Tais questões não foram plenamente abordadas neste projeto para simplificação do escopo.

\subsection{Montagem física do sistema}

O MiniMed CGMS é formado por um monitor (semelhante a um "pager"), que fica conectado ao sensor (na forma de uma agulha flexível) através de um cabo. Para que o MiniMed CGMS possa descarregar os dados para um computador, ele deve ser acoplado (através de encaixe) a uma base de comunicação. 
O MiniMed CGMS é alimentado por baterias. A base de comunicação, entretanto, deve ser conectada, através de uma fonte de alimentação própria, à rede elétrica. Além disso, a base de comunicação deve ser conectada, através de um cabo serial, ao palmtop.

O cabo do MiniMed CGMS (entre o sensor e o monitor) possui uma extensão curta (da ordem de um metro); por isso, todo o conjunto (monitor mais base de comunicação) deve estar fisicamente próximo ao paciente. Isso fere, de certa forma, os critérios de praticidade especificados previamente (seção 4.3); entretanto, essa foi a única formação física possível.

O MiniMed CGMS e o palmtop são conectados através de um cabo serial. O cabo serial pode ter o comprimento de alguns metros; assim, o palmtop pode estar a uma distância razoável do paciente. Para que a conexão com o palmtop seja possível, este também deve estar conectado a uma base de comunicação. Além disso, a base também é necessária para o fornecimento de energia para o palmtop. Embora o palmtop possa ser alimentado por uma bateria interna, esta possui duração limitada (cerca de seis horas, ou menos de duas horas quando conectado à rede sem fio). Assim, quando o aparelho é utilizado por várias horas seguidas, a base do palmtop deve estar conectada, através de uma fonte de alimentação, à rede elétrica.

O vMonGluco transmite, ainda, as leituras de glicemia ao servidor HL7. Essa transmissão é feita através de uma rede sem fio. O palmtop é dotado de uma antena de rede sem fio do tipo WiFi. A rede sem fio é equivalente a uma rede tradicional de computadores (Ethernet), diferindo-se no uso de ondas de rádio para a transmissão de dados, ao invés do uso tradicional de cabos elétricos. Conseqüentemente, deve existir, no local de uso do sistema, um ponto de acesso à rede sem fio. Esse ponto de acesso é composto por uma antena receptora conectada à rede cabeada do hospital. 


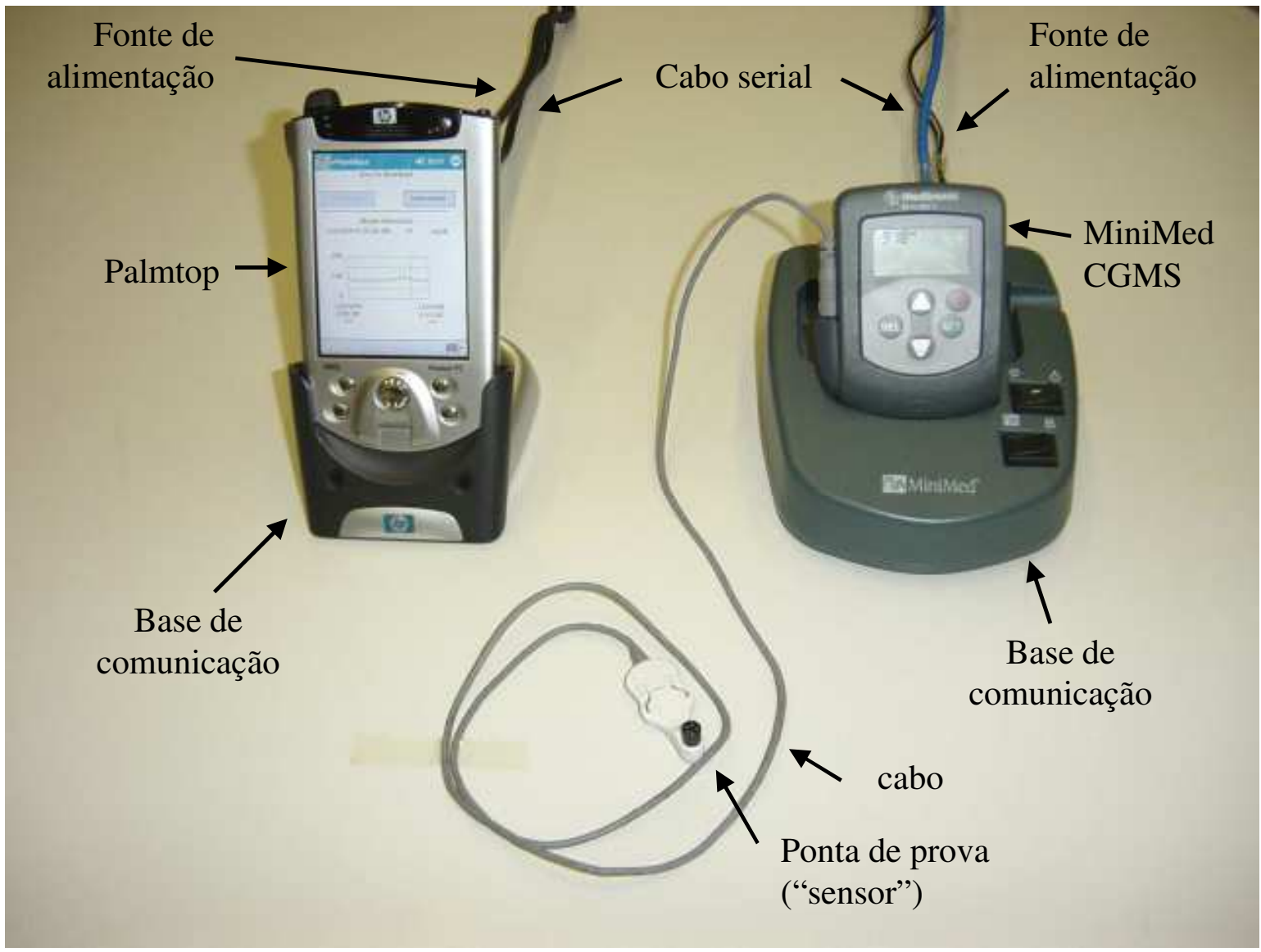

Figura 4.2 - Montagem física do sistema.

Opcionalmente, a transmissão das leituras poderia ser feita através de um cabo USB conectado diretamente a um computador pessoal. Essa opção, entretanto, é inviável, pela necessidade de existência de um computador pessoal no local de uso do vMonGluco.

A Figura 4.2 ilustra a montagem física descrita nesta seção.

O cabo serial, que faz a interligação entre o MiniMed CGMS e o palmtop, mereceu atenção especial durante o desenvolvimento. Devido à configuração elétrica das portas seriais, foi necessário o uso de um cabo serial do tipo null-modem. Devido à dificuldade de se encontrar um cabo null-modem comercial, o cabo foi especialmente confeccionado para este projeto. Detalhes sobre o cabo null-modem são mostrados no Apêndice A. 


\section{5 vMonGluco Client}

O vMonGluco Client é o software que roda no palmtop (Capítulo 1 e seção 4.2). Ele possui as seguintes funções:

- Comunicação com o MiniMed CGMS para a obtenção das leituras (de corrente elétrica) e dos dados de calibração do sensor.

- Conversão das leituras (de corrente elétrica) do sensor em valores de glicemia.

- Exibição dos valores de glicemia na tela do Pocket $P C$ na forma de gráfico e de valores numéricos.

- Transmissão dos valores de glicemia para o vMonGluco Server.

Além disso, o vMonGluco Client deve ser prático e fácil de usar, pois os usuários do software são profissionais de saúde (médicos e enfermeiros). Excepcionalmente, para algumas tarefas específicas de manutenção, a facilidade de uso pode ser reduzida em detrimento da funcionalidade. Segurança (sigilo e autenticidade das informações) também é um requisito importante, embora, nesta primeira versão do software, isso não tenha sido considerado por questões de simplificação (seção 4.3).

O palmtop utilizado baseia-se no sistema operacional Pocket PC 2002. O vMonGluco Client foi implementado em Visual Basic utilizando-se a ferramenta Microsoft eMbedded Visual Basic 3.0 (MICROSOFT CORPORATION, 2005). A ferramenta foi escolhida por ser gratuita, de fácil utilização e adequada às necessidades do processo de desenvolvimento.

Pode-se dividir o vMonGluco Client em quatro partes, de acordo com as funções desempenhadas por cada parte: comunicação com o MiniMed CGMS, calibração de leituras em tempo real, interface com usuário e comunicação com o vMonGluco Server.

A transmissão das leituras de glicemia ao servidor vMonGluco Server é feita através de mensagens HL7. A transmissão das leituras será descrita posteriormente, juntamente com a descrição do vMonGluco Server, na seção 4.6.1. As demais etapas do desenvolvimento do 
vMonGluco Client (comunicação com o MiniMed CGMS, calibração de leituras em tempo real e interface com o usuário) serão descritas em detalhes nas seções a seguir.

\subsubsection{O protocolo de comunicação do MiniMed CGMS}

O software vMonGluco Client gerencia a comunicação com o MiniMed CGMS para o download dos dados. A comunicação entre o vMonGluco Client e o MiniMed CGMS, via cabo serial, deve ser feita utilizando-se um protocolo de comunicação proprietário. Embora o projeto vMonGluco tivesse o apoio da Medtronic do Brasil, a especificação do protocolo de comunicação não foi fornecida. Dessa forma, uma das primeiras etapas da implementação do vMonGluco Client foi a análise do protocolo de comunicação utilizado pelo MiniMed CGMS.

Manteve-se o MiniMed CGMS ligado por algumas horas. No lugar do sensor, foi utilizada uma ponta de teste que gerava um sinal aproximadamente constante. Utilizado dessa maneira, o aparelho acumulou, em memória, uma série de leituras simuladas de corrente elétrica. O MiniMed CGMS foi conectado à base de comunicação, que, por sua vez, foi conectada a um computador pessoal comum. O software que acompanha o MiniMed CGMS (MiniMed CGMS System Solutions Software) foi utilizado para o download dos dados para o computador. Simultaneamente, foi utilizado o programa HDD Free Serial Port Monitor (HDD SOFTWARE, 2004), que registra os dados trafegados pela porta serial. Comparando-se os dados trafegados através da porta serial com as leituras de corrente elétrica produzida, o protocolo de comunicação do MiniMed CGMS foi mapeado. Como o protocolo é de propriedade da Medtronic Diabetes, não serão divulgadas, neste trabalho, maiores informações sobre o mesmo.

Após o trabalho de mapeamento do protocolo, o mecanismo de comunicação com MiniMed CGMS foi incorporado ao vMonGluco Client. O processo de comunicação é disparado a cada cinco minutos. Dessa forma, o vMonGluco Client pode obter, a cada cinco minutos, uma nova leitura da corrente elétrica gerada pelo sensor. 


\subsubsection{O algoritmo de calibração em tempo real}

As leituras de corrente elétrica do sensor, coletadas pelo MiniMed CGMS, devem ser convertidas em valores de glicemia. Usualmente, a conversão de leituras de corrente elétrica em glicemia é feita pelo software do MiniMed CGMS através de um algoritmo de calibração (seção 2.6.2). Entretanto, esse algoritmo de calibração não pode ser utilizado para a geração de leituras em tempo real. Por isso, o algoritmo original sofreu algumas alterações para uso no sistema vMonGluco.

A primeira modificação foi quanto à aplicação do atraso nas leituras. No método original, para o cálculo de uma determinada leitura de glicemia, é utilizado o valor de corrente coletado após dez minutos. Essa diferença de tempo serve para compensar a diferença entre as concentrações de glicose sangüínea e intersticial, além de compensar o tempo de resposta do aparelho.

No método em tempo real, entretanto, se fosse aplicado um atraso nos valores de corrente, o aparelho indicaria sempre o valor de glicemia com um atraso de dez minutos. Por isso, optou-se por aplicar o atraso às leituras de calibração ("glicemias de ponta de dedo"), e não às leituras de corrente elétrica. Assim, uma leitura de calibração é utilizada pelo algoritmo somente dez minutos após a sua coleta (Figura 4.3).

Devemos lembrar que o valor do atraso (dez minutos) foi baseado no valor adotado pelo software do MiniMed CGMS. Outros valores podem ser utilizados, conforme será avaliado posteriormente. 


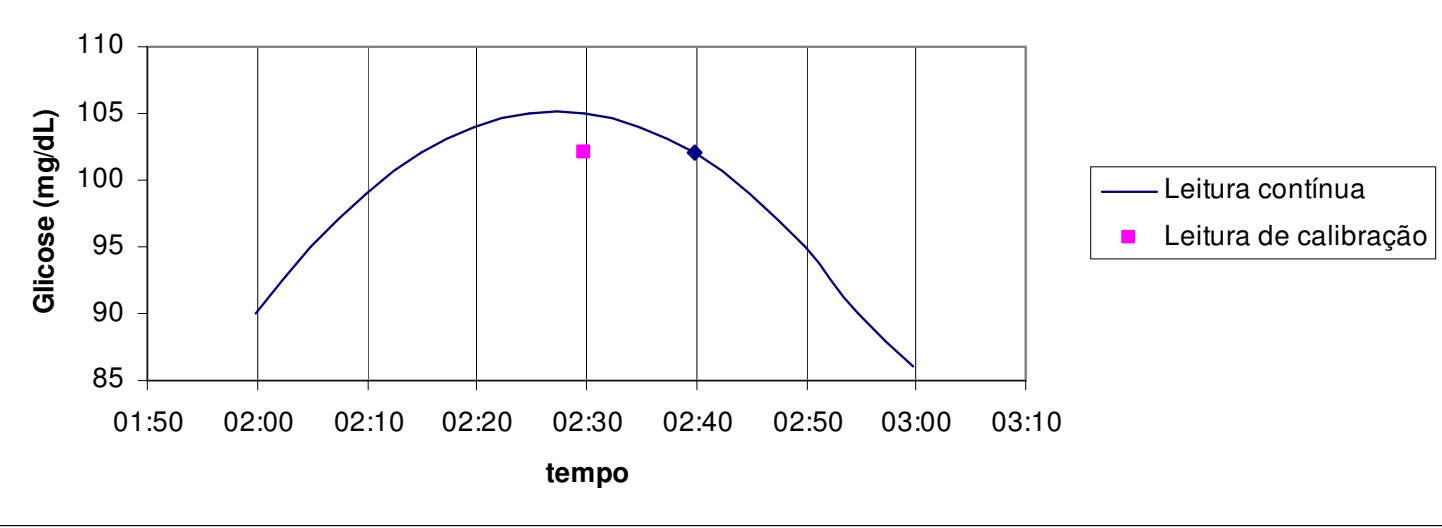

A
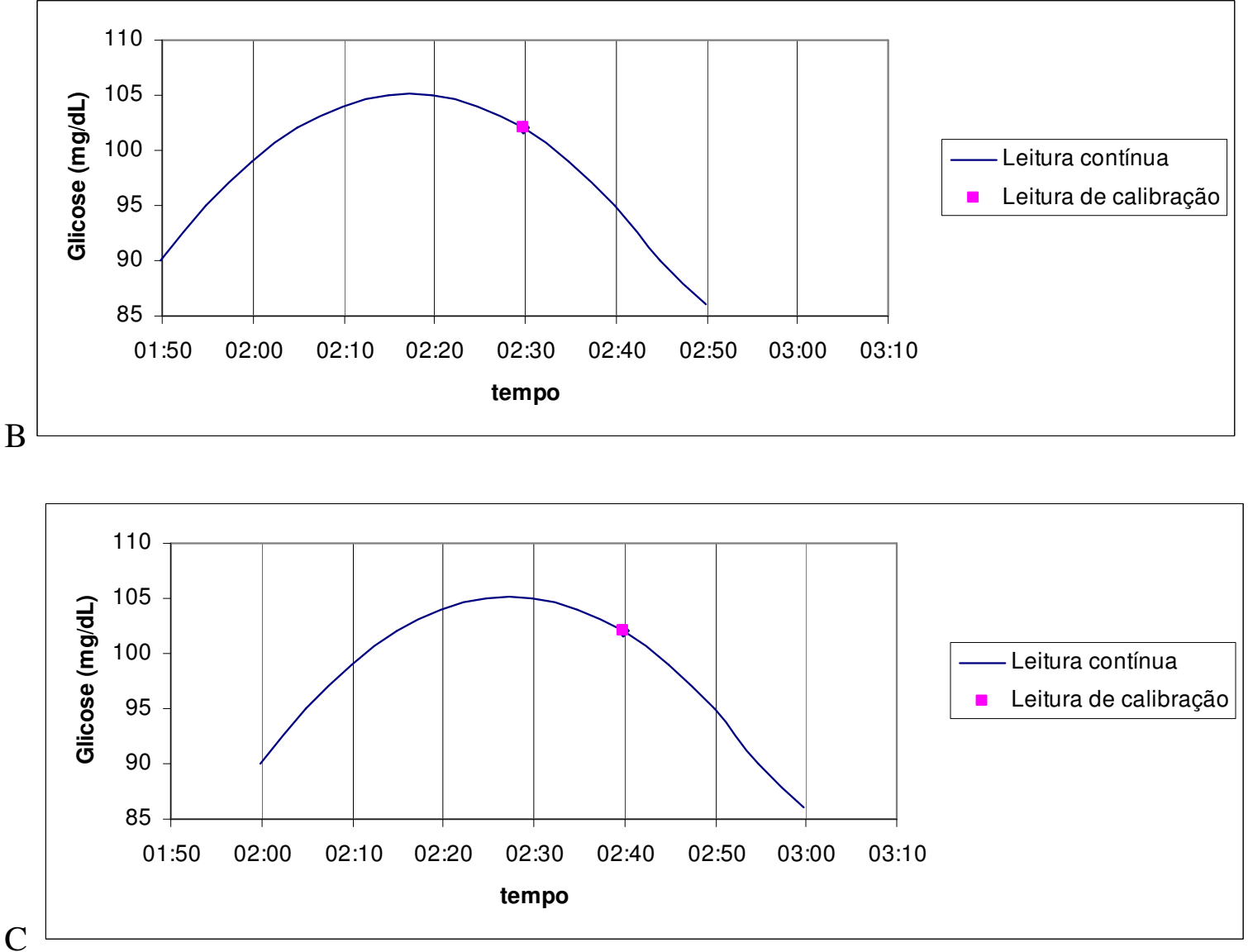

Figura 4.3 - A curva contínua em $A$ indica a leitura contínua obtida a partir de um sensor intersticial de glicose. A leitura de calibração corresponde ao ponto indicado na curva. Nota-se que, entre a leitura de calibração e a leitura contínua, há uma diferença de tempo de dez minutos, pois a leitura de calibração é coletada a partir do sangue e o sinal do sensor, a partir do líquido intersticial. Para corrigir essa diferença, o algoritmo do MiniMed CGMS adota a abordagem mostrada em $B$, onde a leitura contínua é adiantada em dez minutos. Já o gráfico $C$ mostra a abordagem do algoritmo em tempo real, onde a leitura de calibração é atrasada em dez minutos. 
Uma segunda modificação foi quanto à seleção dos pontos de calibração. Para o cálculo de uma leitura de glicemia, o software do MiniMed CGMS seleciona os pontos de calibração presentes em uma janela móvel de 24 horas (de -12 horas até +12 horas). Para uma leitura em tempo real, entretanto, não existem pontos de calibração futuros; o algoritmo só pode utilizar os pontos de calibração coletados até o momento da leitura. Assim, a janela móvel deve ser modificada para, por exemplo, de -12 horas até o presente momento.

O tamanho da janela (número de horas) pode ser reconsiderado. A adoção de uma janela de 12 horas resulta, em média, no uso de apenas dois pontos de calibração (considerando que o procedimento de calibração é feito a cada 6 horas). Um número maior de horas, entretanto, pode levar ao uso de pontos de calibração muito antigos, causando inexatidão dos cálculos.

Outra mudança no algoritmo foi a escolha do OFFSET. No método original, são testados cinco valores pré-definidos de OFFSET, com a obtenção das respectivas leituras de glicemia. Essas leituras são comparadas às glicemias obtidas pelo procedimento de calibração. O valor de OFFSET que minimiza a diferença entre as glicemias é escolhido. Esse valor é único para cada sensor; isto é, o cálculo de todas as leituras para um dado sensor utiliza o mesmo valor de OFFSET. Isso só é possível porque o algoritmo só é executado ao final do uso do sensor. Assim, ele possui, à sua disposição, no momento do cálculo, todos os dados coletados durante o tempo de uso do aparelho.

No cálculo em tempo real, o algoritmo dispõe somente dos dados coletados até o momento. Por isso, o valor ótimo do OFFSET é escolhido, dentre os valores prédeterminados, a cada nova leitura. Isso significa que o valor do OFFSET pode alterar-se à medida que novos dados são coletados pelo MiniMed CGMS. Durante a escolha de OFFSET, são considerados todos os dados coletados desde o início do uso do sensor até o momento da leitura. 
Além disso, no algoritmo em tempo real, há uma pequena mudança na suavização do SLOPE. No algoritmo original, após o cálculo do SLOPE, é aplicada uma suavização nos valores obtidos. A suavização utiliza uma janela móvel de 2 horas (de -1 hora até +1 hora). Isso significa que cada valor do $S L O P E$ é substituído pela média dos valores de SLOPE existentes na janela. Dessa forma, são evitadas mudanças bruscas de $S L O P E$ entre dois pontos adjacentes.

No caso do algoritmo em tempo real, não é possível utilizar a mesma janela móvel de 2 horas. Por isso, foi considerada uma janela móvel de 1 hora (de -1 hora até o momento da leitura). Novamente, o tamanho da janela de suavização pode ser reconsiderado.

Nota-se que o algoritmo em tempo real aqui descrito possui vários parâmetros numéricos que podem ser variados. Tais parâmetros, conforme discutido até o momento, são:

- atraso das leituras de calibração;

- tamanho da janela de calibração;

- tamanho da janela de suavização;

- valores pré-determinados de offset.

Durante os testes com pacientes (Capítulo 5), foi feita a validação do algoritmo apresentado. Foram testados diversos valores para os parâmetros numéricos, de forma a se obter uma configuração ótima para o algoritmo. Além disso, outras variações foram testadas (seção 5.2.1). Os resultados obtidos serão apresentados e analisados posteriormente.

O Algoritmo 4.1 a seguir mostra o algoritmo implementado, incorporando as modificações discutidas ao longo desta seção. Vale notar que o algoritmo foi simplificado para facilitar a compreensão. Em uma real implementação, algumas tarefas, como a seleção das janelas e a regressão linear, tornam o algoritmo mais complexo. 
Algoritmo 4.1 - Algoritmo de calibração em tempo real

Entradas:

- $\quad \operatorname{ISIG}(t)=$ valor de corrente para $o$ instante $t$

- $\operatorname{MeterBG}(t)=$ valor de glicose (obtido no procedimento de calibração) para o instante $t$

Saída:

- SensorBG $(t)=$ valor de glicose estimado (a partir das leituras do sensor) para o instante $t$

\section{Algoritmo:}

//varre as leituras

para cada $t$

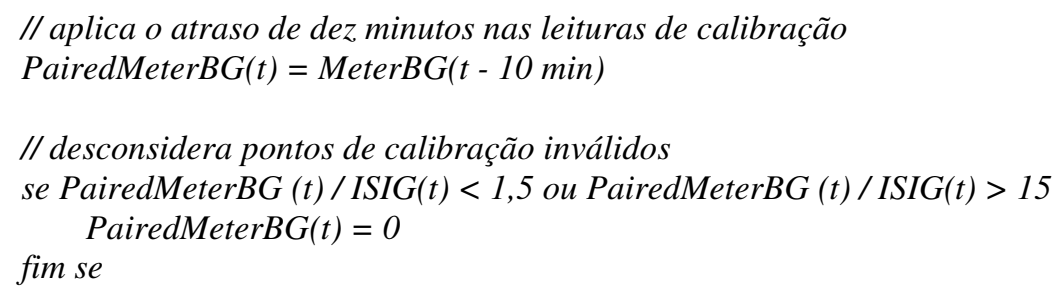




\subsubsection{Interface gráfica do vMonGluco Client}

Através da interface gráfica do vMonGluco Client, o usuário pode controlar o funcionamento básico do programa. Um requisito importante no desenvolvimento da interface é a facilidade de uso para as atividades de rotina, já que o principal usuário do vMonGluco Client é o profissional de saúde. Além de permitir o controle do programa, o vMonGluco Client exibe na tela os valores de glicemia obtidos. Essa exibição deve ser feita de maneira numérica e gráfica.

A Figura 4.4 mostra a interface gráfica do vMonGluco Client. A primeira tela (à esquerda) permite a realização das funções básicas do vMonGluco Client. A tela possui dois botões principais. O botão à direita permite que o usuário inicie ou interrompa o processo. Quando selecionado pela primeira vez, o botão inicia um processo automático de download, cálculo de calibração e exibição das leituras. O processo é repetido de maneira contínua, a intervalos de tempo regulares. Apertando-se o mesmo botão novamente, o processo é interrompido.

A parte inferior da tela mostra as leituras obtidas. A última leitura é exibida de maneira numérica (no centro da tela), enquanto que as leituras obtidas nas últimas horas são exibidas através de um gráfico (na parte inferior da tela).

A tela de configuração, chamada quando o usuário pressiona o botão "Configurar", é mostrada à direita da Figura 4.4. Essa tela permite que o usuário digite uma série de parâmetros para o funcionamento do programa. Esses parâmetros são:

- intervalo de tempo entre dois downloads de dados;

- escala do gráfico de glicemia;

- parâmetros para envio de mensagens HL7 (mensagens para o vMonGluco Server)

- diretório para arquivo de dados $(\log )$. 

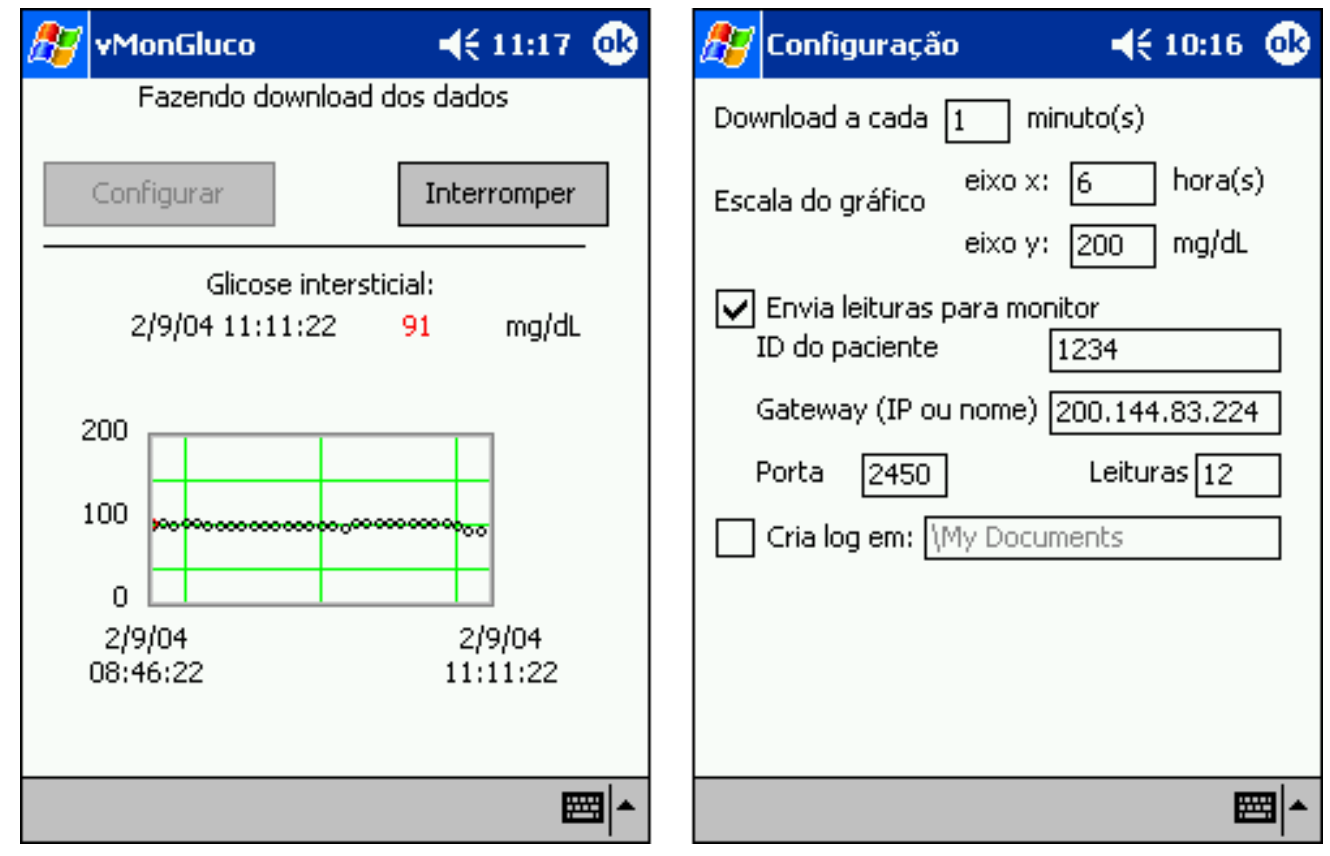

Figura 4.4 - A interface gráfica do vMonGluco Client. A tela à esquerda mostra a última leitura de glicemia obtida, bem como o gráfico com as leituras obtidas nas últimas horas. Na mesma tela, acima e à direita, o botão "Iniciar / Interromper" inicia ou interrompe o processo de leituras. $O$ botão "Configurar", acima e à esquerda, leva à segunda tela do vMonGluco Client, mostrada à direita. Nela, podem se ser configurados diversos parâmetros do programa.

Clicando-se no botão "Ok" (canto superior direito), a tela de configuração é fechada. Clicando-se no mesmo botão na primeira tela, o programa é encerrado.

Pode-se observar que a tela de configuração é substancialmente mais complexa do que a tela inicial. Entretanto, deve-se lembrar que a tela de configuração não será usada, ao menos em toda a sua extensão, pela equipe médica, mas, sim, por um técnico especializado. Assim, a complexidade da tela de configuração não fere os princípios de desenvolvimento discutidos anteriormente (seção 4.3).

\section{6 vMonGluco Server}

O vMonGluco Server é o sistema que faz a integração dos dados de glicemia, gerados pelo vMonGluco Client, ao sistema de prontuário eletrônico. Ele possui as seguintes funções (conforme apresentado no Capítulo 1): 
- O vMonGluco Server recebe as leituras de glicemia geradas pelo vMonGluco Client. A transmissão das leituras é feita através do protocolo HL7.

- O vMonGluco Server armazena as informações coletadas no banco de dados do Instituto do Coração. Com base nas informações disponibilizadas através do vMonGluco Server, foi desenvolvido um aplicativo para a visualização desses dados (vMonGluco Web).

- O vMonGluco Server retransmite as leituras de glicemia, através de um gateway, para um monitor de beira de leito. Dessa forma, as leituras de glicemia podem ser facilmente visualizadas pelo profissional de saúde através de um monitor de beira de leito.

O vMonGluco Server foi implementado em Java, o que permite a sua instalação em qualquer plataforma computacional.

A Figura 4.5 mostra a estrutura básica do vMonGluco Server. Essa figura é um detalhamento da Figura 4.1 apresentada anteriormente. Conforme o diagrama, pode-se dividir o sistema em três partes, conforme a sua função: recepção das mensagens $H L 7$ de glicemia, armazenamento das leituras em banco de dados e envio das leituras ao monitor de beira de leito. Cada uma dessas partes será descrita em maiores detalhes nas seções a seguir.

Nota-se, no diagrama apresentado, uma estrutura semelhante à norma NCCLS POCT1$A$ de integração de sistemas de point-of-care testing (seção 3.5). Comparando-se com a Figura 3.3, vê-se que o MiniMed CGMS é o dispositivo de POCT do sistema, enquanto que o vMonGluco Client equivale ao POC Data Manager. Entre esses dois componentes, é utilizado um protocolo de comunicação proprietário. Como não é possível alterar o protocolo utilizado, o sistema vMonGluco não pode ser compatível como a norma POCT1-A. O vMonGluco Server adiciona uma camada de software extra à estrutura da norma POCT1-A, situando-se entre o sistema de informações hospitalares e o POC Data Manager. 


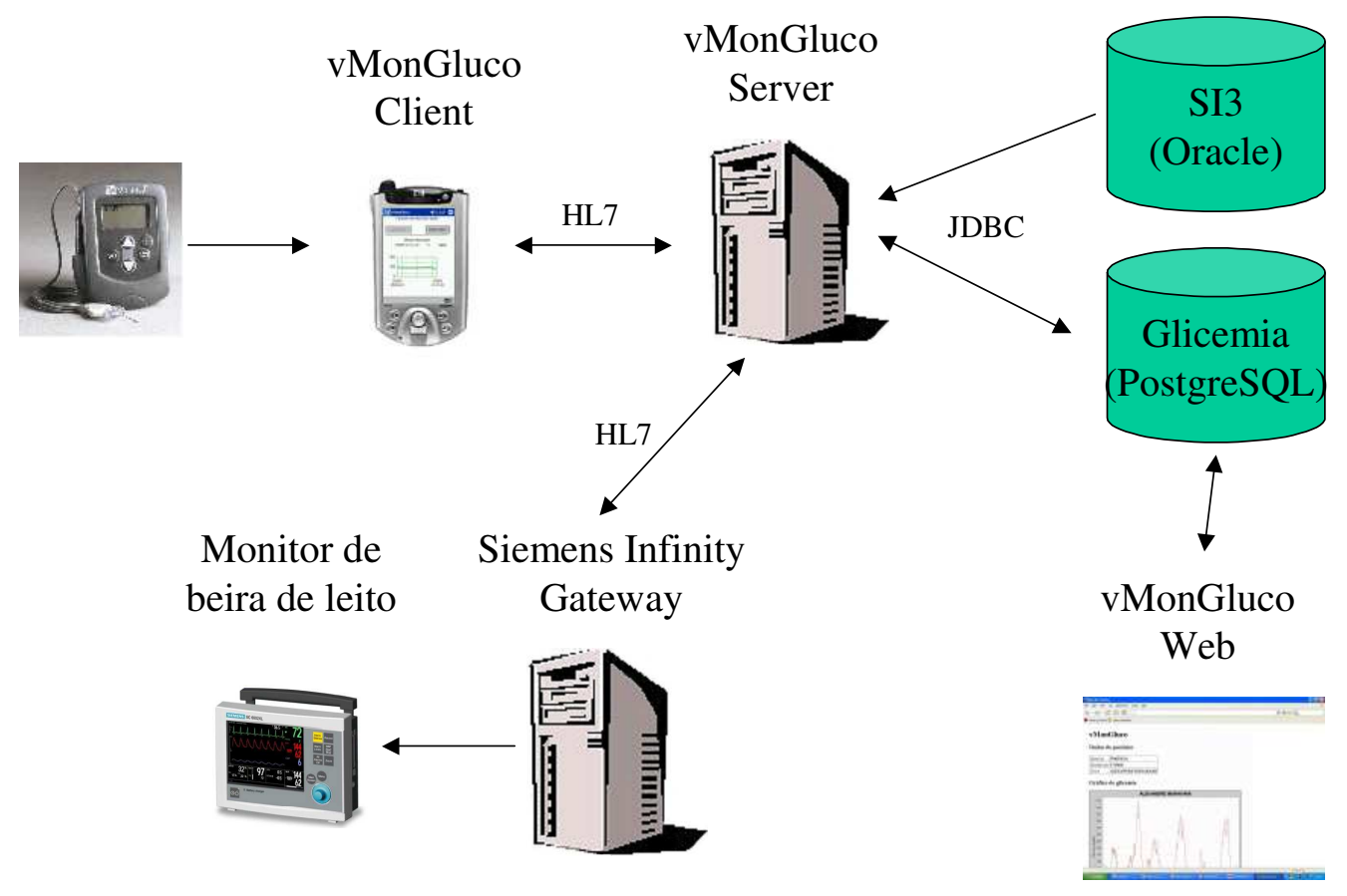

Figura 4.5 - Estrutura básica do vMonGluco Server

\subsubsection{Recepção das mensagens $H L 7$}

Para a recepção de mensagens $H L 7$, foi utilizado um sistema de portas (sockets). $\mathrm{O}$ vMonGluco Server abre uma porta e fica esperando a conexão do vMonGluco Client. Quando essa conexão ocorre, o vMonGluco Client envia uma mensagem HL7 do tipo $O R U^{\wedge} R 01$ contendo as últimas leituras de glicemia, juntamente com o horário de geração de cada uma delas. A mensagem também possui um código de identificação do paciente. A seguir, é apresentada uma mensagem $O R U^{\wedge} R 01$ de exemplo. Em destaque, vê-se o número de identificação do paciente e as leituras de glicemia:

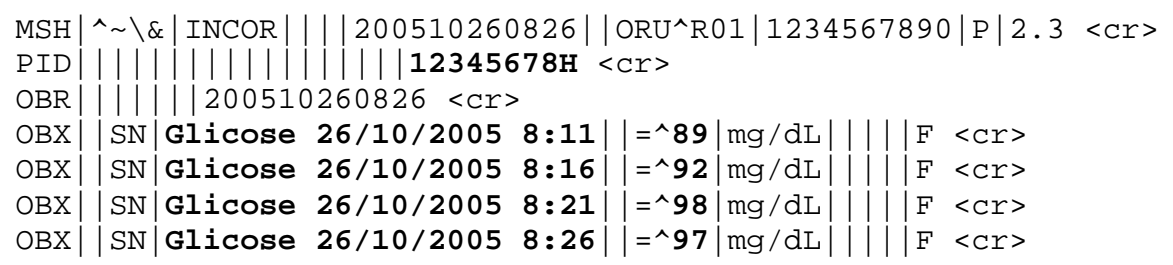


Após o recebimento, é feito o parsing da mensagem, isto é, a mensagem é decomposta em seus elementos básicos. Para essa tarefa, foi utilizada a biblioteca Symphonia 3.0 (ORCHESTRAL DEVELOPMENT, 2004).

Após o processamento da mensagem, que inclui o armazenamento dos dados e a transmissão ao monitor de beira de leito, o servidor envia ao vMonGluco Client uma mensagem de confirmação de recebimento do tipo $A C K^{\wedge} R 01$ como a mostrada a seguir (em destaque, é mostrado o texto com a confirmação do recebimento):

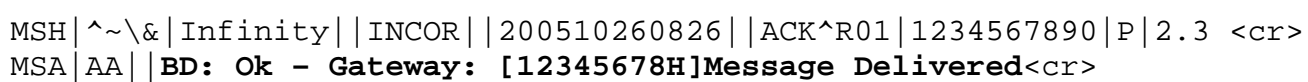

\subsubsection{Armazenamento das informações}

A segunda tarefa de destaque realizada pelo vMonGluco Server é o armazenamento das informações. Na presente versão do software, foram utilizadas duas bases de dados. A primeira é a base do SI3, o sistema de informações hospitalares utilizado no Instituto do Coração. Nela, são consultadas informações sobre o paciente. A segunda base de dados armazena as leituras de glicemia. Essas informações não são armazenadas no $S I 3$ para não interferir no funcionamento de outros sistemas em produção (já que a versão desenvolvida do vMonGluco ainda é um protótipo). Entretanto, todas as informações poderiam ser armazenadas em uma única base de dados sem nenhuma alteração do código do software. Dessa forma, as informações de glicemia ficariam totalmente integradas ao SI3. O acesso às bases de dados é feito através do padrão $J D B C$ (JAVA SE..., 2006). Isso permite o uso de diferentes tipos de bases de dados relacionais, bastando, para tanto, uma reconfiguração do servidor.

\subsubsection{Envio das leituras ao monitor de beira de leito}

A terceira tarefa realizada pelo vMonGluco Server é o envio das leituras ao monitor de beira de leito. Para tanto, foi utilizada a rede de monitores de beira de leito instalada no 
Instituto do Coração, local onde o projeto foi desenvolvido. A rede é composta por monitores Siemens Infinity SC7000 (Siemens Medical Solutions, Massachusetts) separada da rede de computadores do hospital. A única ligação entre a rede dos monitores e a rede do hospital é um computador (chamado aqui de gateway) rodando o programa Siemens Infinity Gateway (SIEMENS MEDICAL SOLUTIONS, 2001).

Através do gateway, os computadores do Instituto do Coração podem comunicar-se com os monitores de beira de leito, obtendo as leituras geradas pelos monitores ou enviando dados para os mesmos (Figura 4.6). A comunicação entre um computador da rede e o gateway pode ser feita através de mensagens HL7. Através do servidor HL7 do gateway, é possível ter acesso às leituras (numéricas) geradas pelos monitores de beira de leito. Por sua vez, os monitores podem obter informações sobre os pacientes a partir do HIS do hospital, além de realizar operações de alocação e desalocação de leito. Além disso, um computador da rede pode enviar dados de laboratório para serem exibidos em um monitor de beira de leito. Esse último recurso foi utilizado para a exibição das leituras de glicemia.

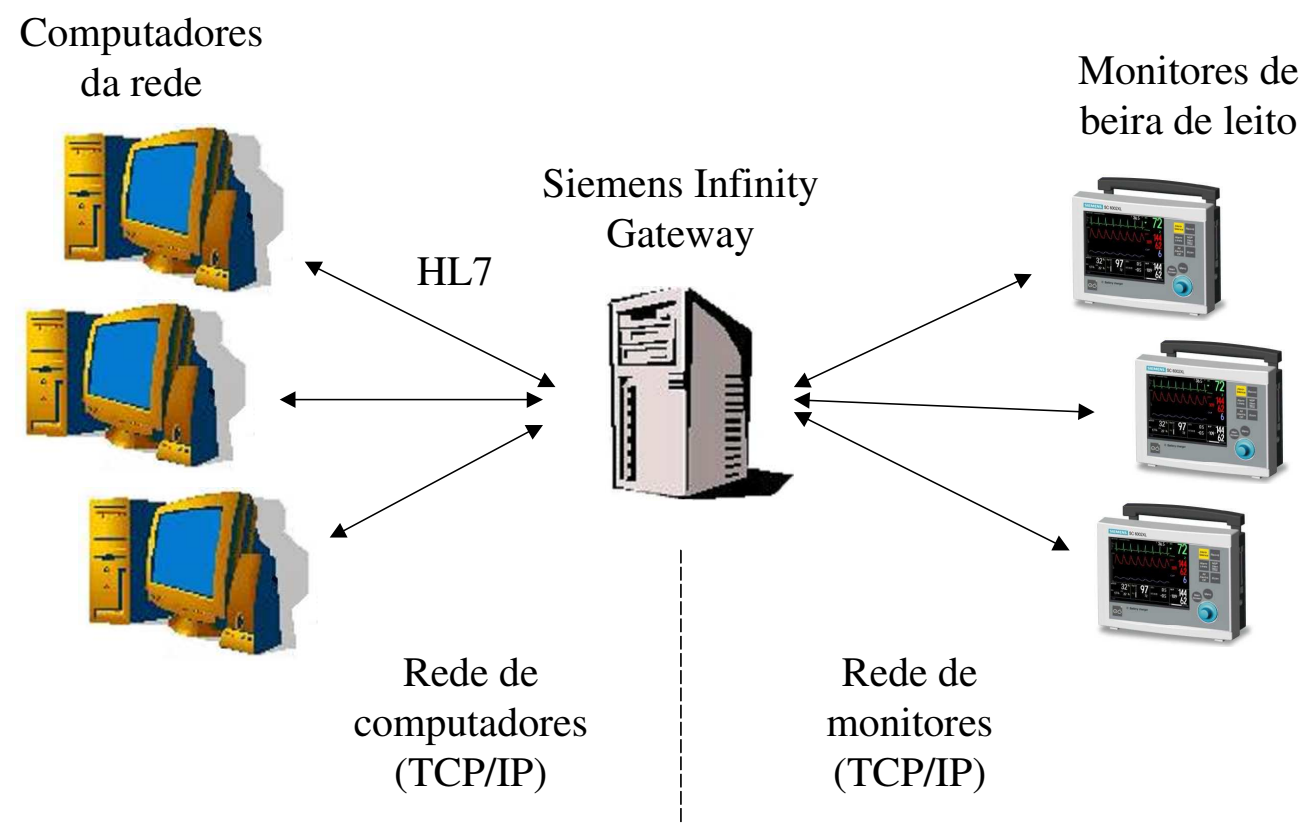

Figura 4.6 - A comunicação entre os monitores de beira de leito e os computadores da rede. 
O vMonGluco Server envia ao gateway uma mensagem $H L 7$ do tipo $O R U^{\wedge} R 01$ contendo as últimas leituras de glicemia. Por sua vez, o gateway envia os dados ao monitor de beira de leito correspondente. No monitor, é exibida a mensagem "Novos dados de laboratório estão disponíveis". Selecionando-se a opção correspondente no monitor de beira de leito, as leituras de glicemia são exibidas na forma de tabela (Figura 4.7). Note que não foi possível a exibição das leituras numa forma gráfica, como seria desejável. Isso acontece porque o monitor de beira de leito não está pronto para a exibição de leituras de glicemia. A exibição desse tipo de informação nunca foi feita em um monitor de beira de leito. Espera-se que, com o desenvolvimento dos medidores contínuos de glicose, os novos monitores passem a incorporar esse tipo de recurso.

\section{7 vMonGluco Web}

O vMonGluco Web é a interface web que permite o acesso às leituras de glicemia armazenadas no banco de dados. Conforme discutido anteriormente (seção 4.3), o uso de páginas web permitiu a criação de uma interface de fácil utilização, que pode ser consultada remotamente de qualquer ponto do hospital ou, eventualmente, fora dele.

O sistema foi desenvolvido em Java Servlets (JAVA SERVLET TECHNOLOGY, 2006) e JavaServer Pages (JAVASERVER PAGES TECHNOLOGY, 2006). Para a geração de gráficos de glicemia, foi utilizada a biblioteca JFreeChart (JFREECHART, 2006).

O vMonGluco Web permite a busca de um paciente por nome ou número de identificação. Após a entrada dos dados do paciente, o sistema mostra uma lista dos pacientes que atendem ao critério de busca especificado. Selecionando-se um dos pacientes encontrados, é exibida uma página com os dados do paciente, juntamente com as leituras de glicemia. As leituras são mostradas na forma de um gráfico e, também, através de uma tabela. A Figura 4.8 mostra uma tela do vMonGluco Web com os dados de um paciente. 


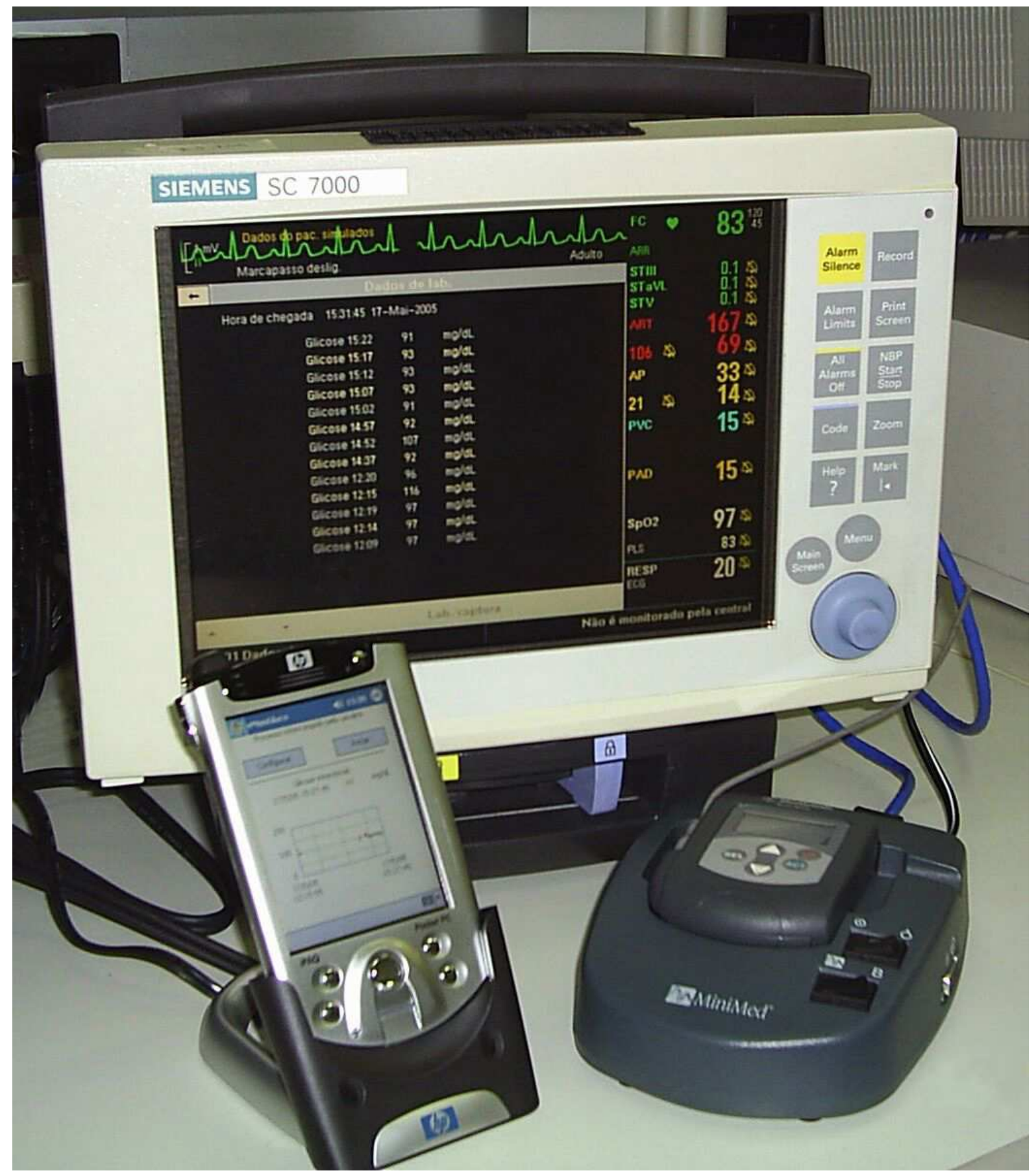

Figura 4.7 - O sistema funcionando em uma bancada de testes. Embaixo, à direita, vê-se o MiniMed CGMS gerando leituras simuladas de glicemia. Embaixo, à esquerda, está o palmtop com o programa vMonGluco Client. Ao fundo, o monitor de beira de leito exibe as leituras de glicemia na forma de uma tabela. 


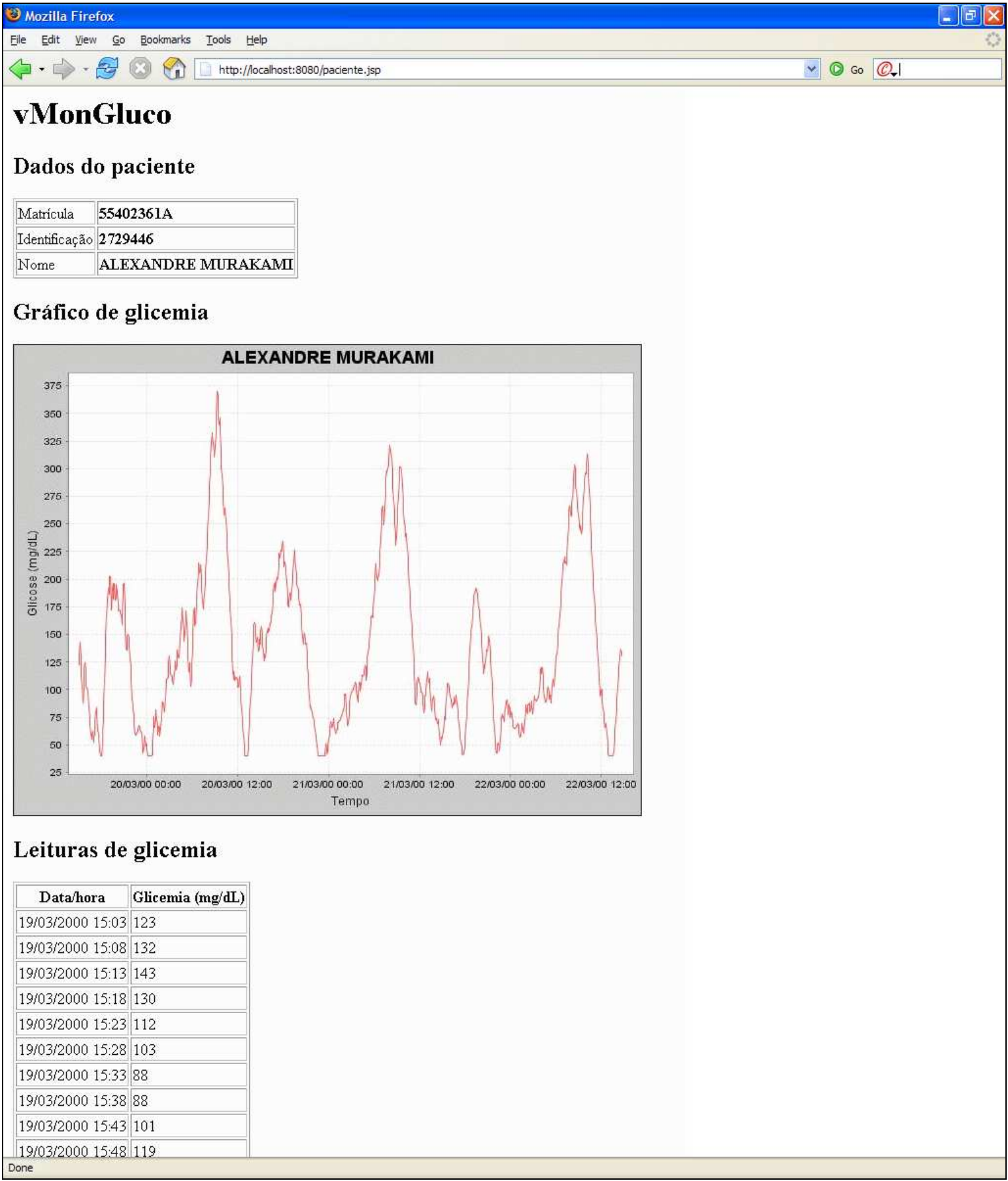

Figura 4.8 - Tela do vMonGluco Web mostrando os dados de um paciente (foi feita uma montagem para que todos os dados fosse exibidos numa única figura). 


\section{Capítulo 5. TESTES EM PACIENTES}

\subsection{Resumo}

Neste capítulo, é apresentada a metodologia de testes do vMonGluco em pacientes críticos. Os testes possuiram, como objetivo principal, a validação das leituras de glicemia geradas pelo sistema vMonGluco. Deve-se notar que o vMonGluco utiliza um método de calibração diferente do software do MiniMed CGMS, o que justifica a realização dos testes. Os testes de campo foram realizados com a colaboração da Unidade de Terapia Intensiva Clínica do Instituto do Coração e seus resultados são apresentados a seguir.

\subsection{Metodologia}

Para a realização dos testes, foram selecionados treze pacientes críticos hiperglicêmicos na Unidade de Terapia Intensiva Coronariana (UCO) do Instituto do Coração para usar o MiniMed CGMS por alguns dias. Os pacientes apresentavam diagnósticos de choque séptico, choque hipotensivo, cardiopatias, insuficiência respiratória, entre outros. Os pacientes são identificados, neste trabalho, apenas pela numeração correspondente à ordem de realização dos testes.

O protocolo de testes foi devidamente analisado e aprovado pelo Instituto do Coração. Para cada paciente selecionado, foi obtido o consentimento formal do mesmo ou dos familiares para a realização dos testes. Após o consentimento, a equipe de enfermagem instalou o MiniMed CGMS da maneira tradicional (ver seção 2.6.1), com o sensor inserido na região subcutânea do abdômen. A inserção do sensor foi feita com o auxílio do MiniMed SenSerter (Medtronic Diabetes, Northridge, EUA), um dispositivo próprio para esse uso. 
Após o processo de inicialização do MiniMed CGMS, a equipe de enfermagem realizou uma medição de glicemia utilizando o medidor de "ponta de dedo" Accu-Check Advantage (ROCHE DIAGNOSTICS, 2004) e registrou a leitura obtida no MiniMed CGMS. A partir da inicialização, o MiniMed CGMS registrou os valores de corrente elétrica gerados pelo sensor até o fim da sua vida útil (até três dias). Durante todo o teste, a equipe de enfermagem realizou medições de glicemia de "ponta de dedo" a um intervalo de tempo que variava entre uma e seis horas. A freqüência da realização dessas medições foi definida pela equipe médica conforme o estado do paciente. A cada seis horas, a leitura de glicemia assim obtida era registrada no MiniMed CGMS para a calibração do algoritmo.

Ao final da vida útil do sensor, o aparelho foi retirado dos pacientes. Os dados foram descarregados para um computador da maneira tradicional, utilizando-se a base de comunicação MiniMed Com-Station e o software MiniMed CGMS System Solutions (versão 3.0C). O software do MiniMed CGMS gerou, a partir dos dados colhidos, valores de glicemia. Todos os dados obtidos foram posteriormente exportados para um programa de planilha eletrônica para a manipulação dos dados.

É importante destacar que, durante este procedimento, o MiniMed CGMS foi utilizado da maneira tradicional, sem a geração de leituras em tempo real. Dessa forma, procurou-se reduzir o transtorno causado pelos testes no trabalho da equipe de enfermagem. Além disso, tal procedimento possibilitou o teste de diversos algoritmos de calibração, conforme será descrito a seguir. Espera-se que, num futuro próximo, a realização de novos testes inclua o uso efetivo do sistema vMonGluco.

A Tabela 5.1 mostra um exemplo de saída gerada pelo software do MiniMed CGMS. Devido ao espaço reduzido, somente algumas linhas e colunas são exibidas aqui. Além das informações aqui presentes, há também algumas informações sobre o paciente (nome, número de identificação), eventos relacionados à condição do aparelho (sensor desconectado, erro de 
calibração e outros), eventos registrados pelo paciente (refeição, uso de insulina) e dados do aparelho e do software (versão, número de identificação).

Foi aplicado, sobre os dados coletados, o algoritmo para cálculo de glicemia em tempo real descrito anteriormente (seção 4.5.2). Dessa forma, procurou-se simular as leituras de glicemia que seriam obtidas, em tempo real, através do uso do sistema vMonGluco. Foram testadas algumas variações nos parâmetros e na forma do algoritmo, conforme descrito a seguir (seção 5.2.1), de forma a otimizar o algoritmo.

A análise dos resultados obtidos foi feita segundo os vários critérios encontrados na literatura (seção 2.3). Os resultados serão apresentados mais a seguir (seção 5.3).

Tabela 5.1 - Exemplo de saída gerada pelo software do MiniMed CGMS.

\begin{tabular}{|c|c|c|c|c|c|c|c|c|c|c|c|c|}
\hline Sample \# & Day & Date & Time & ISIG & VCTR & \begin{tabular}{|c|} 
Meter \\
BG
\end{tabular} & $\begin{array}{c}\text { Paired } \\
\text { Meter } \\
\text { BG } \\
\end{array}$ & Slope & Offset & $\begin{array}{l}\text { Valid } \\
\text { ISIG }\end{array}$ & $\begin{array}{c}\text { Sensor } \\
\text { Glucose }\end{array}$ & $\begin{array}{c}\text { Glucose } \\
\text { Units }\end{array}$ \\
\hline 0 & seg & $22 /$ nov/04 & $10: 05$ & 0 & $-1,3$ & & & & & & & $\mathrm{mg} / \mathrm{dL}$ \\
\hline & seg & $22 /$ nov/04 & $10: 19$ & 6 & $-1,18$ & & & & & & & $\mathrm{mg} / \mathrm{dL}$ \\
\hline 2 & seg & $22 /$ nov/04 & 11:01 & 150,4 & $-0,96$ & & & & & & & $\mathrm{mg} / \mathrm{dL}$ \\
\hline 3 & seg & 22/nov/04 & 11:06 & 26,2 & $-1,27$ & & & & & & & $\mathrm{mg} / \mathrm{dL}$ \\
\hline 4 & seg & 22/nov/04 & 11:11 & 33,2 & $-0,7$ & & & & & & & $\mathrm{mg} / \mathrm{dL}$ \\
\hline 5 & seg & $22 /$ nov/04 & 11:16 & 33,5 & $-0,65$ & & & & & & & $\mathrm{mg} / \mathrm{dL}$ \\
\hline 6 & seg & 22/nov/04 & 11:21 & 32,1 & $-0,65$ & & & & & & & $\mathrm{mg} / \mathrm{dL}$ \\
\hline 7 & seg & 22/nov/04 & 11:26 & 31,5 & $-0,65$ & & & & & & & $\mathrm{mg} / \mathrm{dL}$ \\
\hline 8 & seg & $22 /$ nov/04 & 11:31 & 35,1 & $-0,67$ & & & & & & & $\mathrm{mg} / \mathrm{dL}$ \\
\hline 9 & seg & 22/nov/04 & 11:36 & 35,5 & $-0,68$ & & & & & & & $\mathrm{mg} / \mathrm{dL}$ \\
\hline 10 & seg & $22 /$ nov/04 & 11:41 & 34,5 & $-0,68$ & & & & & & & $\mathrm{mg} / \mathrm{dL}$ \\
\hline 11 & seg & $22 /$ nov/04 & 11:46 & 33,4 & $-0,69$ & & & & & & & $\mathrm{mg} / \mathrm{dL}$ \\
\hline 12 & seg & $22 /$ nov/04 & 11:51 & 33 & $-0,69$ & & & & & & & $\mathrm{mg} / \mathrm{dL}$ \\
\hline 13 & seg & $22 /$ nov/04 & $11: 56$ & 33 & $-0,69$ & & & 3,77 & -6 & 32,3 & 144 & $\mathrm{mg} / \mathrm{dL}$ \\
\hline 14 & seg & 22/nov/04 & 12:01 & 32,6 & $-0,7$ & & & 3,77 & -6 & 31,5 & 141 & $\mathrm{mg} / \mathrm{dL}$ \\
\hline 15 & seg & $22 /$ nov/04 & 12:06 & 32,3 & $-0,7$ & 121 & 121 & 3,77 & -6 & 30,5 & 138 & $\mathrm{mg} / \mathrm{dL}$ \\
\hline 16 & seg & $22 /$ nov/04 & 12:11 & 31,5 & $-0,7$ & & & 3,77 & -6 & 30,3 & 137 & $\mathrm{mg} / \mathrm{dL}$ \\
\hline 17 & seg & $22 /$ nov/04 & 12:16 & 30,5 & $-0,7$ & & & 3,77 & -6 & 29,7 & & $\mathrm{mg} / \mathrm{dL}$ \\
\hline 18 & seg & $22 /$ nov/04 & 12:21 & 30,3 & $-0,7$ & & & 3,77 & -6 & 29,7 & & $\mathrm{mg} / \mathrm{dL}$ \\
\hline 19 & seg & $22 /$ nov/04 & 12:26 & 29,7 & $-0,7$ & & & 3,77 & -6 & 28,7 & 131 & $\mathrm{mg} / \mathrm{dL}$ \\
\hline 20 & seg & $22 /$ nov/04 & 12:31 & 29,7 & $-0,7$ & & & 3,77 & -6 & 27,8 & 127 & $\mathrm{mg} / \mathrm{dL}$ \\
\hline 21 & seg & 22/nov/04 & 12:36 & 28,7 & $-0,7$ & & & 3,77 & -6 & 26,9 & 124 & $\mathrm{mg} / \mathrm{dL}$ \\
\hline 22 & seg & $22 /$ nov/04 & $12: 41$ & 27,8 & $-0,7$ & & & 3,77 & -6 & 26,1 & 121 & $\mathrm{mg} / \mathrm{dL}$ \\
\hline
\end{tabular}




\subsubsection{Variações do algoritmo em tempo real}

Na seção 4.5.2, foi feita uma descrição do algoritmo em tempo real utilizado pelo sistema vMonGluco. Esse algoritmo apresenta vários parâmetros numéricos que podem ser variados, alterando os resultados do cálculo de glicemia. Nos testes com pacientes, foram testadas variações dos seguintes parâmetros numéricos:

- atraso das leituras de calibração;

- tamanho da janela de calibração;

- tamanho da janela de suavização;

- valores possíveis de offset.

Também foram experimentadas variações no formato do algoritmo. Uma primeira variação foi quanto à ponderação dos pontos de calibração. No algoritmo original, todos os pontos de calibração presentes na janela possuem a mesma ponderação nos cálculos. Sabe-se, entretanto, que a sensibilidade do sensor varia à medida que o tempo passa e, por isso, pontos de calibração antigos são menos “confiáveis”. Assim, é razoável atribuir uma ponderação diferente para cada ponto de calibração à medida que o tempo passa. $\mathrm{O}$ cálculo da regressão linear com ponderação é descrito no Apêndice C, Regressão linear ponderada.

Foram implementados dois algoritmos que utilizam critérios diferentes de ponderação (Figura 5.1). O primeiro, nomeado aqui como algoritmo ponderado linear, considera uma função linear crescente para a ponderação dos pontos de calibração. Um ponto de calibração localizado no início da janela de calibração recebe um valor nulo de ponderação (é descartado). Um ponto de calibração recente recebe um valor unitário de ponderação. Pontos intermediários recebem valores intermediários de ponderação (Figura 5.1 - Gráfico B). Para esse algoritmo, foram testados diversos tamanhos para a janela de calibração. 

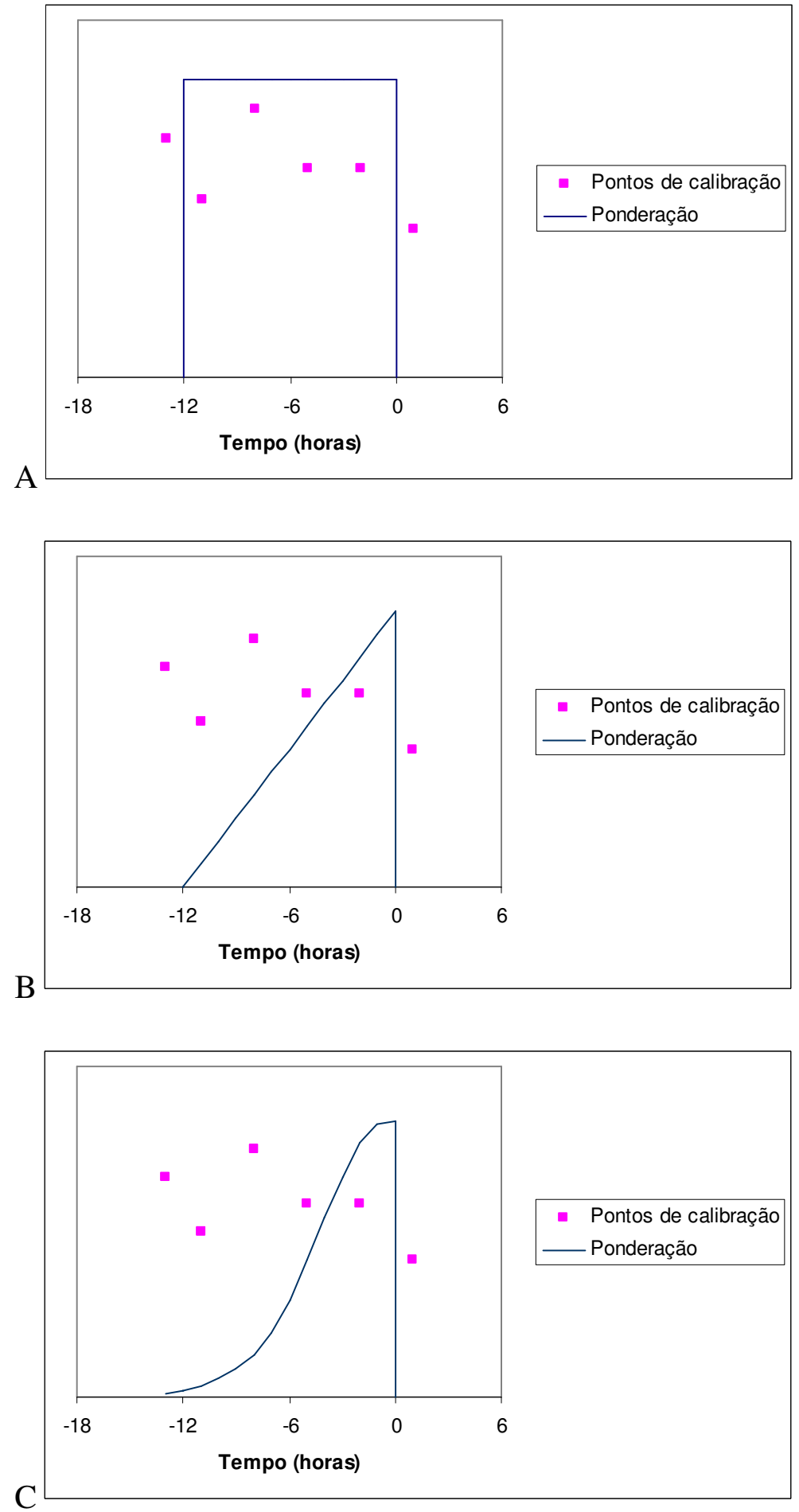

Figura 5.1 - Os gráficos mostram os pontos de calibração coletados no intervalo de tempo de algumas horas. Todos os pontos coletados em uma janela de 12 horas são incluídos no cálculo. $O$ gráfico A representa o algoritmo em tempo real original, onde todos os pontos de calibração recebem a mesma ponderação. No gráfico $B$, os pontos de calibração são ponderados segundo uma função linear crescente. Um ponto no início da janela recebe ponderação nula (é descartado), enquanto que um ponto no fim da janela recebe ponderação unitária. No gráfico $C$, os pontos de calibração são ponderados segundo uma função normal, cujo topo, de valor unitário, localiza-se no final da janela. 

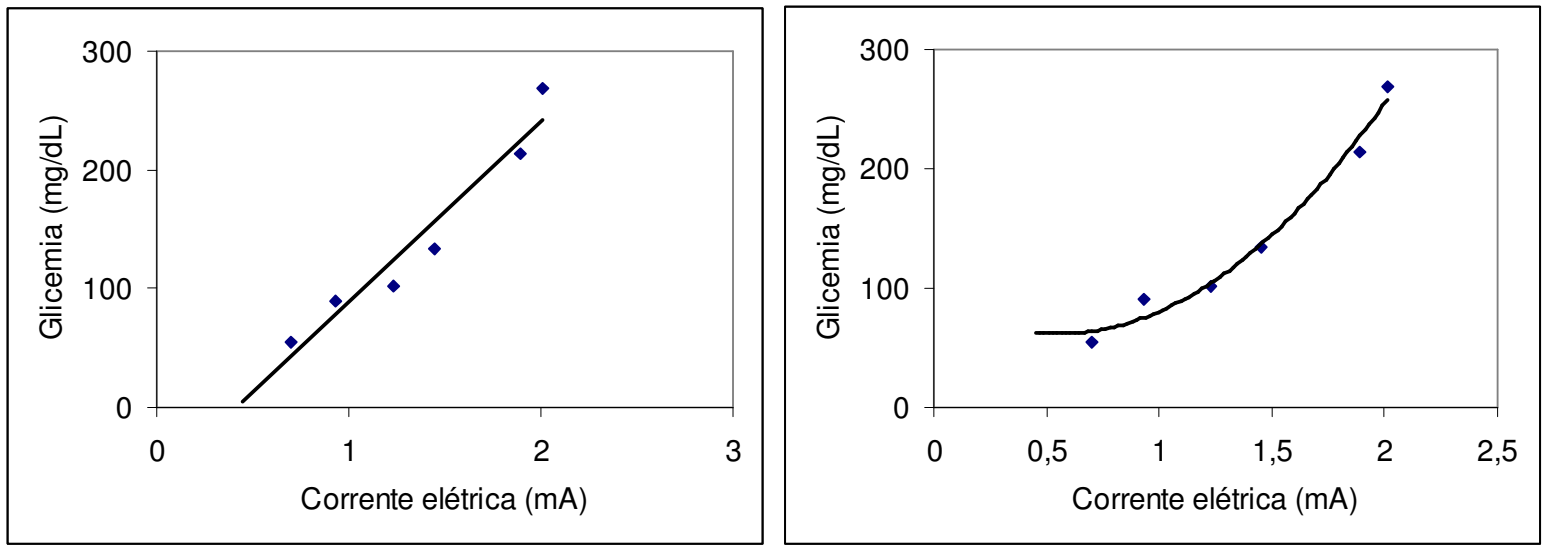

Figura 5.2 - No gráfico à esquerda, a resposta do sensor é aproximada segundo uma função linear. À direita, a resposta do sensor é aproximada segundo uma função quadrática.

No segundo algoritmo, nomeado aqui como algoritmo ponderado normal, os pontos de calibração são ponderados segundo uma curva normal cujo topo, de valor unitário, localiza-se no final na janela de calibração (Figura 5.1 - Gráfico C). Para este algoritmo, testou-se a variação do tamanho da janela, representado pelo desvio padrão da curva normal.

Foi experimentada ainda uma outra variação do algoritmo. Originalmente, a resposta do sensor (relação "corrente elétrica" x "glicemia") é representada através de uma função linear. Experimentou-se aproximar a resposta do sensor por uma função quadrática. Assim, esperou-se obter uma representação mais fiel do comportamento do sensor (Figura 5.2).

No algoritmo proposto, nomeado aqui como algoritmo quadrático, o termo quadrático é escolhido a partir de um conjunto finito de possíveis valores, ao invés de ser calculado pelo algoritmo de regressão linear (ver Apêndice C, Regressão quadrática). Isso permitiu limitar o termo quadrático a valores relativamente baixos, tornando a curva de resposta "quase" linear.

\subsection{Resultados dos testes}

Seguindo a metodologia descrita (seção 5.2), foram coletados os dados dos treze pacientes críticos. Os resultados de cada paciente são mostrados, na forma de gráficos, no Apêndice D. 
O paciente 8 faleceu durante a realização dos testes e, por isso, seus dados não foram considerados neste trabalho.

Para alguns dos pacientes (pacientes 5, 10 e 13), foram reportados alguns erros de calibração ("CAL ERROR”). Tal erro ocorre quando a razão entre a glicemia de calibração (MeterBG) e a corrente elétrica gerada pelo sensor (VALID ISIG) não estiver entre 1,5 e 15 (ver seção 2.6.2). Usualmente, um "CAL ERROR" é causado pelo desgaste prematuro do sensor, má colocação do sensor, falha no cabo ou outro problema relacionado ao sinal gerado pelo sensor. Não foi detectada a causa dos problemas. Os testes não foram interrompidos, o que levou ao surgimento de algumas interrupções nas leituras de glicemia (ver Apêndice D).

A partir dos dados coletados, foram simuladas leituras em tempo real seguindo o algoritmo em tempo real descrito na metodologia (seção 4.5.2). Os parâmetros de entrada do algoritmo foram variados a fim de se verificar sua influência no resultado final. As leituras em tempo real foram comparadas às leituras geradas pelo software do MiniMed CGMS. Foram utilizados como parâmetros de comparação:

- a diferença absoluta média (em porcentagem) entre as leituras;

- o desvio padrão (em porcentagem) das diferenças entre as leituras;

- $\quad$ o coeficiente de correlação.

Os resultados das simulações são apresentados a seguir (Tabela 5.2 a Tabela 5.5). As colunas em destaque mostram o resultado ótimo obtido.

Além do algoritmo em tempo real original, foram feitos testes com as variações de algoritmo descritas na metodologia (seção 5.2.1). Os resultados são apresentados a seguir (Tabela 5.6 a Tabela 5.8). 
Tabela 5.2 - Variação do atraso das leituras de calibração (janela de calibração $=12$ horas, outros parâmetros $=0$ ).

\begin{tabular}{lrrr}
\hline Atraso (min) & 0 & 5 & $\mathbf{1 0}$ \\
\hline Diferença absoluta (\%) & 11 & 10,8 & $\mathbf{1 0 , 7}$ \\
Desvio padrão (\%) & 17,2 & 16,9 & $\mathbf{1 6 , 7}$ \\
Coeficiente de correlação & 0,901 & 0,903 & $\mathbf{0 , 9 0 2}$ \\
\hline
\end{tabular}

Tabela 5.3 - Variação da janela de calibração (atraso de $10 \mathrm{~min}$, outros parâmetros = 0).

\begin{tabular}{lrrrrrrr}
\hline Janela (horas) & 6 & 9 & $\mathbf{1 2}$ & $\mathbf{1 5}$ & 18 & 21 & 24 \\
\hline n (número de leituras geradas) & 8539 & 8929 & $\mathbf{9 0 0 8}$ & $\mathbf{9 0 4 3}$ & 9044 & 9048 & 9048 \\
Diferença absoluta (\%) & 14,7 & 12,4 & $\mathbf{1 0 , 7}$ & $\mathbf{1 1}$ & 11,6 & 12,1 & 12,8 \\
Desvio padrão (\%) & 21,6 & 19 & $\mathbf{1 6 , 7}$ & $\mathbf{1 6 , 2}$ & 16,9 & 17,4 & 18 \\
Coeficiente de correlação & 0,831 & 0,877 & $\mathbf{0 , 9 0 2}$ & $\mathbf{0 , 9 0 7}$ & 0,899 & 0,891 & 0,884 \\
\hline
\end{tabular}

Tabela 5.4 - Variação da janela de suavização (janela de calibração = 12 horas, atraso = 10 min, outros parâmetros = 0).

\begin{tabular}{lrrrr}
\hline Janela (minutos) & $\mathbf{0}$ & 30 & 60 & 90 \\
\hline Diferença absoluta (\%) & $\mathbf{1 0 , 7}$ & 10,8 & 10,8 & 10,9 \\
Desvio padrão (\%) & $\mathbf{1 6 , 7}$ & 16,7 & 16,6 & 16,6 \\
Coeficiente de correlação & $\mathbf{0 , 9 0 2}$ & 0,902 & 0,901 & 0,901 \\
\hline
\end{tabular}

Tabela 5.5 - Variação do offset (janela de calibração $=12$ horas, atraso $=10 \mathrm{~min}$, janela de suavização $=0$ ).

\begin{tabular}{lrrrrrr}
\hline Offset mínimo & -9 & -6 & $\mathbf{- 3}$ & $-1,5$ & $-0,5$ & 0 \\
Offset máximo & 9 & 6 & $\mathbf{3}$ & 1,5 & 0,5 & 0 \\
Step & 4,5 & 3 & $\mathbf{1 , 5}$ & 0,75 & 0,25 & 0 \\
\hline Diferença absoluta (\%) & 12,1 & 10,6 & $\mathbf{1 0 , 2}$ & 10,4 & 10,6 & 10,7 \\
Desvio padrão (\%) & 19,1 & 16,8 & $\mathbf{1 6 , 1}$ & 16,2 & 16,6 & 16,7 \\
Coeficiente de correlação & 0,877 & 0,926 & $\mathbf{0 , 9 2 2}$ & 0,914 & 0,903 & 0,902 \\
\hline
\end{tabular}

Tabela 5.6 - Algoritmo ponderado linear, variação da janela de calibração (atraso = 10 min, janela de suavização $=0$, offset $=-3 / 3 / 1.5$ ).

\begin{tabular}{lrrrrrr}
\hline Janela (horas) & 12 & $\mathbf{1 8}$ & 21 & 24 & 30 & 36 \\
\hline Diferença absoluta (\%) & 11,2 & $\mathbf{1 0 , 3}$ & 10,5 & 10,7 & 11,2 & 11,6 \\
Desvio padrão (\%) & 17,1 & $\mathbf{1 5 , 7}$ & 15,9 & 16 & 16,4 & 16,6 \\
Coeficiente de correlação & 0,91 & $\mathbf{0 , 9 2 6}$ & 0,923 & 0,92 & 0,913 & 0,91 \\
\hline
\end{tabular}


Tabela 5.7 - Algoritmo ponderado normal, variação do desvio padrão (atraso $=10$ min, janela de suavização $=0$, offset $=-3 / 3 / 1.5$ ).

\begin{tabular}{lrrrrrrr}
\hline Janela (horas) & 3 & 6 & $\mathbf{9}$ & 12 & 15 & 18 & 24 \\
\hline Diferença absoluta (\%) & 14,4 & 10,7 & $\mathbf{1 0 , 3}$ & 10,9 & 11,3 & 11,7 & 12,1 \\
Desvio padrão (\%) & 20,9 & 16,2 & $\mathbf{1 5 , 6}$ & 16 & 16,2 & 16,5 & 16,9 \\
Coeficiente de correlação & 0,86 & 0,92 & $\mathbf{0 , 9 2 4}$ & 0,919 & 0,914 & 0,91 & 0,903 \\
\hline
\end{tabular}

Tabela 5.8 - Algoritmo quadrático, variando desvio padrão do termo de segunda ordem (janela de calibração $=12$ horas, atraso $=10 \mathrm{~min}$, janela de suavização $=0$, offset $=$ 3/3/1.5).

\begin{tabular}{lrrrrrrrr}
\hline Slope2 mínimo & $\mathbf{0}$ & $-0,001$ & $-0,002$ & $-0,005$ & $-0,01$ & $-0,02$ & $-0,04$ & $-0,08$ \\
Slope2 máximo & $\mathbf{0}$ & 0,001 & 0,002 & 0,005 & 0,01 & 0,02 & 0,04 & 0,08 \\
Step & $\mathbf{0}$ & 0,00025 & 0,0005 & 0,001 & 0,0025 & 0,005 & 0,01 & 0,02 \\
\hline Diferença absoluta (\%) & $\mathbf{1 0 , 2}$ & 10,5 & 10,5 & 10,5 & 10,6 & 10,7 & 11 & 11,9 \\
Desvio padrão (\%) & $\mathbf{1 6 , 1}$ & 16,9 & 16,8 & 16,9 & 17 & 17,1 & 17,6 & 19 \\
Coeficiente de correlação & $\mathbf{0 , 9 2 2}$ & 0,899 & 899 & 0,898 & 0,897 & 0,896 & 0,891 & 0,884 \\
\hline
\end{tabular}

Pode-se observar que o resultado ótimo do algoritmo em tempo real foi obtido com os seguintes parâmetros numéricos:

- Atraso de 10 minutos nas leituras de calibração.

- Janela de calibração de 12 ou 15 horas.

- Sem suavização (janela de suavização = 0)

- Offset mínimo = 3, offset máximo = 3, diferença entre offsets $=1,5$.

Os algoritmos ponderado linear e ponderado normal obtiveram resultados equivalentes, mas não superiores, ao primeiro algoritmo. Já o algoritmo quadrático gerou resultados inferiores.

A Tabela 5.9 mostra, em maiores detalhes, a comparação entre o algoritmo do software do MiniMed CGMS e o algoritmo em tempo real ótimo. A forma da tabela foi baseada no artigo de Goldberg et al. (2004). Já a Tabela 5.10 mostra a comparação entre o algoritmo em tempo real ótimo e as leituras de "ponta de dedo". Como padrão para comparação, a Tabela 5.11 mostra as diferenças entre os resultados do software do MiniMed $C G M S$ e as "pontas de dedo". 
Tabela 5.9 - Diferença entre os valores de glicemia obtidos pelo algoritmo do software do MiniMed CGMS e pelo algoritmo em tempo real ótimo. O coeficiente de correlação obtido foi 0,922 .

\begin{tabular}{lccccccc}
\hline Faixa & $\mathrm{N}$ & $\begin{array}{c}\text { Média } \\
\text { MiniMed }\end{array}$ & $\begin{array}{c}\text { Média } \\
\text { Tempo Real }\end{array}$ & $\begin{array}{c}\text { Diferença } \\
\pm \text { desvio }\end{array}$ & $\begin{array}{c}\text { Diferença } \\
\pm \text { desvio (\%) }\end{array}$ & $\begin{array}{c}\text { Diferença } \\
\text { Absoluta }\end{array}$ & $\begin{array}{c}\text { Diferença } \\
\text { Absoluta (\%) }\end{array}$ \\
\hline$<100 \mathrm{mg} / \mathrm{dL}$ & 1125 & 81.9 & 88.1 & $6.1 \pm 17.6$ & $9.2 \pm 26.2$ & 13.9 & 18.5 \\
$100-149 \mathrm{mg} / \mathrm{dL}$ & 3495 & 126.3 & 128.1 & $1.8 \pm 17.9$ & $1.3 \pm 13.9$ & 12.1 & 9.6 \\
$150-199 \mathrm{mg} / \mathrm{dL}$ & 2599 & 170.4 & 168.2 & $-2.2 \pm 21.2$ & $-1.3 \pm 12.3$ & 14.0 & 8.2 \\
$200-249 \mathrm{mg} / \mathrm{dL}$ & 1041 & 222.3 & 213.0 & $-9.3 \pm 34.5$ & $-4.1 \pm 15.6$ & 22.6 & 10.2 \\
$>=250 \mathrm{mg} / \mathrm{dL}$ & 748 & 298.0 & 284.2 & $-13.9 \pm 33.3$ & $-4.8 \pm 11.2$ & 22.6 & 7.8 \\
\hline Total & 9008 & 158.8 & 157.4 & $-1.4 \pm 23.5$ & $-0.4 \pm 16.1$ & 15.0 & 10.2 \\
\hline
\end{tabular}

Tabela 5.10 - Diferença entre os valores de glicemia obtidos pelo algoritmo em tempo real ótimo e pelas "pontas de dedo". $O$ coeficiente de correlação obtido foi 0,764 .

\begin{tabular}{lccccccc}
\hline Faixa & $\mathrm{N}$ & $\begin{array}{c}\text { Média } \\
\text { Ponta }\end{array}$ & $\begin{array}{c}\text { Média } \\
\text { Tempo Real }\end{array}$ & $\begin{array}{c}\text { Diferença } \\
\pm \text { desvio }\end{array}$ & $\begin{array}{c}\text { Diferença } \\
\pm \text { desvio }(\%)\end{array}$ & $\begin{array}{c}\text { Diferença } \\
\text { Absoluta }\end{array}$ & $\begin{array}{c}\text { Diferença } \\
\text { Absoluta (\%) }\end{array}$ \\
\hline$<100 \mathrm{mg} / \mathrm{dL}$ & 47 & 81.4 & 103.7 & $22.4 \pm 27.6$ & $37.7 \pm 60.8$ & 28.2 & 44.4 \\
$100-149 \mathrm{mg} / \mathrm{dL}$ & 101 & 122.8 & 124.8 & $2.0 \pm 28.8$ & $2.2 \pm 23.7$ & 22.0 & 18.1 \\
$150-199 \mathrm{mg} / \mathrm{dL}$ & 90 & 171.2 & 157.9 & $-13.2 \pm 33.2$ & $-7.4 \pm 19.5$ & 25.5 & 14.8 \\
$200-249 \mathrm{mg} / \mathrm{dL}$ & 54 & 220.1 & 198.3 & $-21.8 \pm 41.8$ & $-9.9 \pm 19.2$ & 35.4 & 16.1 \\
$>=250 \mathrm{mg} / \mathrm{dL}$ & 40 & 328.0 & 245.2 & $-82.8 \pm 73.7$ & $-24.4 \pm 19.8$ & 86.3 & 25.4 \\
\hline Total & 332 & 170.6 & 157.3 & $-13.3 \pm 49.4$ & $-0.5 \pm 34.8$ & 33.7 & 21.5 \\
\hline
\end{tabular}

Tabela 5.11 - Diferença entre os valores de glicemia obtidos pelo software do MiniMed CGMS e pelas “pontas de dedo". O coeficiente de correlação obtido foi 0,868 .

\begin{tabular}{lccccccc}
\hline Faixa & $\mathrm{N}$ & $\begin{array}{c}\text { Média } \\
\text { Ponta }\end{array}$ & $\begin{array}{c}\text { Média } \\
\text { MiniMed }\end{array}$ & $\begin{array}{c}\text { Diferença } \\
\pm \text { desvio }\end{array}$ & $\begin{array}{c}\text { Diferença } \\
\pm \text { desvio }(\%)\end{array}$ & $\begin{array}{c}\text { Diferença } \\
\text { Absoluta }\end{array}$ & $\begin{array}{c}\text { Diferença } \\
\text { Absoluta (\%) }\end{array}$ \\
\hline$<100 \mathrm{mg} / \mathrm{dL}$ & 46 & 81.5 & 100.4 & $18.8 \pm 24.9$ & $34.2 \pm 59.9$ & 22.8 & 38.7 \\
$100-149 \mathrm{mg} / \mathrm{dL}$ & 105 & 123.1 & 126.8 & $3.7 \pm 22.4$ & $3.5 \pm 18.3$ & 16.4 & 13.4 \\
$150-199 \mathrm{mg} / \mathrm{dL}$ & 89 & 171.4 & 163.5 & $-7.9 \pm 28.8$ & $-4.4 \pm 17.1$ & 20.5 & 12.0 \\
$200-249 \mathrm{mg} / \mathrm{dL}$ & 51 & 220.2 & 210.0 & $-10.2 \pm 36.4$ & $-4.6 \pm 16.6$ & 26.7 & 12.2 \\
$>=250 \mathrm{mg} / \mathrm{dL}$ & 31 & 339.3 & 295.6 & $-43.6 \pm 69.7$ & $-10.7 \pm 18.1$ & 60.9 & 16.5 \\
\hline Total & 322 & 166.7 & 162.6 & $-4.1 \pm 37.6$ & $-3.1 \pm 31.0$ & 24.4 & 16.7 \\
\hline
\end{tabular}

A Figura 5.3 mostra o gráfico de Clarke (CLARKE et al.; 1987), comparando o algoritmo em tempo real com as leituras de "ponta de dedo". Através do gráfico, pode-se observar que $61,5 \%$ das medidas estão na zona $\mathrm{A}, 33,1 \%$ na zona $\mathrm{B}$ e $5,4 \%$ nas zonas $\mathrm{C}$, D e E. Como padrão de comparação, na Figura 5.4, temos o gráfico de Clarke para o algoritmo do software do MiniMed CGMS. Nele, obteve-se 76,5\% das leituras na zona A, 20,5\% das leituras na zona B e 3,0\% nas zonas C, D e E. 


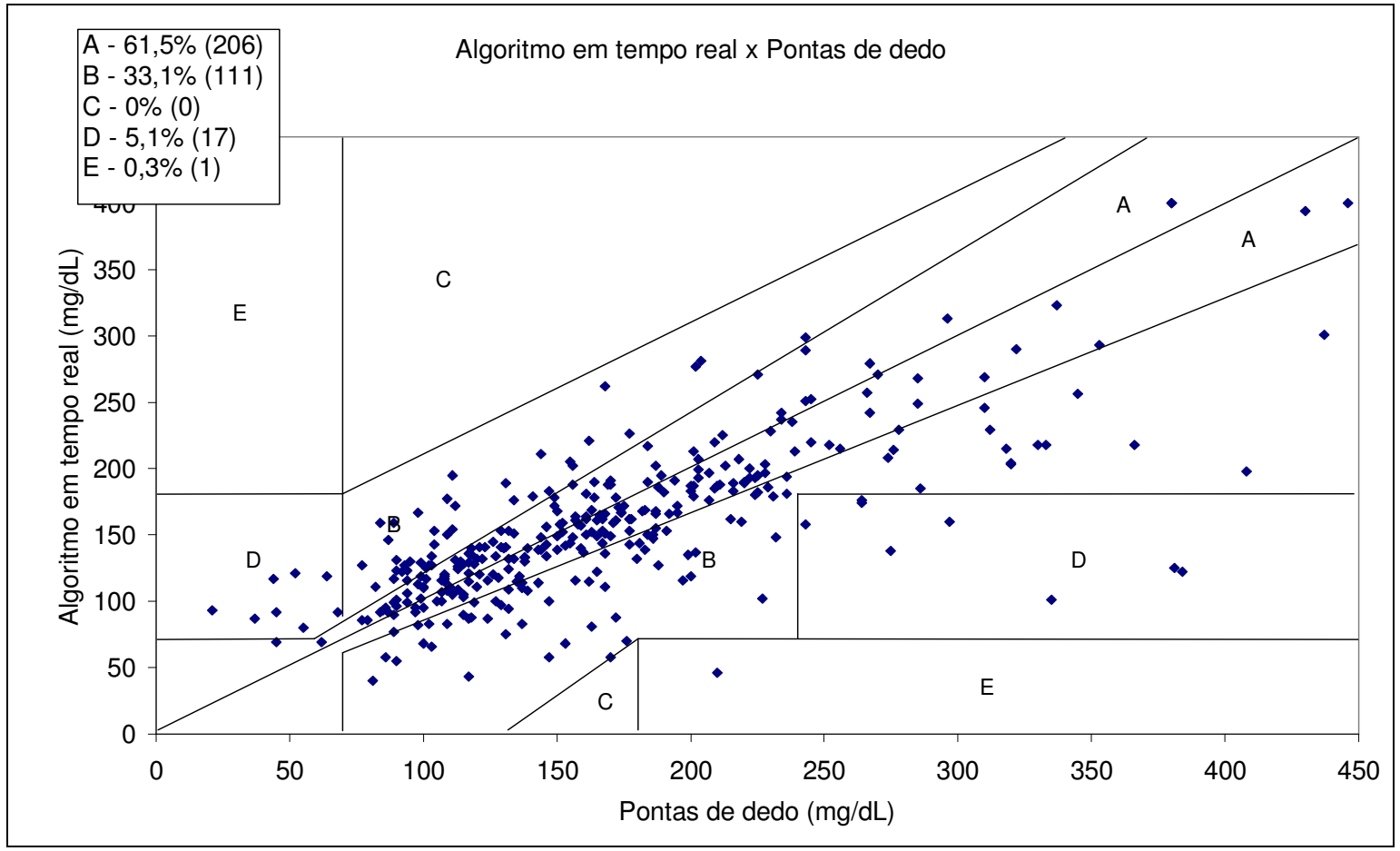

Figura 5.3 - Gráfico de Clarke comparando o algoritmo em tempo real com as leituras de "ponta de dedo".

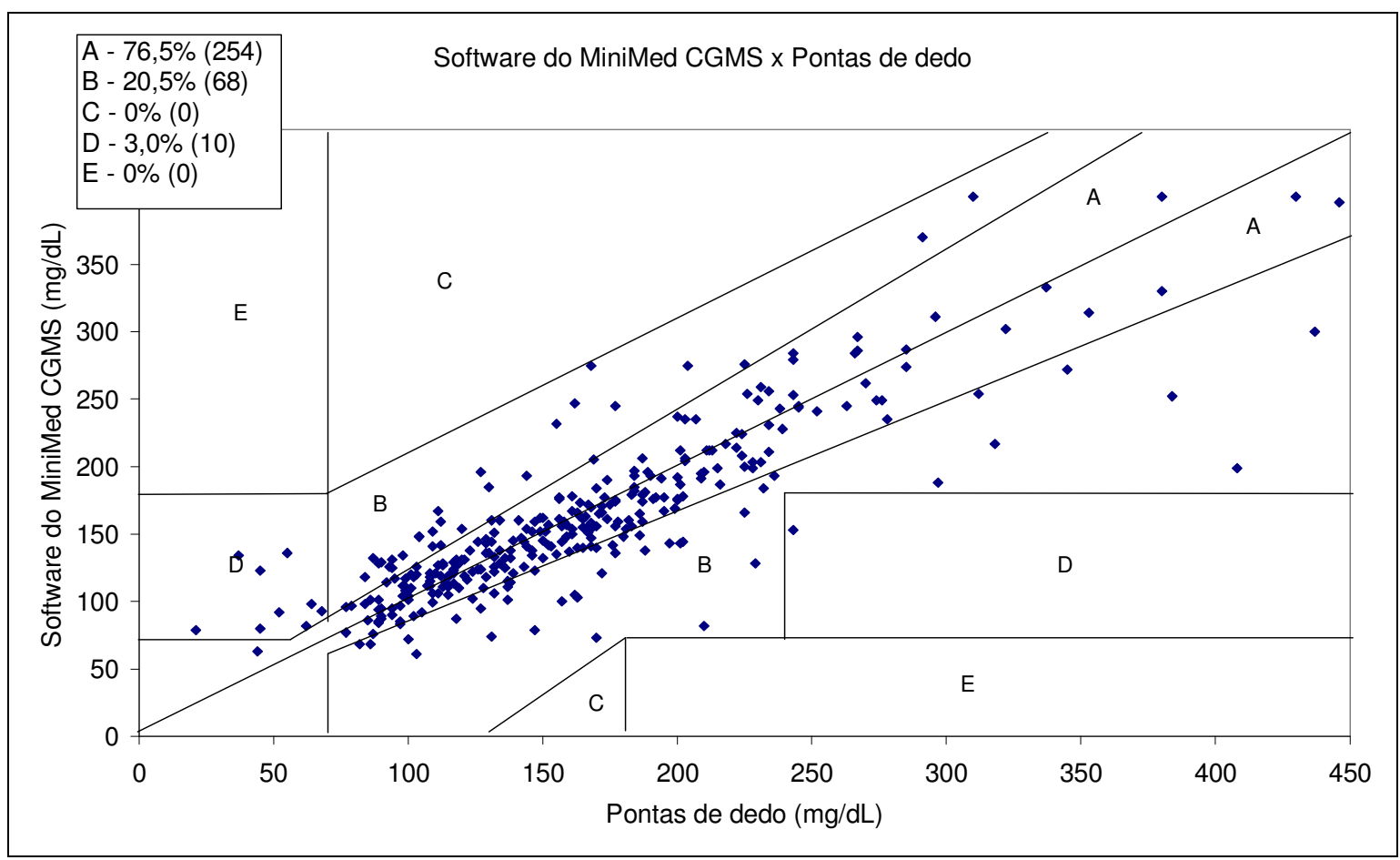

Figura 5.4 - Gráfico de Clarke comparando o software do MiniMed CGMS com as leituras de "ponta de dedo". 


\section{Capítulo 6. DisCUSSÃo}

\subsection{Resumo}

O presente capítulo faz uma discussão dos resultados obtidos sob vários aspectos diferentes. Inicialmente, é feita uma análise da implementação do sistema, abordando aspectos como montagem física, usabilidade e funcionalidade. O vMonGluco também é analisado quanto à sua integração aos monitores de beira de leito e aos sistemas de informação hospitalar. Finalmente, é apresentada uma discussão sobre os testes de campo em pacientes.

\subsection{A Implementação do vMonGluco}

No Capítulo 4, foi apresentada a implementação do sistema vMonGluco. Conforme foi explicado, implementou-se o vMonGluco Client, que obtém leituras de glicemia em tempo real e transmite-as ao servidor vMonGluco Server. Este armazena as leituras em um banco de dados e retransmite os dados a um monitor de beira de leito. Os dados armazenados podem ser visualizados através de uma interface web, o vMongluco Web.

\subsubsection{A Montagem Física do Sistema}

O sistema implementado obteve bons resultados, mesmo existindo, ainda, muitas limitações. A montagem física obtida (seção 4.4), com um palmtop conectado ao MiniMed CGMS através de um cabo serial, não é muito prática. A existência de vários componentes físicos dispersos (MiniMed CGMS, palmtop, bases de comunicação, cabos e fontes) dificultam bastante o uso do sistema. Idealmente, seria desejável que todo o conjunto se restringisse a uma ou duas peças. Por exemplo, o palmtop e o MiniMed CGMS poderiam estar 
integrado em um único componente. Embora, do ponto de vista tecnológico, tal integração seja possível, ela foge do escopo deste projeto.

Outra possibilidade interessante, que aprimoraria a configuração física do sistema, seria a substituição do cabo entre o sensor e o monitor do MiniMed CGMS por uma comunicação sem fio (ondas de rádio). O Guardian $R T$, produto em desenvolvimento pela Medtronic Diabetes, possui esse recurso. A eliminação do cabo permite uma maior distância entre os aparelhos (MiniMed CGMS, palmtop etc.) e o paciente, garantindo maior mobilidade e conforto. Entretanto, novamente, a implementação de tal solução está fora do escopo deste trabalho.

As fontes de alimentação, tanto do MiniMed CGMS quanto do palmtop, também limitam a praticidade física do sistema. Embora o MiniMed CGMS utilize pilhas com boa duração (da ordem de um mês), a sua base de comunicação (MiniMed Com-Station) utiliza uma fonte de alimentação conectada à rede elétrica. A energia consumida pela base de comunicação é baixa, o que possibilitaria o uso de baterias. Entretanto, no projeto da ComStation, a mobilidade não era um requisito importante, o que, provavelmente, levou ao uso da alimentação pela rede elétrica. Lembremos que o equipamento não é utilizado, neste projeto, da maneira como foi concebido, o que implica em algumas inconveniências.

Embora o palmtop disponha de uma bateria interna, ela possui uma autonomia limitada (da ordem de duas horas com o uso contínuo de rede sem fio). Isso implica na dependência de alimentação externa para o palmtop, o que também limita a mobilidade e praticidade do sistema. A autonomia limitada das baterias é um problema em aberto não só neste projeto, mas em muitos dispositivos eletrônicos móveis utilizados na atualidade.

A transmissão das leituras ao vMonGluco Server através da rede sem fio ocorreu sem problemas. Foram realizados alguns testes informais tanto no Serviço de Informática quanto na Unidade de Terapia Intensiva Coronariana (UCO) do Instituto do Coração. Em ambos os 
casos, a transmissão das leituras foi bem sucedida. Devido às limitações apresentadas ao longo desta seção, a mobilidade, principal razão do uso de rede sem fio (seção 4.3), foi prejudicada. De qualquer forma, o uso da rede sem fio permite uma instalação mais rápida do sistema em um quarto de UTI, pois não depende da existência de uma rede cabeada de comunicação. Além disso, é possível a movimentação rápida do paciente para outros quartos ou para outras áreas do hospital (como para a realização de exames) com relativa facilidade.

\subsubsection{A Implementação do Software}

$\mathrm{Na}$ primeira etapa do projeto, foi implementado o vMonGluco Client (seção 4.5), software que faz o download dos dados gerados pelo MiniMed CGMS, calcula valores de glicemia em tempo real e transmite as leituras para um monitor de beira de leito. O programa foi implementado em Visual Basic, utilizando-se a ferramenta Microsoft eMbedded Visual Tools 3.0. A ferramenta escolhida mostrou-se adequada, de implementação rápida, fácil e com resultados bastante satisfatórios. A interface gráfica obtida (seção 4.5.2) é simples, atendendo aos requisitos de usabilidade propostos no início do projeto (seção 4.3).

A implementação do vMonGluco Server também foi bastante satisfatória. O uso da linguagem Java permite a instalação do sistema em diversas plataformas. O padrão $J D B C$ de acesso ao banco de dados permite a rápida integração do sistema, não só ao $S I 3$, mas a outros possíveis sistemas hospitalares. A adoção da norma $H L 7$ de comunicação permitiu uma integração bem sucedida ao sistema de monitores de beira de leito. A norma $H L 7$ possui algumas limitações, como as diversas variações na sua forma de implementação (seção 3.4), o que, entretanto, não invalida os resultados aqui obtidos.

A interface web desenvolvida (vMonGluco Web) é bastante simples e de fácil utilização, o que está de acordo com os critérios estabelecidos para o desenvolvimento. A funcionalidade do sistema é limitada, mas bastante satisfatória dentro do que foi proposto para o projeto. 
O vMonGluco possui uma interface bastante simples, o que facilitou o desenvolvimento do sistema. Algumas funcionalidades importantes foram propositadamente excluídas da implementação realizada. Em especial, vale notar que houve uma preocupação limitada quanto à segurança dos dados transmitidos. A transmissão das leituras de glicemia pela rede sem fio utiliza os procedimentos padrões de criptografia do protocolo WiFi (IEEE $80211 b$ ). Já na transmissão de dados pela rede cabeada, não foi usado nenhum recurso de criptografia, o que permitiu a redução do escopo do projeto. Esse processo de criptografia poderia ser implementado com relativa facilidade na transmissão entre o vMonGluco Client e o vMonGluco Server. Entretanto, o mesmo não ocorreria na transmissão de dados para os monitores de beira de leito, já que o recurso de criptografia não é disponível no Siemens Infinity Gateway, software que administra a comunicação com os monitores. Com isso, algumas questões relativas à segurança e confidencialidade dos dados poderiam exigir uma implementação mais complexa.

A autenticidade dos dados coletados é outro requisito importante. Da maneira como foi implementado, o uso do sistema é liberado a qualquer pessoa. Um sistema de autenticação de usuário (através, por exemplo, de um login e uma senha) é sugerido na literatura (KOST, 2001), mas implica em uma redução na praticidade do sistema, em especial, no vMonGluco Client. É importante também garantir a autenticidade dos dados transmitidos. Por exemplo, seria bastante fácil a transmissão de falsos dados de glicemia a um monitor de beira de leito, já que não existe nenhum serviço de autenticação durante a conexão ao vMonGluco Server e ao Siemens Infinity Gateway. Mais uma vez, as limitações do gateway dificultariam a obtenção de uma solução satisfatória. Cabe salientar novamente que as questões de segurança dos dados não foram plenamente abordadas neste trabalho para simplificação do escopo do projeto. 
A aderência a normas de comunicação é um requisito importante deste projeto (seção 4.3). Contudo, a escolha das normas também deve ser condizente com o hardware e software utilizados. O MiniMed CGMS utiliza um protocolo proprietário, impedindo, assim, a aderência do sistema à norma NCCLS POCT1-A de sistemas de point-of-care testing (POCT). De qualquer forma, as demais partes do sistema implementam o protocolo $H L 7$, o que facilita bastante a sua integração a outros sistemas.

Vale lembrar ainda que, apesar da norma $H L 7$ ser o protocolo de comunicação mais utilizado em aplicações de informática médica, este protocolo é demasiadamente flexível, o que pode causar incompatibilidade mesmo entre dois sistemas que implementem corretamente a norma (seção 3.4). Dessa forma, o sistema implementado deve ser utilizado com cautela em ambientes diferentes daquele para o qual foi originalmente projetado. Por exemplo, o sistema pode não funcionar corretamente, sem as devidas adaptações, com outras marcas de monitores de beira de leito.

É importante mencionar que as leituras de glicemia são exibidas nos monitores de beira de leito na forma de tabelas numéricas. Entretanto, seria muito mais adequado que a glicemia fosse exibida numa forma gráfica. A monitoração contínua de glicemia em tempo real é um recurso ainda pioneiro na Medicina. Por isso, os monitores de beira de leito não possuem, até o presente momento, capacidade para a exibição de leituras de glicemia. Esperase que surjam novos modelos de monitores incorporando tal recurso à medida que o monitoramento contínuo de glicemia seja adotado em maior escala.

\subsection{Testes em pacientes}

No Capítulo 5, foram descritos os testes realizados com o MiniMed CGMS em treze pacientes críticos hiperglicêmicos. O objetivo principal dos testes foi a validação das leituras em tempo real geradas pelo sistema vMonGluco. 
A partir dos dados coletados nos testes preliminares, foram obtidas leituras de glicemia através de dois métodos diferentes. O primeiro método é o utilizado pelo software do MiniMed CGMS (Algoritmo 2.1). O segundo método (Algoritmo 4.1) é utilizado pelo vMonGluco Client para a obtenção de leituras em tempo real. Os dois conjuntos de leituras foram comparados através das várias metodologias encontradas na literatura (seção 2.3). Foram feitas diversas variações no algoritmo em tempo real (seção 5.2.1) de forma a otimizar os resultados obtidos (seção 5.3 e Apêndice D).

Antes de tudo, é importante levantar algumas restrições em relação à metodologia adotada. Um dos objetivos dos testes é avaliar o grau de exatidão das leituras em tempo real, obtidas através do sistema vMonGluco. Para tanto, as leituras em tempo real foram comparadas às leituras obtidas pelo software do MiniMed CGMS. Estas, portanto, foram adotadas como referência ("gold-standard") nesta avaliação. Tal escolha pode ser justificada pela boa exatidão e reprodutibilidade do MiniMed CGMS, conforme é reportado pela literatura (seção 2.6.3).

Entretanto, devemos considerar também os outros tipos de exame existentes atualmente, em especial, o exame laboratorial e o exame de "ponta de dedo". Através do exame laboratorial, pode-se realizar apenas um número muito reduzido de leituras de glicemia, insuficiente para uma comparação estatística com as leituras em tempo real. Já o exame de "ponta de dedo" pode ser realizado a intervalos de tempo menores, comparáveis aos dos sistemas de monitoramento contínuo. Por isso, para a avaliação de monitores contínuos, o exame de "ponta de dedo" é comumente adotado como "gold-standard" na literatura. Entretanto, as leituras assim obtidas possuem desvios da mesma ordem de grandeza dos apresentados pelo MiniMed CGMS. Além disso, a quantidade de leituras de "ponta de dedo" coletadas neste trabalho é comparativamente reduzida. 
Assim, as leituras tradicionais do MiniMed CGMS foram escolhidas como referências na avaliação do algoritmo em tempo real. Em alguns momentos, utilizou-se também o critério das "pontas de dedo", para facilitar a comparação deste trabalho com outros semelhantes encontrados na literatura. Essa comparação, entretanto, deve ser vista com cautela pelos motivos citados anteriormente.

Durante a realização dos testes, ocorreram falhas em alguns dos sensores utilizados. Os sensores apresentaram desvios erráticos na corrente gerada, levando a interrupções na geração de leituras de glicemia. Tais sensores foram substituídos para que o prosseguimento dos testes.

O processo de otimização do algoritmo em tempo real mostra que os parâmetros ótimos são muito próximos dos valores utilizados pelo software do MiniMed CGMS. Esse resultado está de acordo com o esperado, especialmente se considerarmos que o critério de avaliação era a proximidade dos resultados dos dois algoritmos (quanto mais semelhantes forem os algoritmos, mais semelhantes serão os seus resultados).

A otimização mostra também que os algoritmos alternativos experimentados (algoritmo ponderado linear, algoritmo ponderado normal e algoritmo quadrático) obtiveram resultados equivalentes ou inferiores ao algoritmo em tempo real original. Assim, pode-se inferir que as hipóteses sugeridas na seção 5.2.1 (Variações do algoritmo em tempo real) não são verdadeiras ou relevantes. Apenas para relembrar, as hipóteses sugeridas foram:

- pontos de calibração antigos fornecem informações menos confiáveis a respeito da resposta do sensor;

- a resposta do sensor (corrente elétrica gerada x glicemia) não é linear.

A comparação numérica entre o algoritmo em tempo real e o software do MiniMed CGMS (Tabela 5.9) gerou bons resultados. A diferença média de $-0,4 \%$ (desvio padrão de 
$16,1 \%$ ), a diferença média absoluta de $10,2 \%$ e o coeficiente de correlação igual a 0,922 sugerem uma boa coesão entre as leituras obtidas através dos dois métodos.

Quando as "pontas de dedo" são utilizadas como critério de avaliação, ainda se obtém bons resultados. $\mathrm{O}$ algoritmo em tempo real obteve resultados inferiores, mas ainda satisfatórios (diferença absoluta de 21,5\% com desvio padrão de 34,8\%, coeficiente de correlação igual a 0,764, ver Tabela 5.10), quando comparado ao software do MiniMed CGMS (diferença absoluta de 16,7\% com desvio padrão de 31,0\%, coeficiente de correlação igual a 0,868 , ver Tabela 5.11). Os resultados obtidos pelo software do MiniMed CGMS são compatíveis com os encontrados na literatura (seção 2.6.3) e, portanto, são uma referência válida.

O gráfico de Clarke das leituras em tempo real (Figura 5.3) mostra um resultado inferior ao das leituras do software do MiniMed CGMS (Figura 5.4). Observa-se que, para o algoritmo em tempo real, houve um maior espalhamento das leituras $(61,5 \%$ das leituras na zona A, contra 76,5\% das leituras do software do MiniMed CGMS). Mesmo assim, pode-se afirmar que os resultados do algoritmo em tempo real ainda são clinicamente satisfatórios (94,6\% das leituras nas zonas A e B).

Como última observação, deve-se atentar ao fato de que tanto as medições feitas através do MiniMed CGMS quanto as medições de "ponta de dedo" são coletada a partir da circulação periférica. Conforme foi citado na seção 2.7.1, há várias situações clínicas em que a circulação periférica deixa de refletir o real estado fisiológico do paciente. Algumas dessas situações, como choque séptico, desidratação e insuficiência cardíaca, foram apresentadas pelos pacientes selecionados e, por isso, os resultados aqui obtidos devem ser avaliados com cautela. Através da metodologia adotada, não é possível inferir a influência do quadro clínico dos pacientes nos resultados apresentados. 


\section{Capítulo 7. CONCLUSÕES}

\subsection{Resumo}

Neste capítulo, são apresentadas as conclusões a respeito dos resultados do trabalho, além da proposição de trabalhos futuros.

\subsection{Conclusões}

No Capítulo 6, foram analisados os resultados atingidos pelo projeto vMonGluco. No geral, podemos dizer que os resultados foram bastante satisfatórios, mesmo considerando as várias limitações e dificuldades encontradas.

A montagem física do sistema, embora não represente uma solução definitiva, demonstra a viabilidade construtiva do projeto. Alguns dos problemas apresentados, como o uso excessivo de cabos entre os componentes, podem ser resolvidos através do desenvolvimento de novo hardware, o que foge do escopo deste trabalho. Outras limitações, como a autonomia das baterias em dispositivos portáteis, são características de sistemas móveis em geral e ainda não possuem uma solução satisfatória. Dessa maneira, podemos concluir que a instalação física do vMonGluco evidencia algumas possibilidades e também algumas limitações do uso da computação móvel em sistemas médicos. De qualquer forma, considerando-se que o projeto é uma "prova de conceito", pode-se dizer que os resultados atingidos são bastante significativos.

A implementação dos softwares foi bastante simplificada para limitar escopo do projeto. Apesar de terem sido tomados alguns cuidados básicos quanto à segurança das informações (incluindo criptografia dos dados transmitidos), a solução proposta não é completa neste sentido. Há também limitações intrínsecas à norma $H L 7$, especialmente no que 
tange à sua excessiva flexibilidade. A exibição das leituras nos monitores de beira de leito também foi prejudicada devido a limitações existentes nos mesmos. Mesmo assim, o sistema vMonGluco demonstra as possibilidades da integração de um medidor de glicose a monitores de beira de leito, ao Prontuário Eletrônico do Paciente e a outros sistemas de manipulação de informações médicas. Dessa maneira, a versão implementada do vMonGluco cumpre, com sucesso, alguns dos principais objetivos traçados para este projeto.

Os resultados obtidos nos testes com pacientes sugerem uma boa correlação entre as leituras obtidas a partir do software do MiniMed CGMS e as leituras obtidas em tempo real pelo sistema vMonGluco. Quando as "pontas de dedo" são utilizadas como referência, as leituras do sistema vMonGluco mostram-se ligeiramente inferiores ao software do MiniMed $C G M S$. Ainda assim, os resultados são satisfatórios, o que indica que, do ponto de vista da validade das leituras, o sistema vMonGluco cumpre, com algumas restrições, seus objetivos.

Com a conclusão do projeto vMonGluco, esperou-se demonstrar novas possibilidades no tratamento dos pacientes críticos hiperglicêmicos proporcionadas pelo desenvolvimento da tecnologia. O monitoramento contínuo da glicemia permitirá um aprimoramento significativo no atendimento médico a esses pacientes. A obtenção de leituras em tempo real permite respostas mais rápidas da equipe médica a eventos como hipo ou hiperglicemia, altamente prejudiciais e muito comuns nesse tipo de paciente. A integração do monitoramento de glicemia a um sistema de informações médicas permite a rápida transmissão e divulgação das informações à equipe médica. Tal integração fornece, ainda, um registro preciso das condições clínicas do paciente ao longo de sua internação, fornecendo, assim, uma importante fonte de informações para um diagnóstico mais preciso e completo. Dessa forma, com a conclusão do projeto vMonGluco, espera-se trazer uma contribuição prática e significativa no tratamento dos pacientes críticos hiperglicêmicos. 


\subsection{Trabalhos futuros}

Os sistemas de monitoramento de glicemia e a integração de sistemas médicos são dois campos de pesquisa bastante férteis, o que nos permite divisar muitas extensões do presente trabalho.

Conforme foi discutido anteriormente, a busca de uma solução prática mais definitiva depende do desenvolvimento de um novo hardware, com a integração dos vários dispositivos portáteis em uma única peça. A eliminação de cabos é importante para aprimorar a praticidade do sistema. Isso implica no uso mais acentuado de comunicação sem fio, além do aprimoramento das baterias nos dispositivos móveis.

Os softwares implementados não contemplam questões importantes, como o sigilo e a autenticidade das informações dos pacientes. Novas funcionalidades podem ser implementadas, como a ativação de alarmes para eventos de hiperglicemia. Novos monitores de beira de leito devem ser desenvolvidos para que as informações de glicemia possam ser exibidas de maneira apropriada. A transmissão de informações médicas através de $H L 7$ e outras normas de comunicação pode ser explorada de outras formas. Por exemplo, através da integração de novos dispositivos de medição ao sistema de informações médicas, ou através da interligação de diferentes bases de dados médicos.

Um número maior de testes com pacientes pode fornecer resultados mais conclusivos a respeito da validade das leituras de glicemia. A influência do quadro clínico dos pacientes, como a circulação periférica insuficiente nos pacientes críticas, também merece estudo. Os critérios de avaliação dos medidores de glicemia ainda não estão bem definidos, e também podem ser reavaliados. Novos algoritmos de calibração podem ser desenvolvidos, de modo a obter os melhores resultados possíveis com a mesma tecnologia de sensores de glicemia. Mais ainda, o desenvolvimento de novos sensores é um ponto chave no desenvolvimento dos sistemas de monitoramento de glicemia. 


\section{REFERÊNCIAS ${ }^{1}$}

AUSSEDAT, B.; DUPIRE-ANGLE, M; GIFFORD, R.; KLEIN, J. C.; WILSON, G. S.; $\mathrm{REACH}, \mathrm{G}$. Interstitial glucose concentration and glycemia: implications for continuous subcutaneous glucose monitoring. American Journal of Physiology-Endocrinology and Metabolism, USA, v. 278, n. 4, p. E716-E728, abr. 2000.

BAILEY, T. M.; TOPHAM, T. M.; WANTZ, S.; GRANT, M.; COX, C.; JONES, D.; ZERBE, T.; SPEARS, T. Laboratory Process Improvement Through Point-of-Care Testing. The Joint Commission on Accreditation on Healthcare Organizations - Journal on Quality Improvement, USA, v. 23, n. 7, jul. 1997.

BISSELL, M.; SANFILIPPO, F. Empowering patients with point-of-care testing. Trends in Biotechnology, UK, v. 20, n. 6, p. 269-270, jun. 2002.

BLAND, J. M.; ALTMAN, D. G. Statistical methods for assessing agreement between two methods of clinical measurement. The Lancet, UK, p. 307-310, 8 fev. 1986.

BODE, B. W.; GROSS, T. M.; THORNTON, K. R.; MASTROTOTARO, J. J. Continuous glucose monitoring used to adjust diabetes therapy improves glycosylated hemoglobin: a pilot study. Diabetes Research and Clinical Practice, Ireland, v. 46, n. 3, p. 183-190, dez. 1999.

BÖHME, P.; FLORIOT, M.; SIRVEAUX, M. A.; DURAIN, D.; ZIEGLER, O.; DROUIN, P.; GUERCI, B. Evolution of Analytical Performance in Portable Glucose Meters in the Last Decade. Diabetes Care, USA, v. 26, n. 4, p. 1170-5, abr. 2003.

BOLAND, E.; MONSOD, T; DELUCIA, M; BRANDT, C. A, FERNANDO, S.; TAMBORLANE, W. V. Limitations of Conventional Methods of Self-Monitoring of Blood Glucose: Lessons learned from 3 days of continuous glucose sensing in pediatric patients with type 1 diabetes. Diabetes Care, USA, v. 24, n. 11, p. 1858-1862, nov. 2001.

BOYNE, M. S.; SILVER, D. M.; KAPLAN, J.; SAUDEK, C. D. Timing of Changes in Interstitial and Venous Blood Glucose Measured with a Continuous Subcutaneous Glucose Sensor. Diabetes, USA, v. 52, n. 11, p. 2790-2794, nov. 2003.

CGMS SYSTEM GOLD: Continuous Glucose Monitoring System Overview. Medtronic Minimed, 2005. Disponível em <http://www.minimed.com/products/cgms $>$. Acesso em 06 jan. 2007.

CHASE, H. P.; KIM, L. M; OWEN, S. L.; MACKENZIE, T. A.; KLINGENSMITH, G. J.; MURTFELDT, R.; GARG, S. K. Continuous Subcutaneous Glucose Monitoring in Children With Type 1 Diabetes. Pediatrics, USA, v. 107, n. 2, p. 222-226, fev. 2001.

\footnotetext{
${ }^{1}$ De acordo com:

ASSOCIAÇÃO BRASILEIRA DE NORMAS TÉCNICAS. NBR 6023: informação e documentação: referências: elaboração. Rio de Janeiro, 2002.
} 
CHASE, J. G.; SHAW, G. M.; WONG, X. W.; LOTX, T.; LIN, J.; HANN, C. E. Modelbased glycaemic control in critical care - A review of the state of the possible. Biomedical Signal Processing and Control, v. 1, n. 1, p. 3-26, jan. 2006.

CHEE, F.; FERNANDO, T.; VAN HEERDEN, P. V. Closed-Loop Glucose Control in Critically Ill Patients Using Continuous Glucose Monitoring System (CGMS) in Real Time. IEEE Transactions on Information Technology in Biomedicine, USA, v. 7, n. 1, p. 43-53, mar. 2003.

CLARKE, W. L.; COX, D.; GONDER-FREDERICK, L. A.; CARTER, W.; POHL, S. L. Evaluating Clinical Accuracy of Systems for Self-Monitoring of Blood Glucose. Diabetes Care, USA, v. 10, n. 5, p. 622-628, set.-out. 1987.

CONNECTIVITY INDUSTRY CONSORTIUM. The Universal Connectivity Standard for Point-of-Care - Draft Technical Specifications. 8 jan. 2001. Disponível em <http://www.poccic.org/pdfs/cic_drafts_1_8_01.pdf>. Acesso em 03 dez. 2004.

DIABETES CONTROL AND COMPLICATIONS TRIAL Research Group, The. The Effect of Intensive Treatment of Diabetes on the Development and Progression of Long-Term Complications in Insulin-Dependent Diabetes Mellitus. The New England Journal of Medicine, USA, v. 329, n. 14, p. 977-986, 30 set. 1993.

DIABETES MALL - Diabetes Technology - Future Monitoring. Diabetes Services, 2005. Disponível em <http://www.diabetesnet.com/diabetes_technology/new_monitoring.php $>$. Acesso em 23 jun. 2005.

FERMANN, G. J.; SUYAMA, J. Point of Care Testing in the Emergency Department. The Journal of Emergency Medicine, USA, v. 22, n. 4, p. 393-404, mai. 2002.

FOOD AND DRUG ADMINISTRATION. Review Criteria Assessment of Portable Blood Glucose Monitoring In Vitro Diagnostic Devices Using Glucose Oxidase, Dehydrogenase or Hexokinase Methodology - Draft Document. USA, fev. 1997. Disponível em $<$ http://www.fda.gov/cdrh/ode/gluc.html $>$. Acesso em 23 jun. 2005.

FOOD AND DRUG ADMINISTRATION. MiniMed Continuous Glucose Monitoring System (CGMS) - Summary of Safety and Effectiveness Data. USA, 1999. Disponível em $<$ http://www.fda.gov/cdrh/pdf/p980022b.pdf > . Acesso em 07 mar. 2005.

FOOD AND DRUG ADMINISTRATION. GlucoWatch G2 Biographer - Approval Order. USA, 26 aug. 2002. Disponível em <http://www.fda.gov/cdrh/pdf/P990026S008a.pdf>. Acesso em 07 mar. 2005.

FURNARY, A. P.; ZERR, K. J.; GRUNKEMEIER, G. L.; STARR, A. Continuous Intravenous Insulin Infusion Reduces the Incidence of Deep Sternal Wound Infection in Diabetic Patients After Cardiac Surgical Procedures. Annals of Thoracic Surgery, USA, v. 67, n. 2, p. 352-362, fev. 1999.

GLUCODAY S - The Brand New Story. A. Menarini Diagnostics, 2007. Disponivel em $<$ http://www.menarini.com/english/diagnostica/glucoday_00a.htm>. Acesso em 06 jan. 2006.

GLUCOWATCH. Animas Technologies, 2005. Disponível em $<$ http://www.glucowatch.com>. Acesso em 06 jan. 2006. 
GOLDBERG, P. A.; SIEGEL, M. D.; RUSSEL, R. R.; SHERWIN, R. S.; HALICKMAN, J, I.; COOPER, D. A.; DZIURA, J. D.; INZUCCHI, S. E. Experience with the Continuous Glucose Monitoring System in a Medical Intensive Care Unit. Diabetes Technology and Therapeutics, USA, v. 6, n. 3, p. 339-347, 2004.

GOUGH, D. A.; BOTVINICK, E. L. Reservations on the Use of Error Grid Analysis for the Validation of Blood Glucose Assays. Diabetes Care, USA, v. 20. n. 6, p. 1034-1036, jun. 1997.

GROSS, T. M.; BODE, B. W.; EINHORN, D.; KAYNE, D. M.; REED, J. H.; WHITE, N. H.; MASTROTOTARO, J. J. Performance evaluation of the MiniMed continuous glucose monitoring system during patient home use. Diabetes Technology and Therapeutics, USA, v. 2, n. 1, p. 49-56, mai. 2000.

GUTIERRES, S. L.; WELTY, T. E. Point-of-Care Testing: An Introduction. The Annals of Pharmacotherapy, USA, v. 38, p. 119-25, jan. 2004.

HDD SOFTWARE. Free Serial Port Monitor. USA, 2004. Disponível em http://www.serialport-monitor.com/index.html. Acesso em 06 jul. 2005.

HEALTH LEVEL SEVEN. Health Level Seven Implementation Support Guide for HL7 Standard Version 2.3. USA, 1998a. Disponível em $<$ http://www.hl7.org/Special/IG/final.pdf $>$. Acesso em 25 nov. 2004.

HEALTH LEVEL SEVEN. HL7 Version 3 Statement of Principles. USA, jan. 1998b. Disponível em <http://www.hl7.org/Library/data-model/SOP_980123_final.zip $>$. Acesso em 25 nov. 2004.

HEALTH LEVEL SEVEN. HL7 Standard Version 2.3.1 - Draft Version. USA, 1999. Disponível em <http://www.h17.org/Library/General/v231.zip>. Acesso em 04 out. 2004.

HEALTH LEVEL SEVEN. HL7 Standard Version 2.5 - Draft Version 2.5 Membership Level 2 Ballot Chapters. USA, 2003. Disponível em $<$ http://www.hl7.org/memonly/v25/membership2/index.cfm>. Acesso em 04 out. 2004.

HEALTH LEVEL SEVEN. Health Level Seven, 2007. Disponível em <http://www.hl7.org >. Acesso em 06 jan. 2006.

JAREMKO, J.; RORSTAD, O. Advances Toward the Implantable Artificial Pancreas for Treatment of Diabetes. Diabetes Care, USA, v. 21, n. 3, p. 444-459, mar. 1998.

JAVA SE - Java Database Connectivity (JDBC). Sun Microsystems, 2006. Disponível em $<$ http://java.sun.com/javase/technologies/database.jsp>. Acesso em 28 jul. 2006.

JAVA SERVLET TECHNOLOGY. Sun Microsystems, 2006. Disponível em $<$ http://java.sun.com/products/servlet>. Acesso em 28 jul. 2006.

JAVASERVER PAGES TECHNOLOGY. Sun Microsystems, 2006. Disponível em $<$ http://java.sun.com/products/jsp $>$. Acesso em 28 jul. 2006. 
JEONG, R.; HWANG, J. Y.; JOO, S.; CHUNG, T. D.; PARK, S.; KANG, S. et al. In vivo calibration of the subcutaneous amperometric glucose sensors using a non-enzyme electrode. Biosensors and Bioeletronics, UK, v. 19, n. 4, p. 313-319, dez. 2003.

JFREECHART. Object Refinery Limited, 2006. Disponível em $<$ http://www.jfree.org/jfreechart>. Acesso em 28 jul. 2006.

KNAFEL, A. J. Point-of-Care Connectivity - Overview of the CIC/NCCLS/IEE/HL7 Standard. Germany : HL7-Benutzergruppe in Deutschland e.V., 2001. Apresentação de slides em arquivo eletrônico PDF. Disponível em $<$ http://www.hl7.de/veranstaltungen/jahrestagung/jt2001/knafel.pdf $>$. Acesso em 19 jul. 2004.

KNAUS, W. A; DRAPER, E. A.; WAGNER, D. P.; ZIMMERMAN, J. E. APACHE II: A severity of disease classification system. Critical Care Medicine, USA, v. 13, n. 10, p. 818$829,1985$.

KOST, G. J. Preventing Medical Errors in Point-of-Care Testing - Security, Validation, Performance, Safeguards, and Connectivity. Archives of Pathology and Laboratory Medicine, USA, v. 125, p. 1307-1315, out. 2001.

KULCU, E.; TAMADA, J. A.; REACH, G.; POTTS, R. O.; LESHO, M. J. L. Physiological Differences Between Interstitial Glucose and Blood Glucose Measured in Human Subjects. Diabetes Care, USA, v. 26, n. 8, p. 2405-2409, ago. 2003.

MALMBERG, K. Prospective randomized study of intensive insulin treatment on long term survival after myocardial infarction in patients with diabetes mellitus. British Medical Journal, UK, v. 314, p. 1512, 24 mai.1997.

MASTROTOTARO, J. J.; GROSS, T. M. Reproducibility of the Continuous Glucose Monitoring System Matches Previous Reports and the Intended Use of the Product (letter). Diabetes Care, USA, v. 26, n. 1, p. 256, jan. 2003.

MCGOWAN, K.; THOMAS, W.; MORAN, A.. Spurious Reporting of Nocturnal Hypoglycemia by CGMS in Patients with Tightly Controlled Type 1 Diabetes. Diabetes Care, USA, v. 25, n. 9, p. 1499-1503, set. 2002.

MEDTRONIC EUROPE SÀRL. Guardian RT - Continuous glucose monitoring system with real-time display and alarms. Switzerland, 2004. Disponível em $<$ http://www.medtronic.com/UK/downloadablefiles/guardian_rt.pdf $>$. Acesso em 22 jun. 2005.

MEDTRONIC MINIMED. Medtronic MiniMed CGMS System Gold - MMT-7102W User Guide. USA, 2003.

MEDTRONIC MINIMED. The Medtronic MiniMed CGMS System Solutions Software Instructions for Use - MMT-7310 - Version 3.0C. USA, 2004.

METZGER, M.; LEIBOWITZ, G.; WAINSTEIN, J.; GLASER, B.; RAZ, I. Reproducibility of Glucose Measurements Using the Glucose Sensor. Diabetes Care, USA, v. 25, n. 7, p. 1185-1191, jul. 2002. 
METZGER, M.; LEIBOWITZ, G.; WAINSTEIN, J.; GLASER, B.; RAZ, I. Response to Mastrototaro and Gross (letter). Diabetes Care, USA, v. 26, n. 1, p. 256-257, jan. 2003.

MICROSOFT CORPORATION. eMbedded Visual Tools 3.0 - 2002 Edition. USA, 2005. Disponível em <http://www.microsoft.com/downloads/details.aspx?FamilyID=F663BF4831EE-4CBE-AAC5-0AFFD5FB27DD\&displaylang=em>. Acesso em 06 jul. 2005.

MONSOD, T. P.; FLANAGAN, D. E.; RIFE, F.; SAENZ, R.; CAPRIO, S.; SHERWIN, R. S.; TAMBORLANE, W. V. Do sensor glucose levels accurately predict glucose concentrations during hypoglycemia and hyperinsulinemia? Diabetes Care, USA, v. 25, n. 5, p.889-893, mai. 2002.

OLIVEIRA, P. P.; REBELO, M.; PILON, P. E.; GUTIERREZ, M. A.; TACHINARDI, U. vMon-mobile provides wireless connection to the electronic patient record. In: SPIE MEDICAL IMAGING 2002, San Diego. Proceedings of SPIE, USA, v. 4685, p. 438-445, mai. 2002.

ORCHESTRAL DEVELOPMENTS. Symphonia Universal Messaging. USA, 2004. Disponível em <http://support.symphonia3.com>. Acesso em 18 jul. 2005.

PHILIPS MEDICAL SYSTEMS. Intellivue Information Center - HL7 Parameter Data Interface Programmer's Guide. USA, ago. 2003.

PICKUP, J.; MCCARTNEY, L.; ROLLINSKY, O.; BIRCH, D. In vivo glucose sensing for diabetes management: progress towards non-invasive monitoring. British Medical Journal, UK, vol. 319, n. 7220, p. 1-4, nov. 1999.

PITZER, K. R.; DESAI, S.; DUNN, T.; EDELMAN, S.; JAYALAKSHIMI, Y; KENNEDY, J et al. Detection of Hypoglycemia With the GlucoWatch Biographer. Diabetes Care, USA, v. 24, n. 5, p. 881-885, mai. 2001.

POINTOFCARE.NET - Definitions and Glossary of Terms, 2004. Disponível em $<$ http://www.pointofcare.net/definitions.htm $>$. Acesso em 22 jun. 2005.

POIRIER, J. Y.; PRIEUR, N. L.; CAMPION, L.; GUILHEM, I.; ALLANNIC, H.; MAUGENDRE, D. Clinical and Statistical Evaluation of Self-Monitoring Blood Glucose Meters. Diabetes Care, USA, v. 21, n. 11, p. 1919-24, nov. 1998.

REBRIN, K.; STEIL, G. M.; VAN ANTWERP, W. P.; MASTROTOTARO, J. J. Subcutaneous glucose predicts plasma glucose independent of insulin: implications for continuous monitoring. American Journal of Physiology - Endocrinology and Metabolism, USA, v. 277, n. 3, p. 561-571, set. 1999.

ROCHE DIAGNOSTICS. Accu-Chek Advantage II - Test Strips. Mannheim : Roche Diagnostics, 2004.

SIEMENS MEDICAL SOLUTIONS. Infinity Gateway Suite - Developer's Handbook Infinity Gateway Server Release VF1.1. USA, 2001.

SKEIE, S.; THUE, G.; NERHUS, K.; SANDBERG, S. Instruments for Self-Monitoring of Blood Glucose: Comparisons of Testing Quality Achieved by Patients and a Technician. Clinical Chemistry, USA, v. 48, n. 7, p. 994-1003, 2002. 
SOCIEDADE BRASILEIRA DE DIABETES. Simpósio de Atualização SBD - Novas Tecnologias no Tratamento. Reportagens Online, n. 9, 2005. Disponível em $<$ http://www.diabetes.org.br/reportagens_online/reponline.php?ed=9>. Acesso em 20 set. 2005.

STEIL, G. M.; PANTELEON, A. E; REBRIN, K. Closed-loop insulin delivery - the path to physiological glucose control. Advanced Drug Delivery Reviews, Netherlands, v. 56, n. 2, p. 125-144, 10 fev. 2004.

UNIVERSIDADE DE SÃO PAULO - SISTEMA INTEGRADO DE BIBLIOTECAS GRUPO DITESES. Diretrizes para Apresentação de Dissertações e Teses da USP: documento eletrônico e impresso. São Paulo : Serviço de Bibliotecas da USP, 2004. 110 p. Disponível em <http://www.teses.usp.br/info/diretrizesfinal.pdf $>$. Acesso em 20 jul. 2005.

VAN DEN BERGHE, G.; WOUTERS, P. J.; BOUILLON, R.; WEEKERS, F.; VERWAEST, C.; SCHETZ, M. et al. Outcome benefit of intensive insulin therapy in the critically ill: Insulin dose versus glycemic control. Critical Care Medicine, USA, v. 31, n. 2, p. 359-366 2003.

VAN DEN BERGHE, G. How does blood glucose control with insulin save lives in intensive care? The Journal of Clinical Investigation, USA, v. 114, n. 9, p. 1187-1195, nov. 2004.

VAN DEN BERGHE, G.; WILMER, A.; HERMANS, G.; MEERSSEMAN, W.; WOUTERS, P. J.; MILANTS, E. et al. Intensive Insulin Therapy in the Medical ICU. The New England Journal of Medicine, USA, v. 354, n. 5, p. 449-461, 02 fev 2006.

WARD, W. K.; WOOD, M. D.; TROUPE, J. E. Rise in background current over time in a subcutaneous glucose sensor in the rabbit: relevance to calibration and accuracy. Biosensors and Bioelectronics, UK, v. 15, n. 1-2, p. 53-61, mar. 2000.

WILSON, G. S.; ZHANG, Y.; REACH, G.; MOATTI-SIRAT, D.; POLTOUT, V.; THÉVENOT, D. R.; LEMONNIER, F.; KLEIN, J. C. Progress toward the Development of an Implantable Sensor for Glucose. Clinical Chemistry, USA, v. 38, n. 9, p. 1613-17, 1992. 


\section{ProduÇão Bibliográfica}

A seguir, é apresentada a produção bibliográfica gerada pelo projeto.

\subsection{Trabalhos em Congresso Internacional}

GUTIERREZ, M. A.; MURAKAMI, A.; LAGE, S. H. G.. The development of a mobile network for continuous glucose monitoring of critical cardiac patients. Proceedings of the IEEE TridentCom 2007. Aceito.

MURAKAMI, A. GUTIERREZ, M. A.; LAGE, S. G.; REBELO, M. S.; GRANJA, L. A. R.; RAMIRES, J. A. F. Wireless Connection of Continuous Glucose Monitoring System to the Electronic Patient Record. Proceedings of SPIE, v. 6, p. 5748-65, 2005. ISSN 1605-7422.

MURAKAMI, A.; GUTIERREZ, M. A.; LAGE, S. H. G., REBElO, M. F. S., GUIRALDELLI, R. H. G.; RAMIRES, J. A. F. A Continuous Glucose Monitoring System in Critical Cardiac Patients at Intensive Care Unit. Computers in Cardiology 2006, v. 33, p. 233-236, 2006. ISSN 0276-6547.

\subsection{Trabalhos em Congresso Nacional}

MURAKAMI, A.; KOBAYASHI L. O. M.; TACHINARDI, U.; GUTIERREZ, M. A., FURUIE, S. S.; PIRES, F. A. Acesso a Informações Médicas através do Uso de Sistemas de Computação Móvel. Anais do IX Congresso Brasileiro de Informática em Saúde, 2004. Disponível em <http://www.hu.ufsc.br/IX_CIBS/trabalhos/arquivos/18.pdf $>$. Acesso em 28 set. 2005.

\subsection{Prêmios}

Finalista no Prêmio de Incentivo em Ciência e Tecnologia para o SUS - 2005 (categoria “Trabalho Científico Publicado"). Ministério da Saúde - Departamento de Ciência e Tecnologia, 2005.

\subsection{Seminários}

MURAKAMI, A. Um Sistema de Monitoramento de Glicose em Tempo Real. In: CICLO DE SEMINÁRIOS DO SERVIÇO DE INFORMÁTICA DO INSTITUTO DO CORAÇÃO, São Paulo, 08 jul. 2004.

MURAKAMI, A. vMonGluco - Sistema de Monitoramento Contínuo de Glicose. In: CICLO DE SEMINÁRIOS DO SERVIÇO DE INFORMÁTICA DO INSTITUTO DO CORAÇÃO, São Paulo, 09 jun. 2005. 
MURAKAMI, A. vMonGluco - Sistema de Monitoramento Contínuo de Glicose. In: CICLO DE SEMINÁRIOS DO SERVIÇO DE INFORMÁTICA DO INSTITUTO DO CORAÇÃO, São Paulo, 22 set. 2005.

MURAKAMI, A. vMonGluco - Sistema de Monitoramento Contínuo de Glicose. In: CICLO DE SEMINÁRIOS DO SERVIÇO DE INFORMÁTICA DO INSTITUTO DO CORAÇÃO, São Paulo, 13 abr. 2006.

MURAKAMI, A.; SABBATINI, A. Sensores de Glicose e Bombas de Insulina - em Busca do Pâncreas Artificial. Seminário apresentado para a disciplina "PCS-5712 - Computação Pervasiva" da Escola Politécnica da USP, São Paulo, 25 nov. 2004. 


\section{Apêndice A. Cabo Serial Null-Modem}

Para a transmissão serial entre o MiniMed CGMS e o palmtop, fez-se necessário o uso de um cabo serial do tipo null-modem de 9 pinos (duplo macho). Por não ser facilmente disponível no mercado, o item foi especialmente construído para uso no projeto. O presente apêndice traz uma breve descrição técnica do cabo serial.

A Figura A.1 mostra a numeração dos pinos de um conector serial (conector macho) e a Tabela A.1 mostra a função de cada pino. A Tabela A.2 mostra o esquema de ligação dos pinos em um cabo serial null-modem.

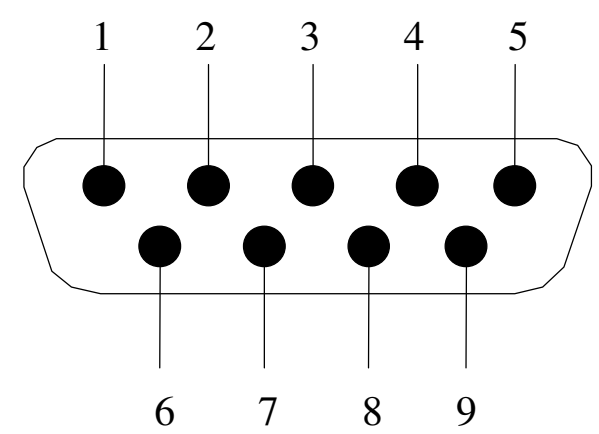

Figura A.1 - Numeração dos pinos de um conector serial (macho - 9 pinos).

Tabela A.1 - Função dos pinos de um conector serial (macho - 9 pinos).

\begin{tabular}{ll}
\hline Pino & Função \\
\hline 1 & received line signal detect (in) \\
2 & received data (in) \\
3 & transmitted data (out) \\
4 & DTE ready (out) \\
5 & signal ground \\
6 & DCE ready (in) \\
7 & Request to send (out) \\
8 & clear to send (in) \\
9 & ring indicator (in) \\
\hline
\end{tabular}


Tabela A.2 - Esquema de ligação de pinos no cabo serial null-modem de 9 pinos (duplo macho).

\begin{tabular}{cc}
\hline $\begin{array}{c}\text { Número do pino no } \\
\text { primeiro conector }\end{array}$ & $\begin{array}{c}\text { Número do pino no } \\
\text { segundo conector }\end{array}$ \\
\hline 1,6 & 4 \\
2 & 3 \\
3 & 2 \\
4 & 1,6 \\
5 & 5 \\
7 & 8 \\
8 & 7 \\
\hline
\end{tabular}

\section{Referências $^{1}$}

ARC ELETRONICS. RS232 Data Interface - a Tutorial on Data Interface and cables. Disponível em $<$ http://www.arcelect.com/rs232.htm>. Acesso em 02 ago. 2004.

STANGIO, C. E. The RS232 Standard - A Tutorial with Signal Names and Definitions. USA : CAMI Research, $1993 . \quad$ Disponível em $<$ http://www.camiresearch.com/Data_Com_Basics/RS232_standard.html>. Acesso em 02 ago. 2004.

\footnotetext{
${ }^{1}$ De acordo com: ASSOCIAÇÃO BRASILEIRA DE NORMAS TÉCNICAS. NBR 6023: informação e documentação: referências: elaboração. Rio de Janeiro, 2002.
} 


\section{Apêndice B. Coeficiente de CORRElaÇão}

O coeficiente de correlação é um valor que indica o grau de associabilidade entre duas variáveis quantitativas. Neste trabalho, foi utilizado o coeficiente de correlação linear, um valor que indica o quanto uma nuvem de pontos do gráfico de dispersão aproxima-se de uma reta.

A título de exemplo, suponhamos que se deseja verificar o grau de correlação entre corrente elétrica (gerada pelo sensor de glicose) e valor de glicemia (obtida através de uma medição de "ponta de dedo"). Neste caso, gostaríamos de saber se a corrente elétrica é diretamente proporcional à glicemia. Considere os valores fictícios apresentados na Figura B.1 e na Tabela B.1.

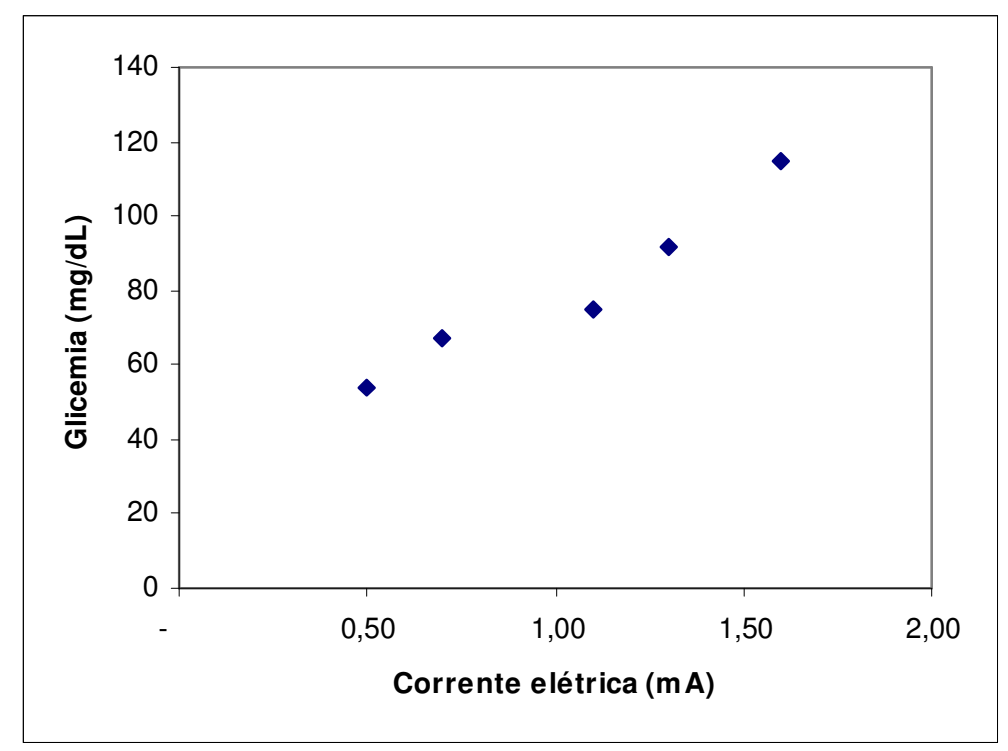

Figura B.1 - Gráfico de correlação. 
Tabela B.1 - Cálculo do coeficiente de correlação.

\begin{tabular}{cccccccc}
\hline & $\begin{array}{c}\text { Corrente elétrica } \\
(\mathrm{mA})\end{array}$ & $\begin{array}{c}\text { Glicemia } \\
(\mathrm{mg} / \mathrm{dL})\end{array}$ & $x-\bar{x}$ & $y-\bar{y}$ & $\frac{x-\bar{x}}{D P(X)}=z_{x}$ & $\frac{y-\bar{y}}{D P(Y)}=z_{y}$ & $z_{x} \cdot z_{y}$ \\
& $\mathrm{X}$ & $\mathrm{y}$ & & & & & \\
\hline & 0,50 & 54 & $-0,54$ & $-26,60$ & $-1,21$ & $-1,12$ & 1,36 \\
& 0,70 & 67 & $-0,34$ & $-13,60$ & $-0,76$ & $-0,58$ & 0,44 \\
& 1,10 & 75 & 0,06 & $-5,60$ & 0,13 & $-0,24$ & $-0,03$ \\
& 1,30 & 92 & 0,26 & 11,40 & 0,58 & 0,48 & 0,28 \\
& 1,60 & 115 & 0,56 & 34,40 & 1,26 & 1,45 & 1,83 \\
\hline Média & 1,04 & 81 & & & & & 0,78 \\
\hline Desvio & 0,44 & 24 & & & & & \\
padrão & & & & & & & \\
\hline
\end{tabular}

Para facilitar a análise da correlação, iremos centrar os pontos do gráfico ao redor do seu ponto médio $(\bar{x}, \bar{y})$. Assim, as coordenadas do novo gráfico são $(x-\bar{x}, y-\bar{y})$. A seguir, as escalas do gráfico são uniformizadas dividindo-se as coordenadas pelo desvio padrão (Figura B.2).

Finalmente, a partir da média dos produtos nas novas coordenadas, obtemos um valor que indica o grau de associabilidade linear entre as duas medidas. No caso, o valor obtido é 0,78 .

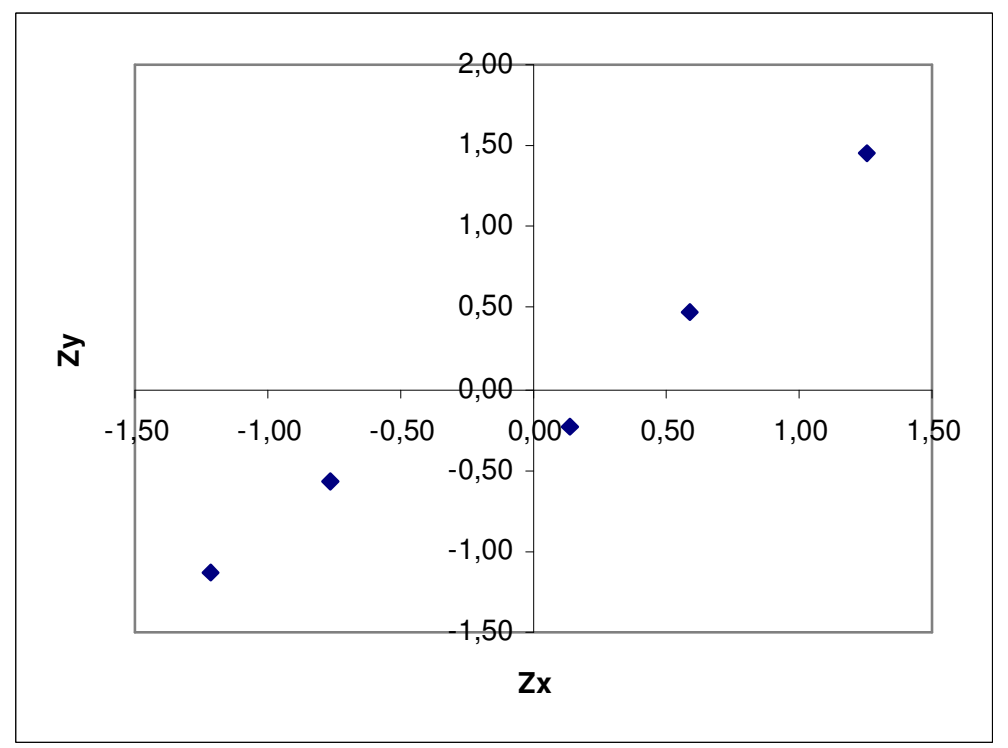

Figura B.2 - Gráfico de dispersão centrado no ponto médio e com escalas uniformes 
Assim, dados $n$ pares de valores $\left(\mathrm{x}_{1}, \mathrm{y}_{1}\right),\left(\mathrm{x}_{2}, \mathrm{y}_{2}\right), \ldots,\left(\mathrm{x}_{\mathrm{n}}, \mathrm{y}_{\mathrm{n}}\right)$, define-se o coeficiente de correlação $r$ entre as duas variáveis X e Y segundo a Equação B.1.

$$
r=\frac{1}{n} \sum_{i=1}^{n}\left(\frac{x_{i}-\bar{x}}{D P(X)}\right)\left(\frac{y_{i}-\bar{y}}{D P(Y)}\right)
$$

Pode-se demonstrar que o coeficiente de correlação varia entre -1 e 1 . Um valor negativo indica uma dependência linear inversa, enquanto que um valor positivo indica uma dependência linear direta. Quando o valor absoluto de $r$ for igual a 1, os pontos do gráfico de dispersão estarão sobre uma reta que passa pela origem. Um valor próximo de zero indica ausência de correlação linear entre as variáveis.

Como a Equação B.1 é de difícil utilização computacional, pode-se utilizar a Equação B.2 equivalente.

$$
r=\frac{\sum x_{i} y_{i}-\frac{\sum x_{i} \sum y_{i}}{n}}{\sqrt{\left(\sum x_{i}^{2}-\frac{\left(\sum x_{i}\right)^{2}}{n}\right)\left(\sum y_{i}^{2}-\frac{\left(\sum y_{i}\right)^{2}}{n}\right)}}
$$

\section{Referências $^{1}$}

BUSSAB, W. O.; MORETTIN, P. A. Estatística Básica. 4 ed. São Paulo : Atual, 1987.

\footnotetext{
${ }^{1}$ De acordo com: ASSOCIAÇÃO BRASILEIRA DE NORMAS TÉCNICAS. NBR 6023: informação e documentação: referências: elaboração. Rio de Janeiro, 2002.
} 


\section{Apêndice C. RegresSÃo LineAR - MÉTOdo doS MíNIMOS QUADRADOS}

Conforme foi discutido ao longo deste trabalho, sabe-se que a corrente elétrica $I$, produzida por um sensor de glicose, e o valor de glicemia $G$ presente no meio possuem uma relação aproximadamente linear. Assim, gostaríamos de obter uma estimativa $\hat{G}$ da glicemia a partir do valor da corrente elétrica. Isso poderia ser feito através da Equação C.1 (onde $S$ e $I_{0}$ são valores constantes).

$$
\hat{G}=S\left(I-I_{0}\right)
$$

Suponhamos, por exemplo, que, através de um procedimento de calibração, foram obtidos os valores mostrados na Tabela C.1.

Tabela C.1 - Valores de exemplo de corrente elétrica e glicemia.

\begin{tabular}{cc}
\hline Corrente elétrica $(\mathrm{mA})$ & Glicemia $(\mathrm{mg} / \mathrm{dL})$ \\
\hline 0,50 & 54 \\
0,70 & 67 \\
1,10 & 75 \\
1,30 & 92 \\
1,60 & 115 \\
\hline
\end{tabular}

Gostaríamos de obter valores de $S$ e $I_{0}$ de modo que a equação C.1 "represente" a Tabela C.1, isto é, ao tomarmos os valores de corrente elétrica $I$ mostrados na Tabela C.1 e aplicarmos à Equação C.1, gostaríamos de obter estimativas de glicemia $\hat{G}$ próximos aos valores $G$ mostrados na tabela. Em outras palavras, gostaríamos que o erro entre $\hat{G}$ e $G$ fosse mínimo. Para isso, é necessária uma definição formal de erro. A Equação C.2 mostra uma definição bastante utilizada (onde $n$ é o número de pontos de calibração). 


$$
\operatorname{erro}(\hat{G}, G)=\sum_{i=1}^{n}\left(G_{i}-\hat{G}_{i}\right)^{2}=\sum_{i=1}^{n}\left(G_{i}-S\left(I_{i}-I_{0}\right)\right)^{2}
$$

A função de erro é definida como a soma dos quadrados das diferenças entre a glicemia estimada e a glicemia medida. Deve-se encontrar o ponto onde o erro, definido pela Equação C.2, é mínimo. Por isso, o presente método é conhecido como “método dos mínimos quadrados". Sabe-se que o valor mínimo da função de erro ocorre em um ponto de derivada nula. Assim, derivando-se a função de erro em função de $S$ e $I_{0}$ e igualando-a a zero, obtém-se um sistema de equações representado pelas equações C.3 e C.4. Resolvendo-se o sistema, é possível obter valores de $S$ e $I_{0}$ de modo que a estimativa da glicemia $G$ seja a melhor possível.

$$
\begin{aligned}
& \frac{\partial e r r o}{\partial S}=\frac{\partial}{\partial S} \sum_{i=1}^{n}\left(G_{i}-S\left(I_{i}-I_{0}\right)\right)^{2}=0 \\
& \frac{\partial e r r o}{\partial I_{0}}=\frac{\partial}{\partial I_{0}} \sum_{i=1}^{n}\left(G_{i}-S\left(I_{i}-I_{0}\right)\right)^{2}=0
\end{aligned}
$$

Entretanto, para simplificar os cálculos, os algoritmos mostrados ao longo deste trabalho assumem uma estratégia diferente. No caso, o valor $I_{0}$ (chamado de offset) é previamente escolhido segundo um certo critério. Assim, a função de erro mostrada na Equação C.2 só precisa ser derivada em função de $S$. O valor de $S$ pode ser obtido através da Equação C.8.

$$
\begin{gathered}
\frac{d(\text { erro })}{d S}=\frac{d}{d S} \sum_{i=1}^{n}\left(G_{i}-S\left(I_{i}-I_{0}\right)\right)^{2}=0 \\
\sum_{i=1}^{n} 2\left(G_{i}-S\left(I_{i}-I_{0}\right)\right)\left(I_{i}-I_{0}\right)=0 \\
I_{0} \sum_{i=1}^{n} G_{i}-\sum_{i=1}^{n} G_{i} I_{i}+S \sum_{i=1}^{n} I_{i}^{2}-2 S I_{0} \sum_{i=1}^{n} I_{i}+n S I_{0}^{2}=0
\end{gathered}
$$




$$
S=\frac{\sum_{i=1}^{n} G_{i} I_{i}-I_{0} \sum_{i=1}^{n} G_{i}}{\sum_{i=1}^{n} I_{i}^{2}-2 I_{0} \sum_{i=1}^{n} I_{i}+n I_{0}^{2}}
$$

Aplicando-se os valores da Tabela C.1 e utilizando-se, neste exemplo, $\mathrm{I}_{0}=0$, obtémse, a partir da Equação C.8, o valor $S=74,2$. Assim, a partir da Equação C.1, pode-se calcular uma estimativa $\hat{G}$ para o valor de glicemia $G$ (Tabela C.2).

Tabela C.2 - Valores de glicemia medidos e estimados.

\begin{tabular}{ccc}
\hline Corrente elétrica $(\mathrm{mA})$ & Glicemia $(\mathrm{mg} / \mathrm{dL})$ & Glicemia estimada $(\mathrm{mg} / \mathrm{dL})$ \\
\hline 0,5 & 54 & 37 \\
0,7 & 67 & 52 \\
1,1 & 75 & 82 \\
1,3 & 92 & 96 \\
1,6 & 115 & 119 \\
\hline
\end{tabular}

\section{Regressão linear ponderada}

Uma variação do método anterior pode ser obtida quando se considera uma ponderação diferente para cada ponto de calibração. Neste caso, cada par de corrente elétrica $I_{i}$ e glicemia $G_{i}$ medidos recebe um valor de ponderação $w_{i}$ variando entre 0 e 1 . Esse valor de ponderação é utilizado no cálculo do erro, que passa a ser representado pela Equação C.9.

$$
\operatorname{erro}(\hat{G}, G)=\sum_{i=1}^{n} w_{i}\left(G_{i}-\hat{G}_{i}\right)^{2}=\sum_{i=1}^{n} w_{i}\left(G_{i}-S\left(I_{i}-I_{0}\right)\right)^{2}
$$

A Equação C.9 deve ser derivada em relação a $S$ e igualada a zero para que o valor mínimo do erro possa ser encontrado (Equação C.10). Resolvendo a equação assim obtida, pode-se obter o valor de $S$ que minimiza o erro (Equação C.12). Nota-se que, para o caso em que $w_{i}=1$ (para qualquer $i$ ), a Equação C.12 equivale à equação C.8.

$$
\begin{gathered}
\frac{d(\text { erro })}{d S}=\frac{d}{d S} \sum_{i=1}^{n} w_{i}\left(G_{i}-S\left(I_{i}-I_{0}\right)\right)^{2}=0 \\
\sum_{i=1}^{n} 2 w_{i}\left(G_{i}-S\left(I_{i}-I_{0}\right)\right)\left(I_{0}-I_{i}\right)=0
\end{gathered}
$$




$$
S=\frac{\sum_{i=1}^{n} w_{i} G_{i} I_{i}-I_{0} \sum_{i=1}^{n} w_{i} G_{i}}{\sum_{i=1}^{n} w_{i} I_{i}^{2}-2 I_{0} \sum_{i=1}^{n} w_{i} I_{i}+I_{0}^{2} \sum_{i=1}^{n} w_{i}}
$$

\section{Regressão quadrática}

No método original, aproximou-se o valor da glicemia por uma função linear (Equação C.1). Uma variação do método pode ser obtida se o valor da glicemia for estimado através de uma função não-linear como, por exemplo, uma equação quadrática (Equação C.13).

$$
\hat{G}=S_{1}\left(I-I_{0}\right)+S_{2}\left(I-I_{0}\right)^{2}
$$

Assim, o erro passa a ser estimado conforme a Equação C.14.

$$
\operatorname{erro}(\hat{G}, G)=\sum_{i=1}^{n}\left(G_{i}-\hat{G}_{i}\right)^{2}=\sum_{i=1}^{n}\left(G_{i}-S_{1}\left(I_{i}-I_{0}\right)-S_{2}\left(I_{i}-I_{0}\right)^{2}\right)^{2}
$$

Para efeitos de simplificação, consideremos o valor de $S_{2}$ previamente conhecido. Assim, para se obter o valor de $S_{1}$ que minimiza o erro, basta derivar a Equação C.14 em relação a $S_{l}$ conforme mostra a Equação C.15. O resultado é mostrado na Equação C.17.

$$
\begin{gathered}
\frac{d(\text { erro })}{d S_{1}}=\frac{d}{d S_{1}} \sum_{i=1}^{n}\left(G_{i}-S_{1}\left(I_{i}-I_{0}\right)-S_{2}\left(I-I_{0}\right)^{2}\right)^{2}=0 \\
\sum_{i=1}^{n} 2\left(G_{i}-S_{1}\left(I_{i}-I_{0}\right)-S_{2}\left(I-I_{0}\right)^{2}\right)\left(I_{i}-I_{0}\right)=0 \\
S_{1}=\frac{\sum_{i=1}^{n} G_{i} I_{i}-I_{0} \sum_{i=1}^{n} G_{i}-S_{2}\left(\sum_{i=1}^{n} I_{i}^{3}-3 I_{0} \sum_{i=1}^{n} I_{i}^{2}+3 I_{0}^{2} \sum_{i=1}^{n} I_{i}-n I_{0}^{3}\right)}{\sum_{i=1}^{n} I_{i}^{2}-2 I_{0} \sum_{i=1}^{n} I_{i}+n I_{0}^{2}}
\end{gathered}
$$

Nota-se que, quando $S_{2}=0$, a Equação C.17 torna-se idêntica ao resultado linear (Equação C.8). Além disso, de maneira equivalente ao caso linear, pode-se aplicar ponderações aos pontos de calibração. Assim, o valor de $S_{1}$ passa a ser calculado pela Equação C.18. 


$$
S_{1}=\frac{\sum_{i=1}^{n} w_{i} G_{i} I_{i}-I_{0} \sum_{i=1}^{n} w_{i} G_{i}-S_{2}\left(\sum_{i=1}^{n} w_{i} I_{i}^{3}-3 I_{0} \sum_{i=1}^{n} w_{i} I_{i}^{2}+3 I_{0}^{2} \sum_{i=1}^{n} w_{i} I_{i}-I_{0}^{3} \sum_{i=1}^{n} w_{i}\right)}{\sum_{i=1}^{n} w_{i} I_{i}^{2}-2 I_{0} \sum_{i=1}^{n} w_{i} I_{i}+I_{0}^{2} \sum_{i=1}^{n} w_{i}}
$$

\section{Referências $^{1}$}

BUSSAB, W. O.; MORETTIN, P. A. Estatística Básica. 4 ed. São Paulo : Atual, 1987.

${ }^{1}$ De acordo com:

ASSOCIAÇÃO BRASILEIRA DE NORMAS TÉCNICAS. NBR 6023: informação e documentação: referências: elaboração. Rio de Janeiro, 2002. 


\section{Apêndice D. GRÁficos DE GLICEMIA dOS Testes CoM PaCientes}

A seguir, são apresentados os gráficos de glicemia obtidos nos testes com pacientes (Capítulo 5, Testes em pacientes). Ao todo, treze pacientes tiveram seus dados coletados. O paciente número 8 , entretanto, faleceu durante a realização dos testes e, por isso, seus dados foram descartados.

Para cada gráfico, são apresentadas três curvas: glicemia gerada pelo software do MiniMed CGMS, glicemia gerada pelo algoritmo em tempo real e glicemia de "ponta de dedo". Para a geração das leituras em tempo real, foi utilizado o algoritmo em tempo real original com os seguintes parâmetros de entrada:

- Atraso de 10 minutos nas leituras de calibração.

- Janela de calibração de 12 horas.

- Sem suavização (janela de suavização = 0)

- Offset mínimo = 3, offset máximo = 3, diferença entre offsets =1,5. 


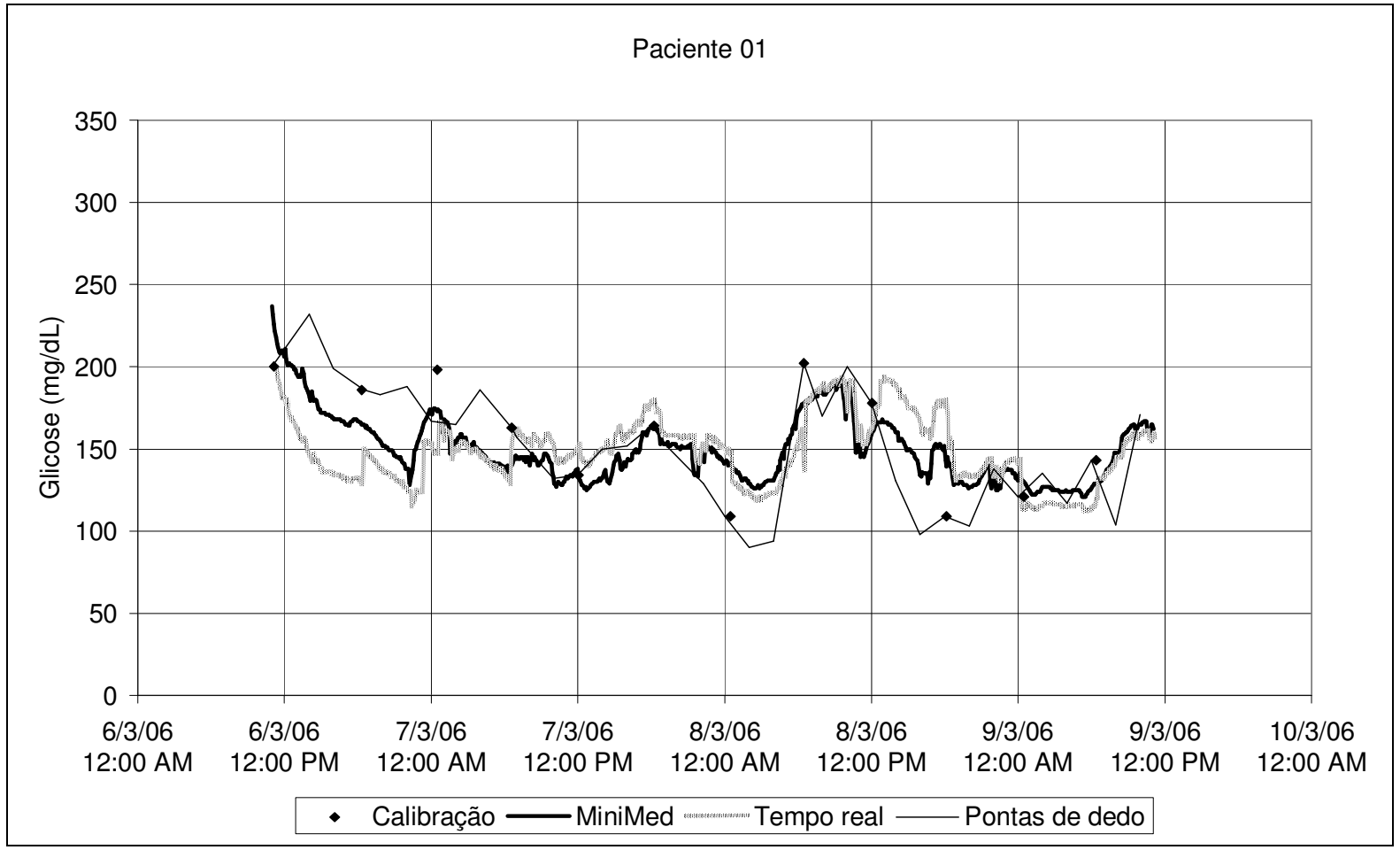

Figura D.1 - Gráfico de glicemia do paciente 1.

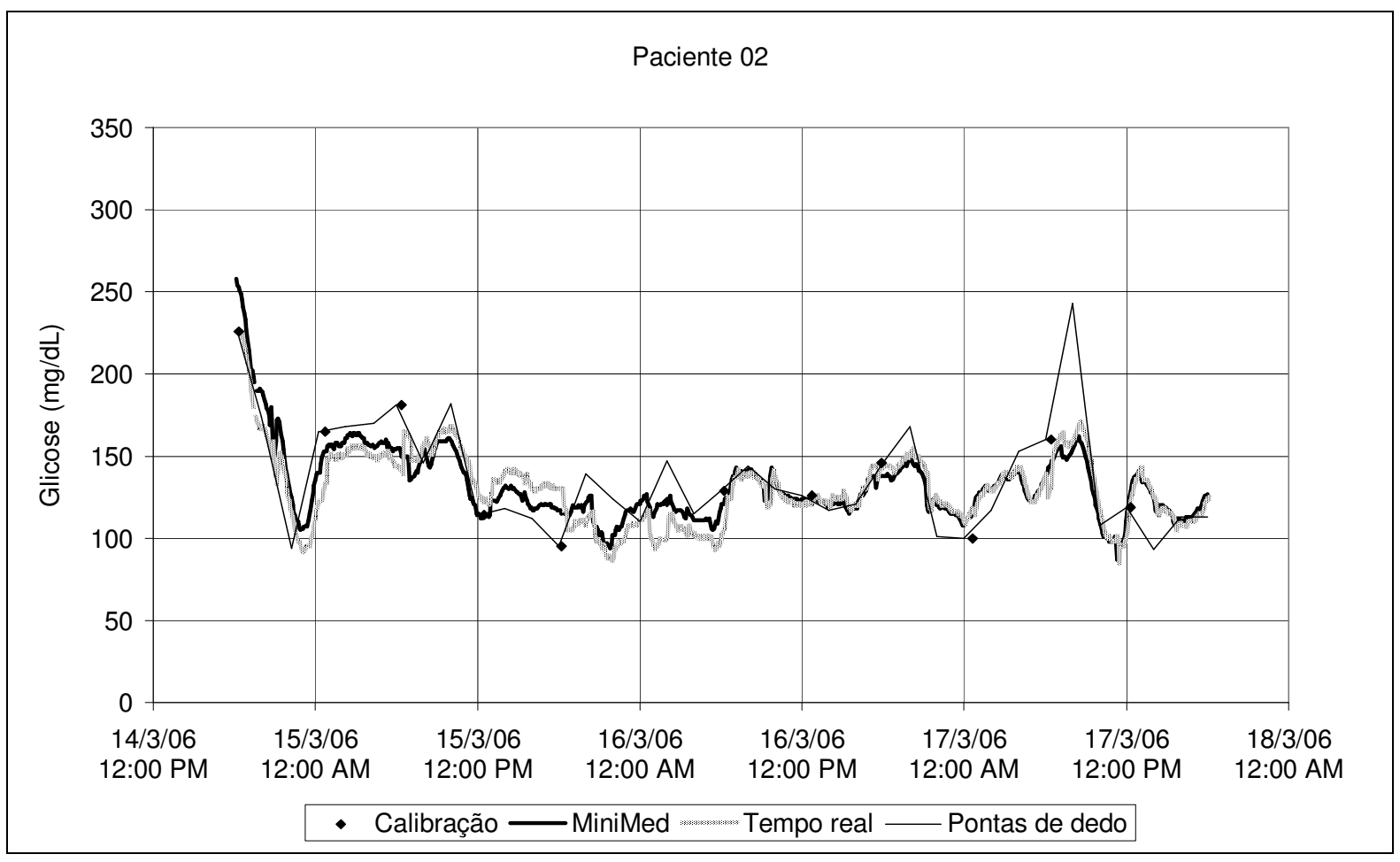

Figura D.2 - Gráfico de glicemia do paciente 2. 


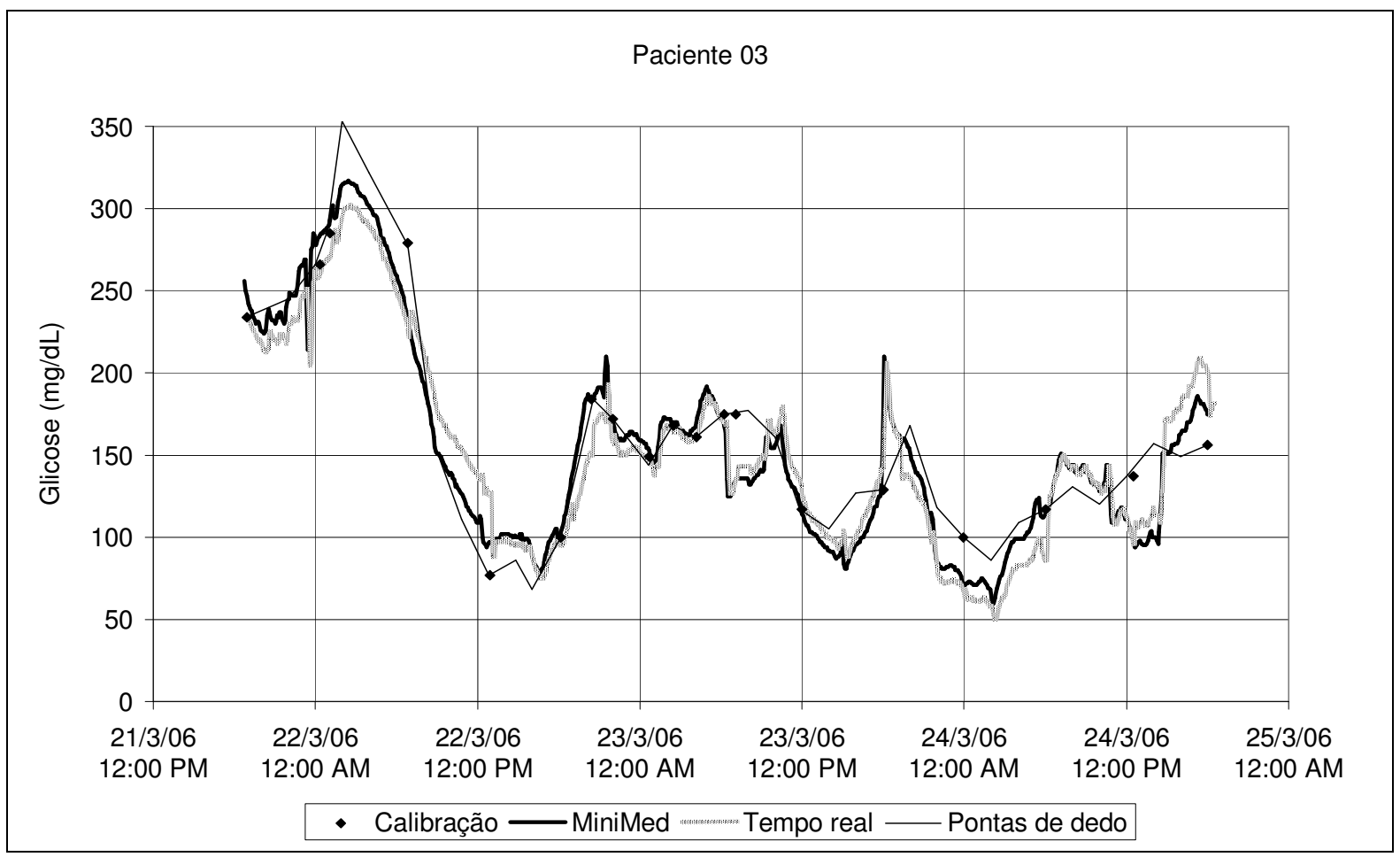

Figura D.3 - Gráfico de glicemia do paciente 3.

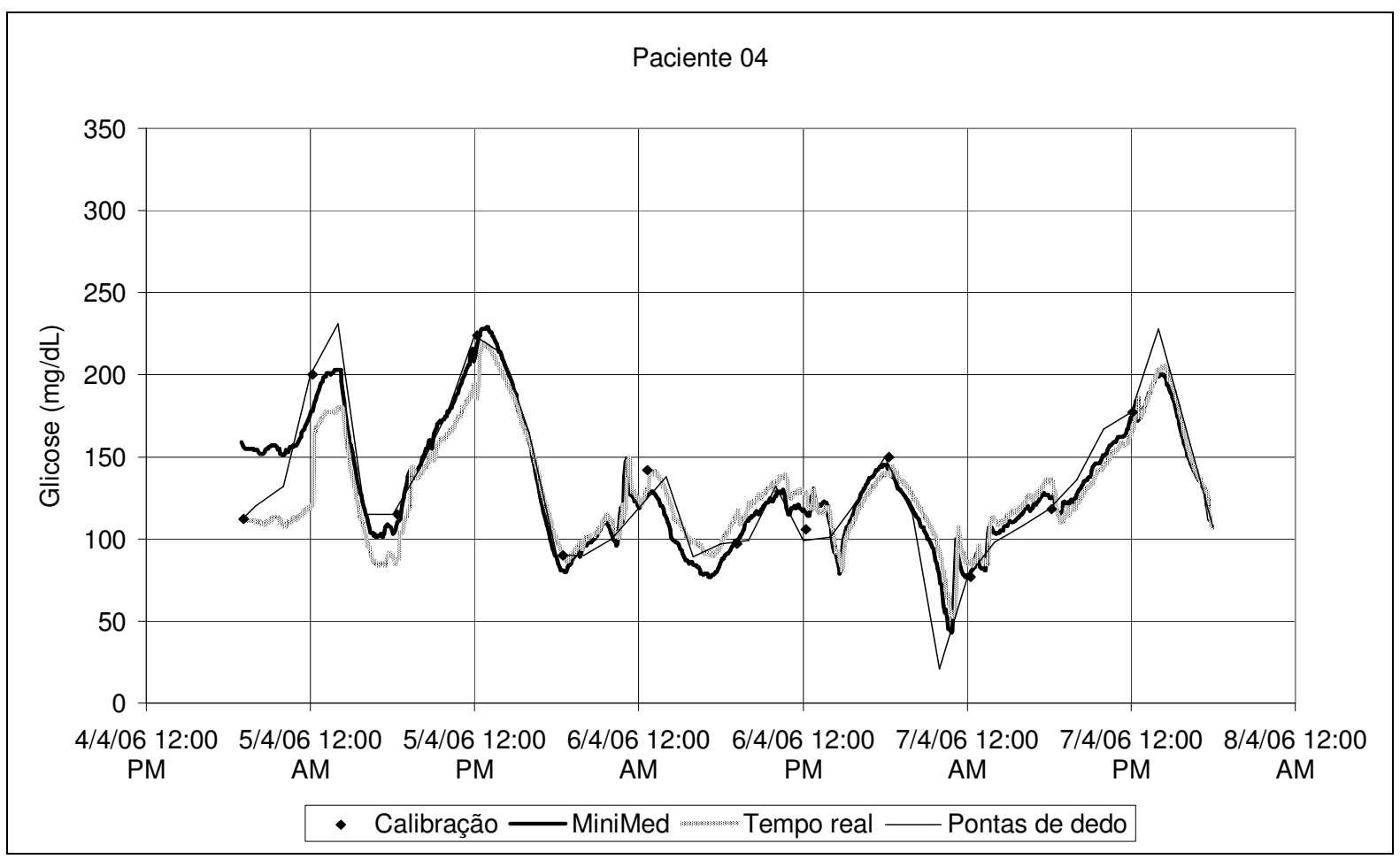

Figura D.4 - Gráfico de glicemia do paciente 4. 


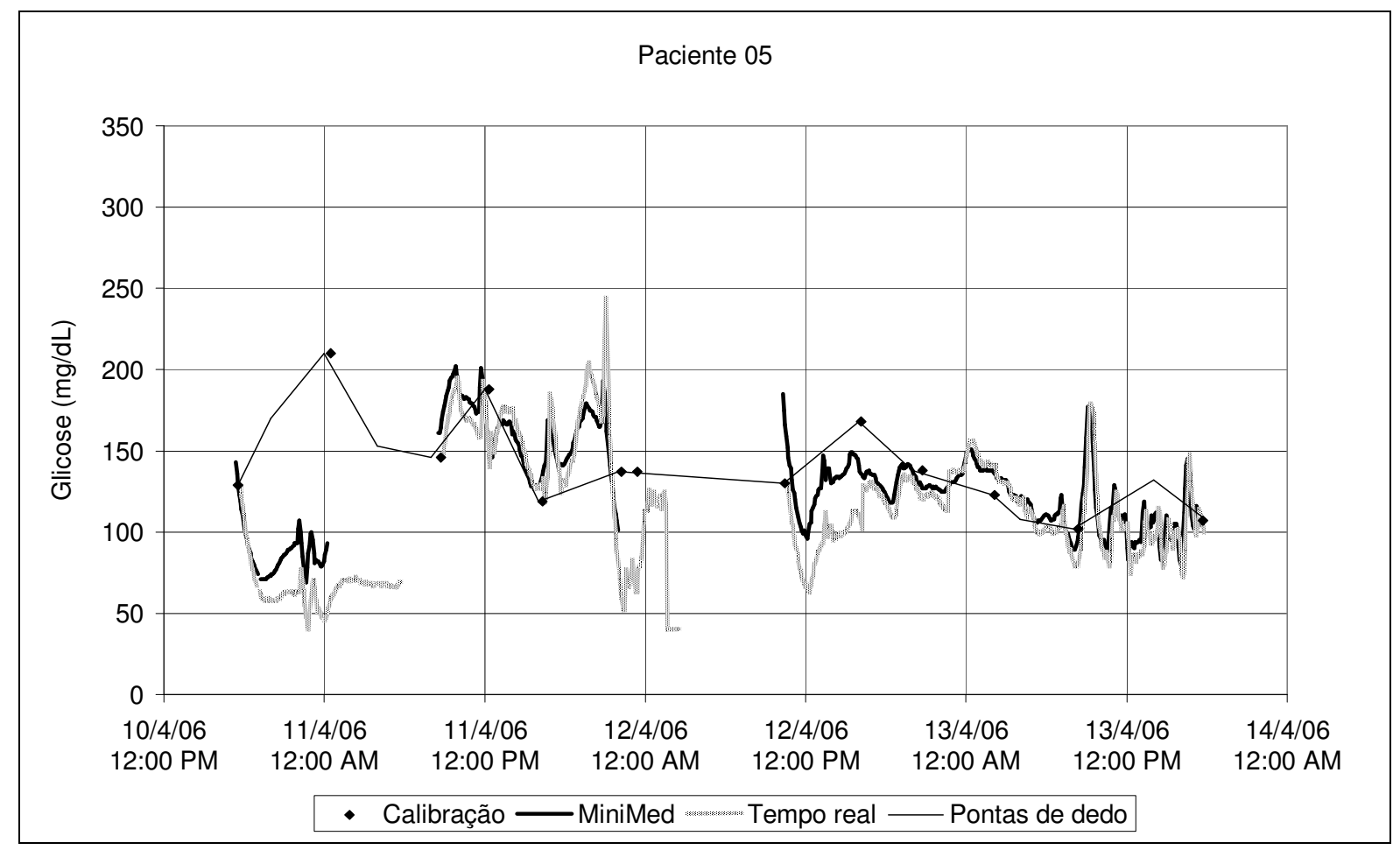

Figura D.5 - Gráfico de glicemia do paciente 5.

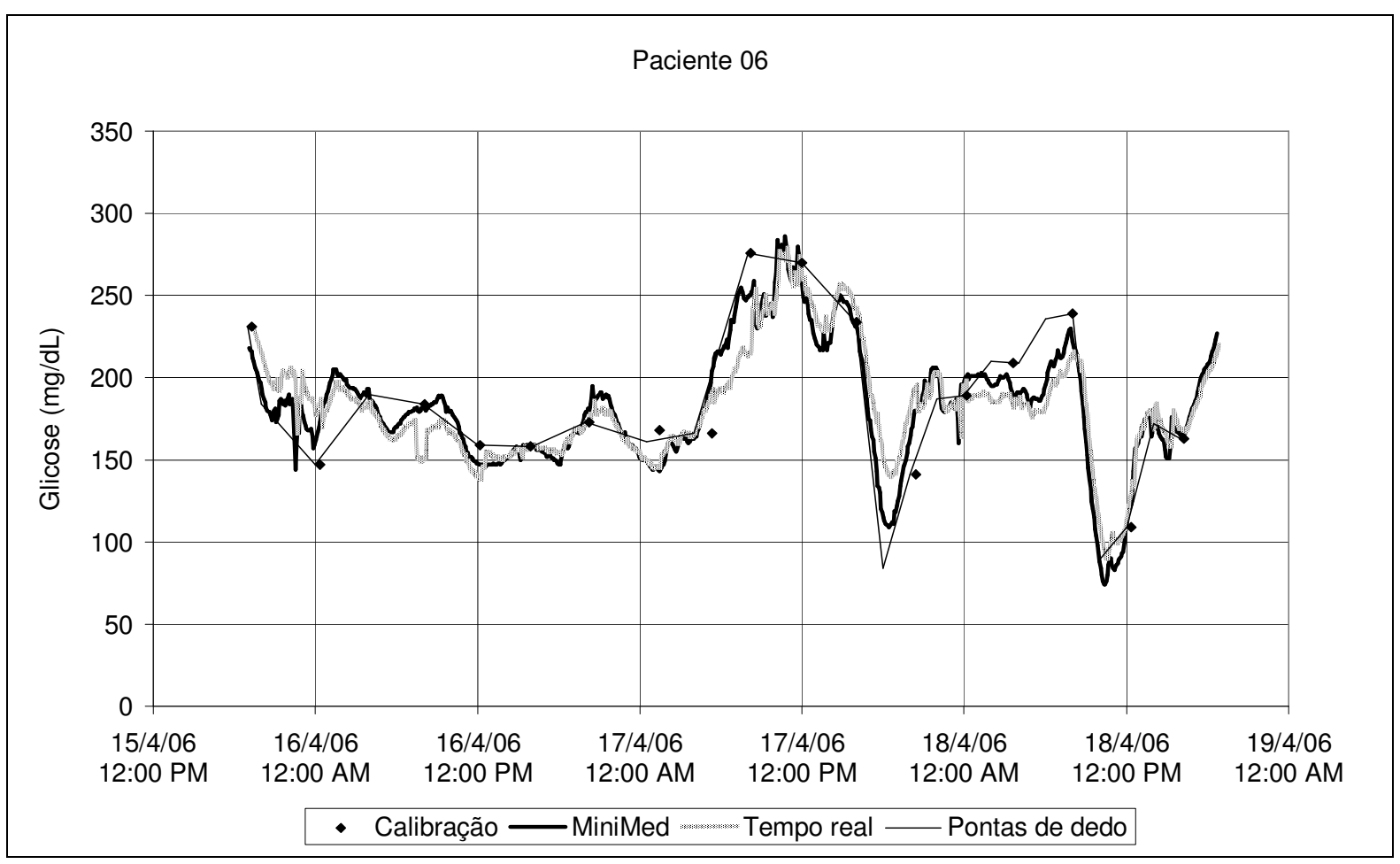

Figura D.6 - Gráfico de glicemia do paciente 6. 


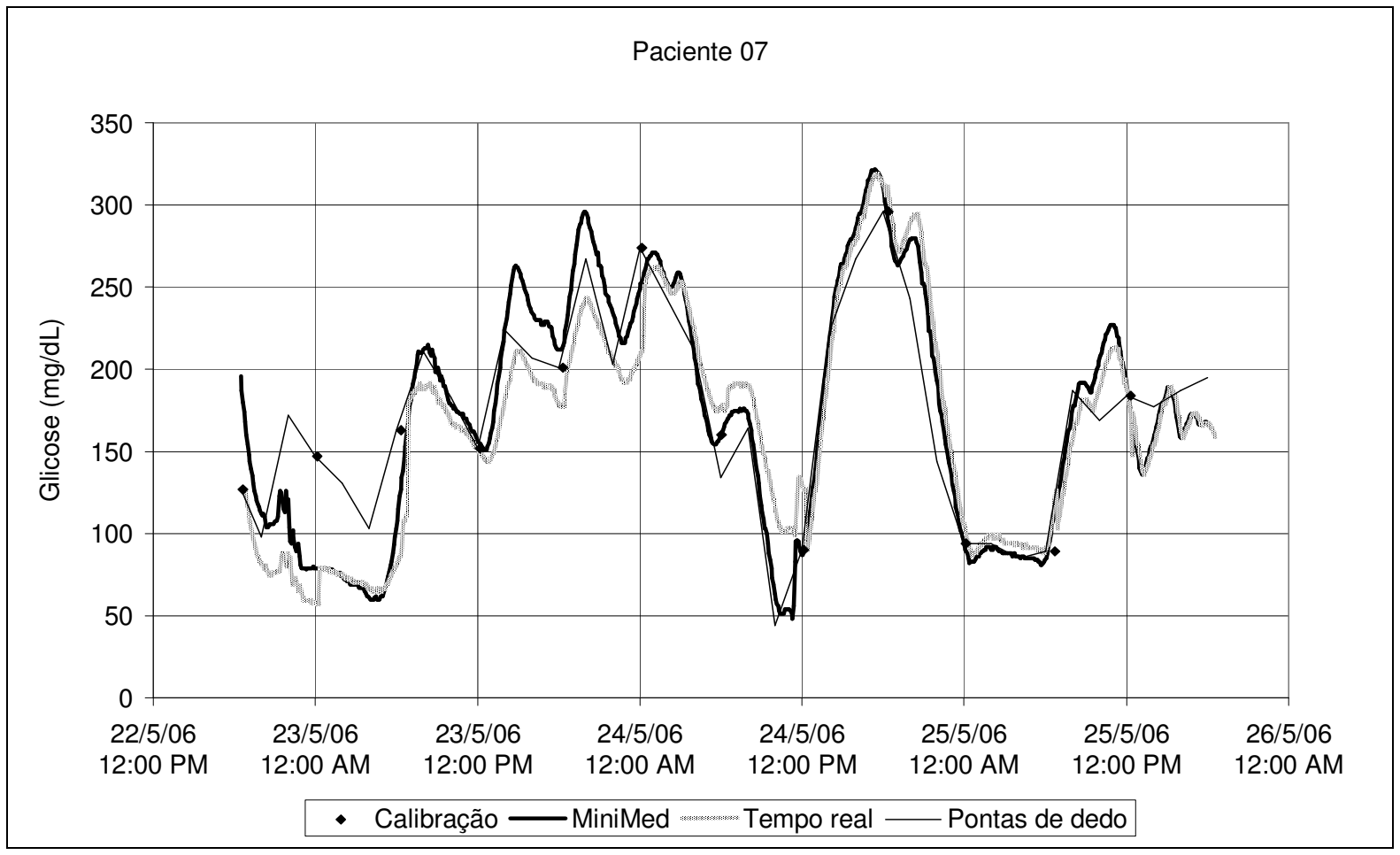

Figura D.7 - Gráfico de glicemia do paciente 7.

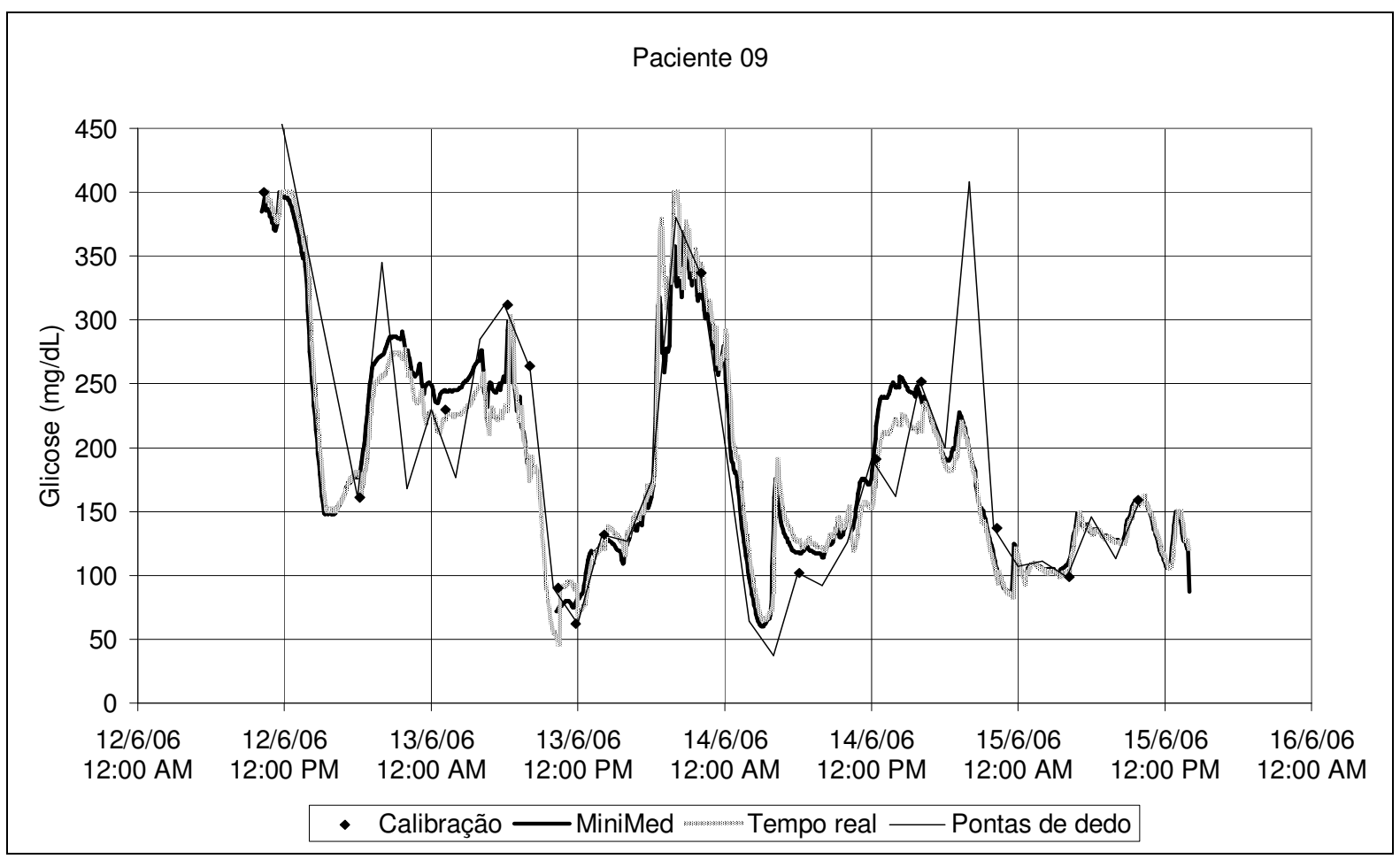

Figura D.8 - Gráfico de glicemia do paciente 9. 


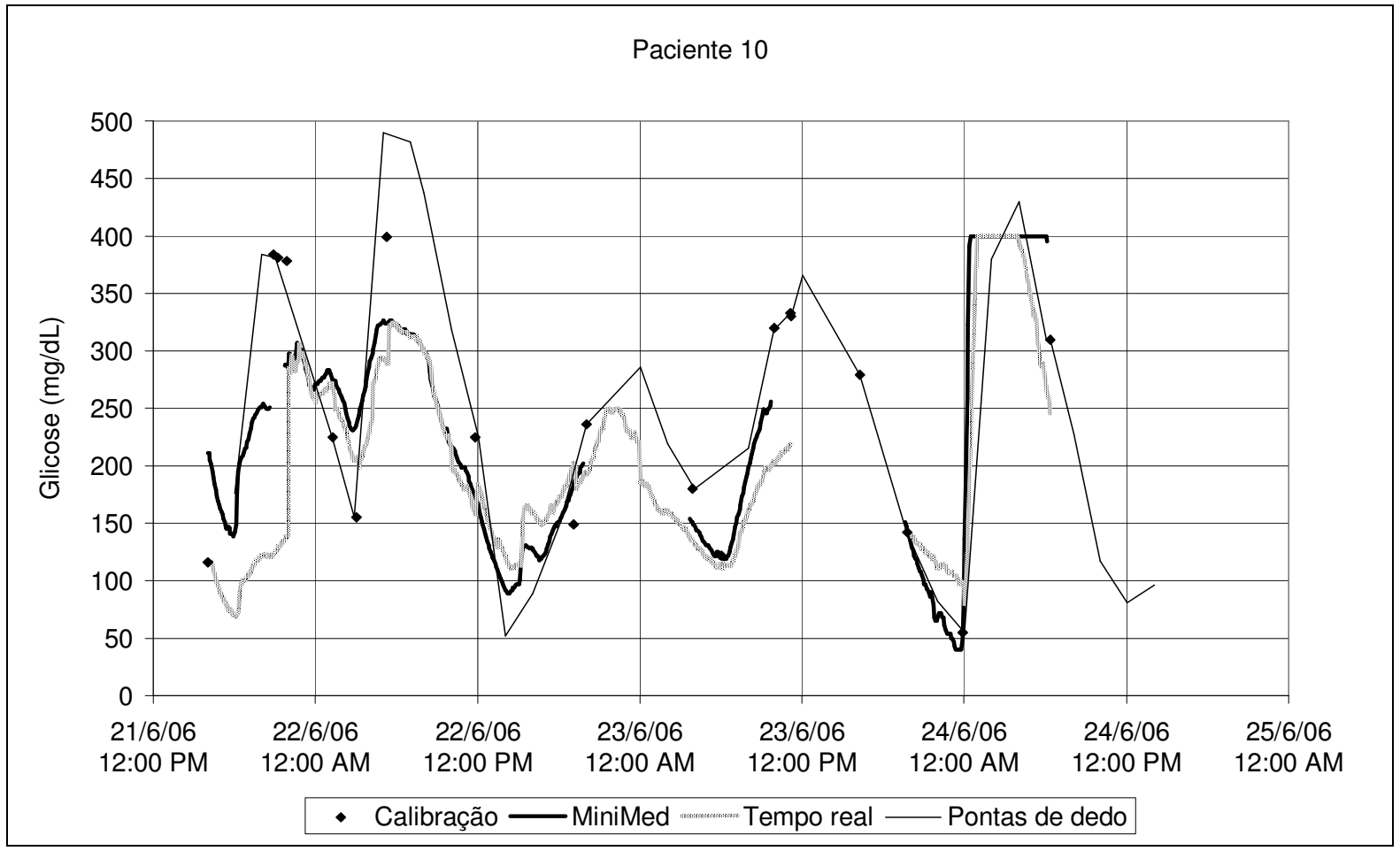

Figura D.9 - Gráfico de glicemia do paciente 10.

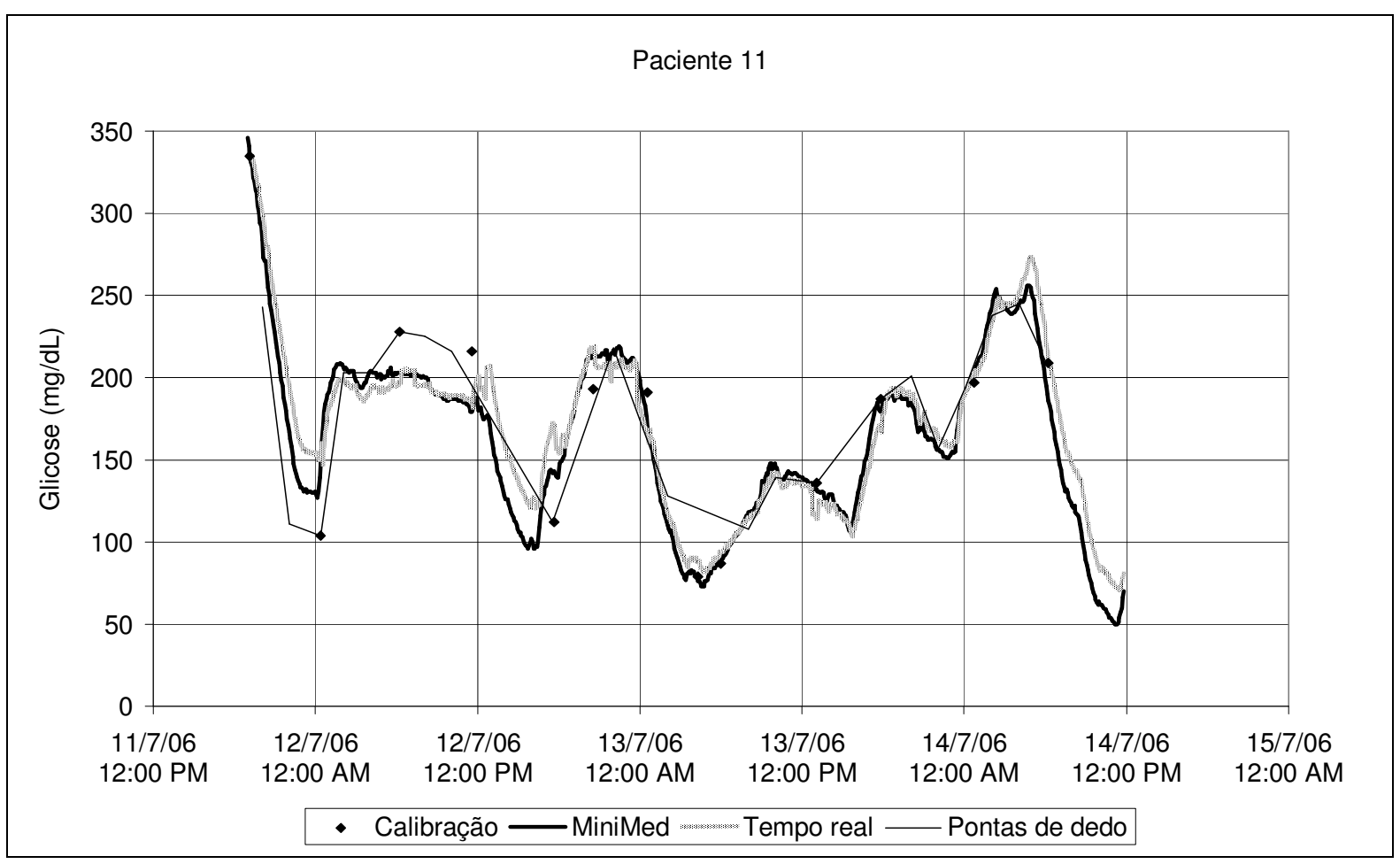

Figura D.10 - Gráfico de glicemia do paciente 11. 


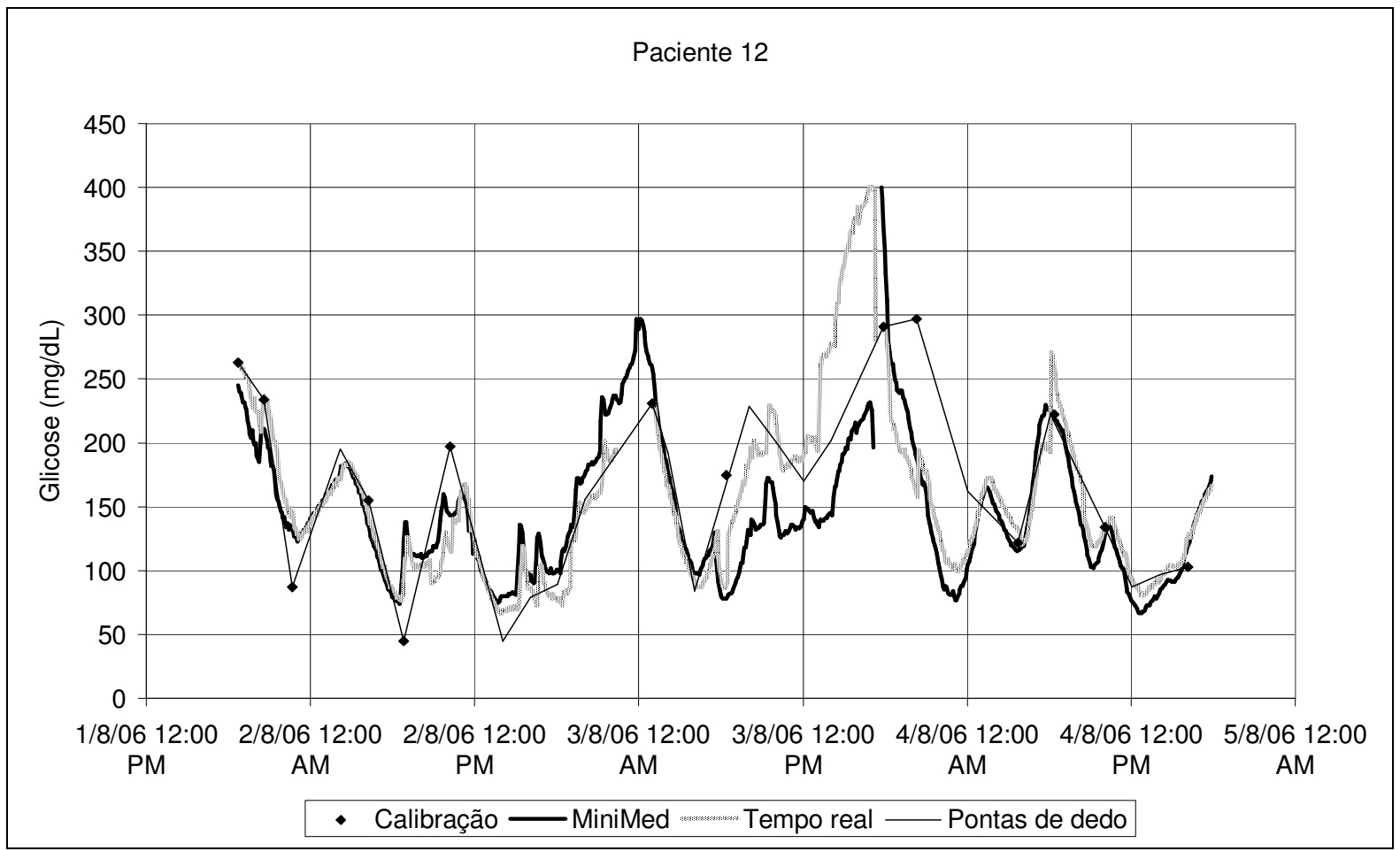

Figura D.11 - Gráfico de glicemia do paciente 12.

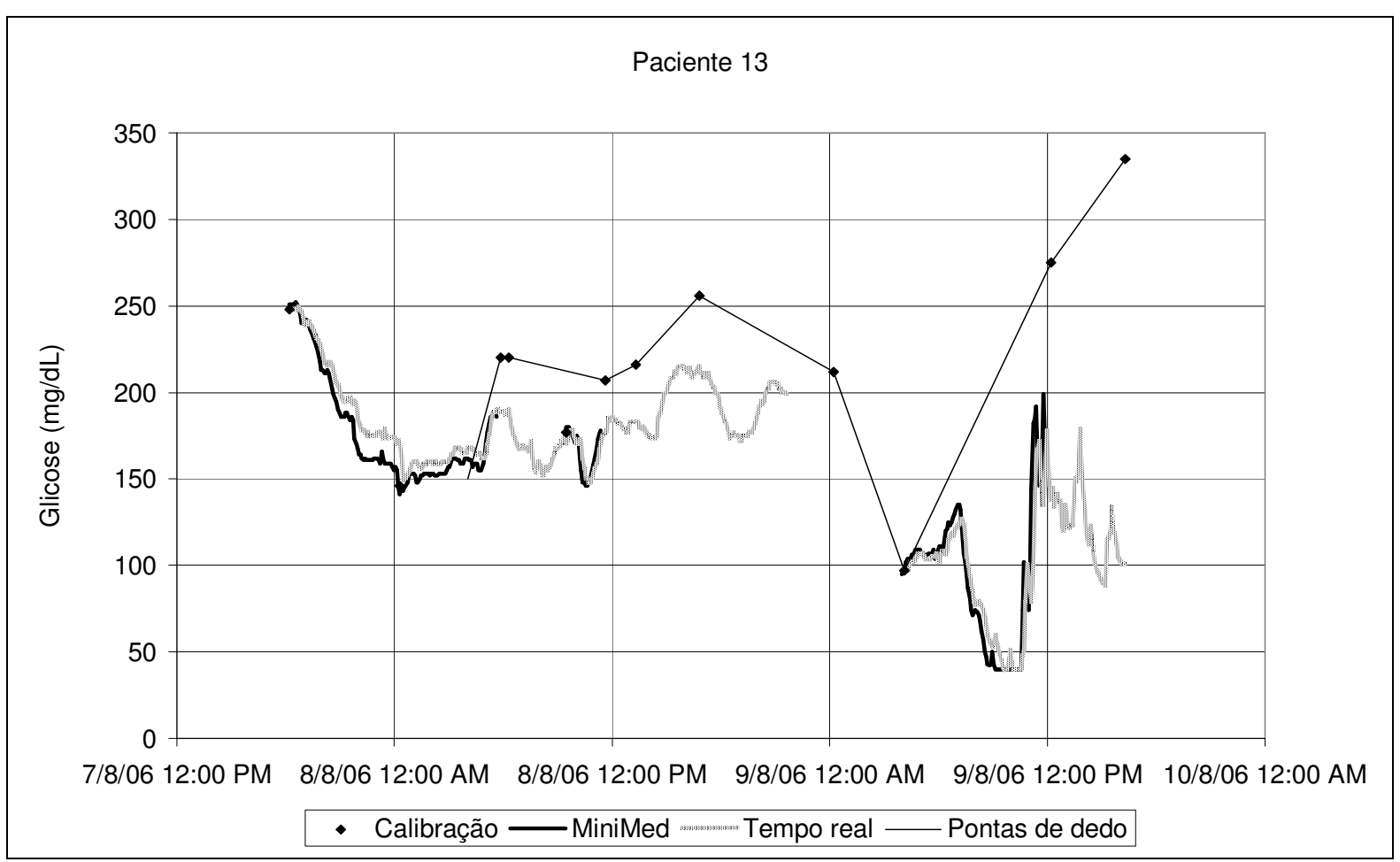

Figura D.12 - Gráfico de glicemia do paciente 13. 


\section{Apêndice E. FolHas de Registro - Protocolo de Testes}

A seguir (Figura E.1 a Figura E.4), são apresentadas as folhas de registro utilizadas nos testes do vMonGluco com pacientes críticos. As folhas foram preenchidas pela equipe de enfermagem durante os testes, servindo como complemento aos dados coletados pelo MiniMed CGMS.

As folhas de registro foram produzidas pelos então alunos de intercâmbio Kim Nielsen e Thomas Iversen, da Dinamarca. Os dados coletados foram utilizados colaborativamente pelo projeto vMonGluco e pelo projeto de graduação dos alunos citados. Por isso, muitas das informações coletadas não foram utilizadas pelo presente projeto. 


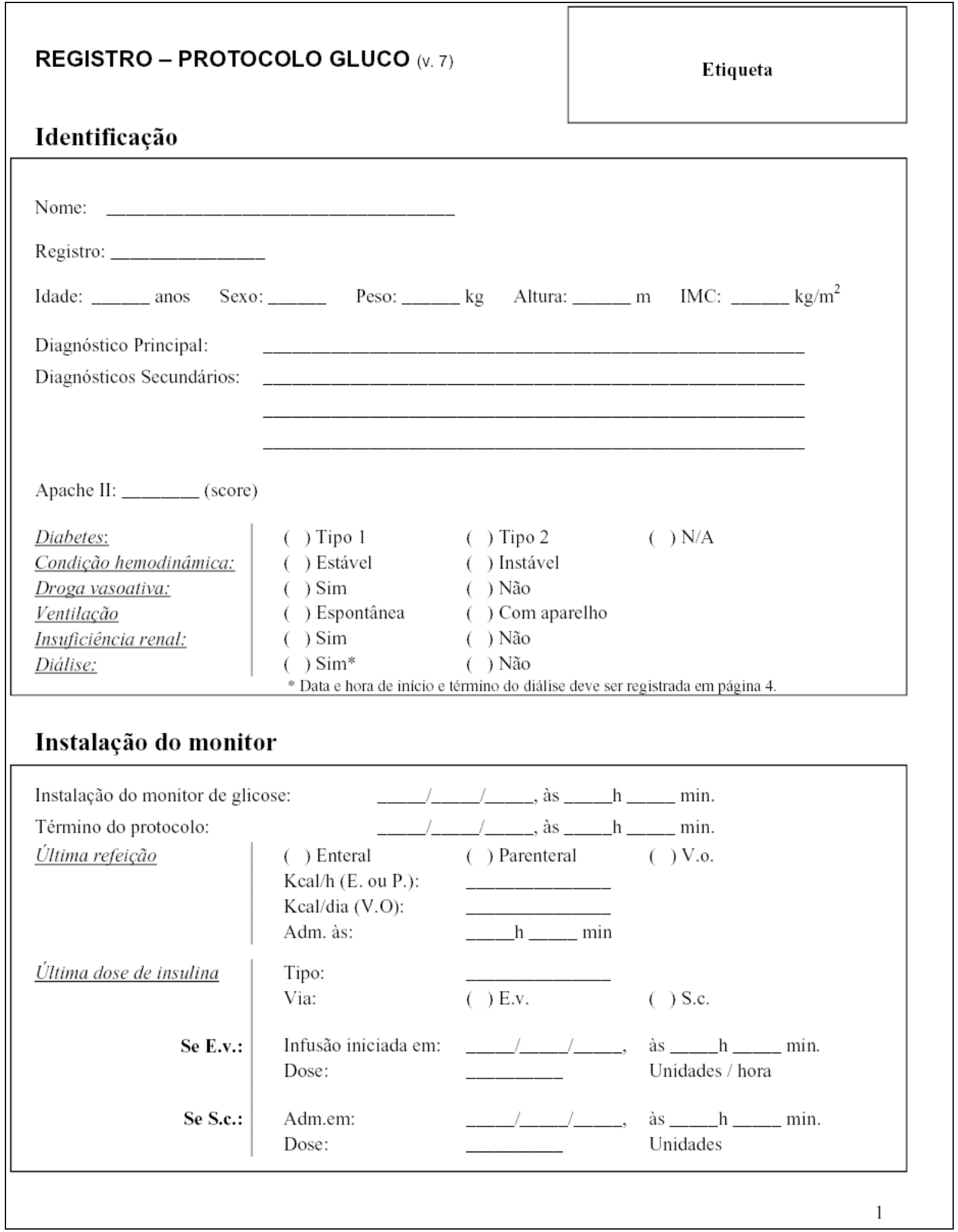

Figura E.1 - Folha de registro do protocolo de testes - página 1. 


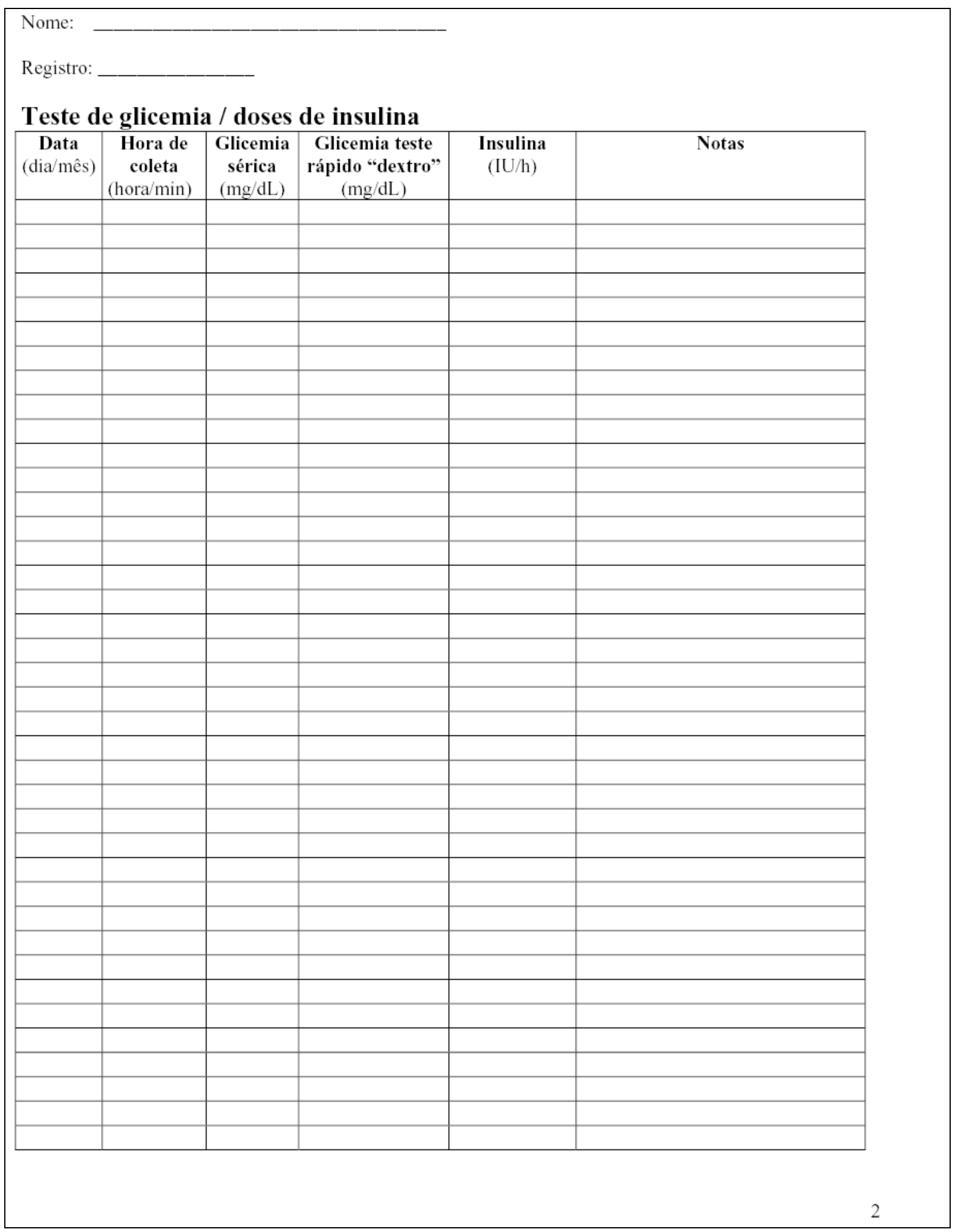

Figura E.2 - Folha de registro do protocolo de testes - página 2. 


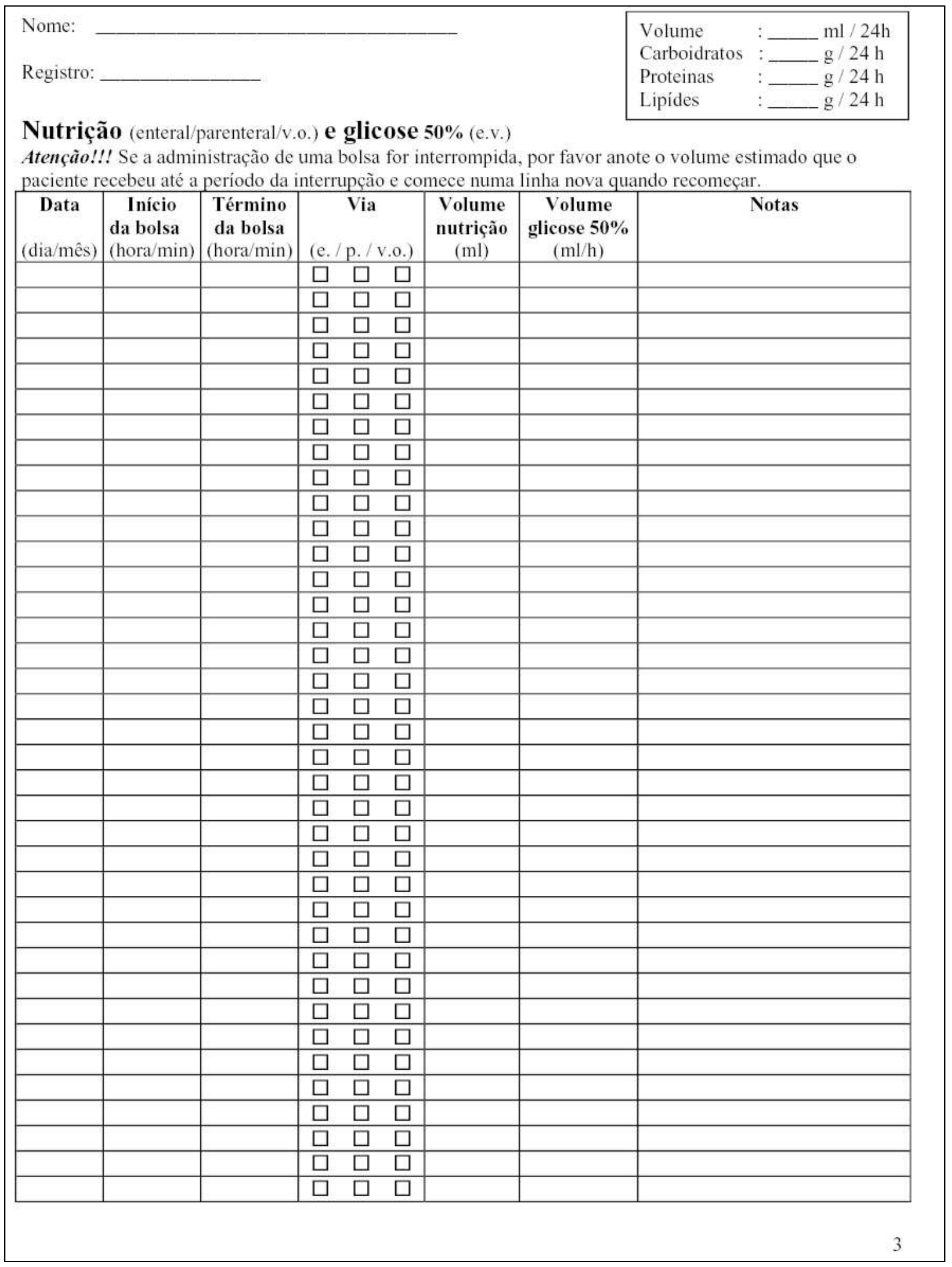

Figura E.3 - Folha de registro do protocolo de testes - página 3. 


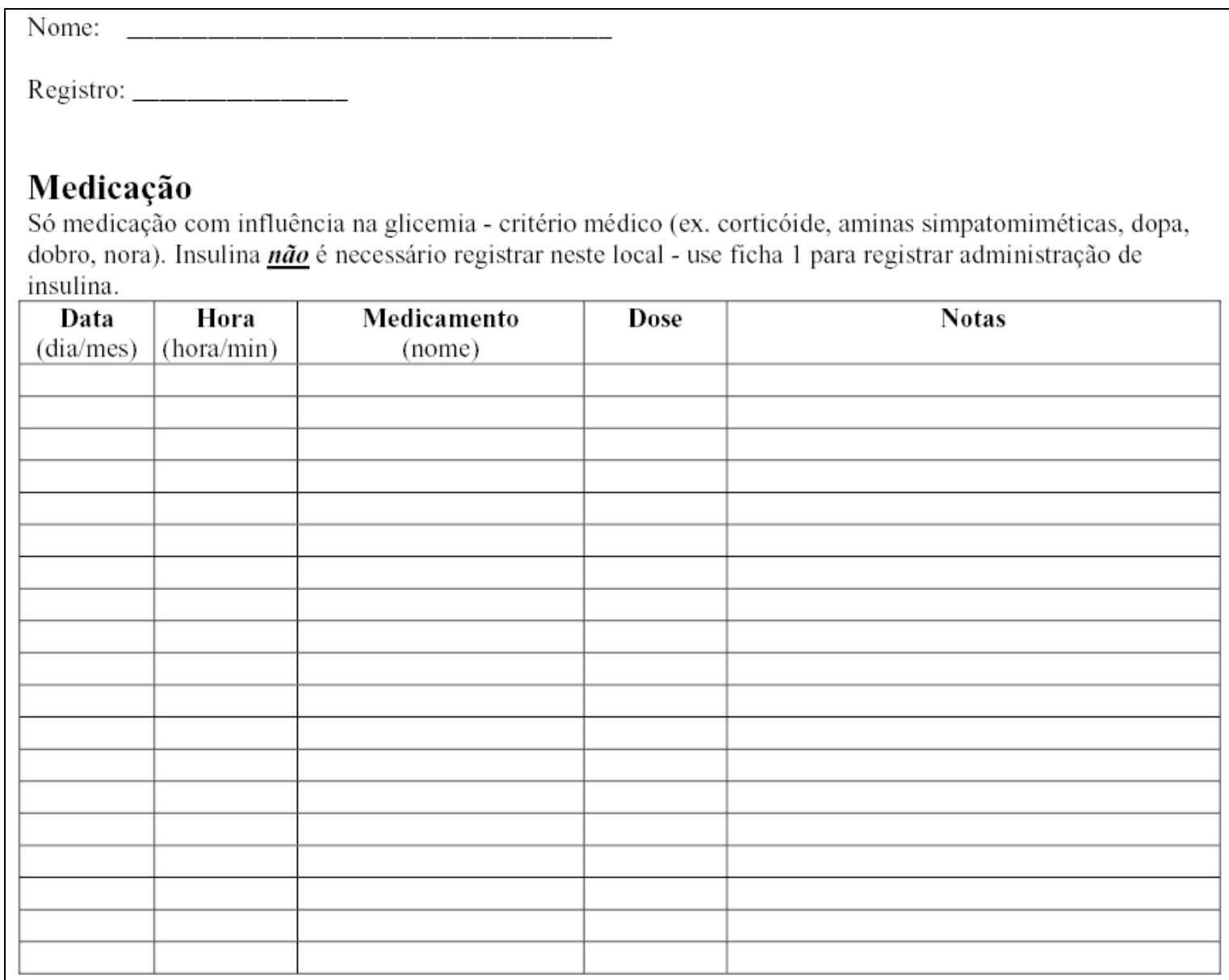

\section{Dialise:}

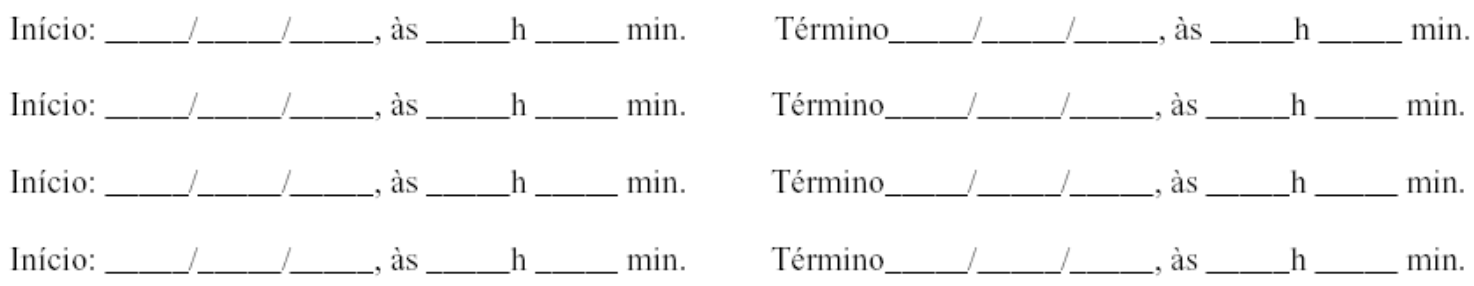

\section{Complicações técnicas (anotar):}

Figura E.4 - Folha de registro do protocolo de testes - página 4. 